ADVANCED STEEL CONSTRUCTION

An International Journal

Volume 4 Number 2

June 2008

CONTENTS

Technical Papers

Preface : S.P. Chiew

A Performance Evaluation of the Arch Bridge Members Using the Strain Index Based on the Parameters Obtained from Linear Buckling Theory

Sujaritpong Atavit and Toshitaka Yamao

Fatigue Strength Characteristics of Welded Stud Joint with Respect to Steel Plate Thickness

John S.E. Koh, O. Minata and A. Muranaka

Aesthetics, Economics and Design of Stainless Steel Structures Leroy Gardner

Behaviour and Design of Steel-Concrete-Steel-Sandwich Construction N. Foundoukos, M. Xie, J.C. Chapman

Stress Analysis and Fatigue Test on Partially Overlapped CHS K-Joints T. Sopha, T.B.N. Nguyen, S.P. Chiew, C.K. Lee and S.T. Lie

Structural Efficiency of Deployable Strut-Tensioned Membrane Structures T.C. Tran and J. Y. R. Liew

Behaviour and Design of Aluminum Alloy Structural Members Ji-Hua Zhu and Ben Young

ISSN 1816-112X

Copyright $\odot 2008$ by :

The Hong Kong Institute of Steel Construction

Website: $h t t p: / / w w w . h k i s c . o r g /$

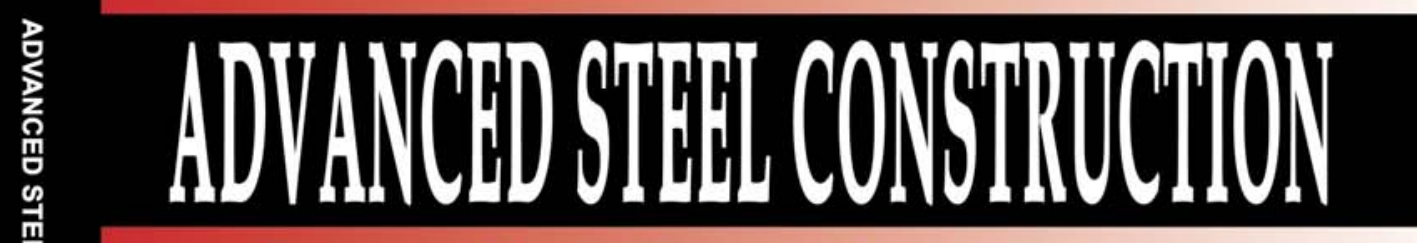

an International Joumal ISSN 1816-112X

Volume 4 Number 2

(Special Issue : Steel Space and Composite Structures)

June 2008

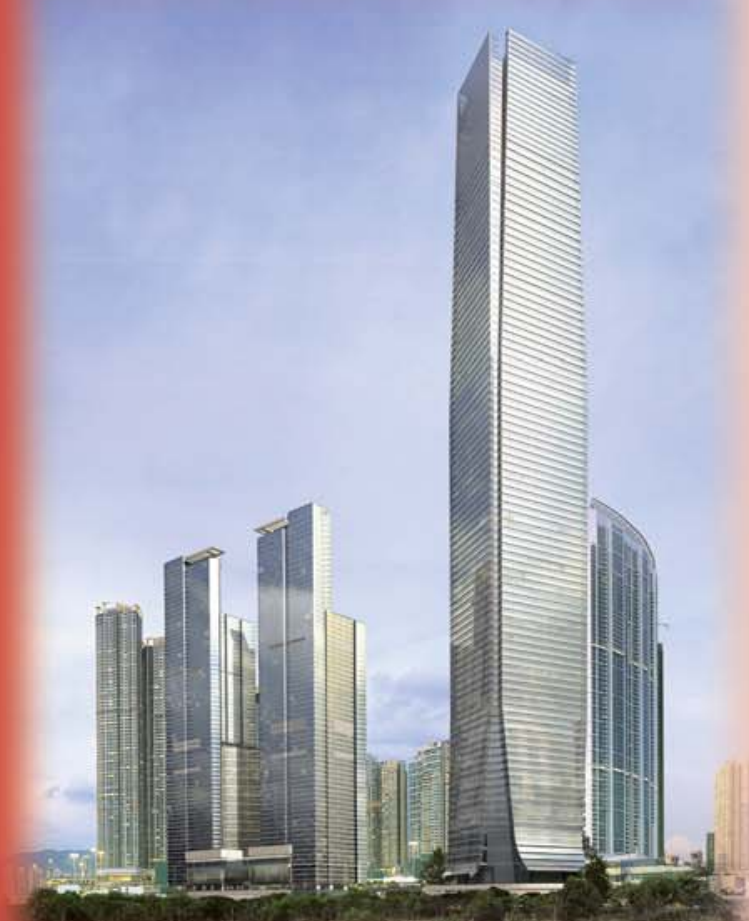

Editors-in-Chief

S.L. Chan, The Hong Kong Polytechnic University, Hong Kong

W.F. Chen, University of Hawaii at Manoa, USA

R. Zandonini, Trento University, Italy 


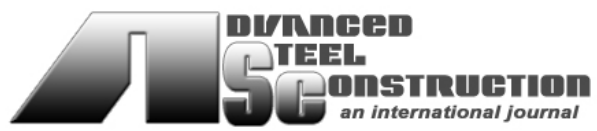

ISSN 1816-112X

\section{Advanced Steel \\ Construction an international journal}

\section{EDITORS-IN-CHIEF}

Asian Pacific, African and organizing Editor

S.L. Chan

The Hong Kong Polyt. Univ., Hong Kong

\section{American Editor \\ W.F. Chen \\ Univ. of Hawaii at Manoa, USA}

\section{European Editor}

R. Zandonini

Trento Univ., Italy

\section{INTERNATIONAL} EDITORIAL BOARD

F.G. Albermani

The Univ. of Queensland, Australia

F.S.K. Bijlaard

Delft Univ. of Technology, The Netherlands

R. Bjorhovde

The Bjorhovde Group, USA

M.A. Bradford

The Univ. of New South Wales, Australia

D. Camotim

Technical Univ. of Lisbon, Portugal

C.M. Chan

Hong Kong Uni v. of Science \& Technolog Hong Kong

S.P. Chiew

Nanyang Technological Univ., Singapore

K.F. Chung

The Hong Kong Polyt. Univ., Hong Kong

G.G. Deierlein

Stanford Univ., California, USA

L. Dezi

Univ. of Ancona, Italy

D. Dubina

The Politehnica Univ. of Timosoara, Romania
R. Greiner

Technical Univ. of Graz, Austria

G.W.M. Ho

Ove Arup \& Pa rtners Hong Kon g Ltd. Hong Kong

B.A. Izzuddin

Imperial College of Science, Technology and Medicine, UK

J.P. Jaspart

Univ. of Liege, Belgium

S. A. Jayachandran

SERC, CSIR, Chennai, India

S. Kitipornchai

City Univ. of Hong Kong, Hong Kong

D. Lam

Univ. of Leeds, UK

G.Q. Li

Tongji Univ., China

J.Y.R. Liew

National Univ. of Singapore, Singapore

X. Liu

Tsinghua Univ., China

E.M. Lui

Syracuse Univ., USA

Y.L. Mo

Univ. of Houston, USA

J.P. Muzeau

CUST, Clermont Ferrand, France

$\mathrm{y}$,

D.A. Nethercot

Imperial College of Science, Technology and Medicine, UK

D.J. Oehlers

The Univ. of Adelaide, Australia

K. Rasmussen

The Univ. of Sydney, Australia

T.M. Roberts

Cardiff Univ., UK

J.M. Rotter

The Univ. of Edinburgh, UK

C. Scawthorn

Scawthorn Porter Associates, USA

P. Schaumann

Univ. of Hannover, Germany
G.P. Shu

Southeast Univ. China

J.G. Teng

The Hong Kong Polyt. Univ., Hong Kong

G.S. Tong

Zhejiang Univ., China

K.C. Tsai

National Taiwan Univ., Taiwan

C.M. Uang

Univ. of California, USA

B. Uy

The Univ. of Wollongong, Australia

M. Veljkovic

Univ. of Lulea, Sweden

F. Wald

Czech Technical Univ. in Prague, Czech

Y.C. Wang

The Univ. of Manchester, UK

D. White

Georgia Institute of Technology, USA

E. Yamaguchi

Kyushu Institute of Technology, Japan

Y.B. Yang

National Taiwan Univ., Taiwan

B. Young

The Univ. of Hong Kong, Hong Kong

X.L. Zhao

Monash Univ., Australia 


\section{General Information Advanced Steel Construction, an international journal}

\section{Aims and scope}

The International Journal of Advanced Steel Construction provides a platform for the publication and rapid dissemination of ori ginal and up-to-date research and tec hnological developments in steel c onstruction, design and anal ysis. Scope of research $p$ apers published in this journal includes but is not limite $d$ to theor etical and expe rimental research on elements, assemblages, sy stems, material, design philosophy and codification, standards, fabrication, projects of innov ative nature and computer tech niques. The journal is specifically $t$ ailored to channel the exchange of tec hnological know-ho w bet ween $r$ esearchers an $d$ practitioners. Contributions from all aspects related to the recent developments of advanced steel construction are welcome.

Instructions to authors

Submission of the manuscript. Authors may submit three double-spaced hard copies of manuscripts together with an electronic copy on a diskette or cd-rom in an editable format (MS Word is preferred). Manuscripts should be submitted to the regional editors as follows for arrangement of review.

Asian Pacific, African and organizing editor : Professor S.L. Chan

American editor :

European editor :

Professor W.F. Chen

Professor R. Zandonini

All manuscripts submitted to the journal are highl y recommended to accompany with a list of four potential reviewers suggested by the author(s). This list should include the complete name, address, telephone and fax numbers, e mail address, and at least five keywords that identify the expertise of each reviewer. This scheme will improve the process of review.

Style of manuscript

General. Author(s) should provide full postal and email addresses and fax number for correspondence. The manuscript including abstract, keywords, references, figures and tables should be in English with pages numbered and typed with double line spacing on single side of A4 or letter-sized paper. The front page of the article should contain:

a) a short title (reflecting the content of the paper);

b) all the name(s) and postal and email addresses of author (s) specifying the author to whom correspondence and proofs should be sent

c) an abstract of 100-200 words; and

d) 5 to 8 keywords.

The paper must contain an introduction and a conclusion. The length of paper should not exceed 25 journal pages (approximately 15,000 words equivalents).

Tables and figures. Tables and figures including photographs should be typed, numbered consecutively in Arabic numerals and with short titles. They should be referred in the text as Figure 1, Table 2, etc. Originally drawn figures and photographs should be provided in a form suitable for photographic reproduction and reduction in the journal.

Mathematical expressions and units. The Systeme Internationale (SI) should be followed whenever possible. The numbers identifying the displayed mathematical expression should be referred to in the text as Eq. (1), Eq. (2).

References. References to published literature should be referred in the text, in the order of citation with Arabic numerals, by the last name(s) of the author(s) (e.g. Zandonini and Zanon [3]) or if more than three authors (e.g. Zandonini et al. [4]) . References should be in English $w$ ith occasional allow ance of 1-2 e xceptional referenc es in local lang uages and $r$ eflect the curren $t$ state-of-technology. Journal titles should be abbreviated in the style of the Word List of Scientific Periodicals. References should be cited in the following style [1, 2, 3].

Journal: [1] Chen, W.F. and Kishi, N., "Semi-rigid Steel Beam-to-column Connections, Data Base and Modellin g", Journal of Structural Engineering, ASCE, 1989, Vol. 115, No. 1, pp. 105-119.

Book: [2] Chan, S.L. and Chui, P.P.T., "Non-linear Static and Cyclic Analysis of Semi-rigid Steel Frames", Elsevier Science, 2000

Proceedings: [3] Zandonini, R. a nd Zanon, P., "Experimental Analy sis of S teel Beams with Semi -rigid Joint s", Proceedings of International Conference on Advances in Steel Structures, Hong Kong, 1996, Vol. 1, pp. 356-364.

Proofs. Proof will be sent to the c orresponding author to correct an y typesetting errors. Alternations to the original manuscript at this stage will not be accepted. Proofs should be returned within 48 hours of receipt by Express Mail, Fax or Email.

Copyright. Submission of an article to "Advanced Steel Construction" implies that it presents the original and unpublished work, and not under consideration for publication nor published elsewhere. On acceptance of a manuscript submitted, the copyright thereof is transferred to th e publisher $b y$ the Transfer of $C$ opyright Agreement and upon $t$ he acceptance of publication for the $p$ apers, the corresponding author must sign the form for Transfer of Copyright.

Permission. Quoting from this journal is granted provided that the customary acknowledgement is given to the source.

Page charge and Reprints. There will be no page charges if the length of paper is within the limit of 25 journal pages. A total of 30 free offprints will be supplied free of charge to the corresponding author. Purchasing orders for additional offprints can be made on order forms which will be sent to the authors. These instructions can be obtained at the Hong Kong Institute of Steel Construction, Journal website: http://www.hkisc.org

The International Journal of Advanced Steel Construction is published quarterly by non-profit making learnt society, The Hong Kong Institute of Steel Construction, c/o Department of Civil \& Structural Engineering, The Hong Kong Polytechnic University, Hung Hom, Kowloon, Hong Kong.

Disclaimer. No responsibility is assumed for a ny injury and / or damage to per sons or property as a matter of products liability, negligence or otherwise, or from any use or operation of any methods, products, instructions or ideas contained in the material herein.

Subscription inquiries and change of address. Address all subscription inquiries and correspondence to Member Records, IJASC. Notify an address change as soon as possible. All communications should include both old and new addresses with zip codes and be accompanied by a mailing label from a recent issue. Allow six weeks for all changes to become effective.

The Hong Kong Institute of Steel Construction

HKISC

clo Department of Civil and Structural Engineering

The Hong Kong Polytechnic University,

Hunghom, Kowloon, Hong Kong, China

Tel: 852- 27666047 Fax: 852- 23346389

Email: ces/chan@polyu.edu.hk Website: http://www.hkisc.org/

ISSN 1816-112X

Copyright $\odot 2008$ by:

The Hong Kong Institute of Steel Construction. 


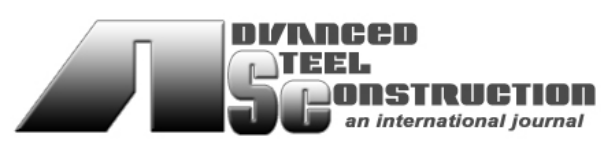

ISSN 1816-112X

EDITORS-IN-CHIEF

Asian Pacific, African and organizing Editor

S.L. Chan

The Hong Kong Polyt. Univ., Hong Kong

\section{American Editor}

W.F. Chen

Univ. of Hawaii at Manoa, USA

\section{European Editor}

R. Zandonini

Trento Univ., Italy

\section{Advanced Steel \\ Construction an international journal}

VOLUME 4 NUMBER 2

JUNE 2008

Technical Papers (Special Issue)

Preface

S.P. Chiew

A Performance Evaluation of the Arch Bridge Members Using the Strain Index Based on the Parameters Obtained from Linear Buckling Theory

Sujaritpong Atavit and Toshitaka Yamao

Fatigue Strength Characteristics of Welded Stud Joint with Respect to Steel Plate Thickness

John S.E. Koh, O. Minata and A. Muranaka

Aesthetics, Economics and Design of Stainless Steel Structures Leroy Gardner

Behaviour and Design of Steel-Concrete-Steel-Sandwich

Construction

N. Foundoukos, M. Xie and J.C. Chapman

Stress Analysis and Fatigue Test on Partially Overlapped CHS K-Joints

T. Sopha, T.B.N. Nguyen, S.P. Chiew, C.K. Lee and S.T. Lie

Structural Efficiency of Deployable Strut-Tensioned Membrane Structures

T.C. Tran and J. Y. R. Liew

Behaviour and Design of Aluminum Alloy Structural Members Ji-Hua Zhu and Ben Young

ICASS’09 Conference Announcement 


\section{PREFACE}

\section{SPECIAL ISSUE ON STEEL SPACE AND COMPOSITE STRUCTURES THE INTERNATIONAL JOURNAL OF ADVANCED STEEL CONSTRUCTION (IJASC SPECIAL ISSUE)}

In 1984, the Singapore Stru ctural Steel Society organized the first i naugural conference on steel and space $s$ tructures to mark the inception and formation of the Society. Since then, this conference se ries has always been supported by the SSSS and her sister steel associations from th e region. The previous conferences have been held in Singapore and other capital cit ies, and the $8^{\text {th }}$ conference, for the first time, was held in Kuala Lumpur, the capital city of Malaysia.

In addition to our traditional s ubject areas within steel and space structures, the 8 th presentation was enlarged to include papers related to composite structures where much developments and applications involving the best usage of steel, concrete and advanced polymer composite materials hav e taken place in the past decade.

Advances in Steel, Space and Composite structures are very important due to the potentially huge dem and for infrastructural dev elopments and maintenanc es in this region over the next decade. Steel, space and composite constructions are often adopted in high-rise buildings, long-span bri dges and long-span clear roof structures due to its s peed and ease of co nstruction, inherent ductility and structural efficiency with large strength-to-weight ratios as well as large flexur al rigidities agains $t$ instability and serviceability problems. It is important to keep abreast with its latest innovations and technical developments to maintain our competitivenes $\mathrm{s}$. The conference continue to provide a platfo rm where practising en gineers, ar chitects, construction professionals, researchers and scholars can come together and share your common interest in various aspects re lated to the conception, analys is, design, construction and performance of steel, s pace and composite structures. In the process, we hope to promot e international communica tion and dissemination o $f$ ideas, dev elopments and innov ations, and to bridge the gaps between the various parties.

The $8^{\text {th }}$ conference proceedings volume cove red a wide spectrum of topics and contained more than 65 papers from 25 different countries worldwide. Seven papers were shorlisted for commendable awards and the authors were invited to expand their conference papers for publication in this spec ial iss ue on steel s pace and composite structures of the International Journal of Advanced Steel Construction.

Our grateful thanks to Prof S.L. Chan, Chie f Editor of the International Journal of Advanced Steel Construction for publishing this special issue.

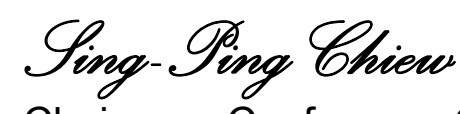

Chairman, Conference Organizing Committee

The Eighth International Conference on Steel, Space and Composite Structures Kuala Lumpur, Malaysia, 15 -17 May 2006 


\title{
A PERFORMANCE EVALUATION OF THE ARCH BRIDGE MEMBERS USING THE STRAIN INDEX BASED ON THE PARAMETERS OBTAINED FROM LINEAR BUCKLING THEORY
}

\author{
Sujaritpong Atavit ${ }^{1, *}$ and Toshitaka Yamao ${ }^{2}$ \\ ${ }^{1}$ Graduate School of Science and Technology, Kumamoto University, 2-39-1 Kurokami, \\ Kumamoto 860-8555, Japan \\ ${ }^{2}$ Department of Civil Engineering and Architectures, Kumamoto University, 2-39-1 Kurokami, \\ Kumamoto 860-8555, Japan.Fax: (096)342-3507, E-mail: tyamao@kumamoto-u.ac.jp \\ *(Corresponding author: E-mail: s_atavit@hotmail.com)
}

\begin{abstract}
To develop a seismic performance evaluation method based on the strain demand control of some critical parts when the arch bridges are subjected to the strong ground motions, it is necessary to establish the method to determine the ultimate strain of each segment (defined as the limit of the strain) which has reached the corresponding critical stress. In this study, the empirical formulas of the ultimate strain corresponding to the failure criterions by in-plane buckling and out-of-plane buckling are investigated and proposed emphasized on the stiffened box-section with longitudinal stiffeners. The applicability of box-cross sections with the longitudinal stiffeners and concrete filled is also been brought into one of the ideas to strengthen the arch bridge where the plasticization are formed in some segments due to the strong ground motion. To perform the analyses, the aspect ratio of the arch member which the lowest maximum strength may be expected was determined beforehand by considering the parameters obtained from linear buckling theory. Then the bending analyses under various axial load ratio parameters were examined to clarify the effect of failure segments in both stiffened sections with and without concrete filled models by the FEM analyses. The post buckling behaviors of concrete filled sections were also observed and compared to the stiffened box-cross sections for each width-to-thickness ratio parameter. Based on the numerical results of the stiffened sections with and without concrete filled models, empirical formulas of the ultimate strain were proposed in functions of width-to-thickness ratio parameter and axial load ratio parameter.
\end{abstract}

Keywords: Steel arch bridge, performance evaluation, ultimate strain, width-to-thickness ratio parameter, stiffened box-section, concrete filled, post buckling

\section{INTRODUCTION}

After the 1995 Hyogoken-Nanbu earthquake, the design code recommends that the structures exhibiting complicated seismic behaviors in case of a strong earthquake should be examined based on the results of a dynamic analysis. The two-level ground motion has been proposed for moderate (Level I) and extreme (Level II) ground motions in the earthquake design methodology and the acceptable performance under Level II earthquake has also been established for two objectives which are the safety of the whole structure and the post-earthquake serviceability. This acceptable performance is based on the strain demand control of some critical parts [1]. The dynamic behavior of steel arch bridges can be investigated by one of the simplified methods proposed by dividing the arch ribs and the other members in to beam-column elements and considering each member as a fibered beam element [2]. However, when such members usually composed of thin-walled plates are subjected to the seismic load during a strong earthquake, local buckling of steel members always governs the capacity of the structure. Thus, the effects of local buckling of plate elements in the analysis should also be considered into the design methodology. Furthermore, the equivalent strain over the effective length in each segment at a critical place in failure criterion must be evaluated if the corresponding ultimate strain over the excitation history has been reached. The segment is judged as safe if the average strain time history is always smaller than the ultimate strain in quantity. 
To develop a seismic performance evaluation based on response strain index for the arch bridge members, it is necessary to establish the method that is capable to determine the maximum restoring force and the ultimate strain of each segment of the arch ribs. This ultimate strain is defined as the limit of the strain when the steel segments have reached the corresponding critical stress. These sectional strength and strain formula including the effects of interactive local and overall buckling of thin-walled structures can be predicted as a function of the width-to-thickness ratio that is defined by introducing a buckling coefficient based on the elastic buckling analysis [3]. Box-section with a relatively large width-to-thickness ratio was introduced to improve the ductility after buckling behavior in the seismic design. This leads to the improvement of the ductile sections including the use of longitudinal stiffened box- member cross sections. The stiffened box-members have been studied and found to enhance the ductility after buckling behavior if the use of buckling parameters and number of stiffeners are conducted appropriately.

Anyway, to gain high ductility, the large number of stiffeners and uneconomic sizes are required. Moreover, the out-of-plane local buckling caused by the horizontal load is also significant in the ultimate strength of the arch bridge. Thus, the applicability of box-cross section with

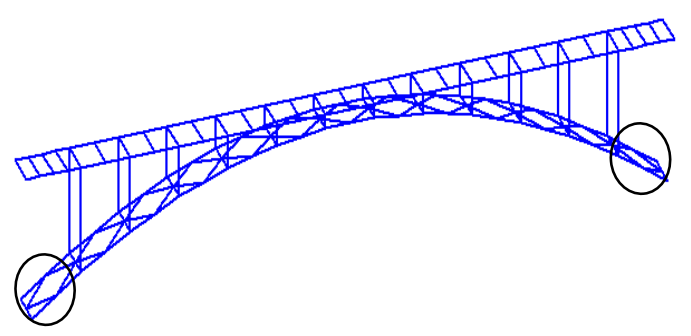

Figure 1. Applied Locations for the Concrete Filled Section the longitudinal stiffeners and concrete filled has also been brought into one of the ideas to strengthen the arch bridge where the segments are strongly subjected to high transverse ground motion such as near support locations as shown in Figure 1. However, only few studies have been reported on the ultimate state and local post buckling behavior of the component plates when such a member is subjected to the compressive load and out-of-plane bending moment.

The object of this paper are to propose the empirical formulas of the ultimate strain in order to investigate the failure by in-plane buckling and out-of-plane buckling in frame analyses emphasized on the stiffened box-section with longitudinal stiffeners and to present the post buckling behavior of the box-cross sections with the longitudinal stiffeners and concrete filled following by the empirical formula of the ultimate strain in out-of-plane. To perform the analyses, the aspect ratio representing the diaphragm length of the arch member which the lowest maximum strength may be expected was determined beforehand by considering the parameters obtained from linear buckling theory [4] from the stiffened sections without concrete filled models. Numerical analyses were carried out by the second order elasto-plastic finite element method [7] under the pure compression analysis. Then the bending analyses under various axial load ratio parameters were examined to clarify the effect of failure segments in both stiffened sections with and without concrete filled models. The equivalent section was brought in to the concrete filled models in order to simplify the analyses. The effect of residual stresses and initial crookedness were contemplated and the various buckling parameters which are width-to-thickness ratio and rigidity of stiffeners were also considered. The moment versus rotation angle $(M-\theta)$ curves were plotted and compared the differences in ductility after the post buckling behavior while the local buckling failure modes were also observed. Based on the numerical results, empirical formulas to predict the ultimate strain were proposed in a function of the width-to-thickness ratio parameter and axial load ratio parameter. 


\section{NUMERICAL MODELS AND METHODS}

\subsection{Stiffened Box-member Cross Sections}

A unit length steel arch rib composed of box-profile rectangular cross section member with two or fours stiffeners positioned symmetrically about one axis with respect to member geometry shown in Figure 2 represents the analytical models, Figure 3 shows the cross sectional profile of the box-members. Height, flange width and web width of the analytical models are defined as $L_{d}, F$ and $W$ respectively. The aspect ratio for the arch rib are defined as $\alpha=\left(L_{d} / F\right)$ and the values of $t_{f}$, $t_{w}, b_{f}$ and $b_{w}$ are the thickness of flange, the thickness of web, the width of panel in the flange and the width of panel in the web. In addition $t_{s f}, t_{s w}, h_{s f}$ and $h_{s w}$ represent the thickness of stiffener plates and the height of stiffener plates in flange and web sides, respectively.

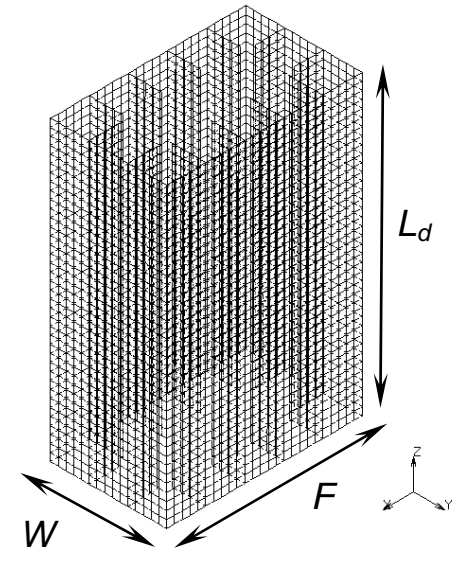

Figure 2. Analytical Model

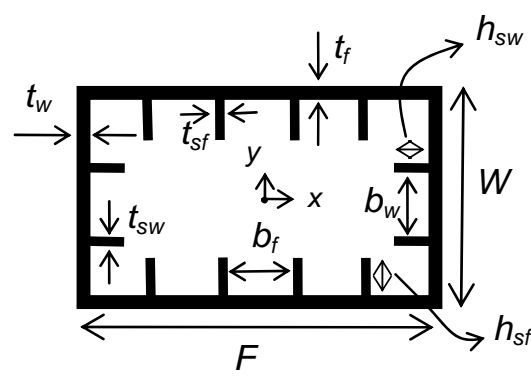

Figure 3. Cross Sectional Profile

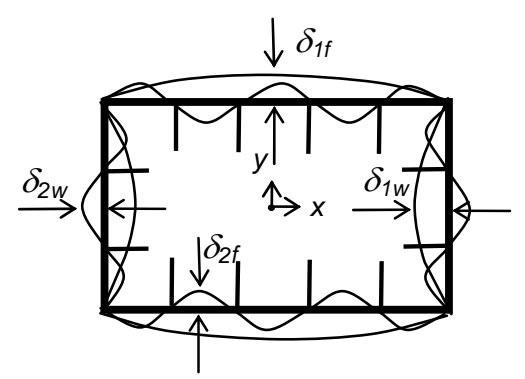

Figure 4. Initial Crookedness of Stiffened Plates

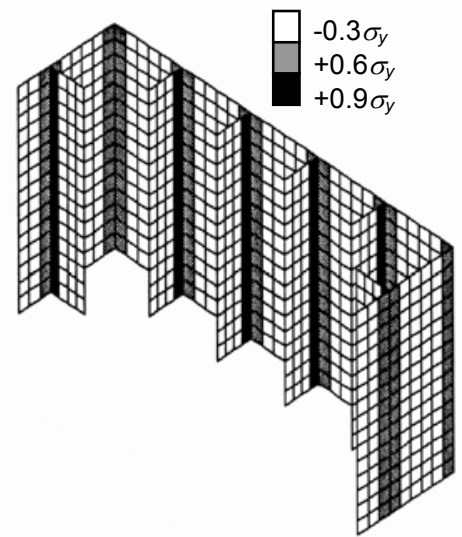

Figure 5. Distribution of Residual Stress

The steel material was assumed to be JIS-SM490 with a yield stress $\left(\sigma_{y}\right) 314 M P a$, modulus $E$ of $206 \mathrm{GPa}$, and poison's ratio $(v)$ of 0.3. The initial crookedness of both the panel flange and web plates surrounded by longitudinal stiffeners and the stiffeners were assumed to be a sinusoidal half-wave shape in transverse direction as shown in Figure 4, where its amplitude was assumed to be $\delta_{1}$ and $\delta_{2}$ as given in Eq. (1) and Eq. (2) [5]. Residual stresses distributed in trapezoidal pattern in each panel plate were assumed to be $\sigma_{r t}=0.6 \sigma_{y}, 0.9 \sigma_{y}$ and $\sigma_{r c}=-0.3 \sigma_{y}$ as indicated in Figure 5.

$$
\begin{array}{ll}
\delta_{l f} / F=7.5 \times 10^{-6}\left(F / t_{f}\right), & \delta_{1 w} / W=7.5 \times 10^{-6}\left(W / t_{w}\right) \\
\delta_{2 f} / b_{f}=5.0 \times 10^{-5}\left(b_{f} / t_{f}\right), & \delta_{2 f} / b_{w}=5.0 \times 10^{-5}\left(b_{w} / t_{w}\right)
\end{array}
$$

The structural parameters obtained from linear buckling theory are described as the followings; 
The width-to-thickness ratio parameters of the plate panel surrounded by the longitudinal stiffeners for flange and web are defined as $R_{r f}, R_{r w}$ and varied from 0.3 to 0.7 respectively. In this study, the value of $R_{r f}$ was taken to be equal to that of $R_{r w}$ and denoted as $R_{r}$. The equations are determined by.

$$
\begin{aligned}
& R_{r f}=\frac{F}{t_{f}} \sqrt{\frac{\sigma_{y}}{E} \frac{12\left(1-v^{2}\right)}{k \pi^{2}}} \\
& R_{r w}=\frac{W}{t_{w}} \sqrt{\frac{\sigma_{y}}{E} \frac{12\left(1-v^{2}\right)}{k \pi^{2}}}
\end{aligned}
$$

Where $k$ is a buckling coefficient $\left(k=4.0 n^{2}, n=\right.$ number of panels).

The width-to-thickness ratio parameters of the stiffener for flange and web are $R_{s f}$ and $R_{s w}$ and kept to be around 0.7 through all models and denoted as $R_{s}$. They are defined by the following equations.

$$
\begin{aligned}
& R_{s f}=\frac{h_{s f}}{t_{s f}} \sqrt{\frac{\sigma_{y}}{E} \frac{12\left(1-v^{2}\right)}{k \pi^{2}}} \\
& R_{s w}=\frac{h_{s w}}{t_{s w}} \sqrt{\frac{\sigma_{y}}{E} \frac{12\left(1-v^{2}\right)}{k \pi^{2}}}
\end{aligned}
$$

The rigidity of the longitudinal stiffeners compared to a panel plate in the flange side referred to the stiffness ratio of the stiffeners $\left(\gamma_{f} / \gamma_{f}^{*}\right)\left(\gamma=\right.$ relative flexural rigidity of stiffener, $\gamma^{*}=$ optimum value of $\gamma$ obtained from linear buckling theory), are defined by.

$$
\begin{aligned}
& \gamma_{f}=\frac{I_{s f}}{F t_{f}{ }^{3} / 11} \\
& \gamma_{f}^{*}=4 \alpha_{f}{ }^{2} n\left(1+n \delta_{1}\right)-\frac{\left(\alpha_{f}{ }^{2}+1\right)^{2}}{n}, \quad t_{f}<t_{o}, \alpha \leq \alpha_{o} \\
& \gamma_{f}^{*}=4 \alpha_{f}{ }^{2} n\left(1+n \delta_{1}\right)\left(\frac{t_{o}}{t_{f}}\right)^{2} \frac{\left(\alpha_{f}{ }^{2}+1\right)^{2}}{n}, t_{f} \geq t_{o}, \alpha \leq \alpha_{o}
\end{aligned}
$$

Where $I_{s f}$ is the moment of inertia of each stiffener about the base axis

$\alpha_{f}$ is the aspect ratio compared to the flange side and can be obtained from $L_{d} / F$

$L_{d}$ is the diaphragm spacing in the arch member

$n$ is number of panels in the flange side

$t_{o}=F /(24 f n)$

$f=1$ for pure compression or compression through bending.

$\delta_{1}=A_{s f} / F t_{f}$, where $A_{s f}$ is the cross sectional area of a stiffener

$\alpha_{o f}$ is the limitation of an aspect ratio in the flange side and can be obtained from

$\alpha_{o}=\sqrt[4]{1+n \gamma}$ 
The stiffener's slenderness ratio parameter [6] in the flange side, $\bar{\lambda}_{s f}$ is given by

$\bar{\lambda}_{s f}=\frac{1}{\sqrt{Q}} \frac{L_{d}}{r_{s}} \frac{1}{\pi} \sqrt{\frac{\sigma_{y}}{E}}$

Where $Q$ is the local buckling strength of the sub-panel plate and defined by

$$
\begin{aligned}
& Q=\frac{1}{2 R_{r f}}\left[\beta-\sqrt{\beta^{2}-4 R_{r f}}\right] \leq 1 \\
& \beta=1.33 R_{r f}+0.868
\end{aligned}
$$

$r_{s}$ is the radius of gyration of the T- cross section consisting of one longitudinal stiffener and the adjacent sub-panel of width $F / n$

The rigidity of the longitudinal stiffeners compared to a panel plate $\left(\gamma_{w} / \gamma_{w}{ }^{*}\right)$ and the stiffener's slenderness ratio parameter $\left(\lambda_{s w}\right)$ in the web side can also be obtained from the similar equations calculated for the flange side.

The analyses were carried out by using the FEM package program [7] on the full section of members along the unit length and simply supported boundary conditions were applied in all cases. The elasto-plastic large displacement analyses were performed and a plate element type of fournode quad was applied. The stress-strain curve used in these analyses was assumed to be multi-linear where strain hardening first occurs at the strain $\varepsilon_{s t}, 7$ times of the yield strain $\varepsilon_{y}$ and the hardening modulus $E_{s t}$ is $E / 30$ as shown in Figure 6.

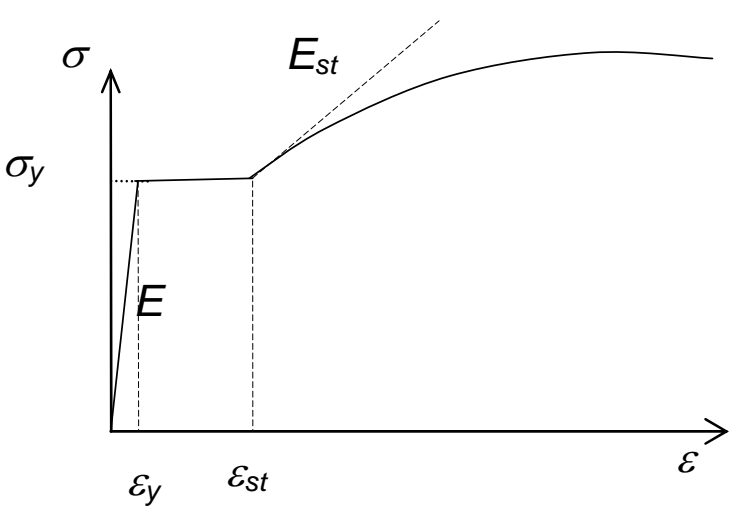

Figure 6. Multi-linear Stress-strain Relationship

\subsection{Aspect Ratio of the Arch Member obtained from the Pure Compression Analysis}

Rectangular cross section $1500 \mathrm{~mm}$ x $900 \mathrm{~mm}$ was chosen to determine the aspect ratio of the arch rib which the lowest maximum strength is expected under the pure compression analysis by using the displacement control as shown in Figure 7. By considering the parameters obtained from linear buckling theory as mentioned above, six values of the aspect ratio of the stiffened plate in the flange side $\left(\alpha_{f}\right)$ applied for the real arch bridges were chosen to be 1.0, 1.1, 1.2, 1.3, 1.4 and 1.5 and represented to be A, B, C, D, E, and F models, respectively. The width-to-thickness ratio parameters of the plate panel surrounded by the longitudinal stiffeners for flange and web $\left(R_{r f}\right.$ and $R_{r w}$ ) were ranged from 0.3 to 0.7 . The width-to-thickness ratio parameters of the stiffener for web

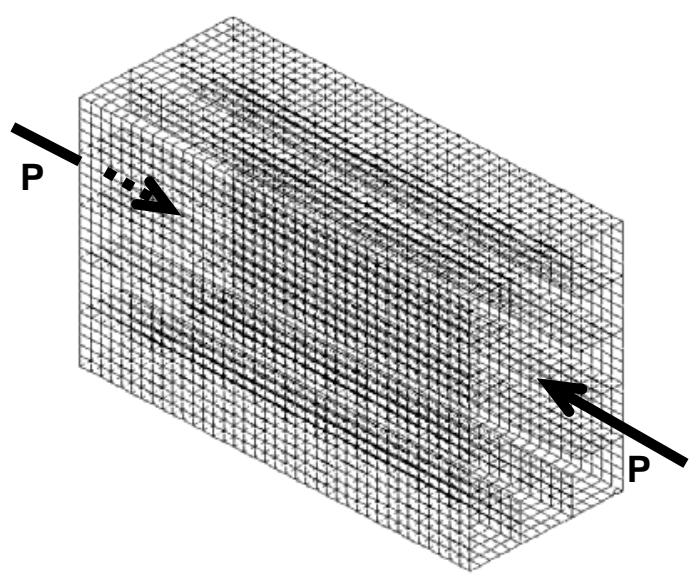

Figure 7. Pure Compression Analysis Model 
and flange ( $R_{s f}$ and $R_{s w}$ ) were fixed to be 0.7 and the stiffness ratio of the stiffeners in both flange and web panels $\left(\gamma / \gamma^{*}\right)$ was also kept to be 3.0 constantly. Table 1 shows the geometries and structural parameters obtained from linear buckling theory for these models. Figure 8 shows the plots between the equivalent strength ratio $\sigma / \sigma_{y}$ versus the equivalent strain ratio $\varepsilon / \varepsilon_{y}$ for the values analyzed from F models. The optimum aspect ratio in the arch member could be obtained by considering the minimum ultimate strength ratio versus $R_{r}$ values in Figure 9 where the value of $\alpha$ equal to1.5 (F model) gave the lowest ultimate strength ratio in all cases

Table 1. Geometries and Structural Parameters used in Pure Compression Analysis

\begin{tabular}{|c|c|c|c|c|c|c|c|c|c|c|c|c|c|c|c|}
\hline \multirow{2}{*}{ No. } & \multirow{2}{*}{$\begin{array}{c}\text { Model } \\
\text { types }\end{array}$} & \multicolumn{6}{|c|}{ Structural parameters } & \multicolumn{4}{|c|}{ Flange side $(\mathrm{mm})$} & \multicolumn{4}{|c|}{ Web side $(\mathrm{mm})$} \\
\hline & & $R_{s}$ & $\gamma / \gamma^{*}$ & $\alpha_{f}$ & $\widehat{\alpha_{0 f}}$ & $\alpha_{\text {ow }}$ & $R_{r}$ & \multirow[t]{2}{*}{$F$} & $\overrightarrow{t_{f}}$ & $\overrightarrow{h_{s f}}$ & $\overline{t_{s f}}$ & $W$ & $t_{w}$ & $h_{s w}$ & $t_{s w}$ \\
\hline 1 & $\mathrm{~A} 03$ & \multirow{18}{*}{0.7} & \multirow{18}{*}{3.0} & \multirow{3}{*}{1.0} & 3.54 & 3.30 & 0.3 & & 20.5 & 187.3 & 16.8 & \multirow{18}{*}{900} & 20.5 & 174.6 & 15.7 \\
\hline 2 & A05 & & & & 4.73 & 4.64 & 0.5 & \multirow{17}{*}{1500} & 12.3 & 171.0 & 15.4 & & 12.3 & 167.6 & 15.1 \\
\hline 3 & A07 & & & & 4.64 & 4.54 & 0.7 & & 8.8 & 130.0 & 11.7 & & 8.8 & 127.3 & 11.5 \\
\hline 4 & B03 & & & \multirow{3}{*}{1.1} & 3.76 & 3.47 & 0.3 & & 20.5 & 198.6 & 17.9 & & 20.5 & 183.4 & 16.5 \\
\hline 5 & B05 & & & & 5.03 & 4.92 & 0.5 & & 12.3 & 181.8 & 16.4 & & 12.3 & 177.7 & 16.0 \\
\hline 6 & B07 & & & & 4.92 & 4.80 & 0.7 & & 8.8 & 137.9 & 12.4 & & 8.8 & 134.7 & 12.1 \\
\hline 7 & $\mathrm{C} 03$ & & & \multirow{3}{*}{1.2} & 3.96 & 3.62 & 0.3 & & 20.5 & 209.6 & 18.6 & & 20.5 & 191.6 & 17.2 \\
\hline 8 & $\mathrm{C} 05$ & & & & 5.33 & 5.19 & 0.5 & & 12.3 & 192.4 & 17.3 & & 12.3 & 187.6 & 16.9 \\
\hline 9 & $\mathrm{C} 07$ & & & & 5.19 & 5.06 & 0.7 & & 8.8 & 145.7 & 13.1 & & 8.8 & 141.9 & 12.8 \\
\hline 10 & D03 & & & \multirow{3}{*}{1.3} & 4.17 & 3.77 & 0.3 & & 20.5 & 220.4 & 19.8 & & 20.5 & 199.1 & 17.9 \\
\hline 11 & D05 & & & & 5.61 & 5.46 & 0.5 & & 12.3 & 202.9 & 18.3 & & 12.3 & 197.4 & 17.6 \\
\hline 12 & D07 & & & & 5.47 & 5.31 & 0.7 & & 8.8 & 153.3 & 13.8 & & 8.8 & 149.0 & 13.4 \\
\hline 13 & E03 & & & \multirow{3}{*}{1.4} & 4.37 & 3.90 & 0.3 & & 20.5 & 231.0 & 20.8 & & 20.5 & 206.0 & 18.5 \\
\hline 14 & E05 & & & & 5.90 & 5.73 & 0.5 & & 12.3 & 213.3 & 19.2 & & 12.3 & 207.0 & 18.6 \\
\hline 15 & E07 & & & & 5.74 & 5.55 & 0.7 & & 8.8 & 160.9 & 14.5 & & 8.8 & 155.8 & 14.0 \\
\hline 16 & F03 & & & \multirow{3}{*}{1.5} & 4.56 & 4.01 & 0.3 & & 20.5 & 241.4 & 21.7 & & 20.5 & 212.1 & 19.1 \\
\hline 17 & F05 & & & & 6.19 & 5.99 & 0.5 & & 12.3 & 223.5 & 20.1 & & 12.3 & 216.5 & 19.5 \\
\hline 18 & F07 & & & & 6.00 & 5.79 & 0.7 & & 8.8 & 168.3 & 15.2 & & 8.8 & 162.5 & 14.6 \\
\hline
\end{tabular}

\subsection{Concrete Filled Sections}

The concrete filled box sections with longitudinal stiffeners were further investigated by focusing on the $\mathrm{F}$ model $(\alpha=1.5$ ) which the lowest maximum strength had been obtained. In order to validate the analytical results and to understand their behavior gradually, the five values of $R_{r}$ ranged from 0.3 to 0.7 increasing in 0.1 steps would be analyzed and represented by CF03 to CF07 models respectively. The equivalent section concept was brought to transform the original stiffened section to the equivalent section by preserving the constant sectional area $A$, and plastic section modulus $Z$ [8]. The original and equivalent sections are shown in Figure 10. Flange and web widths of transformed section were kept to be constant as same as the original one. Equivalent flange and web thicknesses are defined as $\bar{t}_{f}$ and $\bar{t}_{w}$ respectively, and the equivalent sectional area can be calculated by Eq. (13) to Eq. (15).

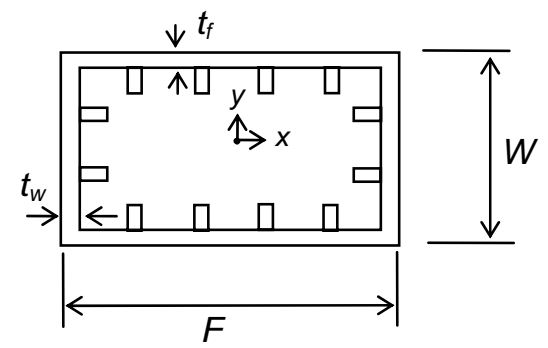

(a) Original Section

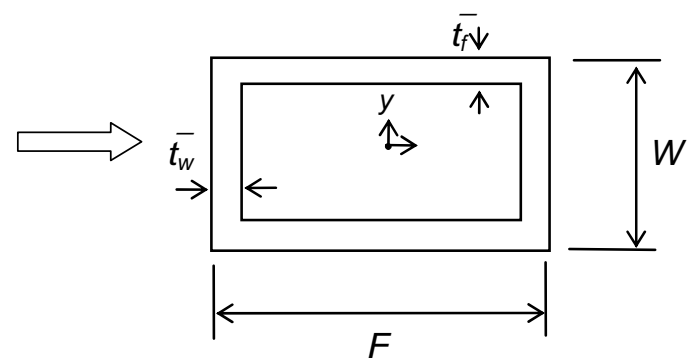

(b) Equivalent Section

Figure 10. Transformation of Concrete Filled Box-section $A=2 \overline{F t_{f}}+\left(W-2 \bar{t}_{f}\right) \bar{t}_{w}$ 
$\bar{t}_{f}=\frac{4 Z-A W}{2(F W-A)}$

$\bar{t}_{w}=\frac{A-2 \overline{F t}_{f}}{2\left(W-2 \bar{t}_{f}\right)}$

Note that $Z$ is the plastic section modulus about the $x$ axis.

The plastic moment about the $x$-axis, $M_{p}$ is also defined by Eq. (16)

$M_{p}=F \bar{t}_{f}\left(W-\bar{t}_{f}\right) \sigma_{y f}+\frac{1}{2}\left(W-2 \bar{t}_{f}\right)^{2} \bar{t}_{w} \sigma_{y w}$

Which $\sigma_{y f}$ and $\sigma_{y w}$ represent the yield stress of the steel, $\sigma_{y}$.

The structural, geometrical and sectional properties of the original and equivalent sections of $\mathrm{F}$ models are shown in Table 2. For the concrete material's properties, the Young's modulus $(E)$ was assumed to be $24.5 \mathrm{GPa}$, compressive strength $\left(\sigma_{c}\right) 23.5 \mathrm{MPa}$ and poison's ratio $(v)$ of 0.20 , respectively. The same residual stresses distributed in trapezoidal pattern applied to the stiffened box-sections were treated. The initial crookedness shown in Figure 11 was assumed to be a cosine half-wave where its amplitude was assumed to be $F / 150$ and $W / 150$ in flange and web panels, respectively.

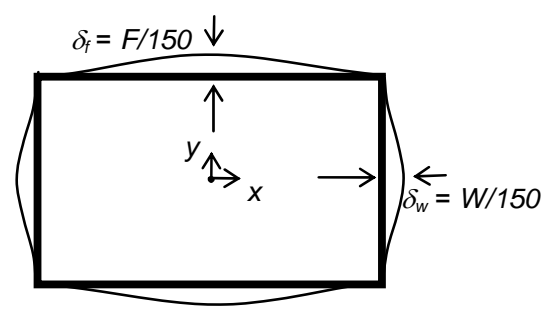

Figure 11. Cosine Half-wave Initial Crookedness

Table 2. Structural, Geometrical and Sectional Properties of CF Models

\begin{tabular}{|c|c|c|c|c|c|c|c|c|c|c|c|c|c|}
\hline \multirow{2}{*}{ No } & \multirow{2}{*}{$\begin{array}{l}\text { Model } \\
\text { Types }\end{array}$} & \multicolumn{3}{|c|}{ Structural parameters } & \multicolumn{5}{|c|}{ Original geometries (mm) } & \multicolumn{2}{|c|}{$\begin{array}{l}\text { Transformed } \\
\text { Geometries } \\
(\mathrm{mm})\end{array}$} & \multicolumn{2}{|c|}{$\begin{array}{l}\text { Sectional } \\
\text { properties }\end{array}$} \\
\hline & & $\mathrm{Rr}$ & $\lambda s f$ & $\lambda s w$ & $\mathrm{tf}, \mathrm{tw}$ & hsf & tsf & hsw & tsw & $\bar{t}_{f}$ & $\bar{t}_{w}$ & $\begin{array}{c}\mathrm{A}(\mathrm{mm} 2) \\
\times 102\end{array}$ & $\begin{array}{c}\mathrm{Z}(\mathrm{mm} 3) \\
\mathrm{X} 103\end{array}$ \\
\hline 1 & CF03 & 0.3 & 0.3435 & 0,4072 & 20.5 & 241.4 & 21.7 & 212.1 & 19.1 & 25.3 & 46.5 & 1549 & 49965 \\
\hline 2 & $\mathrm{CFO4}$ & 0.4 & 0.3303 & 0.3549 & 15.4 & 232.7 & 20.9 & 220.2 & 19.8 & 19.8 & 40.6 & 1293 & 41213 \\
\hline 3 & CF05 & 0.5 & 0.3366 & 0.3506 & 12.3 & 223.5 & 20.1 & 216.5 & 19.5 & 16.6 & 35.5 & 1114 & 35359 \\
\hline 4 & CF06 & 0.6 & 0.4035 & 0.4214 & 10.3 & 191.6 & 17.2 & 185.2 & 16.7 & 14.1 & 26.1 & 876 & 28597 \\
\hline 5 & CF07 & 0.7 & 0.4741 & 0.4957 & 8.8 & 168.3 & 15.2 & 162.5 & 14.6 & 12.1 & 20.3 & 718 & 23884 \\
\hline
\end{tabular}




\section{BENDING ANALYSIS UNDER AXIAL COMPRESSION}

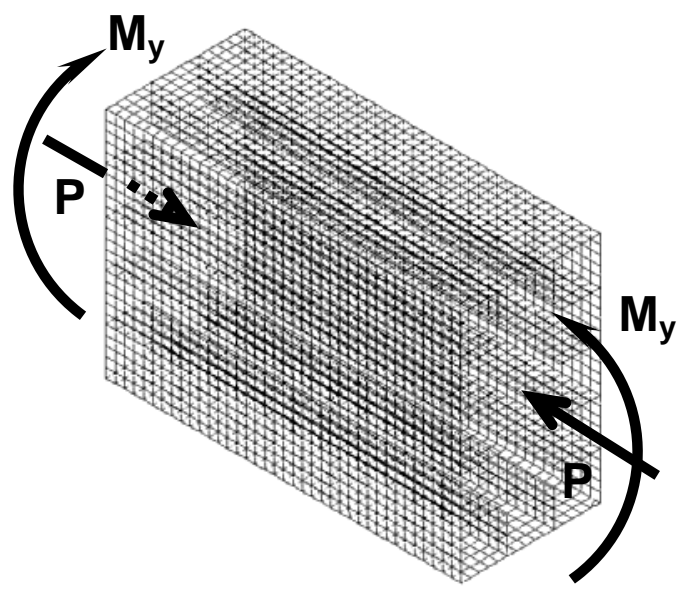

(a) In-plane Bending Moment

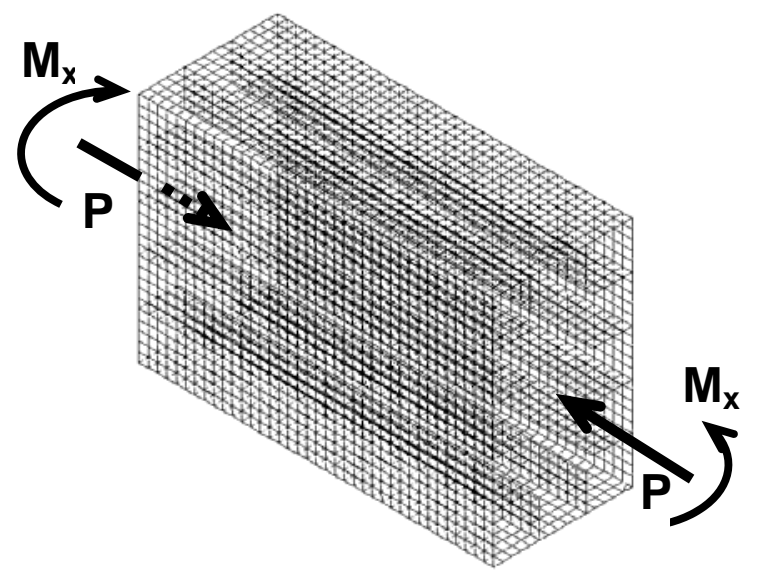

(b) Out-of-plane Bending Moment

Figure 12. Bending Analytical Models under Axial Compression

These analyses were performed in two stages, initially, the F models of stiffened box cross-sections would be investigated the ultimate state of the stub column subjected to the in-plane and out-of-plane bending moment (about y and x-axes in this case) by using the rotation control under various ratios of compressive load. Latterly, the $\mathrm{F}$ models of the equivalent stiffened ones with concrete filled would be further examined by emphasizing on the ultimate state of the stub column subjected to the out-of-plane bending moment by using the same method mentioned previously. The analytical models under the compressive loads subjected to in-plane and out-of-plane bending moments are shown in Figures 12(a) and 12(b), respectively. In all analyses, both bending moment and compressive load were applied to only on the steel section through the top and bottom rigid plates and the concrete elements were merely allowed to prevent the failure from the concave local buckling of the component plates. In order to investigate the effect of axial load on the ultimate moment and ultimate strain, the load ratios $P / P_{y}$, were ranged from 0 to 0.8 , where $P_{y}$ represents the yield compressive strength obtained from the elastic theory. For the concrete filled model analyses, the same numerical analyses and boundary conditions applied for the stiffened box-cross section were applied to the steel in these equivalent sections. A type of eight-node hex solid element was applied to concrete elements and the contact bodies analysis was applied to constrain the nodes on the exterior surfaces in both steel and concrete elements not to penetrate to each other including their own bodies. 
4. RESULTS AND DISCUSSIONS

\subsection{Stiffened Box Cross-section Models}

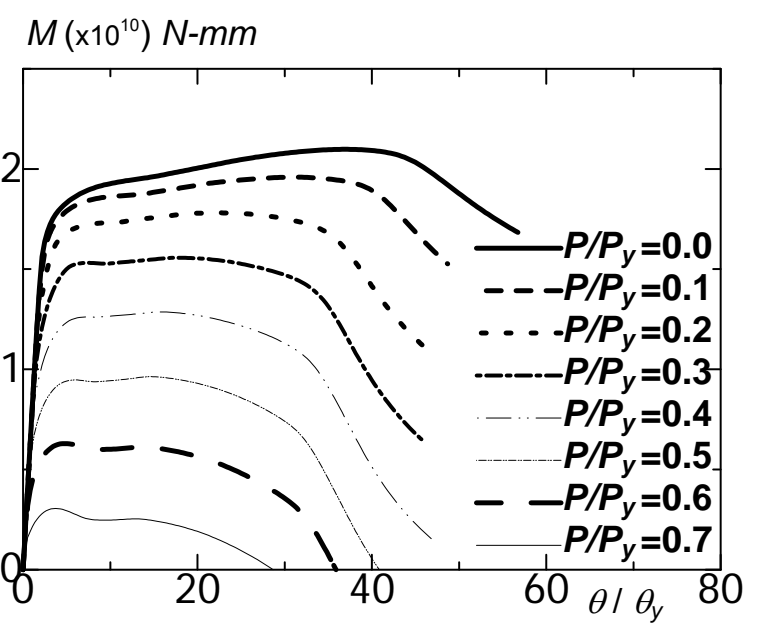

(a) $R_{r}=0.3$

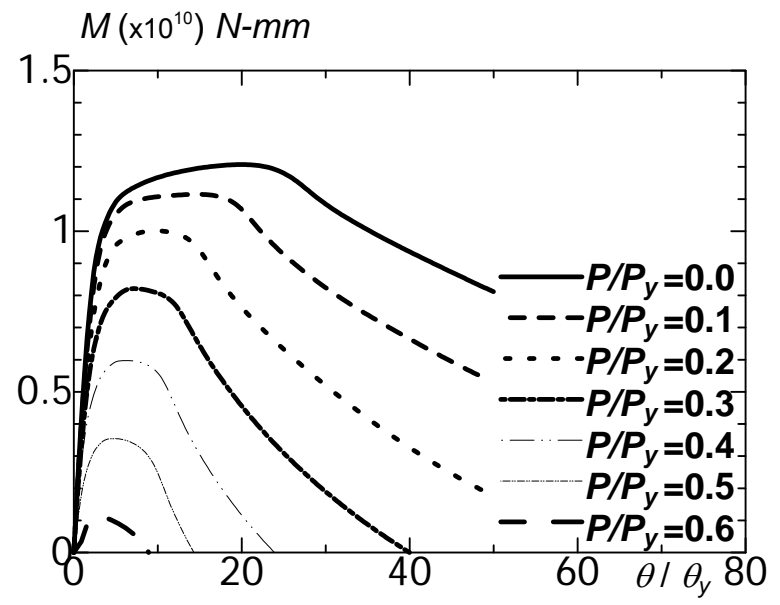

(b) $R_{r}=0.5$

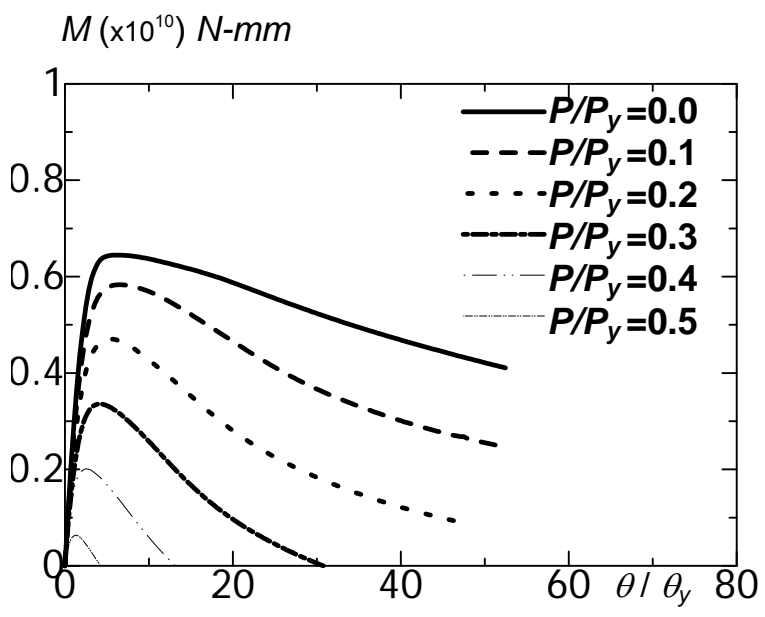

(c) $R_{r}=0.7$

Figure 13. Results obtained from In-plane Bending Analyses
$M\left(\times 10^{10}\right) N-m m$

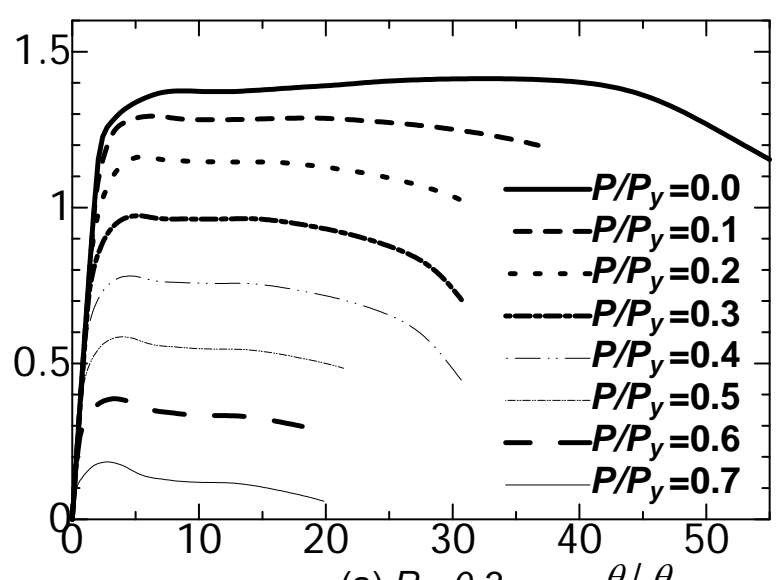

(a) $R_{r}=0.3$

$\theta / \theta_{y}$

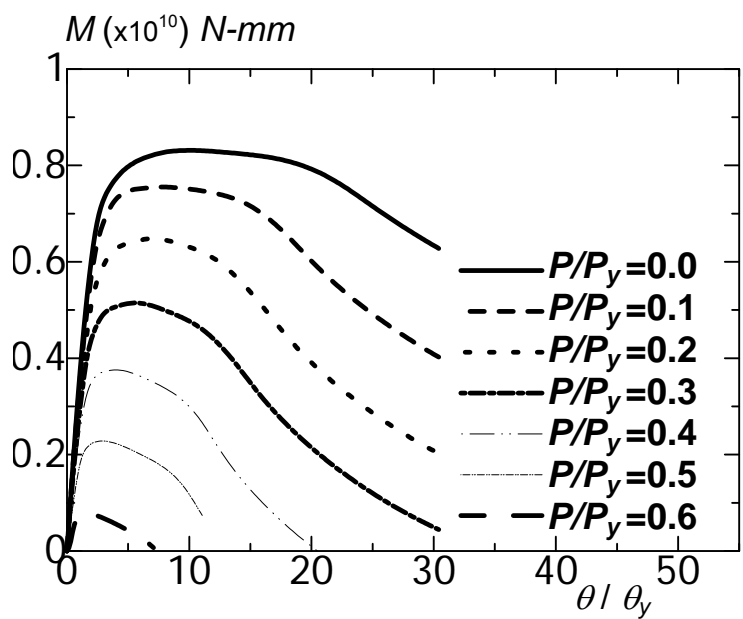

(b) $R_{r}=0.5$

$M\left(\times 10^{10}\right) N-m m$

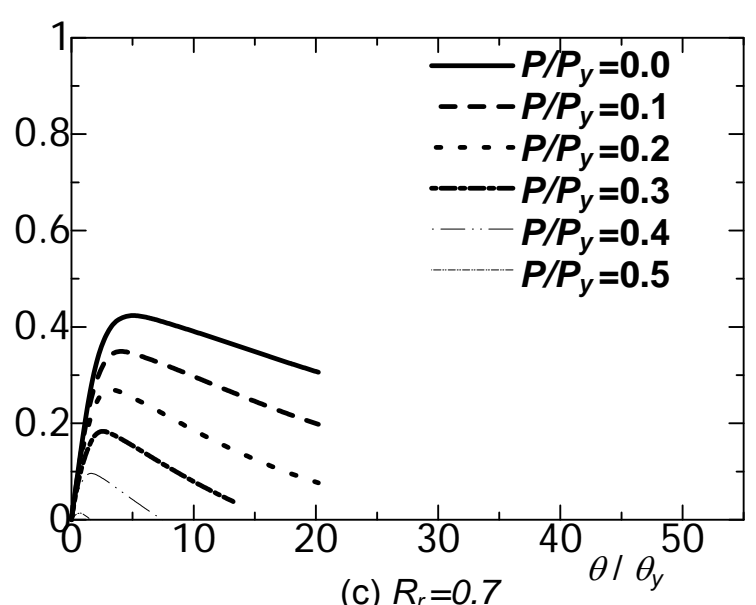

Figure 14. Results obtained from Out-of-plane 
The analytical results would be plotted between the reaction moment $M$ versus the applied rotation angle ratio $\theta / \theta_{y}$, where $\theta_{y}$ refers to the yield rotation angle which induces the axial yield strain $\varepsilon_{y}$. Figures 13(a), 13(b), 13(c) show the analytical results obtained from the in-plane bending analyses of the stiffened box cross-sections while Figures 14 (a), 14 (b) and 14 (c) are taken from the out-of-plane. Both results from in-plane and out-of-plane analyses clearly showed the similar phenomenon. It was found that for the same value of $R_{r}$, the reaction moment tended to decrease when the load ratio increased. When $R_{r}$ equals to 0.5 and 0.7 , the moment values were found to decrease more rapidly than when $R_{r}$ equals to 0.3 for the same ratio of axial load in the large amount of rotation after the local buckling of the component plates had occurred. Numerical analyses of the load ratios over than 0.7 in model $R_{r}=0.3,0.6$ in model $R_{r}=0.5$ and 0.5 in model $R_{r}$ $=0.7$ could not be achieved because the severe local buckling occurred in the early stage of the analyses and the calculations could not be longer performed. The results suggested that the effects of the axial load ratio and the structural parameter $R_{r}$ on the ultimate strength of the member considered as a stub column were large. The analytical results also indicate that the reaction maximum moments obtained from the in-plane bending analyses were larger than the out-of-plane's results in any cases of the $R_{r}$ and the axial load values. In order to consider the ultimate state of stub columns, the plots of ultimate moment $M_{u}$ versus $R_{r}$ and the plots of ultimate strain ratio $\varepsilon_{u} / \varepsilon_{y}$ versus the product of structural parameters $R_{r}\left(\bar{\lambda}_{\mathrm{sf}} \bar{\lambda}_{\mathrm{sw}}\right){ }^{0.09}$ were considered, where $M_{u}$ is defined as the moment corresponding to $95 \%$ of the maximum moment after the peak region and $\varepsilon_{u}$ refers to the strain corresponding to $M_{u}$ at the outmost edge of the compressive side. The ultimate moment values are shown in Figure 15(a), 15(b) and the ultimate strain ratios are shown in Figure 16(a) and Figure 16(b) while (a) and (b) represent the results obtained from in-plane and out-of-plane analyses respectively. It was obviously recognized that the ultimate moment decreased when the load ratio increased for all values of $R_{r}$. The slightly difference in the ultimate moment compared to the result obtained from the next value of load ratio were found when the load ratios were small and these differences in the ultimate moment tended to increase when the load ratios were larger.

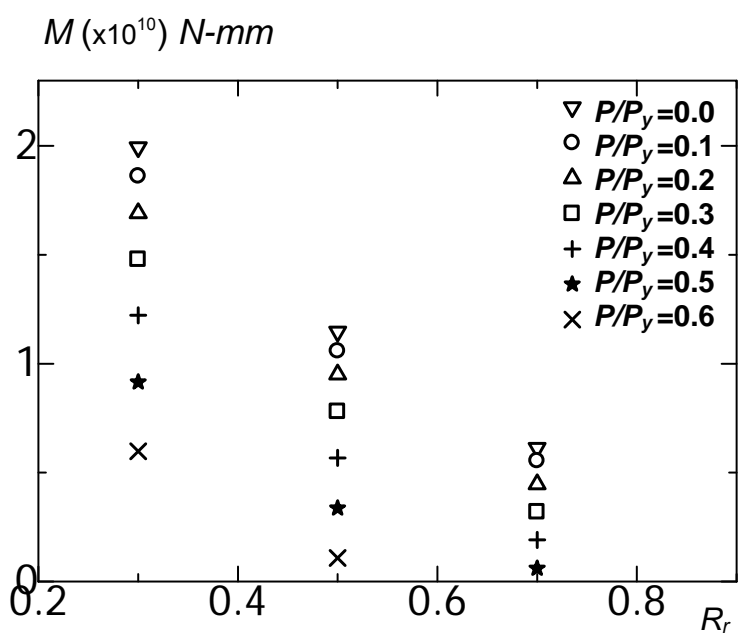

(a) In-plane Analyses

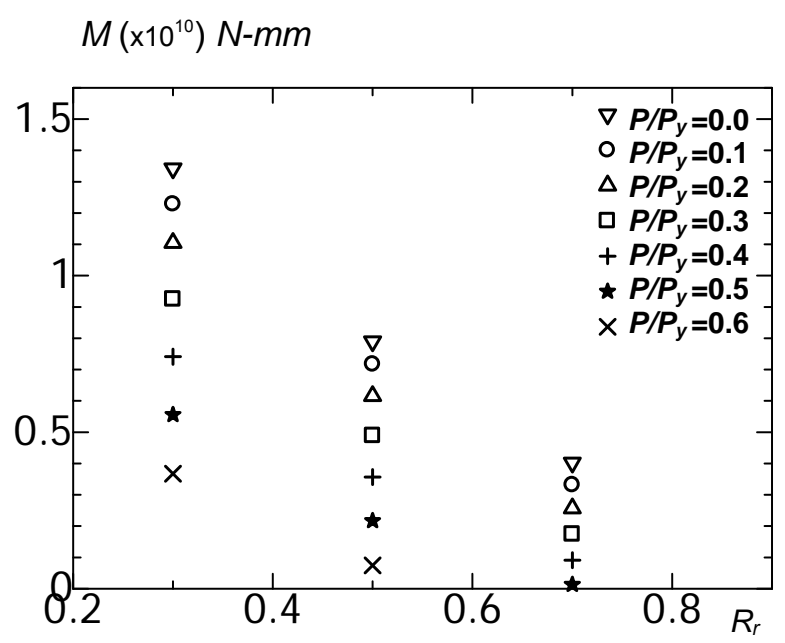

(b) Out-of-plane Analyses

Figure 15. The Ultimate Moment Values at the Ultimate State 


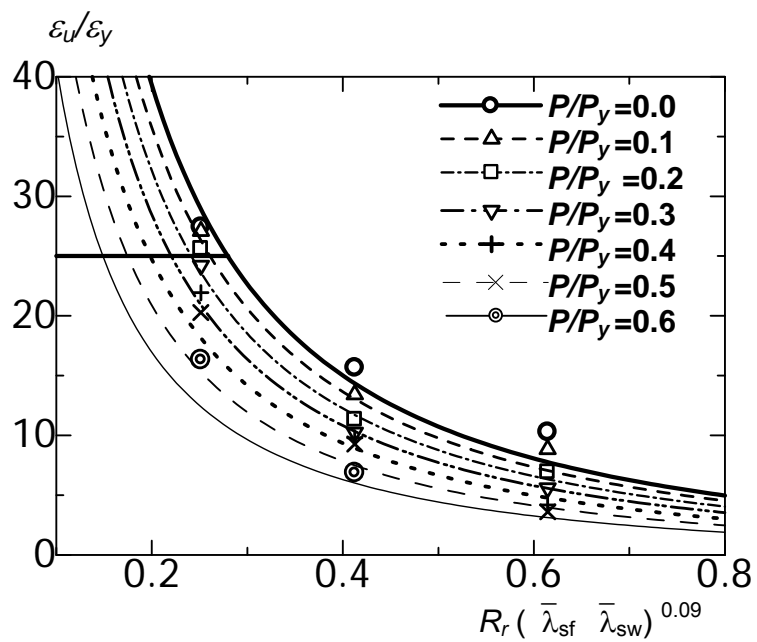

(a) In-plane Analyses

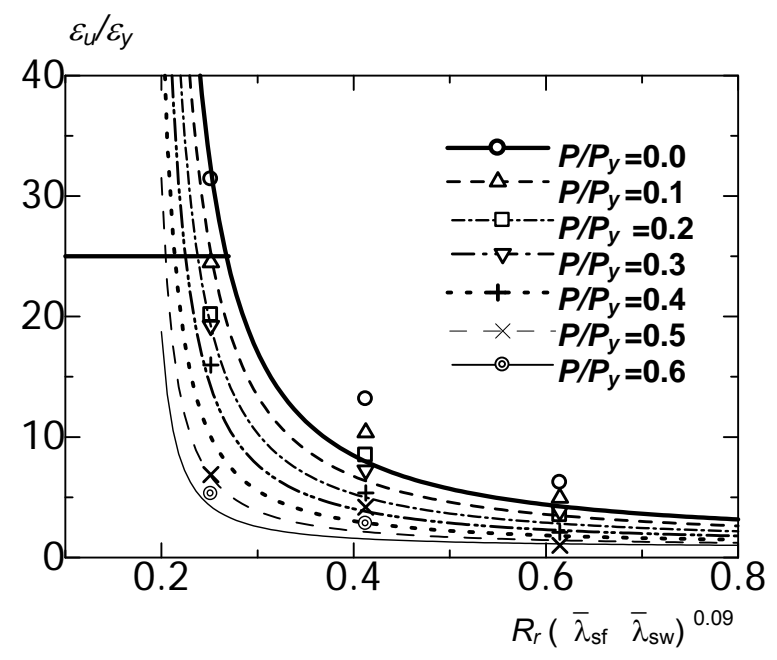

(b) Out-of-plane Analyses

Figure 16. The Ultimate Strain Ratios at the Ultimate State

By considering the results in Figure 16(a) and Figure 16(b), the strain ratios obtained from in-plane analyses were mostly found slightly higher than the ones obtained from out-of-plane analyses for the same values of the structural parameters and the axial load ratio. The design formulas obtained from the least square method of the ultimate strains judged from the safety of the whole segments in both in-plane and out-of-plane can be proposed by the following equations.

In-plane, $\quad \varepsilon_{u} / \varepsilon_{y}=\frac{4.9}{\left(R_{r}\left(\bar{\lambda}_{s f} \bar{\lambda}_{s w}\right)^{0.09}-0.16\right)^{1.4}\left(1-P / P_{y}\right)^{0.9}}-\frac{1.5}{\left(1+P / P_{y}\right)} \leq 25$

Out-of-plane, $\quad \varepsilon_{u} / \varepsilon_{y}=\frac{1}{\left(R_{r}\left(\bar{\lambda}_{s f} \bar{\lambda}_{s w}\right)^{0.09}-0.18\right)^{1.3}\left(1-P / P_{y}\right)^{2.4}}+\frac{1.3}{\left(1+P / P_{y}\right)} \leq 25$

When $0.3 \leq R_{r} \leq 0.7$ and $0 \leq P / P_{y} \leq 0.6$

\subsection{Equivalent Stiffened Box Cross-section Models with Concrete Filled}

Figure 17(a) to Figure 17(e) show the analytical results obtained from the out-of-plane bending analyses of the equivalent stiffened box cross-section models with concrete filled. It can be noted that the concrete filled models can develop the out-of-plane ultimate moment at the ultimate state compared to the results obtained from the stiffened box cross-section models and the greater values were found where the width-to-thickness ratio parameters and the axial load ratios were small. To obtain the ultimate state of the members, the same method used previously was applied by considering the plots of ultimate moment and ultimate strain ratio as shown in Figure 18 and Figure 19. Because of the difference and complexity of the post buckling modes occurred due to the different values of $R_{r}$ and the axial load values, the moment corresponding to $97 \%$ of the maximum moment after the peak region was determined to represent the ultimate moment, $M_{u}$ and the ultimate strain, $\varepsilon_{u}$ still refers to the strain corresponding to $M_{u}$. In order to clearly understand the behavior during the ultimate state, the post buckling behaviors and mode shapes observed in steel plates during the ultimate state and the failure of concrete characteristics will be described in next topic. 
$M\left(\times 10^{10}\right) N-m m$

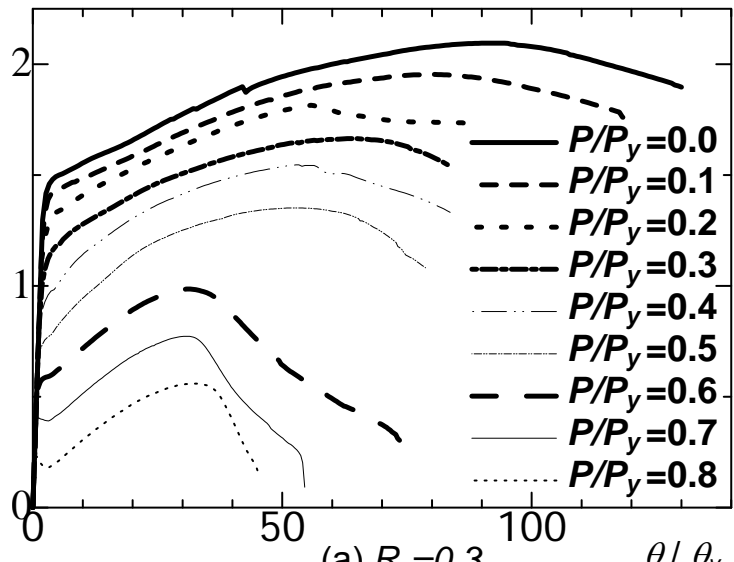

(a) $R_{r}=0.3$

$M\left(\times 10^{10}\right) N-m m$

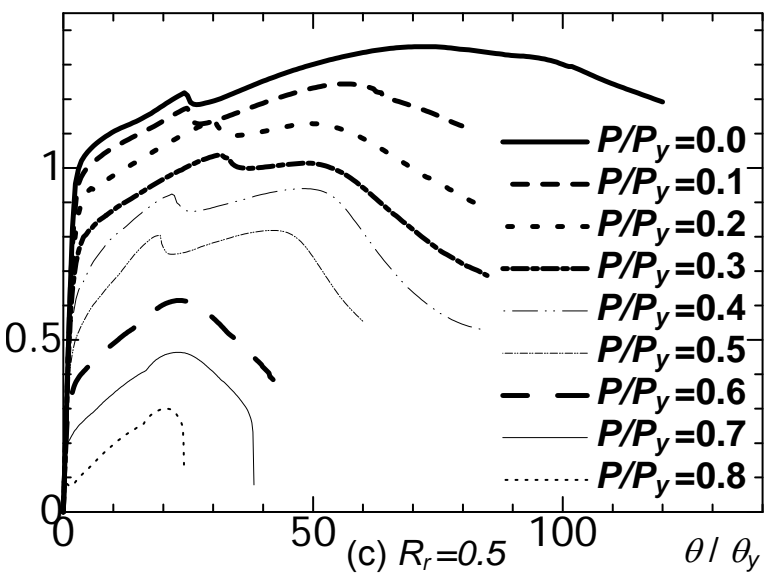

$M\left(\times 10^{10}\right) N-m m$

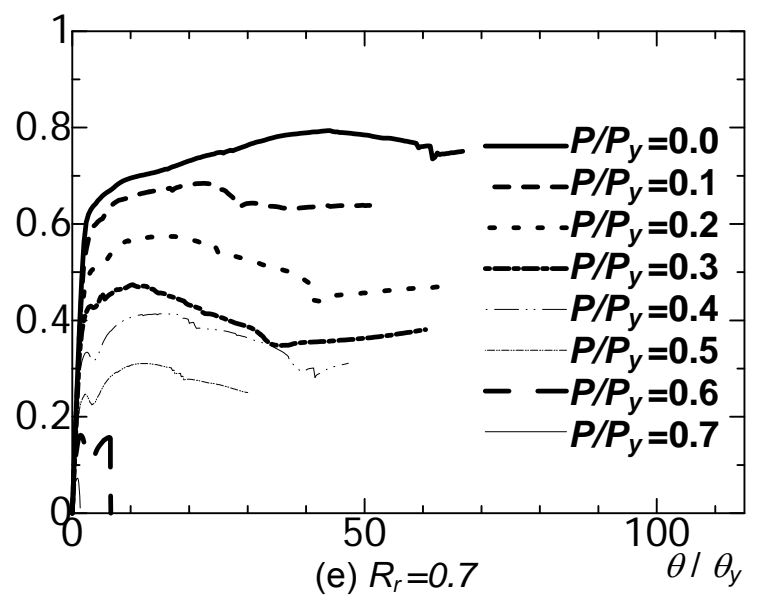

Figure 17. Results obtained from Equivalent Stiffened Box -section with Concrete Filled Models

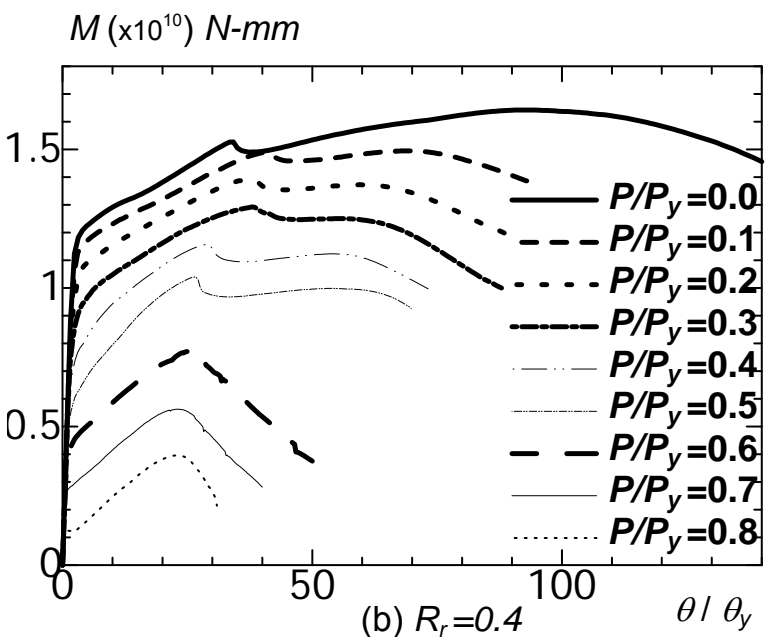

$M\left(\times 10^{10}\right) N-m m$

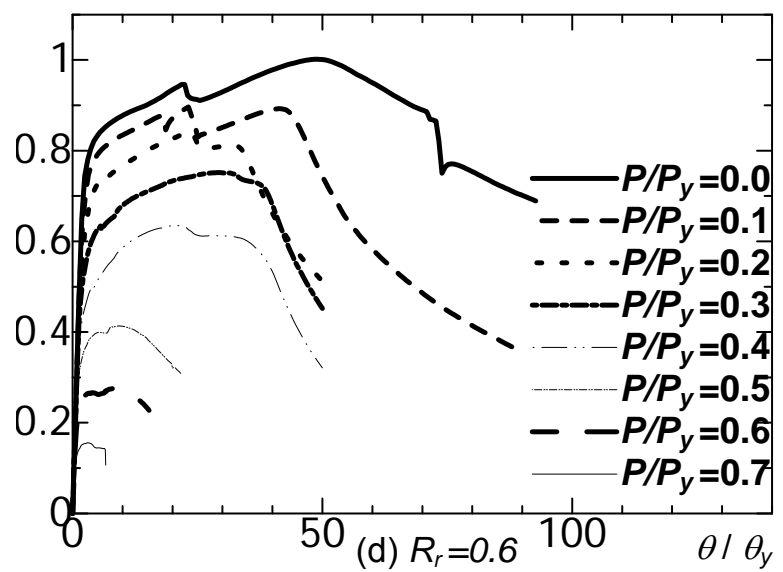

$M\left(\times 10^{10}\right) N-m m$

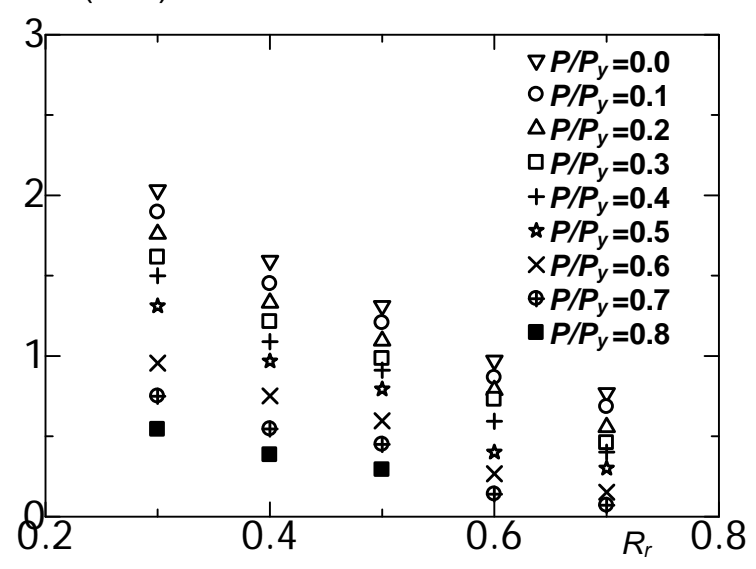

Figure 18. The Ultimate Moment Values 


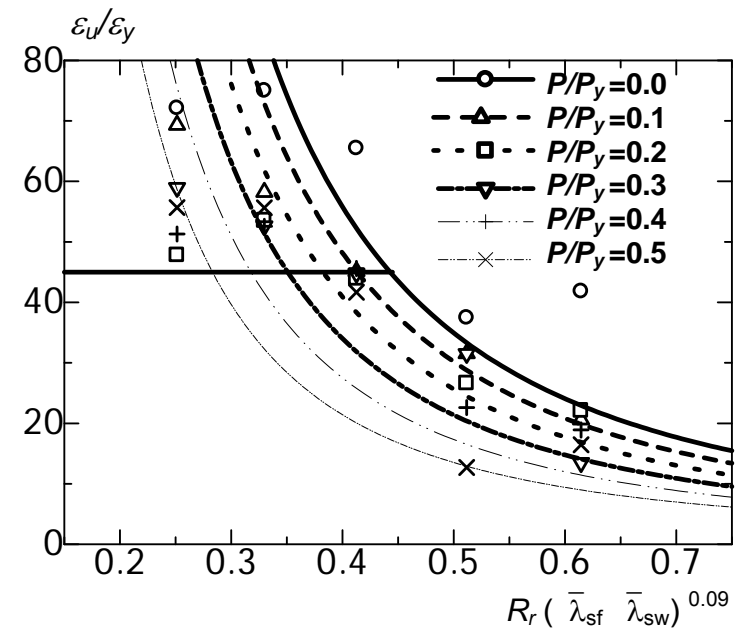

(a) $0.0 \leq P / P_{y} \leq 0.5$

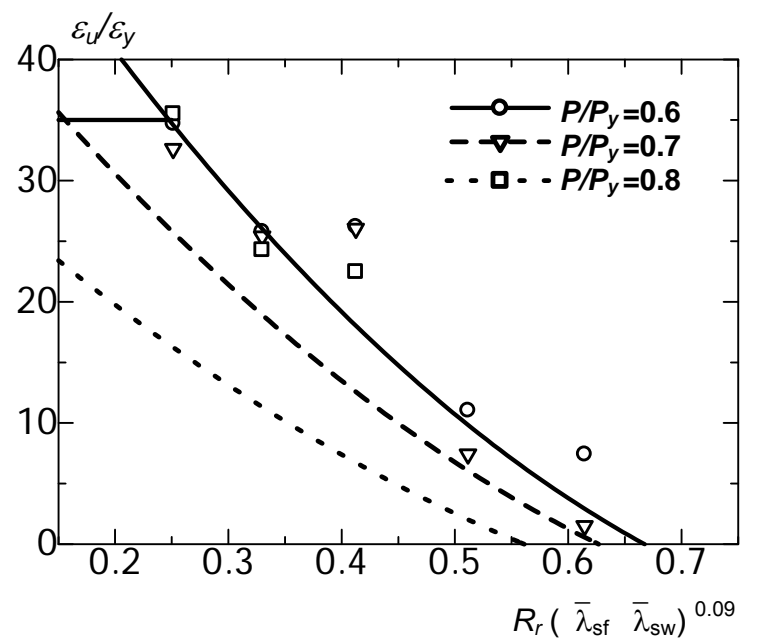

(b) $0.6 \leq P / P_{y} \leq 0.8$

Figure 19. The Ultimate Strain Values obtained from Concrete Filled Models

Because the local buckling modes observed when the axial load ratios are higher than 0.5 differed from the others, the ultimate strain values will also be considered separately as shown in Figure 19(a) and Figure 19(b) respectively. Once again, the empirical formula obtained from the least square method of the ultimate strain for the equivalent stiffened box cross-section models with concrete filled in out-of-plane can be proposed by the following equations.

$\varepsilon_{u} / \varepsilon_{y}=\frac{7.5}{\left(R_{r}\left(\bar{\lambda}_{s f} \bar{\lambda}_{s w}\right)^{0.09}-0.03\right)^{2}\left(1-P / P_{y}\right)^{1.4}}+\frac{1}{\left(1+P / P_{y}\right.} \leq 45$

When $0.3 \leq R_{r} \leq 0.7$ and $0 \leq P / P_{y} \leq 0.5$

$\left.\varepsilon_{u} / \varepsilon_{y}=160\left(R_{r}\left(\bar{\lambda}_{s f} \bar{\lambda}_{s w}\right)^{0.09}-1\right)^{2}\left(1-P / P_{y}\right)^{0.8}\right)-8.5 \leq 35$

When $0.3 \leq R_{r} \leq 0.7$ and $0.6 \leq P / P_{y} \leq 0.8$

\subsection{Post Buckling Behavior of Stiffened Box Cross-section Models with Concrete Filled}

Finally, the post buckling behavior of the concrete filled models will be investigated by the comparison of the moment ratio $M / M_{p}$ versus the rotation angle ratio $\theta / \theta_{y}$ plots between the out-of-plane's numerical results obtained from stiffened box sectional models (F) and concrete-filled models (CF) for $R_{r}=0.3$ and 0.5 as shown in Figures 20(a) and 20(b), respectively. The relations show that after the buckling occurs, the increasing of moment ratio in the large rotation applied region is observed for each concrete filled model and it can be implied that the use of concrete with stiffeners in arch member box-section can improve the member's ductility in the post buckling state. In order to discuss the development in ultimate moment and ductility phenomena, two observations are suggested in the following comments. 


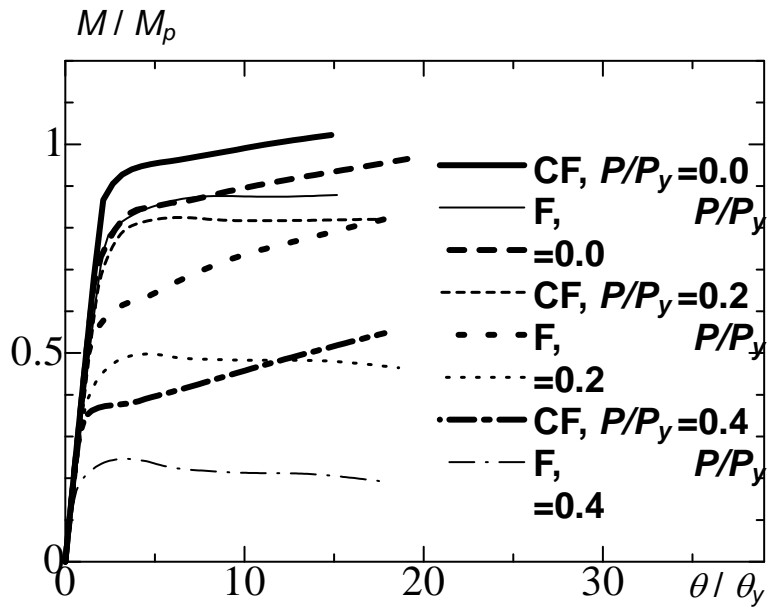

(a) $R_{r}=0.3$

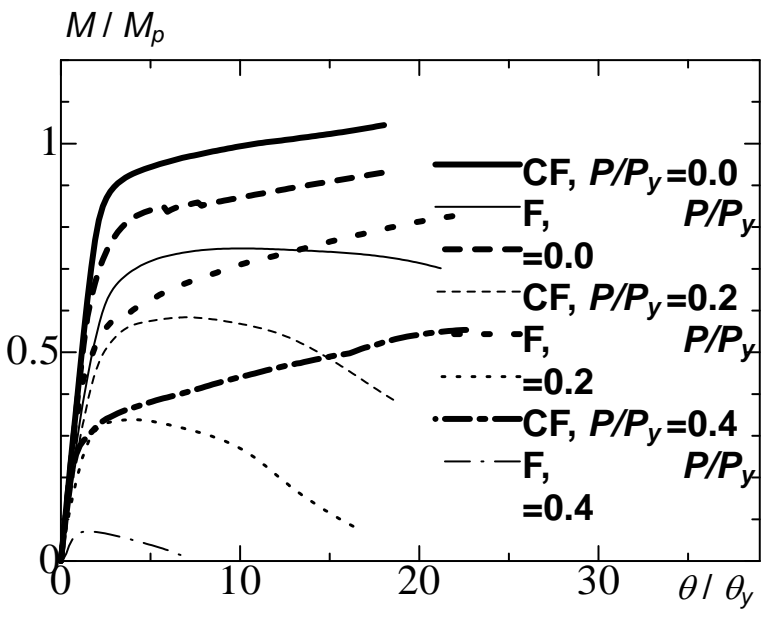

(b) $R_{r}=0.5$

Figure 20. Comparisons between Stiffened Box Sectional Models and Concrete Filled Models

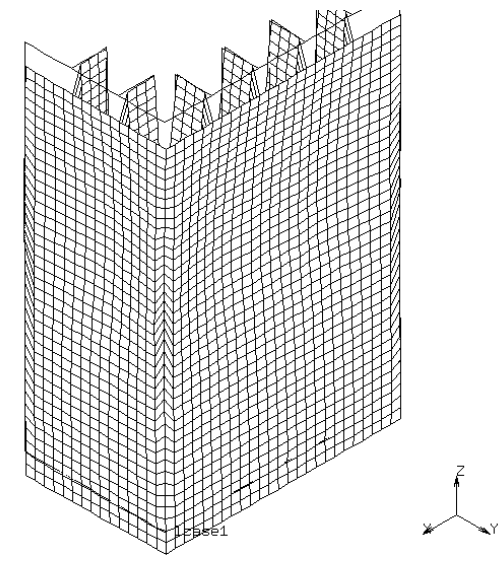

(a) 3-D View

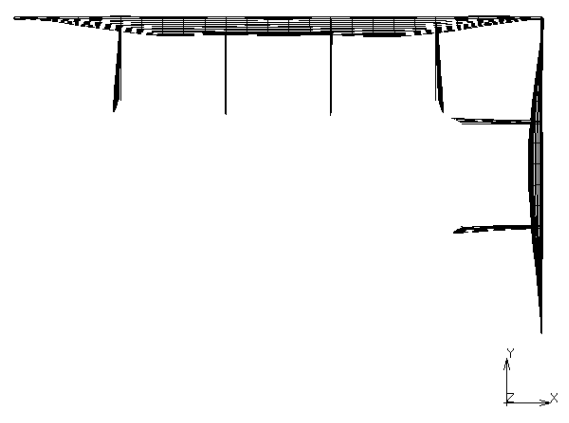

(b) Top View

Figure 21. Typical Local Buckling Mode Shape Found in Stiffened Box Sectional Models

The local buckling modes during the ultimate state were observed and found that in the stiffened box sectional models, the inward buckling occurred in both the surrounding plates and stiffeners as shown in Figures 21 followed by the failure of the whole structure, while in concrete filled models, the outward buckling was found in web and flange panels subjected to the compressive flexural stress. Three different types of buckling shape shown in Figure 22 (a) to Figure 22 (c) were found in different width-to-thickness ratio parameters, $R_{r}$ and the values of axial load ratio $P / P_{y}$. The secondary local buckling mode shapes similar to Figure 22(a) was found in models CF03, CF04, CF05 and CF06 when the values of load ratio are smaller than 0.6 and the one similar to Figure 22 (b) was found in models CF07, respectively. When the axial load ratios being higher than 0.5 , the single local buckling mode similar to Figure 22 (c) was formed in every CF models. The stress concentration in concrete commenced from both middle corners of the concrete height in the compressive side and expanded over the local buckling effective length during the ultimate state. The intense stress concentration was particularly found in the middle zone coincidently where the component plate in the middle flange had buckled and the stress intensity was mostly found higher than the compressive strength of concrete material. The stress concentration generated from the tension side was similar to the compressive side but less intensity. It can be suggested that in concrete filled box-section models, the mode shapes when the component plates buckled are influenced by the structural parameter $R_{r}$, and the compressive load ratio, $P / P_{y}$. Due to the inward 
buckling prevention of concrete in core, the members could sustain the load and bending moment after the local buckling had occurred and then revealed the ductility behavior of the members

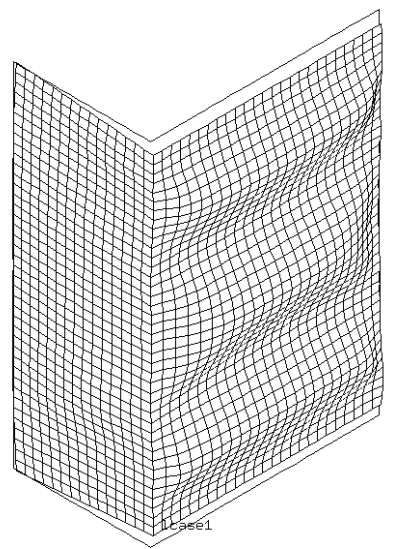

(a) In Models CF03-CF06

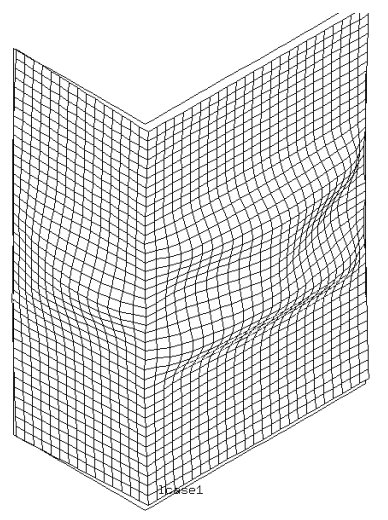

(b) In Models CF07

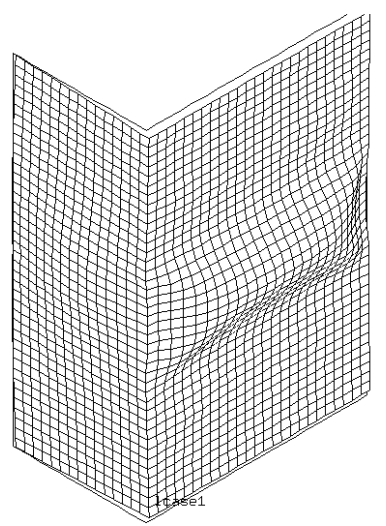

(c) When $P / P_{y}>0.5$

Figure 22. Local Buckling Modes Observed in Concrete Filled Models

Horizontal displacements at the center in y-direction of the flange plates subjected to the compressive flexural stress were continually investigated in order to clarify the effect of the buckling mode shapes to the failure behaviors when the component plates have buckled. Figures 23 shows the comparison between the horizontal displacements in y-direction taken from the models $R_{r}=0.5$ versus analytical increment steps. The left portion represents the results obtained from concrete filled box-section models (CF) while stiffened box-cross section' ones (F)are shown in the right side.

From Figure 23, it can be apparently noticed that in CF models, when the load ratios are less than 0.6, the incremental displacements in Y-direction increase differently compared to when the load ratios are over than 0.6 and can be separated in two main stages. The rapid increasing in horizontal displacements was formed in the earlier steps of the analyses following by the sudden shift when the displacements had reached the values approximately 120 to $150 \mathrm{~mm}$ and continued until the last analytical steps. In the latter stage, only slightly decreasing in displacements was also observed in some cases. This plot's characteristic refers that in the earlier stage of the load applied, the single local buckling mode is formed in the middle part of the component plate until a specific value of the horizontal displacement has been reached. After that, the secondary buckling will gently take place in the top and bottom portions until the member reaches its ultimate state and continue performing thorough the failure stage. On the other hand, the results found in the other CF models including results obtained from the $\mathrm{F}$ models indicate that only the single buckling mode was formed since the plate had buckled until the component plate had attained its ultimate horizontal displacement. Regarding to the result obtained from the $F$ model of the load ratio equals 0.8 , the abrupt

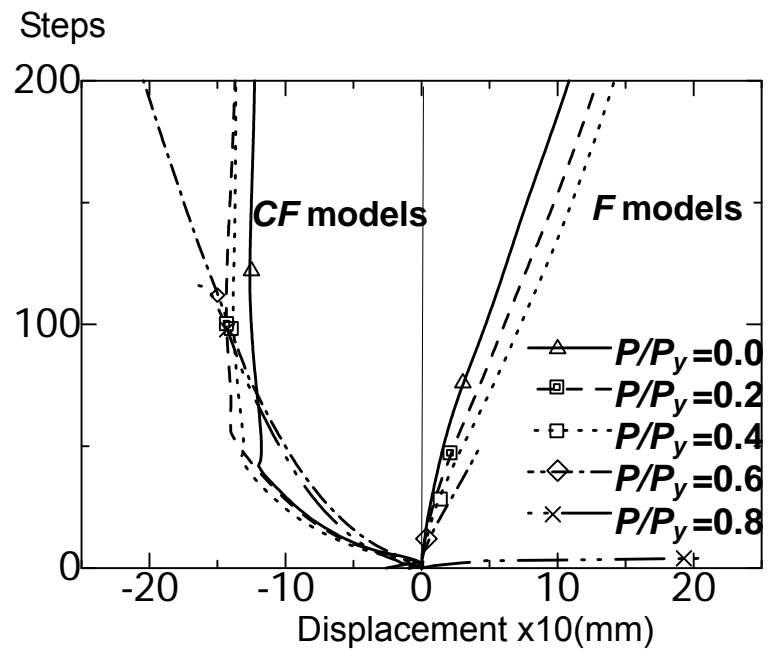

Figure 23. Horizontal Displacements at the Mid-height Point taken from Models $R_{r}=0.5$ 
failure is noticeable due to the infinite displacement in the earlier stage of the applied load. Horizontal displacements measured at the ultimate state of the F and CF models are coincident with the post buckling behavior during the ultimate state. The horizontal displacements measured in CF models have slightly differences among them but largely differ from the results obtained from the F models. The mark symbols in Figure 23 identify the positions corresponding to when the ultimate states have been reached and these horizontal displacements at the ultimate states are plotted versus the axial load ratio parameters and compared in Figure 24. Results obtained for the F models (represented by the solid circles) show that when there is no compressive load applied, $P / P_{y}$ $=0$, only small horizontal ultimate displacements were found and these displacements would slightly decrease when the load ratio increased. In CF models, the large amount in horizontal displacements was found and slightly differences were observed when the axial load ratio parameters were varied. When the load ratios are less than 0.6, note that the ultimate horizontal displacements were all found during the secondary buckling modes had been being formed. Due to the large amount in horizontal displacements and local buckling modes, the concrete filled models could attain the higher ultimate moment than those obtained form the stiffened box cross-section ones.
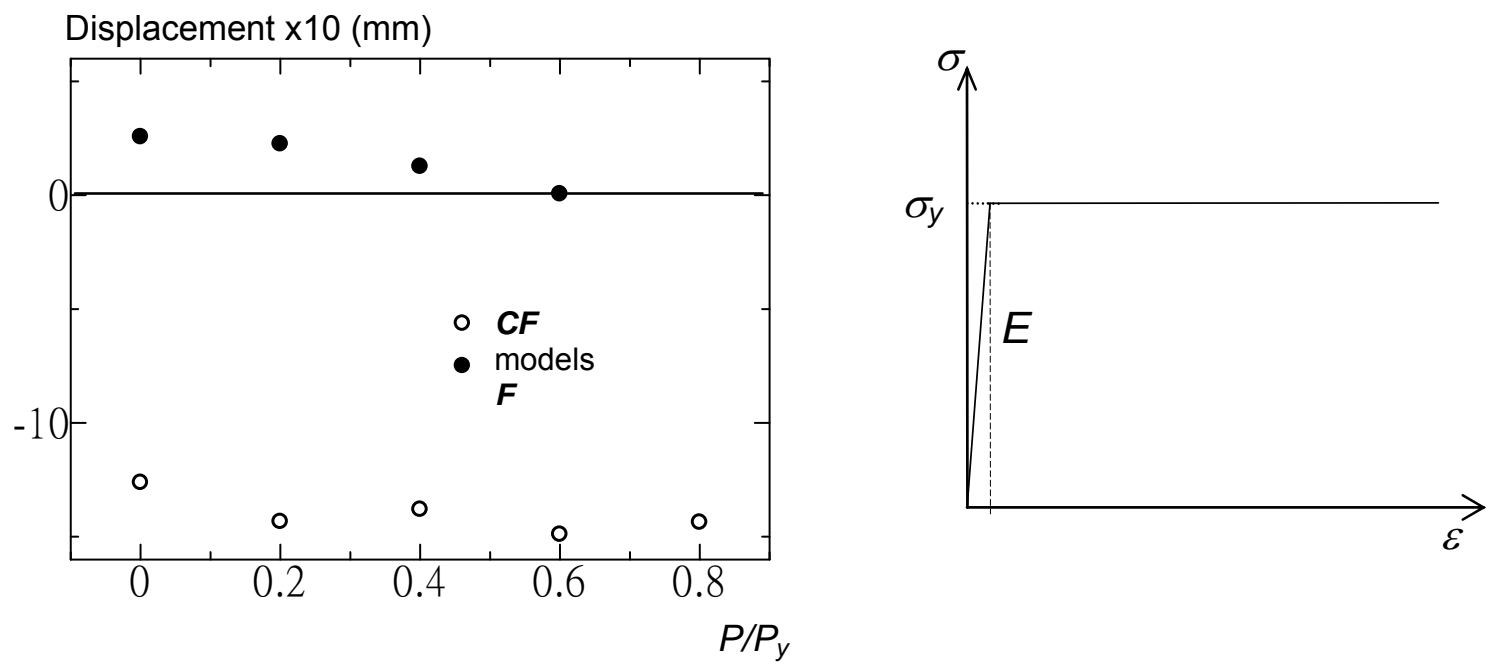

Figure 24. Horizontal Displacements Measured at the Ultimate State

Figure 25. Bi-linear Stress-strain Relationship

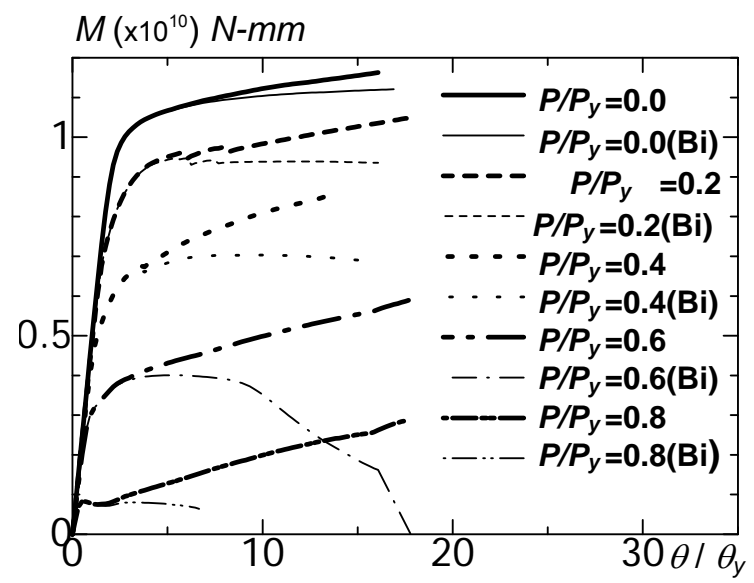

Figure 26. Effect of Strain Hardening in Multi-linear Stress-strain Relationship 
Another suggestion was made by the consideration in material's properties. Bi-linear stress-strain curve as shown in Figure 25 was input into the analyses to compare the effect of the strain hardening during the post buckling state in the component steel plates. The analyses were conducted and compared to the analytical results obtained when the multi-linear stress-strain relationship was applied for the models $R_{r}=0.5$. These comparisons are plotted and shown in Figure 26. The reaction moment results obtained when the bi-linear stress-strain relationship was considered in the analyses are represented by the thin lines. It is clearly understood from the figure that the effect of strain hardening in steel material are dominant after the local buckling behavior. The numerical results indicated that the use of concrete with stiffeners in arch member box-section can improve the member's ductility in the post buckling state.

\section{CONCLUSIONS}

The unit length of steel arch bridge box-members composed of stiffeners in flange and web panels were investigated to obtain the formulas which can determine the ultimate strain of each segment of the arch ribs respect to in-plane and out-of-plane of the arch. The application of concrete-filled was also considered to improve the ultimate strength and ductility of the members thus, the equivalent stiffened box cross-section with concrete filled models were introduced into the analyses. From the numerical results obtained, the main conclusions of this study are summarized as the followings.

1) The aspect ratio of the arch bridge member with the cross section 1500x900 mm obtained from the pure compression test is determined to be 1.5 .

2) From the numerical results obtained from stiffened box-member cross sections and equivalent stiffened box cross-section with concrete filled models subjected to bending moment under various compressive loads, it is found that the ultimate moment ratio tends to decrease when the load ratio increases for the same value of width-to-thickness ratio parameters, $R_{r}$.

3) The ultimate state of the box members subjected to bending analysis under compressive load is considered by the ultimate moment ratio and ultimate strain ratio and the latter can be proposed as functions of the axial load parameter $P / P_{y}$ and the width-to-thickness ratio parameter.

4) In concrete filled box-section models, the mode shapes when the component plates have buckled are influenced by the structural parameter $R_{r}$, and the compressive load ratio, $P / P_{y}$.

5) By the equivalent section applied concept, the numerical results obtained from the FEM analysis show that the use of concrete filled stiffened box-section in arch members can improve the ultimate strength and ductility in the post buckling stage because of the influences of the difference in local buckling failure mode shapes and the effect of the strain hardening in steel material. 


\section{REFERENCES}

[1] Usami, T. Lu, Z. Ge, H.B. and Kono, T., "Seismic Performance Evaluation of Steel Arch Bridges Against Major Earthquakes. Part 1: Dynamic Analysis Approach”, Earthquake Engng. Struct. Dyn., 2004, pp. 1337-1354.

[2] Sakimoto, T., Watanabe, H., Tsuchida, S. and Miwa, K., “A Simplified Analysis of Steel Frames Fail by Local and Global Instability”, Proc. of the 5th International Colloquium on Stability and Ductility of Steel Structures, 1977, Vol. 2, pp. 777-784.

[3] Zheng, Y., Usami, T., Ge, H.B., "Ductility Evaluation Procedure for Thin-walled Steel Structure”, Journal of Structural Engineering, ASCE, 2000, Vol. 126, pp.1312-1319.

[4] "Design Specifications for Highway Bridges”, Part II Steel Bridge and Part V Seismic Design, Japan Road Association, 2002. (In Japanese)

[5] Komatsu, S. Ushio, M. and Kitada, T., "An Experimental Study on Residual Stresses and Initial Deformations of Stiffened Plates”, Proceedings, JSCE, 1997, pp. 25-35. (In Japanese)

[6] Zheng, Y., Usami, T., Ge, H.B., “Ductility of Thin-walled Steel Box Stub-columns”, Journal of Structural Engineering, ASCE, 2000, Vol. 126, pp. 1304-1311.

[7] “MARC K7 User Manual”, A-E., NIPPON MARC, 2001.

[8] Usami, T., Suzuki, M., Iraj, H.P. Mamaghani and Ge, H.B.., “A Proposal for Check of Ultimate Earthquake Resistance of Partially Concrete Filled Steel Bridge Piers”, Journal of Structural Mechanics and Earthquake Engineering, 1995, Vol. 353, No. 525, pp. 69-82. (In Japanese)

[9] Zhanfei, W. Yamao, T. Ishii, Z. and Iwatsubo, K., “Applicability of Static-dynamic Verification Method for Seismic Design of Bridge Piers with Inner Cruciform Walls”, Proceedings ICSCS’04, 2004, pp. 789-798.

[10] Mohamed, O., Sakimoto, T. and Yamao, T., "Ductility of Stiffened Plates after Buckling as a Component of a Box Cross-section”, Proceedings ICSCS’04, 2004, pp. 299-308. 


\title{
FATIGUE STRENGTH CHARACTERISTICS OF WELDED STUD JOINT WITH RESPECT TO STEEL PLATE THICKNESS
}

\author{
John S.E. Koh ${ }^{1, *}$, O. Minata ${ }^{2}$ and A. Muranaka ${ }^{3}$ \\ ${ }^{1}$ Consulting Engineer, Structural Technology Division, Fukken Co., Ltd. Consulting Engineers, \\ 10-11, 2-Chome Hikari-Machi, Higashi-Ku, Hiroshima 732-0052, Japan \\ ${ }^{2}$ Professor, Graduate School of Engineering, Hiroshima Institute of Technology, Japan \\ ${ }^{3}$ Assistant Professor, Graduate School of Engineering, Hiroshima Institute of Technology, Japan \\ *(Corresponding author: E-mail: john@fukken.co.jp or johnhitjp@yahoo.co.jp)
}

\begin{abstract}
Since 1954, a great number of study and research has been carried out on fatigue behaviors of stud shear connectors and much useful information have been obtained and reported. Nowadays, stud is becoming the most common type of mechanical shear connector available and it is being used exclusively in composite structure such as bridge, large gravity type structure (breakwater, bulkhead wharf, coastal revetment etc) and Very Large Floating Structure (VLFS) consists of hybrid caisson and pontoon. Hybrid caisson and pontoon structure used at the coast and offshore is built from multiple layers of extremely thin steel plate which form the box of steel shell where large number of studs are welded onto it and embedded into concrete. Over decades, stud has been of important role as shear connector in composite structure; a number of rules and regulations have been set for its design and application. However, at present, the fatigue strength relation between stud diameter (d) and steel plate thickness (t) is not being established in any design guidelines or specifications for steel structure. In such present condition, this research is carried out to establish a fatigue design method with respect to diameter-thickness relation of stud and steel plate by conducting experiment on a series of test specimens. A modified S-N fatigue equation by introducing $\mathrm{d} / \mathrm{t}$ element based on the results from experimental data is introduced here as a future reference for design of stud and steel structure.
\end{abstract}

Keywords: Stud; mechanical shear connector; thin steel plate; stud diameter; steel plate thickness; modified S-N fatigue equation

\section{INTRODUCTION}

Hybrid caisson and pontoon structures are often used as pier (quay, wharf, dock etc.) and floating wave-absorbing structures [1]. Normally, the inner sections are made from shell of steel plates embedded in concrete and these two elements are tied together by using a large number of studs.

At present, the strength characteristic between the stud diameter and steel plate thickness is not being considered for the design of hybrid caisson and pontoon structure. This research is carried out with the aim to establish fatigue design method for offshore hybrid structure by conducting experiment on series of test specimens under two objectives :

i ) Study the fatigue strength of thin steel plate welded with studs

ii) Study the fatigue strength of thin steel plate welded with group of studs

\section{OUTLINE OF TEST SPECIMEN}

The studs are of 'round headed' type. It is made from material called Si-Killed Steel based on Design Specification for Highway Bridge of Japan Road Association. Headed studs are used exclusively as shear connectors in various steel-concrete composite constructions [2]. Round headed stud (Figure 1) consists of a bolt that is electrically welded to the steel member using an automatic welding procedure. Stud welding process is conducted using electric arc method. 
Steel plates are of type SS400 according to Japan Industrial Standard:JIS, and the mechanical properties are as shown in Table 1. According to past research, there are three types of typical crack failures that can occur as shown in Figure 2 [3].

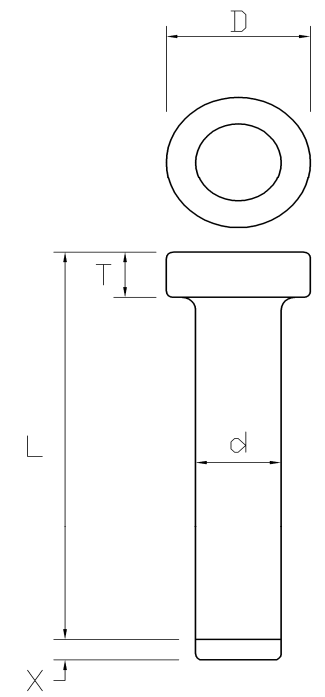

Figure 1. Dimensions of Round Headed Stud

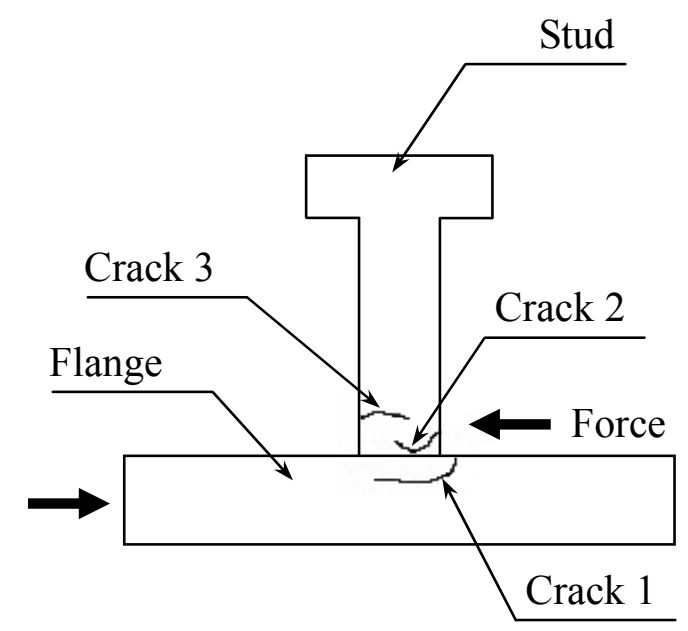

Figure 2. Typical Types of Crack Failure

Table 1. Mechanical Property of JIS:SS400

\begin{tabular}{|c|c|c|c|}
\hline Type & $\begin{array}{c}\text { Yield stress } \\
\left(\mathrm{N} / \mathrm{mm}^{2}\right)\end{array}$ & $\begin{array}{c}\text { Tensile strength } \\
\left(\mathrm{N} / \mathrm{mm}^{2}\right)\end{array}$ & $\begin{array}{c}\text { Elongation } \\
(\%)\end{array}$ \\
\hline $\begin{array}{c}\text { SS400 } \\
\text { (below } 16 \mathrm{~mm})\end{array}$ & Above 245 & $400-510$ & Above 20 \\
\hline
\end{tabular}

\subsection{Steel Plate Welded With Studs}

Specimen consists of $700 \times 80 \mathrm{~mm}$ steel plate welded with two different stud diameters (Figure 3). Combination for stud diameter, $\mathrm{d}$ of $13,16,19,22 \mathrm{~mm}$ and plate thickness, $\mathrm{t}$ of $6,12,22 \mathrm{~mm}$ are used.

\subsection{Steel Plate Welded With Group of Studs}

Two different types of specimen (type A and type B) are used; each consists of $620 \times 210 \times 9 \mathrm{~mm}$ steel plate welded with six studs of $13 \mathrm{~mm}$ diameter (Figure 4).

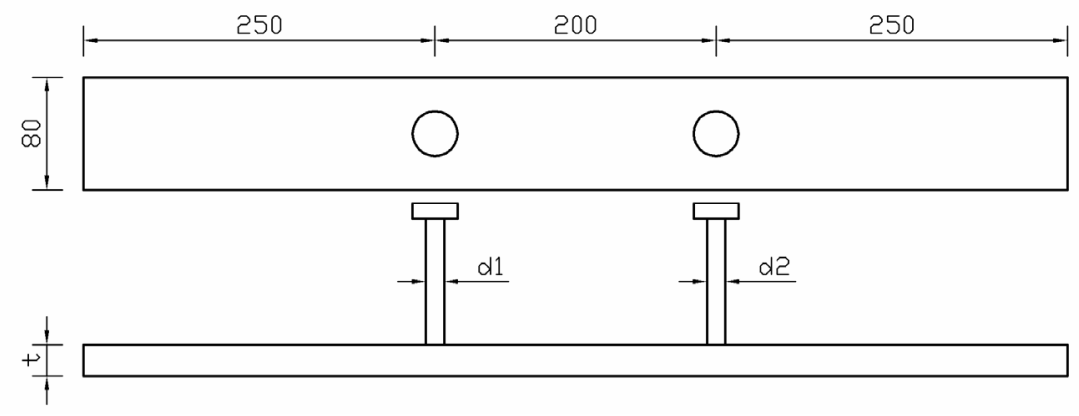

Figure 3. Dimensions of Plate Welded with Studs 

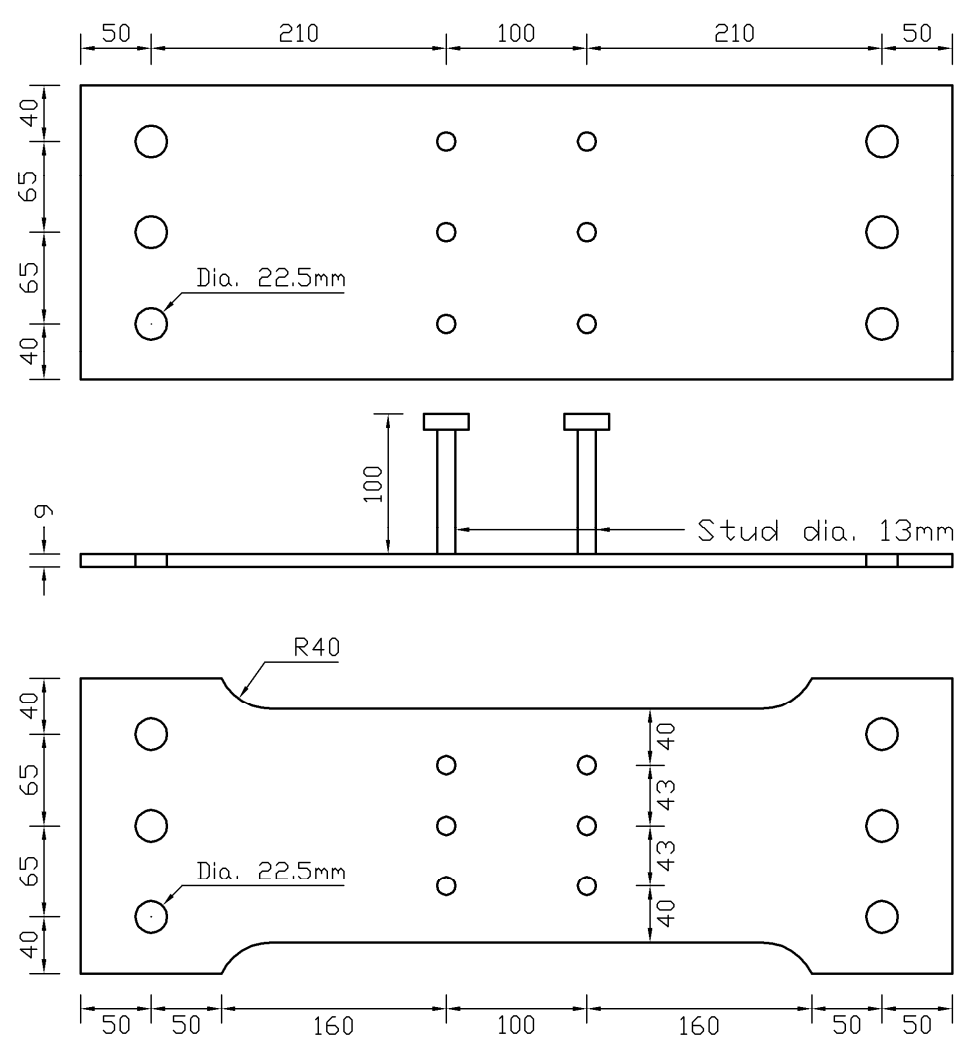

Plan view : type A (above); type B (below)

Figure 4. Dimensions of Plate Welded with a Group Studs

\section{TEST PROCEDURES}

Fatigue tests are conducted using Shimadzu test machine model EHF-U50. Uni-directional form of loading (Figure 5) is applied to test specimens. Minimum load is set to zero and axial tensile cyclic load is applied at 480 cycles per $\min (8 \mathrm{hz})$ to one end of steel plate with the other end in fixed state. For specimens with group studs, steel plate is clipped at both ends with two slices of steel plates using 3 bolts ( $\phi 22.5 \mathrm{~mm}$ ) at each end (Figure 4) before load is applied. During testing, maximum and minimum loads are automatically kept constant at the preselected values. Testing for plate welded with studs is conducted until complete failure; testing for group studs is terminated at 'passing-through crack' state.

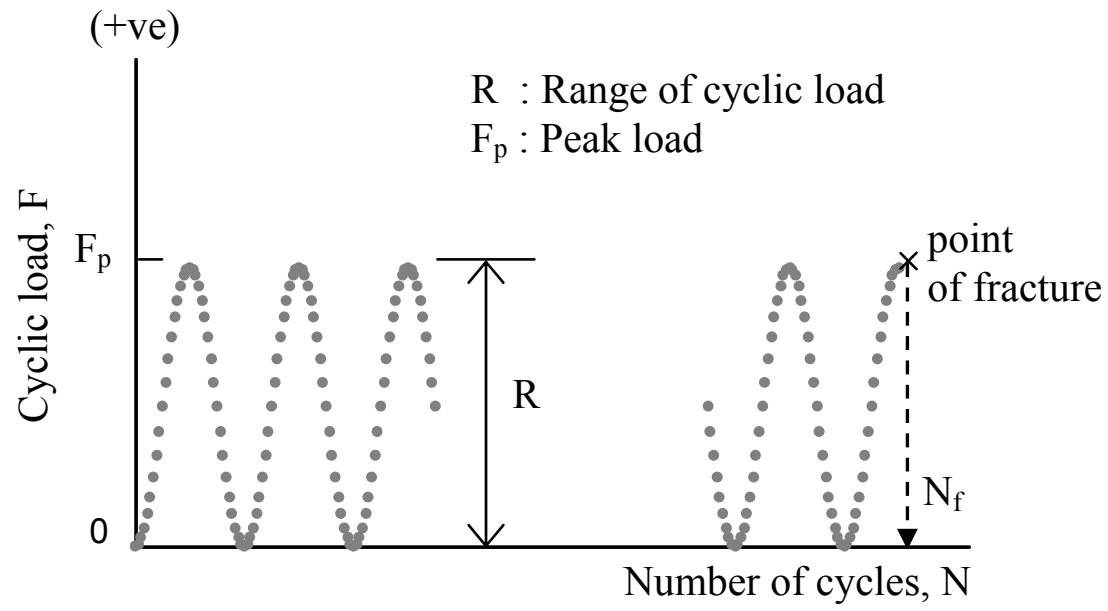

Figure 5. Uni-directional Form of Fatigue Test Loading 


\section{TEST RESULTS AND EVALUATIONS}

14 specimens from various combinations of stud diameter and steel plate thickness are tested for steel plate welded with studs ( 2 studs/specimen) while 6 specimens ( 6 studs $=1$ group/specimen $)$ are tested for steel plate welded with group of studs. All specimens failed by crack line perpendicular to longitudinal axis at weld toe. Test results for one stud $(14 \times 2=28$ data $)$ and group of studs $\left(6 \times 1=6\right.$ data) are plotted in Figure 6 . In Figure 6 , it can be seen that at $\mathrm{N}_{\mathrm{f}}=2 \times 10^{6}$ cycles, S-N curve for 'group of studs' (at passing-through crack state) is lower compare to 'one stud'. This shows that fatigue strength decreases with increasing number of stud welded on the steel plate. Next, fatigue strength for different $\mathrm{d} / \mathrm{t}$ ratio $(\mathrm{d}=$ stud diameter; $\mathrm{t}=$ plate thickness $)$ are extracted from one stud data as shown in Figure 7. It can be seen that the fatigue strength decrease with increasing in $\mathrm{d} / \mathrm{t}$. Note that all test results meet the minimum requirement for Fatigue Design Code for Steel Structures by Japanese Society of Steel Construction (JSSC) Class E design curve [4].

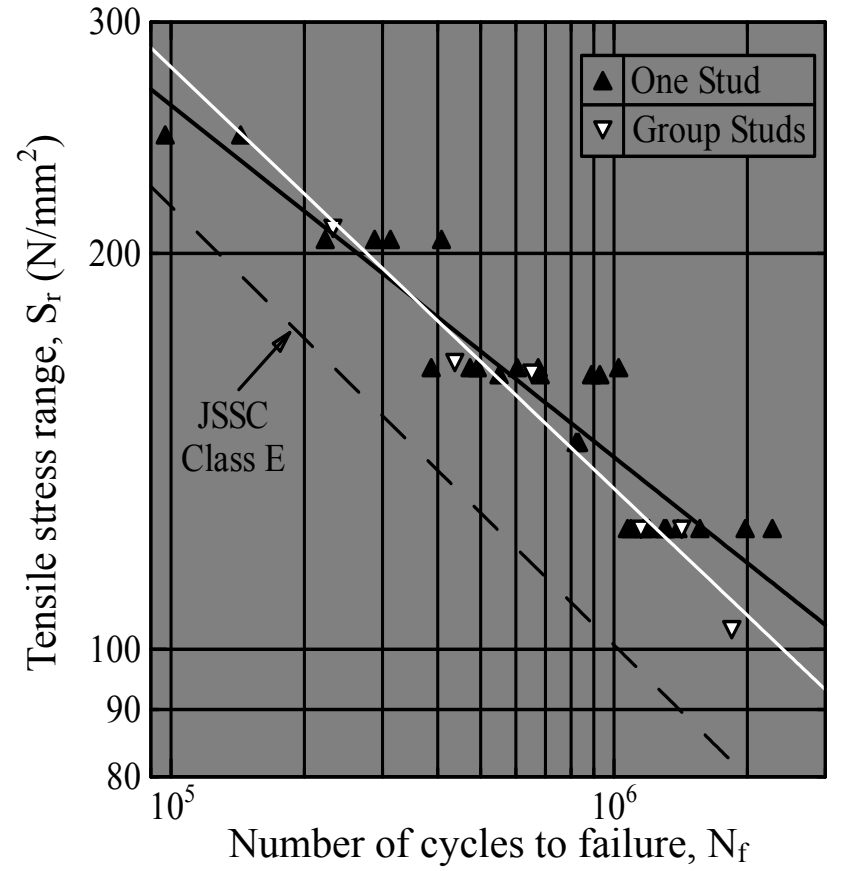

Figure 6. S-N Curve for Test Results of One Stud and Group of Studs Data

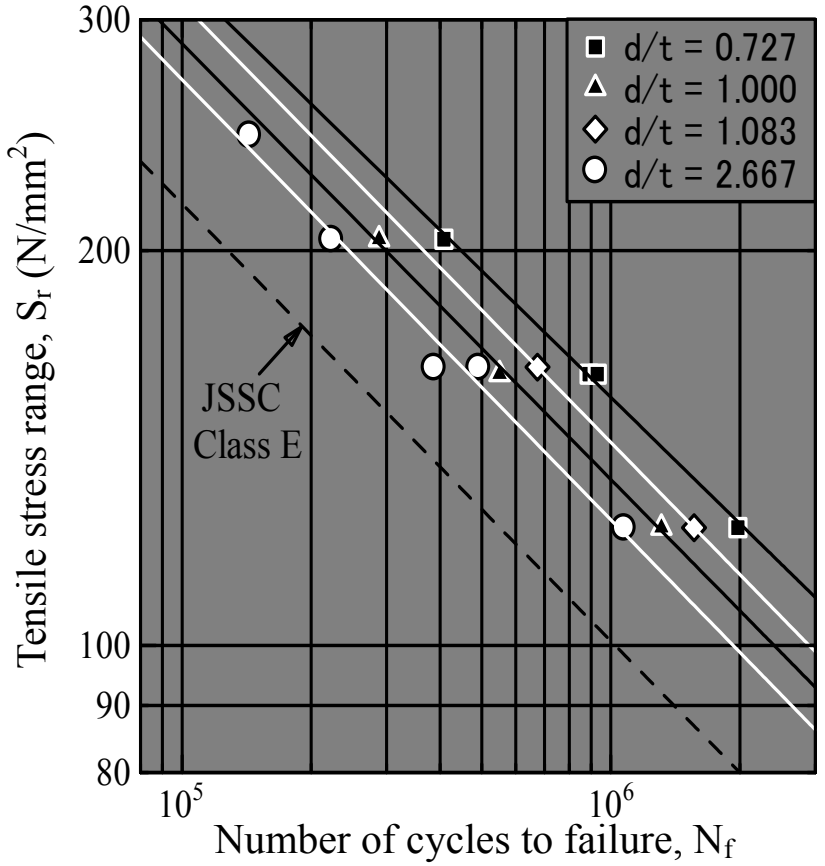

Figure 7. S-N Curve for d/t Ratio Extracted from One Stud Data in Figure 6

From Figure 6, mean value for fatigue strength of 'one stud', $\mu=116.35 \mathrm{~N} / \mathrm{mm}^{2}$ is obtained at $\mathrm{N}_{\mathrm{f}}=$ $2 \times 10^{6}$ cycles and standard deviation is calculated as $\sigma=11.91 \mathrm{~N} / \mathrm{mm}^{2}$. Using statistic equation [5] as shown by Eq. (1), value of $\mu$ and $\sigma$ at probability of failure, $2.5 \%$ of normal distribution as suggested by JSSC are obtained for number of studs, $n=1,5,10,15,20$ and 25 . Normal distribution graph are plotted in Figure 8 for respective $n$.

$$
\begin{aligned}
& p_{\text {min }}(x)=n\left[1-\Phi\left(\frac{x-\mu}{\sigma}\right)\right]^{n-1} \phi\left(\frac{x-\mu}{\sigma}\right) \frac{1}{\sigma} \\
& P_{\text {min }}(x)=1-\left[1-\Phi\left(\frac{x-\mu}{\sigma}\right)\right]^{n}
\end{aligned}
$$

From Figure 8, it can be seen that fatigue strength decrease exponentially; $\mu$ and $\sigma$ decrease with increasing number of studs. Using $\mu=116.35 \mathrm{~N} / \mathrm{mm}^{2}$ and $\sigma=11.91 \mathrm{~N} / \mathrm{mm}^{2}$, number of studs that are needed to meet the minimum requirement for JSSC Class E curve (given by $\mathrm{S}_{\mathrm{r}}=80 \mathrm{~N} / \mathrm{mm}^{2}$ at 
$\mathrm{N}_{\mathrm{f}}=2 \times 10^{6}$ cycles) is calculated and the result gives $n=23$. This means that maximum number of studs that can be welded in a row for an area of steel plate surface in the direction of force is 23 studs $(n \leq 23)$. The result is illustrated in Figure 9 for $n=23$.

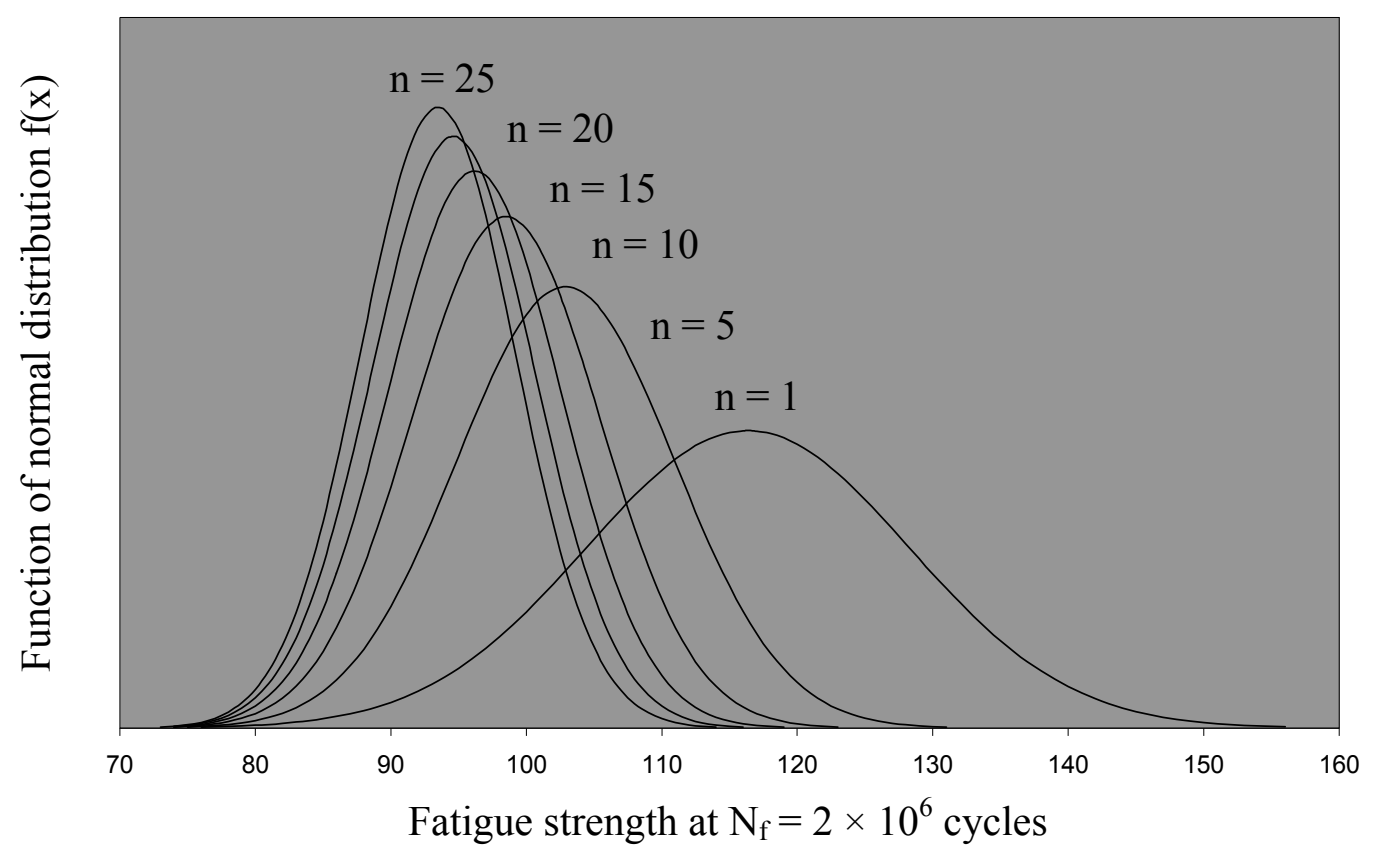

Figure 8. Normal Distribution for Number of Studs, $n$

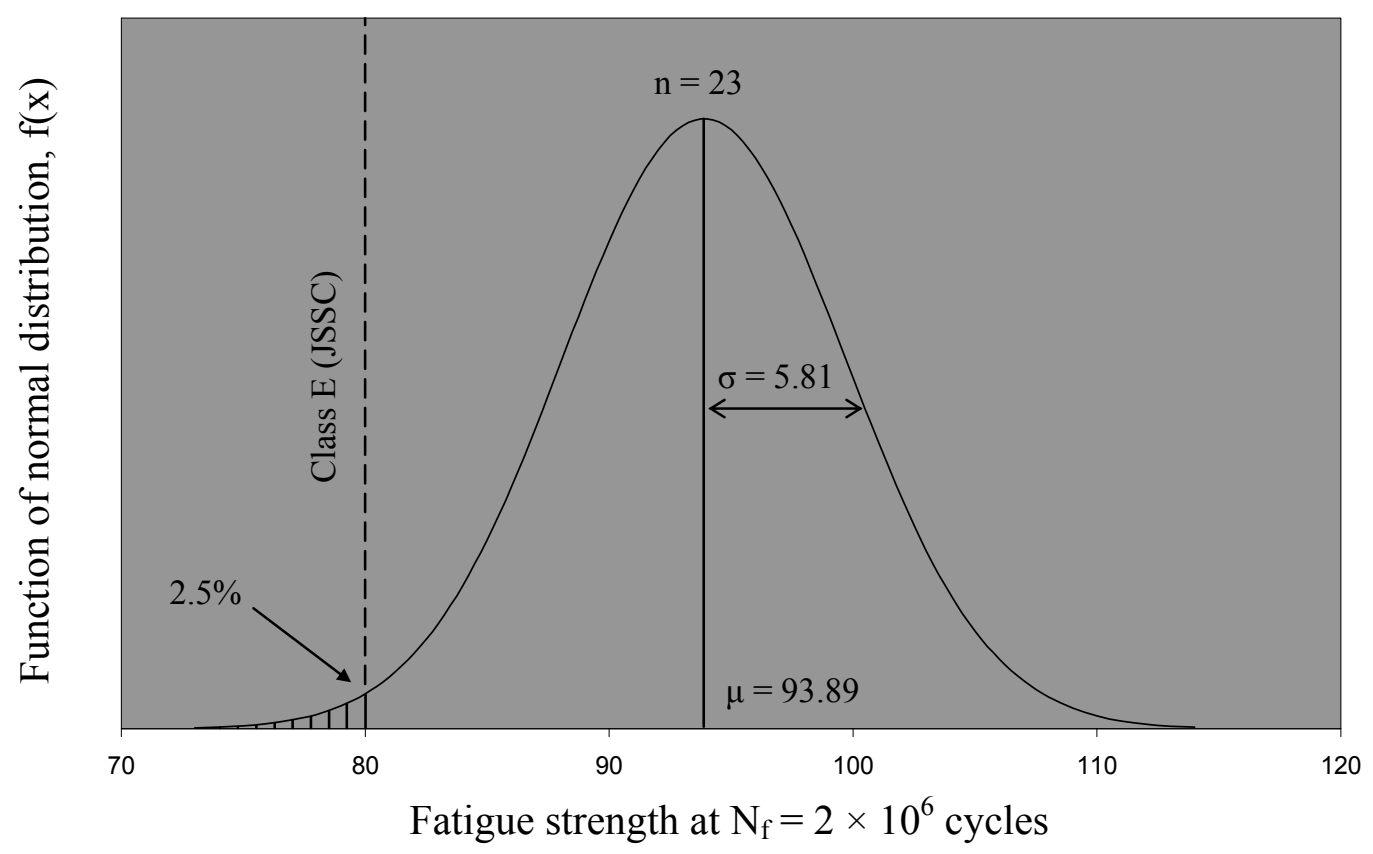

Figure 9. Normal Distribution for $\mathrm{n}=23$

The comparison of test results for steel plate welded with group of studs (type A and type B; consists of 3 specimens each) are not presented here because the S-N curve for both types are almost identical. This means that decreasing the spacing interval of $22 \mathrm{~mm}$ (refer Figure 4, 65-43 $=22 \mathrm{~mm}$ ) in the transverse direction to applied load has insignificant effect on fatigue strength of the studs. 


\section{DESIGN FORMULA USING d/t RATIO}

Test results data obtained for 'one stud' shown in Figure 6 are used to modify normal S-N equation by introducing ratio $d / t(d=$ stud diameter; $t=$ plate thickness $)$. Since the aim of this research is to deal with high cycle fatigue of offshore hybrid structures, the minimum cycles allowed are set to $1 \times 10^{5}$ cycles. For design purposes, using probability of failure of $2.5 \%$ of normal distribution as suggested by JSSC, the modified S-N equation for steel plate welded with stud is proposed under 2 conditions :

$$
S=\left[305\left(\frac{d}{t}\right)^{-\frac{3}{19}}-22\right]\left(\frac{N}{10^{5}}\right)^{-\frac{1}{3}}
$$

Conditions : 1) $\quad \mathrm{N} \geqslant 1 \times 10^{5}$ cycles

2) $d / t \leqslant 4.67$ (to be revised)

The value of $d / t=4.67$ in condition 2 is obtained by substituting $S_{r}=80 \mathrm{~N} / \mathrm{mm}^{2}$ (given by JSSC Class $\mathrm{E}$ curve) into modified equation at $\mathrm{N}_{\mathrm{f}}=2 \times 10^{6}$ cycles. However, it is to bear in mind that condition 2 is not practical and applicable because 4.67 is somehow an irrational value for $\mathrm{d} / \mathrm{t}$. Hence, future study on allowable limit of $d / t$ and/or revision of $S_{r}=80 \mathrm{~N} / \mathrm{mm}^{2}$ used in JSSC Class $\mathrm{E}$ are of important necessity for the proposed modified $\mathrm{S}-\mathrm{N}-\mathrm{d} / \mathrm{t}$ equation to be applied more effectively.

It is necessary to prove the reliability of statistical analysis used for derivation of modified equation. Referring to Figure 6, comparison is to be made for fatigue strength at $\mathrm{N}_{\mathrm{f}}=2 \times 10^{6}$ cycles between 'one stud' and 'group of studs' at $n=3$. Number of studs, $n$ is set as 3 because 3 studs failed along the cracking line for each specimen of steel plate welded with group studs. Fatigue strength for $n=$ 3 based on 'one stud' data is calculated using statistical equation in section 4 while fatigue strength of $n=3$ for 'group of studs' are obtained directly, based on experimental data from Figure 6 .

Using $\mu=116.35 \mathrm{~N} / \mathrm{mm}^{2}$ and $\sigma=11.91 \mathrm{~N} / \mathrm{mm}^{2}$ obtained from 'one stud' data, and $n=3$ :

$$
\begin{aligned}
\mathrm{P}[\mathrm{X}<116.35] & =1-\left[1-\phi\left(\frac{x-116.35}{11.91}\right)\right]^{n} \\
0.5 & =1-\left[1-\phi\left(\frac{x-116.35}{11.91}\right)\right]^{3} \\
{\left[1-\phi\left(\frac{\mathrm{S}-116.35}{11.91}\right)\right]^{3} } & =0.5 \\
\frac{\mathrm{S}-116.35}{11.91} & =-0.8193 \\
\mathrm{~S} & =106.6 \mathrm{~N} / \mathrm{mm}^{2}
\end{aligned}
$$

Next, with reference to Figure 6, the equation of S-N curve for 'group studs' is obtained as :

$$
\mathrm{S}=11098 N^{-0.3205}
$$


Since the comparison is made at number of cycles, $\mathrm{N}_{\mathrm{f}}=2 \times 10^{6}$ cycles :

$$
\begin{aligned}
\mathrm{S} & =11098\left(2 \times 10^{6}\right)^{-0.3205} \\
& =106.1 \mathrm{~N} / \mathrm{mm}^{2}
\end{aligned}
$$

Consequently, the fatigue strength for number of studs, $n=3$ for 'one stud' and 'group of studs' are obtained as $106.6 \mathrm{~N} / \mathrm{mm}^{2}$ and $106.1 \mathrm{~N} / \mathrm{mm}^{2}$ respectively with merely a difference of $0.5 \%$. This shows that statistical analysis method is reasonably reliable for derivation of modified equation.

Modified S-N-d/t equation is compared against actual test data in Figure 7. The results give positive satisfaction where actual test data for $\mathrm{d} / \mathrm{t}$ of $0.727,2.167,2.667$ and 3.167 surpassing the modified $\mathrm{S}-\mathrm{N}-\mathrm{d} / \mathrm{t}$ equation respectively (actual test data should always above $\mathrm{S}-\mathrm{N}$ curve in design) as shown in Figure 10.

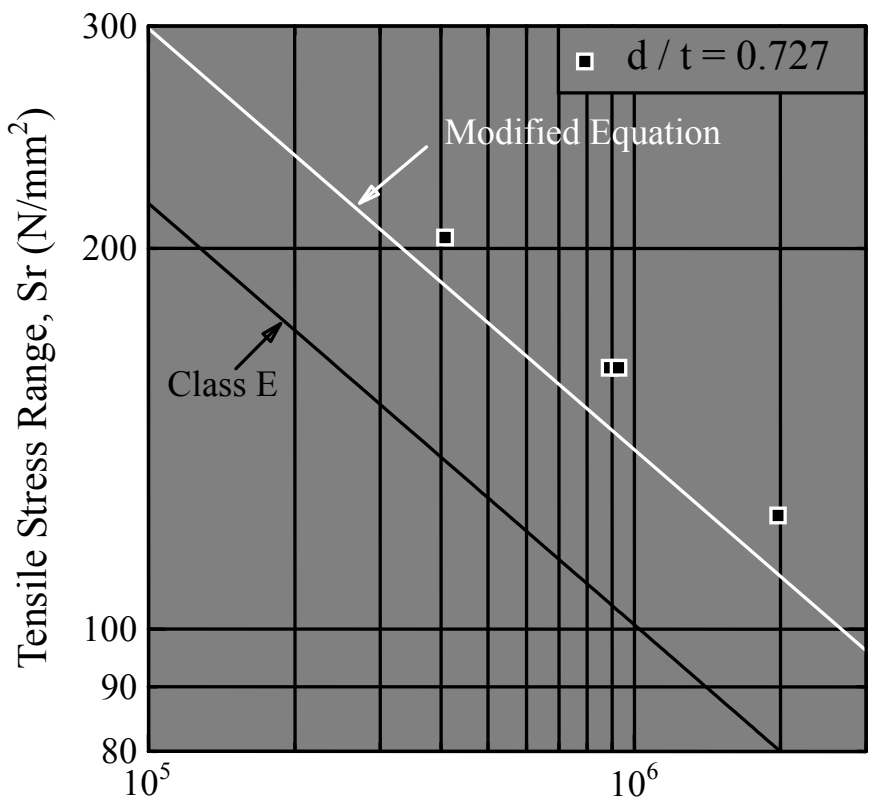

Number of Cycle to Failure, $\mathrm{N}_{\mathrm{f}}$

(a)

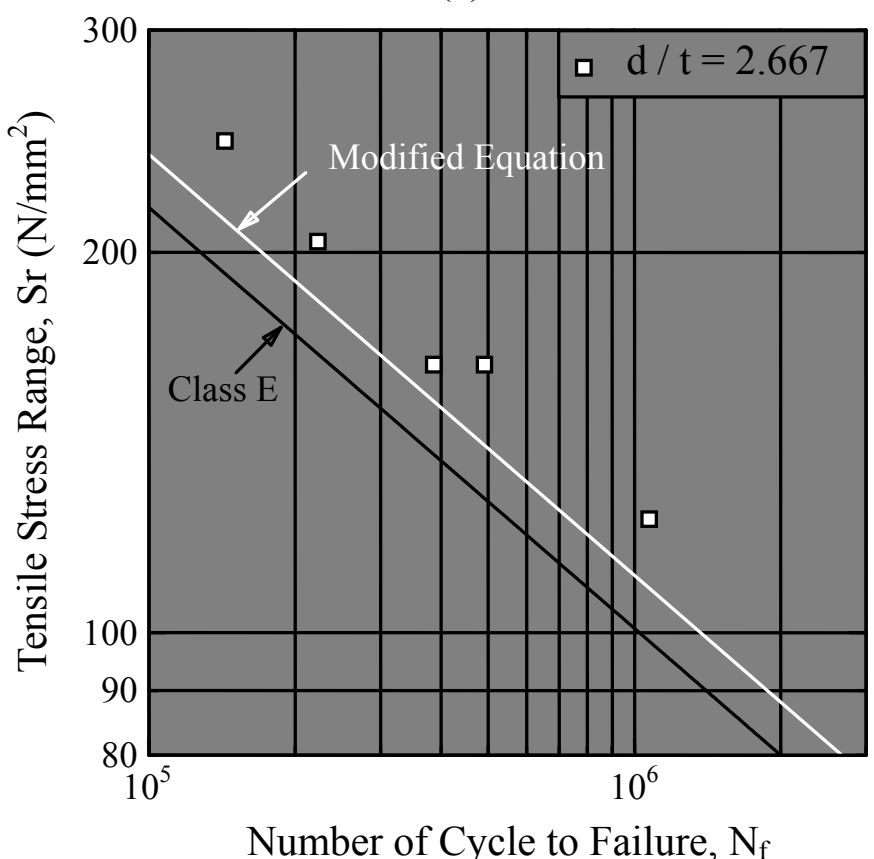

(c)

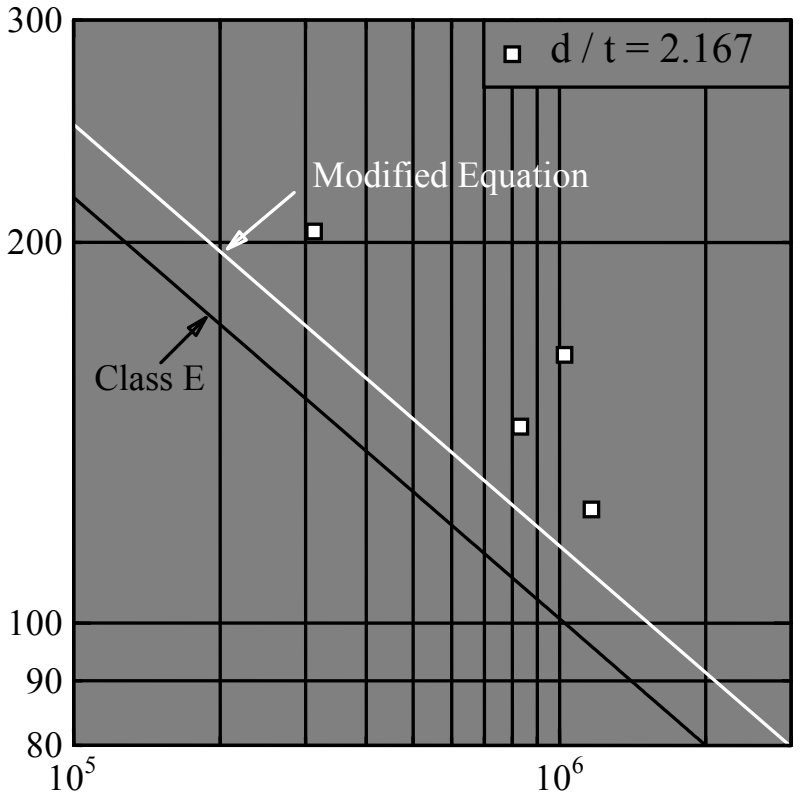

Number of Cycle to Failure, $\mathrm{N}_{\mathrm{f}}$

(b)

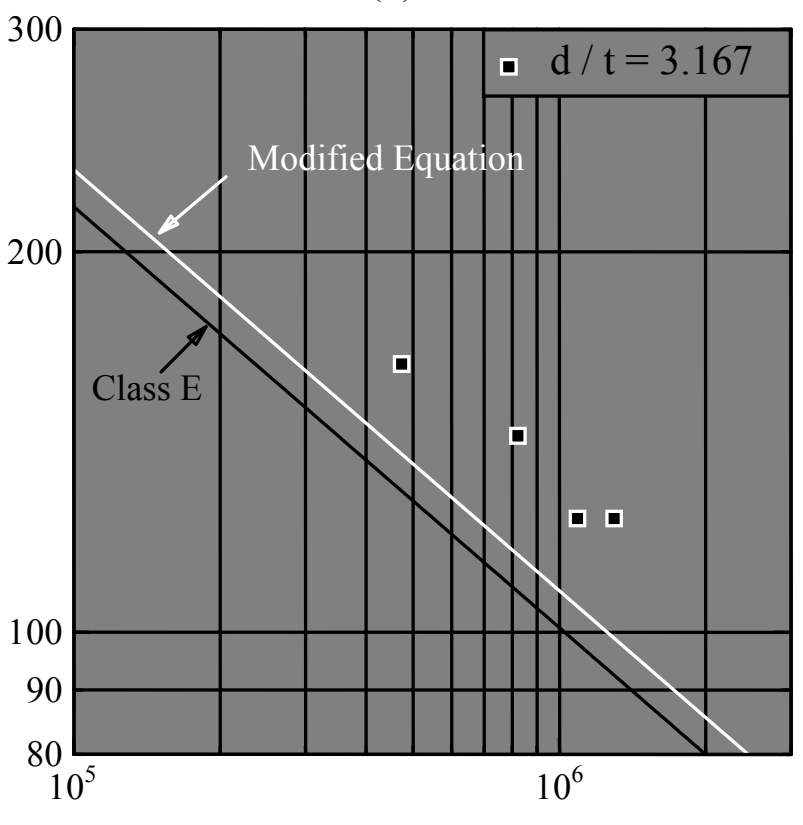

Number of Cycle to Failure, $\mathrm{N}_{\mathrm{f}}$

(d)

Figure 10. Actual Test Data Plotted Against Modified S-N-d/t Equation 


\section{FINITE ELEMENT METHOD (FEM) ANALYSIS}

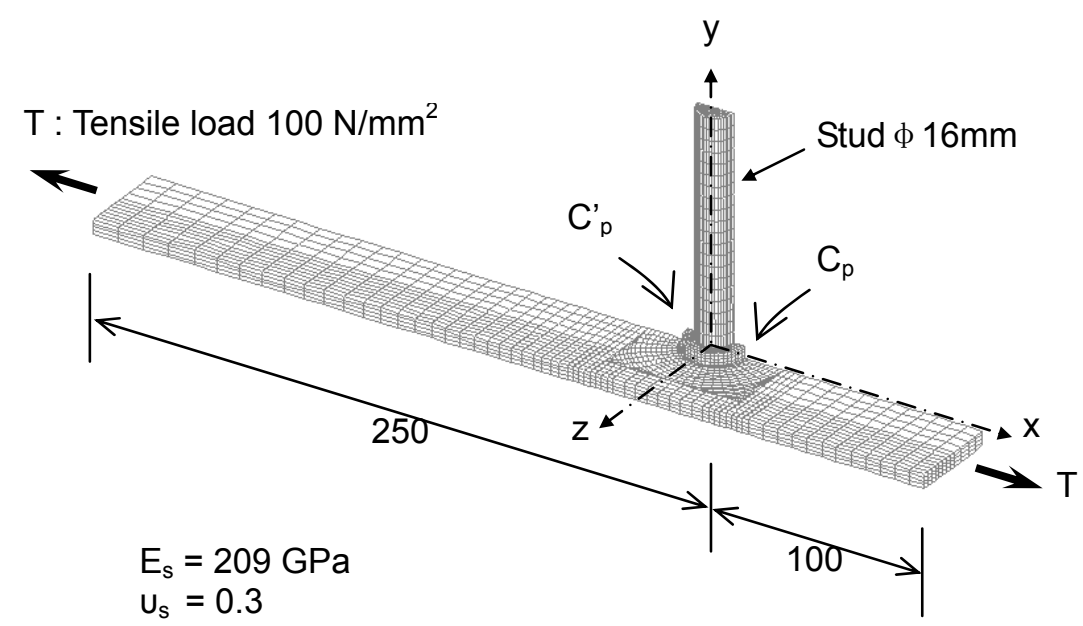

Figure 11. Finite Element Mesh Division (Half Model)

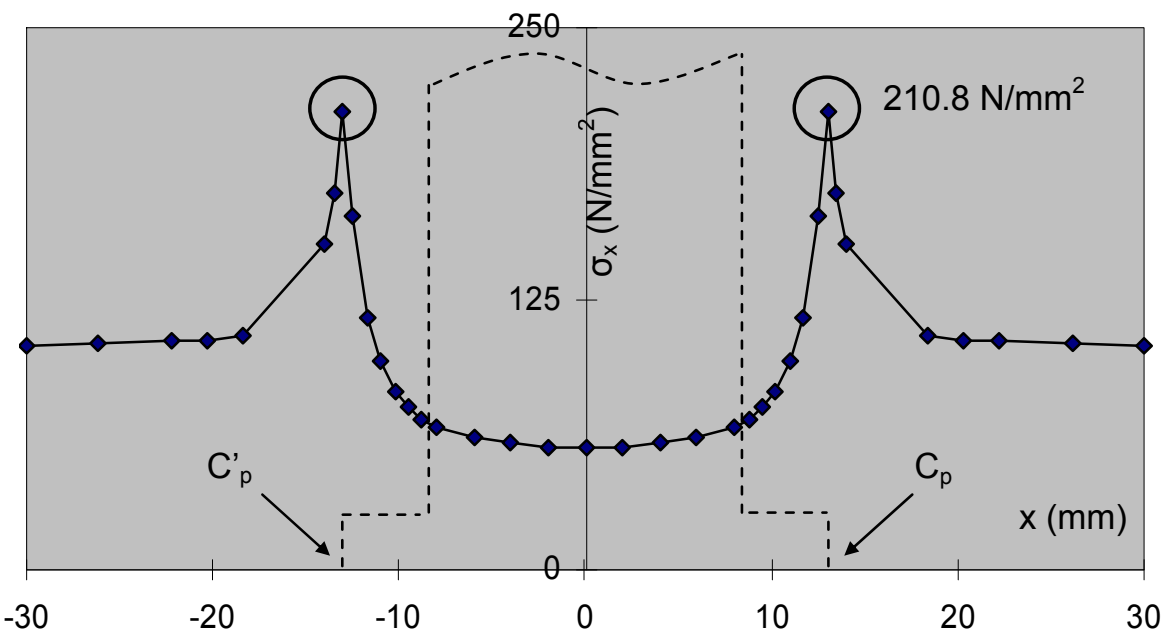

(a) x-direction

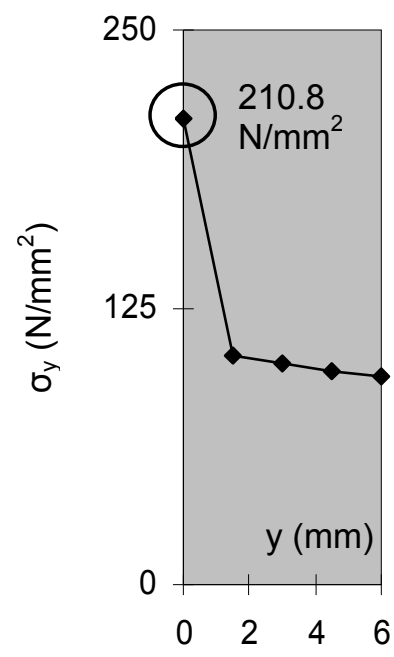

(b) y-direction

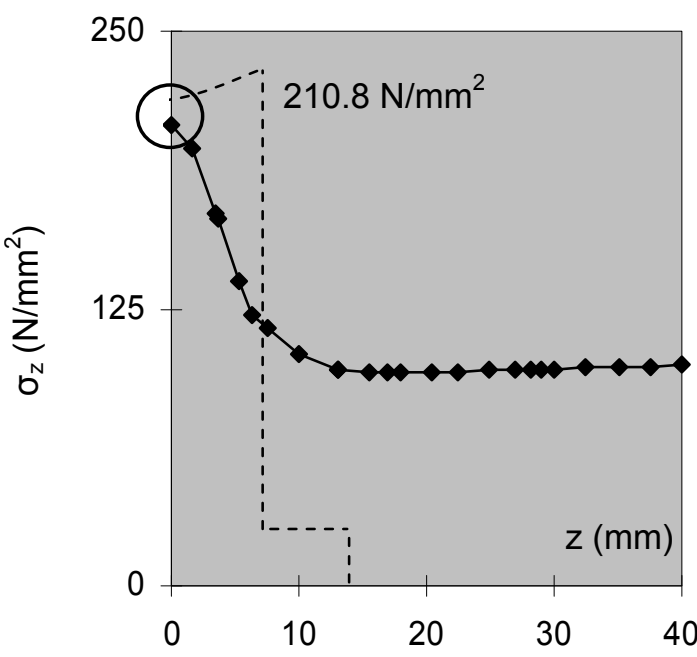

(c) z-direction

Figure 12. Stress Distribution under Tensile Load in $\mathrm{x}, \mathrm{y}$ and z-direction 
Software analyses are performed using LUSAS finite element analysis for steel plate welded with stud. Model is built in 3D $(350 \times 80 \times 6 \mathrm{~mm})$ with stud diameter of $16 \mathrm{~mm}$. Distributed tensile load of $100 \mathrm{~N} / \mathrm{mm}^{2}$ is applied to the specimen (Figure 11). The load is applied at an end distance of 250 $\mathrm{mm}$ and $100 \mathrm{~mm}$ from center of stud in order to simulate the half model condition of fatigue tests for steel plate welded with studs (Figure 3). Specimen is fixed in y-direction and critical points for maximum stresses at the edge of weld collar are represented by coordinate $C_{p}$ and $C_{p}$.

Stress distribution at weld collar of stud in $\mathrm{x}, \mathrm{y}$ and $\mathrm{z}$ direction are as shown in Figure 12. The value of maximum stress at $C_{p}$ (or $C_{p}^{\prime}$ ) is obtained as $210.8 \mathrm{~N} / \mathrm{mm}^{2}$ which gives a stress concentration factor approximately 2.1 , twice the applied tensile load of $100 \mathrm{~N} / \mathrm{mm}^{2}$. It is assumed that the factor that gives dominant impact to deterioration of fatigue strength is due to the discontinuity of geometrical form of weld collar especially at the bottom surface of the weld [6]. By referring to the modified S-N-d/t equation, an increase of stress concentration factor will results in the decrease of fatigue life, $\mathrm{N}$.

\section{CONCLUSIONS}

Few main conclusions that can be derived are listed as below :

i) Increasing the number of studs results in the decrease of fatigue strength (Figure 8). This is due to the fact that natural cracks will occur at the time when stud is welded to steel plate. Hence, number of cracks will increase with number of welded studs, resulting in decrease of fatigue strength. This statement is referred to Figure 6 ; it can be seen that S-N curve at $2 \times 10^{6}$ cycles for 'group studs' is lower than 'one stud'.

ii) Due to reason in i), maximum number of studs that can be welded in a row for an area of steel plate surface in the direction of force has to be obtained. By using statistical approach and conditions provided by Class E curve (JSSC), maximum number of studs are obtained as 23 . This means that as long as the numbers of welded studs are less than 23 ( $n \leq 23)$, Class $\mathrm{E}$ is safe to be used as design limit curve.

iii) It is thought that $\mathrm{d} / \mathrm{t}$ ratio will has effect on the fatigue strength, and this is confirmed by the experimental data as shown in Figure 7. Using the combination of statistical approach and experiment data, normal S-N curve is modified by inserting $d / t$ element and the new S-N design limit curve is proposed under 2 conditions as below :

$S=\left[305\left(\frac{d}{t}\right)^{-\frac{3}{19}}-22\right]\left(\frac{N}{10^{5}}\right)^{-\frac{1}{3}}$

Conditions : $\quad 1) \mathrm{N} \geqslant 1 \times 10^{5}$ cycles (high cycle fatigue)

2) $d / t \leqslant 4.67$ (to be revised)

iv) Experiment is also conducted with the aim to test the validity of JSSC Class E design limit curve. The results show that all test data surpass JSSC Class E design limitation curve as shown in Figure 6.

v) FEM analysis is performed to observe the stress distribution in the vicinity of stud in $\mathrm{x}, \mathrm{y}$ and $\mathrm{z}$-direction. Analysis results show that the maximum stress is as high as twice the applied load, i.e. $210.8 \mathrm{~N} / \mathrm{mm}^{2} \div 100 \mathrm{~N} / \mathrm{mm}^{2}=$ stress concentration factor of 2.1 (Figure 12), in all direction 
occurring at the edge of weld collar. A higher stress concentration factor will results in the decrease of fatigue life, $\mathrm{N}$ as suggested by the modified $\mathrm{S}-\mathrm{N}-\mathrm{d} / \mathrm{t}$ equation.

vi) Further studies are needed on the limitations so as to enable the modified $\mathrm{S}-\mathrm{N}-\mathrm{d} / \mathrm{t}$ equation to be applied more effectively. Allowable limit of $\mathrm{d} / \mathrm{t}$ ratio and spacing interval between studs in the direction of applied load will be important topics for future research. Also, since the studs are mostly used in composite structures, the effect of concrete strength should be taken into consideration to remodify the proposed modified equation. Despite the fact that fatigue test is a time-consuming experiment, future experiments should be carried out with ample specimens in order to obtain higher accurate data for higher reliability of analysis.

\section{REFERENCES}

[1] Tanaka, M., Uebayashi, S., Wakana, H., and Watabiki, T., "Application of Caisson as Hybrid Structure in Harbor Construction (in Japanese)", $2^{\text {nd }}$ Symposium on Application of Composite Structure, Society of Civil Engineering, 1989, pp. 385-390.

[2] Maeda, Y., Matsui, S., and Hiragi, H., "Effects of Concrete-Placing Direction on Static and Fatigue Strengths of Stud Shear Connectors (in Japanese)", Technology Reports of The Osaka University, 1983, Vol. 33, No. 1733, pp. 397-406

[3] Nobuhito, O., Akimitsu, K., Keiichi, K., and Yasuhiro, I., "Experimental Study on Static and Fatigue Characteristics of Grouped Stud", Journal of Structural Engineering III, 2002, Vol. 48A, No. 13-14, pp. 1391-1398.

[4] "Fatigue Design Code for Steel Structures (in Japanese)", Japanese Society of Steel Construction (JSSC), 1993, pp. 6, 24.

[5] Eiichi, M., "Statistical Mathematics", Japan Science and Engineering Ltd., 1974, pp. 155-156.

[6] Kajikawa, Y., and Maeda, Y., "Fatigue Strength of Flange Plate with Stud Shear Connector Subjected to Combined Tension and Shear (in Japanese)", Journal of Civil Engineering, 1985, Vol. 362, No. I-4, pp. 285-292. 


\title{
AESTHETICS, ECONOMICS AND DESIGN OF STAINLESS STEEL STRUCTURES
}

\author{
Leroy Gardner \\ Department of Civil and Environmental Engineering, Imperial College London, South Kensington Campus, \\ London, SW7 2AZ, UK. Tel: +44 (0)207 5946058. Fax: +44 (0)207594 5934 \\ *(Corresponding author: E-mail: leroy.gardner@imperial.ac.uk)
}

\begin{abstract}
The use of stainless steel in structural and architectural applications is growing due, in part, to the material's attractive appearance, corrosion resistance, ease of maintenance, low life cycle costs and fire resistance, alongside improved and more widespread design guidance and enhanced product availability. This paper explores the aesthetics, economics and design of stainless steel structures, highlighting recent applications in practice and recent advances in research. Increasingly, the construction industry, in common with most other industries, is expected to consider the longer term economic and environmental implications of material specification. Whilst structural carbon steel generally offers the most economic solution based on initial material costs, alternative metallic materials such as aluminium and stainless steel offer long-term benefits and associated cost savings. Life-cycle cost analyses of carbon steel and stainless steel employed in a range of structural applications are summarized herein. Although a number of similarities between stainless steel and ordinary carbon steel exist, there is sufficient diversity in their physical properties to require separate treatment in structural design. In addition to the straightforward differences in basic material properties (such as Young's modulus and yield strength), further fundamental differences exist, such as the nature of the stress-strain curve and the material's response to cold-work and elevated temperatures; these have implications at ultimate, serviceability and fire limit states. Current design rules for stainless steel structures and deficiencies thereof are described in this paper.
\end{abstract}

Keywords: Aesthetics, cold-work, deformation capacity, design, economics, stainless steel, structures

\section{INTRODUCTION}

The elegance of metallic structures has long been a feature of the construction industry, and whilst carbon steel remains the predominant material choice, there is an increasing use of alternative metallic materials, such as stainless steel, to meet rising demands on the durability, efficiency and sustainability of structures. The greatest advantage that stainless steel offers over other structural materials is its durability - appropriately specified, stainless steel requires no corrosion protection and minimal maintenance, leading to low life-cycle costs, reduced environmental impact and considerably extended design lives. Further benefits include high ductility, impact resistance and fire resistance, though it is the aesthetic appeal of stainless steel that has often been a central factor in its specification. The principal drawback to stainless steel is the material cost - approximately four times that of carbon steel. A review of the use of stainless steel in structures has been presented [1] and a number of case studies have been collated [2].

Significant progress has been made in recent years in the development of structural stainless steel design guidance and in the enhancement of product availability. Although a number of similarities between stainless steel and ordinary carbon steel exist, there is sufficient diversity in their physical properties to require separate treatment in structural design. In addition to the straightforward differences in basic material properties (such as Young's modulus and yield strength), further fundamental differences exist, such as the nature of the stress-strain curve and the material's response to cold-work and elevated temperatures; these have implications at ultimate, serviceability and fire limit states. This paper explores the aesthetics, economics and design of stainless steel structures, highlighting recent applications in practice and recent advances in research. 


\section{STRUCTURAL APPLICATIONS AND AESTETICS}

Historically, the aesthetics of stainless steel has been an important factor in its specification for structural and architectural applications. Consequently, many existing examples of stainless steel structures display a high level of exposed structural members, commonly of tubular cross-section, and are often of a prestigious or landmark nature. Its appeal is principally due to the surface finish and its ability to retain its appearance without deterioration over time.

Following its invention in 1912, the first significant application of stainless steel in construction was the upper facade of the Chrysler Building in New York, completed in 1930 (see Figure 1). This building now serves to exemplify the aesthetics and longevity of the material which, despite the aggressive atmosphere and proximity to the ocean, has shown no deterioration with time and remains bright and clean.

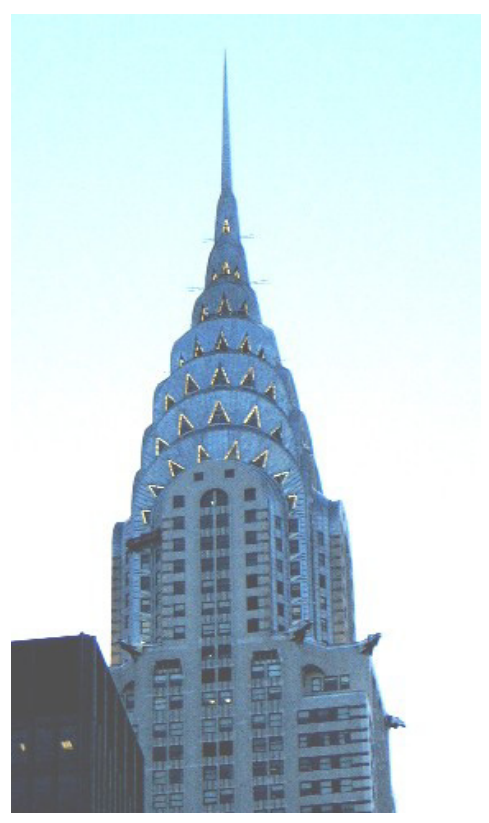

Figure 1. Chrysler Building, New York

In the 1920s and 1930s, the influential Swiss architect Le Corbusier set out his vision for a modern city - central to his vision was to embrace new technology and new materials. Although only to be truly realised some 30 years later, Le Corbusier's ideas [3] to consider buildings as machines heightened the eras drive towards creating buildings that communicated their efficiency, function and cleanliness, in contrast to the Victorian precedents. Built between 1971 and 1977, Richard Rogers' and Renzo Piano's Pompidou Centre in Paris took modernist ideas and industrial design to spectacular extremes. With the aim of providing the maximum interior space and greatest internal flexibility, the structure and services were all located external to the building, celebrating rather than concealing their presence and purpose. The main structural material of the Pompidou Centre is steel (see Figure 2), though stainless steel is also employed as a cladding material.

Following on from the Pompidou Centre, Richard Rogers' next landmark project was the Lloyds Building, situated in the City of London and completed in 1986. Once again, the services and stairs were located on the outside of the building (Figure 3). The main structure of the Lloyds Buildings is reinforced concrete, but stainless steel plays a prominent role in the external architecture. In addition to the cladding of the main stair and technical units, stainless steel also features in the handrail and balustrade systems (Figure 4) and in the main entrance canopy (Figure 5). 
General details and discussion of the architecture of both the Pompidou Centre and the Lloyds Building, along with a number of other projects that incorporate stainless steel (including the Grande Arche de la Défense and the Grand Louvre in Paris) may be found in [4]. Stainless steel is frequently adopted for handrails, and in combination with glass for partitioning due to its aesthetic appeal, high durability and ease of cleaning (see Figure 6).

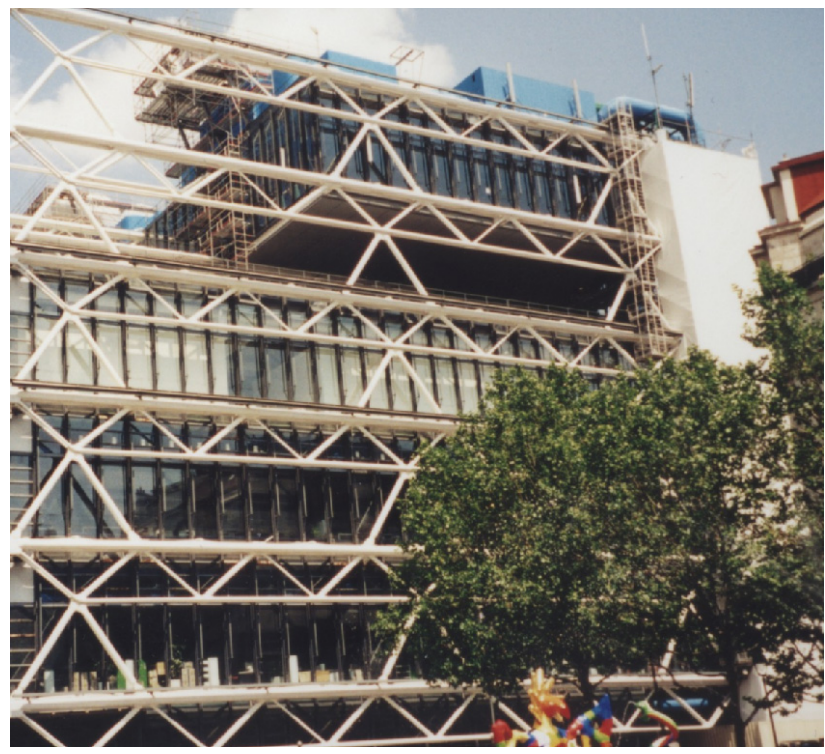

Figure 2. Pompidou Centre, Paris

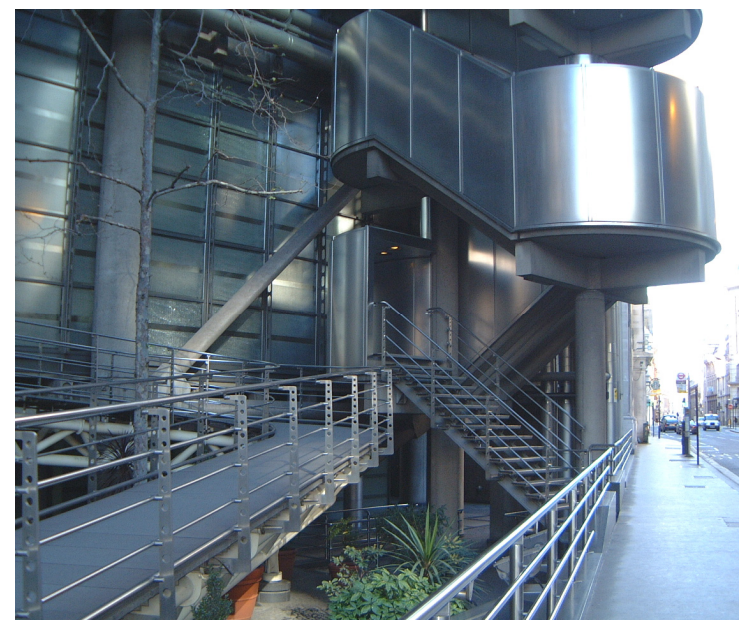

Figure 4. Stainless Steel Cladding, Handrails and Balustrade Systems (Lloyds Building, London)

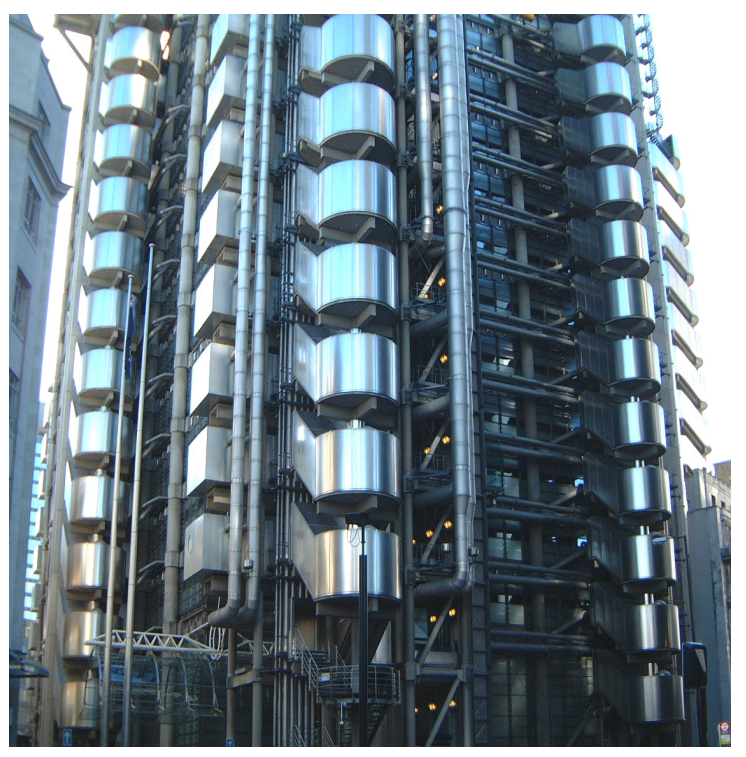

Figure 3. Services and Stairs Located on the Exterior of the Lloyds Building in London

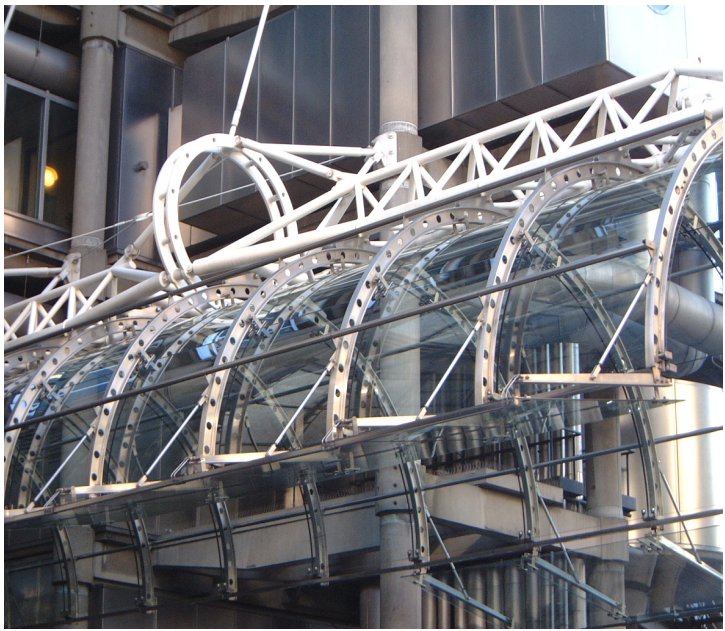

Figure 5. Stainless Steel Entrance Canopy of Lloyds Building, London

The surface finish of structural and architectural products is key to the aesthetics of stainless steel structures, whilst fundamental to the preservation of the surface finish is corrosion resistance. Upon exposure to air, stainless steel reacts with the oxygen to form a protective oxide layer (chromium oxide). This oxide layer adheres to the surface of the material and prevents the occurrence of further oxidation or corrosion. When damaged, provided oxygen is present, this oxide layer very rapidly reforms. Carbon steel also oxidises to form iron oxide. However, unlike chromium oxide, iron oxide does not adhere to the material, but rather occupies a larger volume and becomes detached from the surface, exposing un-corroded material to further oxidation. In certain conditions, stainless steel can be susceptible to corrosion. 
Aggressive environments, where particular care needs to be taken to select appropriate material grades to avoid severe corrosion, include strongly acidic or alkaline conditions; sea water, for example, is a weak chloride solution. General guidance on the corrosion of stainless steel is available [5].

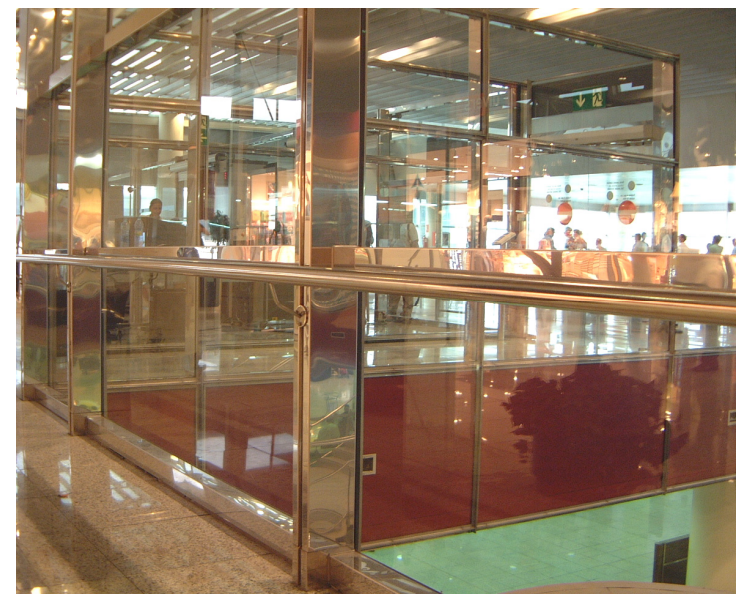

Figure 6. Stainless Steel Partitions and Handrails at Barcelona Airport

A wide range of surface finishes of stainless steel is available. These may be divided into two basic groups: standard mill finishes and finishes obtained by polishing. Standard mill finishes are the basic supply conditions for all stainless steel hot-rolled or cold-rolled flat products. For architectural and building applications, surface finish designations $1 \mathrm{D}, 2 \mathrm{D}, 2 \mathrm{~B}$ and $2 \mathrm{R}$ are the most important [6]. The 1D finish is hot-rolled, annealed and pickled (to remove mill scale) to form a slightly coarse surface with low reflectivity - this finish is acceptable for non-decorative structural applications. The 1D surface finish may be refined by cold-rolling, heat treating and pickling to form a low reflective matt surface designated 2D. A final light rolling using highly polished rollers will convert a $2 \mathrm{D}$ finish into a $2 \mathrm{~B}$ finish. The $2 \mathrm{~B}$ finish is smooth and reflective and is the most widely used. By bright annealing in an oxygen-free atmosphere following cold-rolling using polished rolls, a highly reflective $2 \mathrm{R}$ finish may be achieved. Further details of the described surface finishes, together with additional finishes and effects (including patterned finishes, electro-polished finishes and coloured finishes) may be found in [6]. The different surface finishes available in stainless steel allow the designer the opportunity to modulate how the structural presence is felt. High shines, for example, allow the structure to dissipate into reflections of light held in the surrounding space, and with the reflections continuously capturing a changing environment, a sense of uncontained space is promoted. Stainless steel can also be effectively used in combination with glass creating a feeling of immateriality to divide spaces physically but not visually.

Stainless steel product forms include plate, sheet, strip, tube, bar, cold-formed and hot-rolled structural sections, castings, fasteners and fixings. For structural members, the most commonly used products are cold-formed sections, predominantly because these are the most readily available, require relatively low investment to achieve production capabilities, and are suitable for light structural applications with high structural (and material) efficiency. Hot-rolled and built-up sections are relatively scarce, though structural design guidance is available. Cold-formed sections may be formed from flat sheet either by press-braking or roll-forming; press-braking is generally limited to simple shapes and low production levels and is often used for prototyping, whereas roll-forming is a continuous process suitable for larger quantities. Due to the material's response to cold-work, the strength of cold-formed structural stainless steel sections can be considerably enhanced during the forming process. These enhancements may arise during the production of the flat sheet or during the formation of the 
final cross-section. Strength enhancements in the sheet material may be utilised in design, with material strengths provided on the basis of the level of cold-work that the sheet receives. Strength enhancements during the cold-forming of the cross-sections are not included in existing design methods because there are currently no tools to determine the level and distribution of these enhancements for the particular process routes. Progress on the development of such tools is underway at Imperial College London. There are also currently no standard sizes for stainless steel sections, with sections often made to order. However, most suppliers stock commonly requested section sizes, and geometric properties and member capacities for such sections have been tabulated based on British [7, 8] and European [9] rules.

To date, the use of stainless steel in load bearing applications has been less extensive than its general use in architecture and amongst other industries. More widespread use has been partly inhibited by a lack of availability of design guidance and structural products, and limited knowledge amongst structural engineers regarding the specification, properties and benefits of the material. However, following significant recent research activity there is now a range of design guidance for stainless steel structures, including dedicated provisions in Europe, North America, Australian/ New Zealand and Japan. Structural applications of stainless steel are consequently becoming increasingly frequent. Recent examples are shown in Figures 7 to 11. The Grande Arche de la Défense in Paris, completed in 1989, incorporates a $91 \mathrm{~m}$ high external stainless steel lift structure (Figure 7). The structural members are grade 1.4462 (duplex stainless steel) tubular cross-sections varying from $60 \mathrm{~mm}$ to $244 \mathrm{~mm}$ in diameter. Figure 8 shows an external stainless steel lateral bracing system and façade supporting structure on the nine-storey Sanomatalo Building in Helsinki. The project was completed in 1999, utilises hot-rolled and cold-formed sections and includes welded and bolted details (see Figure 9).

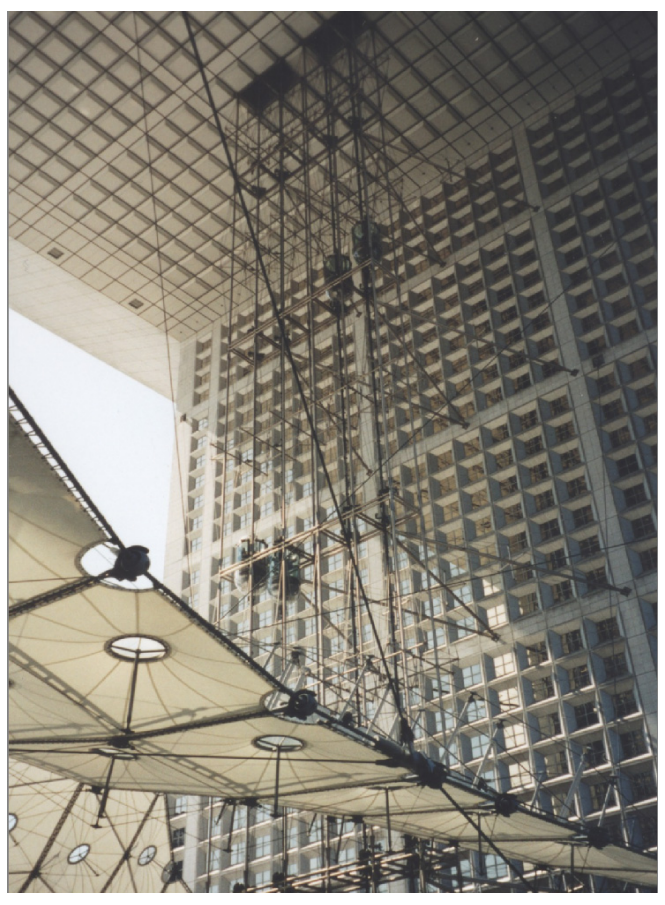

Figure 7. Grande Arche de la Défense, Paris

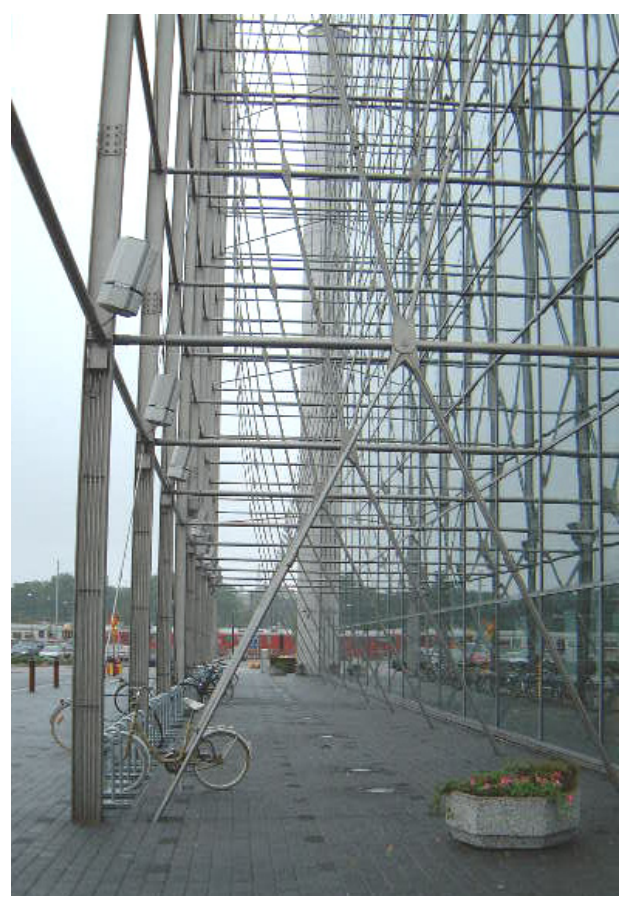

Figure 8. Sanomatalo Building, Helsinki 
A number of examples of the use of stainless steel for the primary structural elements of bridges have also recently emerged, including road bridges in Siena and Menorca and footbridges in London, Paris, Stockholm, and York. The road bridge in Menorca, Spain has an overall length of $55 \mathrm{~m}$ and a width of $13 \mathrm{~m}$, carrying two lanes of traffic. The structural system comprises two parallel duplex stainless steel arches, longitudinal beams and transverse beams that act compositely with a reinforced concrete deck. A full description of the Menorca road bridge, including details of the construction may be found in [10]. The Millennium footbridge in York (Figure 10) incorporates an $80 \mathrm{~m}$ duplex stainless steel inclined arch and was completed in 2001. Further details of the York Millennium Bridge and numerous other examples of stainless steel footbridges may be found in [11].

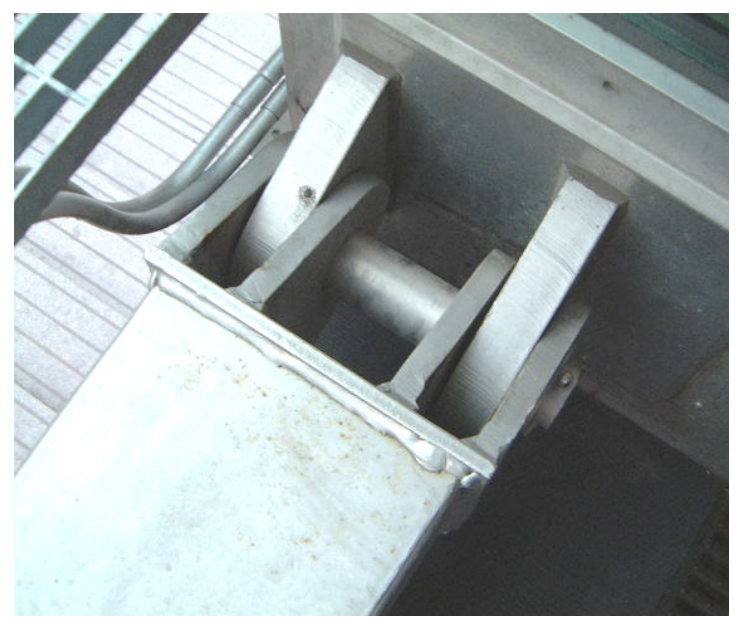

Figure 9. Connection detail in the Sanomatalo Building, Helsinki

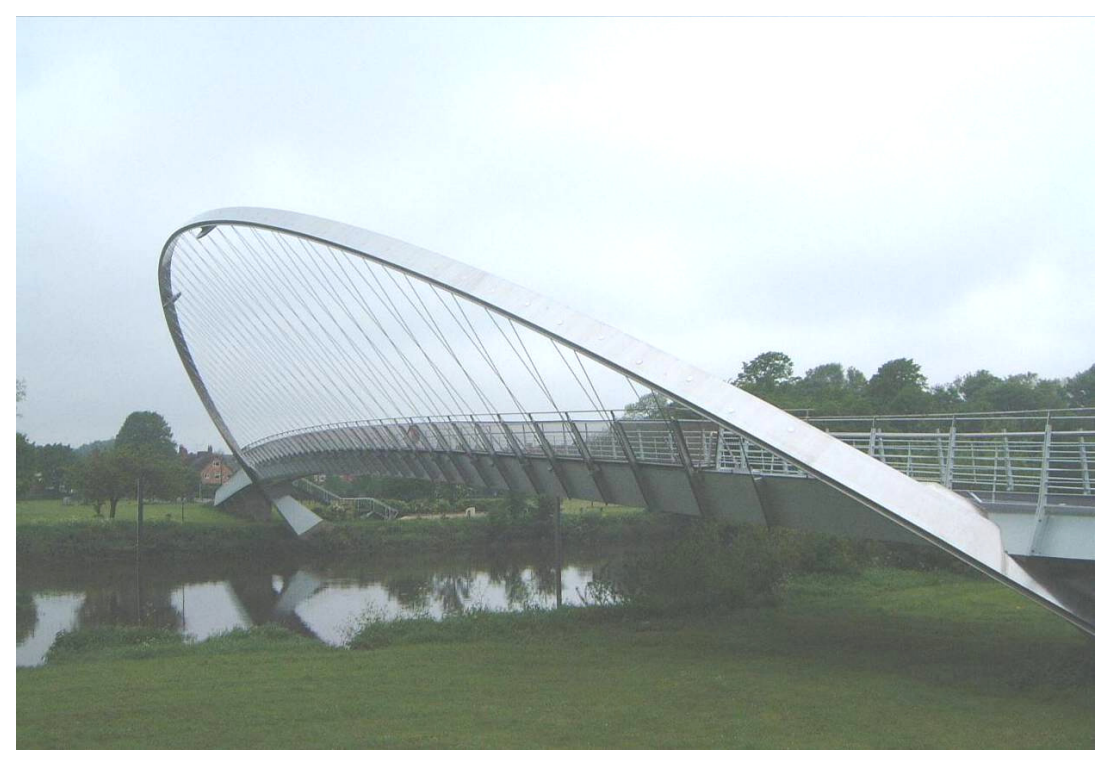

Figure 10. Millennium Footbridge, York

Figures 7 to 10 all show examples of the use of stainless steel in exposed structural applications, where the form and function of the structure are clearly visible. Stainless steel, with its natural corrosion resistance, appealing surface finishes and good fire resistance clearly lends itself to such expressive architecture. Exposure of the natural surface of the material also generates a non-artificial environment where the structure can be made to feel like a sculptural part of the space not just a functional necessity, which is boxed or painted to reduce its impact or excuse its existence. The ability of the exposed finish to remain constant over time presents a sense of permanence and quality. 


\section{ECONOMICS AND SUSTAINABILITY}

Within the construction industry, material selection has traditionally been based largely on initial material cost leading to the dominance of structural carbon steel over other metallic materials. Familiarity and ease of design and construction using carbon steel, together with a comprehensive range of structural products, have also contributed. The high cost of stainless steel (approximately four times that of ordinary structural carbon steel) is a clear and significant disincentive to its application. However, growing pressure on the construction industry to consider the longer term financial and environmental implications of projects is encouraging a more holistic approach. Thus, materials such as stainless steel with higher initial costs, but which offer cost savings over the life cycle of a structure, are gaining increasing recognition.

Recent studies $[12,13]$ have considered the relative life cycle costs of stainless steel and carbon steel structures employed in building, bridge and offshore applications. These applications differ in scale, life time expectancy, environmental corrosivity, maintenance requirements, cost of disrupted use and in the manner in which they are funded. The life cycle cost calculations incorporated initial material costs and the costs associated with initial corrosion and fire protection taken at their present values, and maintenance costs, end of life costs and the residual value of the structure discounted to their present value by means of a discount rate. The studies found that, on an initial cost basis, carbon steel consistently offered the most competitive solution. However, although carbon steel offered the most competitive life cycle solution for the building, stainless steel was found to be more economic over the life-cycle of both the bridge and offshore structures. Overall, it was concluded that on a whole-life basis stainless steel may offer more competitive solutions than carbon steel for bridges, exposed areas of building structures and offshore structures.

A further consideration is that the construction industry is a major producer of waste material and a major consumer of void (landfill) space. Increasing emphasis is now being placed on the minimisation of construction waste, with financial incentives such as the Landfill and Aggregates Levies operating in the UK. Stainless steel possesses a combination of high residual value (due to the alloy content) and excellent durability, lending itself to widespread re-use and recycling, bringing practical, financial and environmental advantages. Re-melting scrap using the electric arc process is the dominant means of production of stainless steel.

The high initial material cost of stainless steel is partly due to the relatively low volume of production, but is primarily linked to the cost of the constituent alloying elements (principally chromium and nickel), and it is not anticipated that the relative material costs of stainless steel and carbon steel will alter significantly in the foreseeable future. Therefore, in addition to exploiting the favourable properties of stainless steel, there is also a clear need to ensure that stainless steel is utilised efficiently and to develop the availability and diversity of the current product range. Notable recent advances include the development of a deformation based approach to the design of stainless steel elements which harness the strain hardening characteristics of the material $[14,15]$, and the generation of structural design guidance for high strength cold-formed stainless steel $[16,17]$.

\section{STRUCTURAL DESIGN}

Significant progress has been made in recent years towards the development of comprehensive and efficient structural design guidance for stainless steel. The earliest dedicated stainless steel structural design Standard was published by the American Iron and Steel Institute (AISI) in 
1968 as the Specification for the Design of Light Gauge Cold-formed Stainless Steel Structural Members. With an increased availability of test results, a revised version of the Standard was published in 1974. Further research enabled the development of the American Society of Civil Engineers (ASCE) structural stainless steel design Standard, first published in 1991 and more recently in 2002 [18], which effectively superseded the AISI Standard in North America. In Europe, design rules were first published by Euro Inox in 1994 as the Design Manual for Structural Stainless Steel. In 2002, a second edition of the Design Manual was released [19]. Part 1.4 of Eurocode 3 is also dedicated to the design of stainless steel structures; the pre-standard, ENV 1993-1-4 was published in 1996, whilst the final EN 1993-1-4 [20] is due to be published in 2006. In 1995, the first Japanese stainless steel structural design Standard was issued; it is only available in Japanese and is focussed on the design of fabricated (welded) sections. Based largely on the Canadian design Standard for cold-formed carbon steel structures, the South African structural stainless steel Standard was published in 1997. Most recently, in 2001, the Australia/New Zealand design Standard for cold-formed stainless steel structures [21] was issued.

The material properties of stainless steel vary with chemical composition and heat treatment (i.e. grade), product type, level of cold-worked, material thickness, direction of rolling (i.e. longitudinal or transverse), and direction of loading (i.e. tension or compression). This variation is recognised in codes, though some simplifications are employed to facilitate design. The design of stainless steel cross-sections follows the familiar carbon steel approach, utilising the concepts of cross-section classification and, for slender elements susceptible to local buckling, the effective width method. For the calculation of effective widths, the European guidance given in EN 1993-1-4 refers to the equivalent carbon steel parts (Part 1.1 for hot-rolled sections and Part 1.3 for cold-formed sections). The behaviour of stainless steel members differs from that of carbon steel members due to the gradual yielding nature of the material stress-strain curve and variation in other characteristics such as the level of geometric imperfections and residual stresses. The European provisions for stainless steel member design mirror those for carbon steel. The basic formulations are the same, though differences exist in the selection of the imperfection parameter $\alpha$ and the non-dimensional limiting slenderness $\bar{\lambda}_{0}$ (the plateau length), both of which effectively define the shape of the buckling curves. The buckling curves have been calibrated against all available stainless steel test data to provide a suitably conservative fit for design purposes. For simplicity (to avoid the need for iteration) and consistency with the carbon steel approach, no explicit allowance is made for the effect of gradual material yielding in the member buckling formulations. In addition to providing for the flexural buckling of columns and the lateral-torsional buckling of beams, guidance is also given for design against torsional and torsional-flexural buckling of compression members (by reference to Eurocode 3 Part 1.3). Since stainless steel structural members are generally cold-formed (i.e. relatively thin material) and are often open-sections (i.e. low torsional stiffness), susceptibility to these modes of failure should be checked. The US provisions for stainless steel member design follow the AISI recommendations for carbon steel, except, to account for the non-linear (gradual yielding) stress-strain response, the tangent modulus $E_{t}$ is used in place of the usual initial modulus $E_{0}$ in the buckling formulations. Additionally, for buckling modes with torsional components (lateral torsional buckling of beams and torsional and torsional-flexural buckling of columns), the initial shear modulus $\mathrm{G}_{0}$ is replaced by the tangent shear modulus $\mathrm{G}_{\mathrm{t}}$. The non-linear stress-strain behaviour is described by the well known Ramberg-Osgood expression. Since the tangent modulus is dependent upon the buckling stress level, the US member design procedure is necessarily iterative. 
For the determination of deflections in stainless steel flexural members, account must be taken of the non-linear stress-strain characteristics of the material; simply assuming the initial tangent modulus $\mathrm{E}_{0}$ will result in an under-estimation of deflections. The European, US and Australia/New Zealand design Standards all adopt essentially the same treatment, whereby deflections are calculated based on a reduced modulus of elasticity. In all Standards the reduced modulus of elasticity is taken as the average of the secant moduli in tension and compression corresponding to the maximum serviceability stresses that occur along the member length.

Although a significant step forward, current design methods do no adequately allow for the rounded nature of the stress-strain curve of stainless steel and the considerable strain-hardening. A new, approach has been developed that replaces the current discretised system of cross-section classification based on bi-linear material assumptions with a continuous, deformation capacity based measure of resistance. The new approach utilises an accurate material description and yields average increases in member resistance of around $20 \%$ over current design methods. The method has been verified on the basis of existing test data and numerical data and is detailed in [14] and [15].

\section{CONCLUSIONS}

The aesthetics of stainless steel has been an important factor in its specification in the construction industry. Its appeal, exemplified in landmark structures such as the Chrysler Building in New York, the Lloyds Building in London and the Grande Arche in Paris, is principally associated with the surface finish of the material, but also its ability to retain this finish over time. Whilst most existing applications of stainless steel in construction have been of a primarily architectural nature, use in load-bearing applications is growing. In particular, a range of examples of the use of stainless steel in road bridges and pedestrian bridges has recently emerged.

The initial material cost of stainless steel is about four times that of ordinary structural carbon steel - this represents the most significant factor in inhibiting more widespread use, though limited design guidance and a lack of familiarity amongst structural engineers and fabricators have also contributed. Significant progress has been made in recent years in the development of design guidance and verified structural design rules are now widely available, although further improvements in efficiency are necessary. By considering the additional benefits of stainless steel over carbon steel, including corrosion resistance, durability, ductility, fire resistance, residual value and sustainability, structural application of the material becomes more economically and environmentally appealing.

\section{REFERENCES}

[1] Gardner, L., "The Use of Stainless Steel in Structures", Progress in Structural Engineering and Materials, 2005, Vol. 7, No. 2, pp. 45-55.

[2] Baddoo, N.R., Burgan, R. and Ogden, R., "Architects' Guide to Stainless Steel", SCI-P-179. The Steel Construction Institute, UK, 1997.

[3] Le Corbusier, "Towards a New Architecture". First published in French, 1923, translated by F. Etchells. The Architectural Press, London, 1946.

[4] Tzonis, A. and Lefaivre, L., "Architecture in Europe since 1968 - Memory and Invention", Thames and Hudson Ltd, London, 1992. 
[5] Sedriks A.J., "Corrosion of Stainless Steels", John Wiley \& Sons, Inc, 2nd Edition, 1996.

[6] Cochrane, D. and Helzel, M., "Guide to Stainless Steel Finishes”, Euro Inox Building Series, Vol. 1, Third Edition, 2005.

[7] Chung, K.F., Baddoo, N.R. and Burgan, B.A., "Section Property and Member Capacity Tables for Cold-Formed Stainless Steel", SCI-P-152. The Steel Construction Institute, UK, 1995.

[8] Baddoo, N.R. and Burgan, B.A., "Structural Design of Stainless Steel”, SCI-P-291. The Steel Construction Institute, UK, 2001.

[9] The Steel Construction Institute, "Stainless Steel in Construction - Design Software for Cold-formed Stainless Steel", Retrieved from www.steel-stainless.org.

[10] Sobrino, J.A., "Stainless Steel Road Bridge in Menorca, Spain", Structural Engineering International, 2006, Vol. 16, No. 2, pp. 96-100.

[11] Helzel, M. and Taylor, I., "Pedestrian Bridges in Stainless Steel", Euro Inox Building Series, 2004, Vol. 7.

[12] Gardner, L., Cruise, R.B., Sok, C.P., Krishnan, K. and Ministro, J., "Life Cycle Costing of Metallic Structures", Engineering Sustainability, ICE, submitted.

[13] Shuttleworth, E.P., "Structural Applications for Stainless Steel Offshore - Report to The Nickel Development Institute", Report No. SCI-RT-030, The Steel Construction Institute, 1989.

[14] Gardner, L. and Nethercot, D.A., "Stainless Steel Structural Design: A New Approach", The Structural Engineer, 2004, Vol. 82, No. 21, pp. 21-28.

[15] Gardner, L. and Ashraf, M., "Structural Design for Non-linear Metallic Materials", Engineering Structures, 2006, Vol. 28, No. 6, pp. 926-934.

[16] Young, B and Lui, W-M., "Behavior of Cold-formed High Strength Stainless Steel Sections", Journal of Structural Engineering, ASCE, 2005, Vol. 131, No. 11, pp. 1738-1745.

[17] Gardner, L., Talja, A. and Baddoo, N.R., "Structural Design of High Strength Austenitic Stainless Steel", Thin-Walled Structures, in Press.

[18] ASCE, "Specification for the Design of Cold-Formed Stainless Steel Structural Members", SEI/ASCE 8-02, (Standard No. 02-008), American Society of Civil Engineers, New York, 2002.

[19] Euro Inox/SCI, "Design Manual for Structural Stainless Steel”, Second Edition, NiDI. Toronto, Canada, 2002.

[20] EN 1993-1-4, "Eurocode 3:Design of Steel Structures - Part 1.4: General Rules Supplementary Rules for Stainless Steel", CEN, 2006.

[21] Aust/NZS, "Cold-formed Stainless Steel Structures", Australian/New Zealand Standard AS/NZS 4673:2001, Sydney, Australia: Standards Australia, 2001. 


\title{
BEHAVIOUR AND DESIGN OF STEEL-CONCRETE-STEEL-SANDWICH CONSTRUCTION
}

\author{
N. Foundoukos ${ }^{1, *}$, M. Xie ${ }^{2}$, and J.C. Chapman ${ }^{3}$ \\ ${ }^{1}$ Imperial College of Science Technology and Medicine, London SW7 2AZ, UK, , fax 00442075945934 \\ ${ }_{2}^{2}$ KW Ltd, Fetcham Park House, Lower Road, Fetcham, Surrey KT22 9HD, UK, mxie@kwltd.com \\ ${ }^{3}$ Imperial College of Science Technology and Medicine, London SW7 2AZ, UK, jcrbchapman@globalnet.co.uk \\ *(Corresponding author: E-mail: nf2@ic.ac.uk)
}

\begin{abstract}
Static and fatigue tests have been conducted on Bi-Steel steel-concrete-steel sandwich beams. A truss mi with tapering web compression members is proposed for calculating the forces within the beams. The model $\mathrm{g}$ conservative predictions of the failure loads and modes of the beams. A deflection equation has been developed taking account the slip between steel plates and concrete, giving good agreement with measured values. A fatigue life calcula method has been proposed which takes into account interaction of the applied forces at bar-plate connections and $\mathrm{g}$ conservative predictions of fatigue life.
\end{abstract}

Keywords: Sandwich construction, bi-steel, static tests, beams, strength, deflection, fatigue

\section{INTRODUCTION}

Bi-Steel is an innovative form of steel-concrete-steel sandwich construction invented by Bowerman [1], in which the two steel plates are inter-connected by a series of transverse bar connectors simultaneously friction welded at both ends (Figure 1). A design guide was published by CORUS [2], based on testing and on existing design codes for steel and reinforced concrete.

The prime function of shear connectors in conventional composite beams is to resist longitudinal shear, but they also prevent uplift of the slab from the beam. In Bi-Steel members the bar connectors are connected to the plates at both ends, and their function is to resist both longitudinal and transverse shear, in addition to preventing plate buckling. The connectors are subjected to shear, tension or compression, and bending. The purpose of the research project at Imperial College was to validate or improve the existing design recommendations. Static and fatigue tests on components under single and combined loads were performed $[3,4]$ to give the load capacity and fatigue life of the connection. The results of the static and fatigue tests on Bi-Steel beams were used in design formulation.

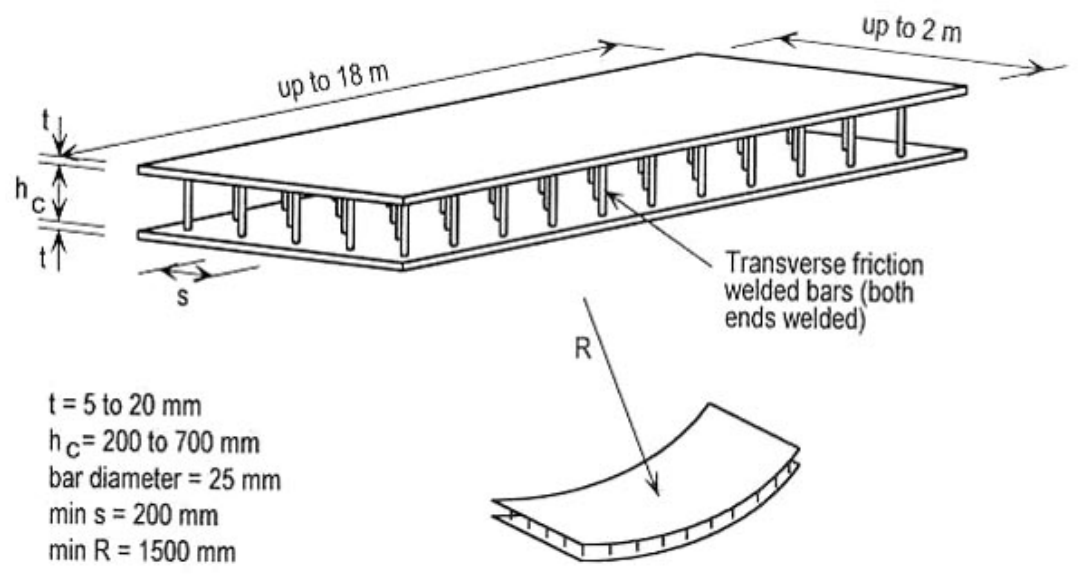

Figure 1. Bi-Steel Sandwich Construction 


\section{ANALYTICAL MODELS}

\subsection{Equivalent Steel Beam}

The equivalent steel beam approach (Figure $2 b$ ) is recommended in the current design guide. The assumptions are that the steel and concrete are elastic, but the concrete has no tensile strength, and that the plates are continuously connected to the concrete. The width of concrete is assumed to be reduced in proportion to the modular ratio $\mathrm{m}$ between steel and concrete $\left(\mathrm{m}=\mathrm{E} / \mathrm{E}_{\mathrm{c}}\right)$. The bar connector shear forces can then be estimated from the change in plate force over a length equal to the bar spacing. The model does not provide a means for calculating bar tension, or for resisting transverse shear. The assumption of continuous connection leads to an incorrect estimate of force in the compression plate. The model does not provide for a rigorous method for calculating the slip deflection which was found to be the largest deflection component.

\subsection{Truss Model}

A truss model with tapering web compression members is proposed for analysis of Bi-Steel beam member forces (Figure 2a, c). The area of concrete in longitudinal compression can be determined from the equivalent steel section. The truss model consists of pin jointed line elements in which the axial stress is uniform across a section. To achieve this the uniform web thickness over which, according to the equivalent beam model, the stress varies, is replaced by a tapering web across which the stress is constant, with the requirement that the total compressive forces are equal to that in the equivalent beam model, and that the depth of the compression zones $y_{m}$ are also equal. The depth $\mathrm{h}$ of the truss is equal to the distance from the mid-thickness of the bottom plate to the centroid of the compression area (Figure 2c); h is given by Eqs. (1), (2), (3).

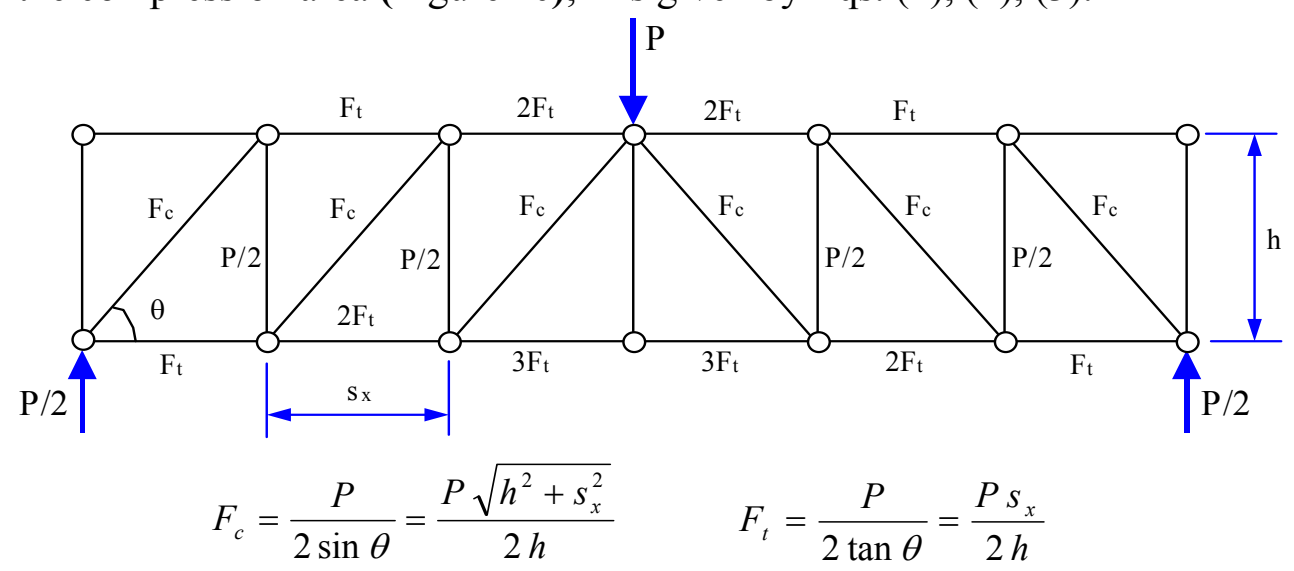

(a) Truss model for a Bi-Steel beam

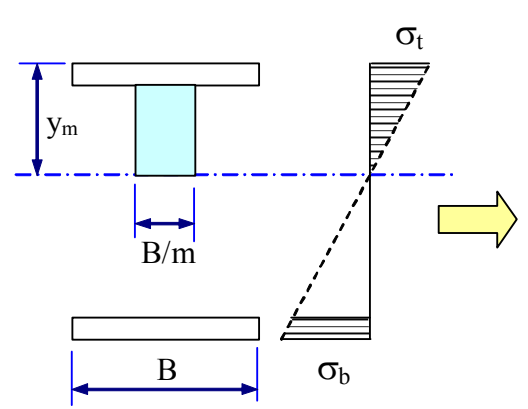

(b) Equivalent steel section

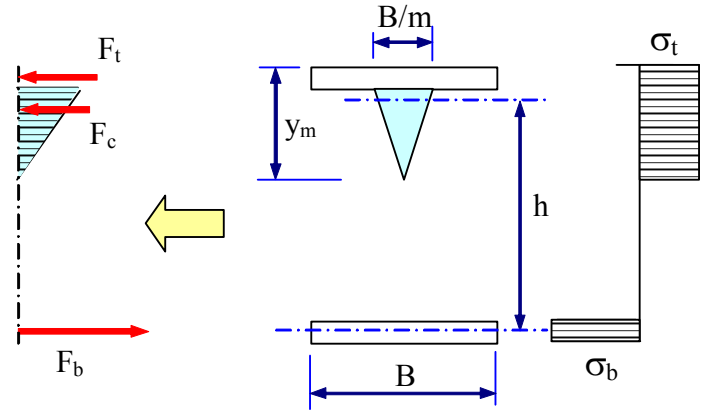

(c) Cross section of truss members

Figure 2. Calculation of the Depth of Truss, $h$ 
$h=\frac{m t_{t}\left(2 h_{c}+t_{t}+t_{b}\right)+\left(y_{m}-t_{t}\right)\left[h_{c}-\left(y_{m}-t_{t}\right) / 3+t_{b} / 2\right]}{2 m t_{t}+y_{m}-t_{t}}$

where $\mathrm{y}_{\mathrm{m}}$ is given by: $y_{m}=-\alpha+\sqrt{\alpha^{2}-2 \beta}$

with: $\alpha=m\left(t_{t}+t_{b}\right)-t_{t} \quad \beta=-\left(h_{c}+t_{t}+t_{b}\right) m t_{b}+\left(m t_{b}^{2}-m t_{t}^{2}+t_{t}^{2}\right) / 2$

An inherent characteristic of this model is that the plates are connected to the concrete only at the nodal points. That is, there is no bond between steel and concrete, as in reality, which gives a correct estimate of the plate forces.

\section{EXPERIMENTATION}

Eighteen beams were tested statically. The beams were designed to cover a range of geometrical properties, and to enable different failure modes to be observed. Details of the beams are given in Table 1 and illustrated in Figure 3.

Table 1. Geometrical Dimensions of the Test Beams and Material Properties

\begin{tabular}{ccccccccccc}
\hline $\begin{array}{c}\text { Beam } \\
\text { No. }\end{array}$ & $\begin{array}{c}\mathrm{t}_{\mathrm{b}} \\
(\mathrm{mm})\end{array}$ & $\begin{array}{c}\mathrm{t}_{\mathrm{t}} \\
(\mathrm{mm})\end{array}$ & $\begin{array}{c}\mathrm{h}_{\mathrm{c}} \\
(\mathrm{mm})\end{array}$ & $\begin{array}{c}\mathrm{s}_{\mathrm{x}} \\
(\mathrm{mm})\end{array}$ & $\mathrm{L}(\mathrm{mm})$ & $\begin{array}{c}\mathrm{f}_{\mathrm{yP}}{ }^{*} \\
\left(\mathrm{~N} / \mathrm{mm}^{2}\right)\end{array}$ & $\begin{array}{c}\mathrm{f}_{\mathrm{uP}}{ }^{*} \\
\left(\mathrm{~N} / \mathrm{mm}^{2}\right)\end{array}$ & $\begin{array}{c}\mathrm{f}_{\mathrm{yB}} \\
\left(\mathrm{N} / \mathrm{mm}^{2}\right)\end{array}$ & $\begin{array}{c}\mathrm{f}_{\mathrm{uB}} \\
\left(\mathrm{N} / \mathrm{mm}^{2}\right)\end{array}$ & $\begin{array}{c}\mathrm{f}_{\mathrm{cu}} \\
\left(\mathrm{N} / \mathrm{mm}^{2}\right)\end{array}$ \\
\hline BS1 & 6.23 & 6.23 & 400 & 200 & 1200 & 384 & 507 & 541 & 566 & 58 \\
BS2 & 7.91 & 7.91 & 400 & 200 & 1200 & 381 & 518 & 541 & 566 & 58 \\
BS3 & 11.96 & 11.96 & 400 & 200 & 1200 & 419 & 563 & 541 & 566 & 58 \\
BS4 & 6.13 & 11.95 & 200 & 200 & 1200 & 384 & 507 & 541 & 566 & 58 \\
BS5 & 7.91 & 11.93 & 200 & 200 & 1200 & 381 & 518 & 541 & 566 & 58 \\
BS6 & 11.83 & 11.83 & 200 & 200 & 1200 & 419 & 563 & 541 & 566 & 58 \\
BS7 & 6.20 & 11.93 & 200 & 300 & 1800 & 384 & 507 & 541 & 566 & 58 \\
BS8 & 7.98 & 11.82 & 200 & 300 & 1800 & 381 & 518 & 541 & 566 & 58 \\
BS9 & 11.90 & 11.90 & 200 & 300 & 1800 & 419 & 563 & 541 & 566 & 58 \\
BS10 & 6.10 & 11.95 & 200 & 400 & 2400 & 384 & 507 & 541 & 566 & 58 \\
BS11 & 7.98 & 11.88 & 200 & 400 & 2400 & 381 & 518 & 541 & 566 & 58 \\
BS12 & 11.92 & 11.92 & 200 & 400 & 2400 & 419 & 563 & 541 & 566 & 58 \\
BS13 & 10.31 & 10.21 & 300 & 200 & 1600 & 430 & 548 & 553 & 586 & 40 \\
BS14 & 11.88 & 11.83 & 300 & 200 & 1600 & 431 & 571 & 553 & 586 & 40 \\
BS15 & 10.02 & 10.27 & 300 & 300 & 1800 & 430 & 548 & 553 & 586 & 40 \\
BS16 & 11.76 & 11.83 & 300 & 300 & 1800 & 431 & 571 & 553 & 586 & 40 \\
BS17 & 10.18 & 10.21 & 300 & 300 & 2400 & 430 & 548 & 553 & 586 & 40 \\
BS18 & 11.93 & 11.89 & 300 & 300 & 2400 & 431 & 571 & 553 & 586 & 40 \\
\hline
\end{tabular}

* Note: The yield stress and the ultimate strength of the tension steel plates are listed. 


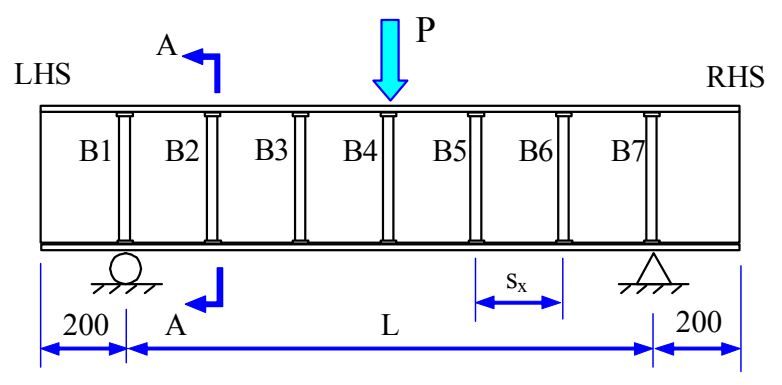

$\mathbf{L} / \mathbf{s}_{\mathbf{x}}=\mathbf{6}$

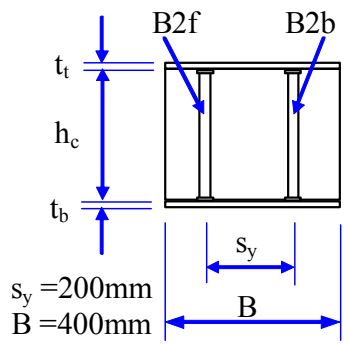

$\underline{\mathbf{A}-\mathbf{A}}$

Figure 3. Details of the Test Beams. $B=400 \mathrm{~mm}, s_{y}=200 m m, s_{x}, h_{c}, t_{t}$ and $t_{b}$ Vary

The beams were supported on a fixed cylindrical bar at one end and a roller at the other end. Equal forces were applied by two 100ton (static) jacks at midspan. Strain gauges and displacement transducers were used to record strains, slip and deflections at key positions in the beams.

\section{TEST RESULTS AND COMPARISONS}

\subsection{Failure Loads and Modes}

The measured failure loads and failure modes for the 18 beams are summarised in Table 2. Figure 4 illustrates the four elementary modes of failure observed in the test beams.

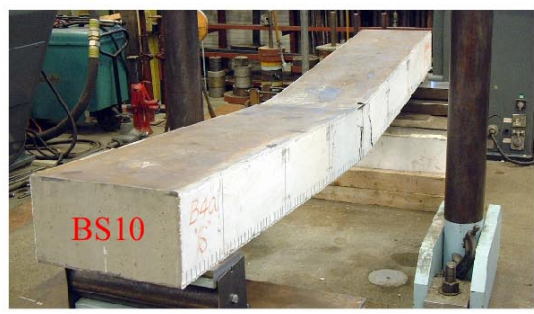

Tension plate failure

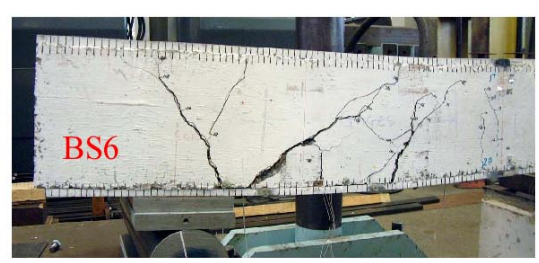

Concrete shear failure

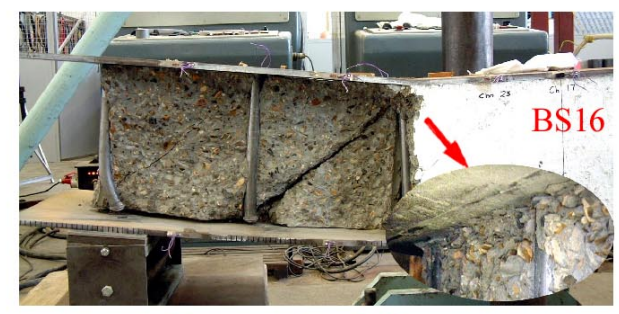

Bar tension failure

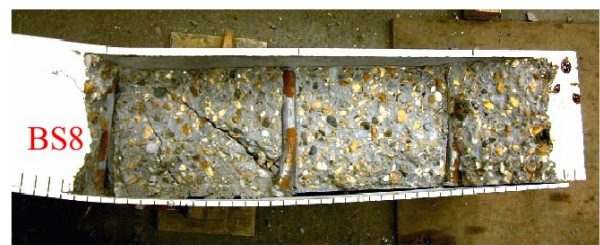

Bar shear failure

Figure 4. Typical Beam Static Failure Modes

Failure loads were calculated using the truss model. The failure load for each possible failure mode was determined in terms of the ultimate strength of the bar-plate connection in plate tension, bar shear and bar tension, as determined from static tests on bar-plate connection components [3, 4]. These tests showed that for plates having t> $8 \mathrm{~mm}$ the connection tensile strength (in the absence of bar shear) is governed by the strength of the bar material. The strength of the connection in bar shear is given by the following equation:

$H_{u B}=\left\{\begin{array}{l}210(t / 10)^{0.45} \mathrm{kN} \quad \text { for } t \leq 10 \mathrm{~mm} \text { and } d=25 \mathrm{~mm} \\ 210 \mathrm{kN} \text { for } t>10 \mathrm{~mm} \text { and } d=25 \mathrm{~mm}\end{array}\right.$ 
The tensile strength of the plate was assumed to be given by the uni-axial tensile strength of the steel plate material. The axial tensile forces in the bar connectors were calculated using the truss model, but factored by $\mathrm{s}_{\mathrm{x}} / \mathrm{h}_{\mathrm{c}}$ when $\mathrm{s}_{\mathrm{x}} / \mathrm{h}_{\mathrm{c}} \neq 1$ as suggested from static test measurements and finite element analysis [5]. Transverse shear resistance was calculated using the modified Eurocode2 [6] method as recommended in the Bi-Steel design guide.

Table 2. Ratio of Calculated to Measured Failure and Yield Loads and Midspan Deflections

\begin{tabular}{|c|c|c|c|c|c|c|c|c|c|c|c|}
\hline \multirow{2}{*}{ Beam } & \multicolumn{3}{|c|}{ Test measurements } & \multicolumn{6}{|c|}{ Prediction/Test } & \multicolumn{2}{|c|}{ Failure modes } \\
\hline & $\Delta_{0}$ & $\mathrm{P}_{0 \mathrm{P}}$ & $\mathrm{P}_{\mathrm{u}}$ & $\Delta_{0}$ & $\mathrm{P}_{0 \mathrm{P}}$ & $\mathrm{P}_{\mathrm{uP}}$ & $\mathrm{P}_{\mathrm{uBS}}$ & $\mathrm{P}_{\mathrm{uBT}}$ & $\mathrm{P}_{\mathrm{uVS}}$ & Predicted & Test \\
\hline BS1 & 2.6 & 1096 & 1591 & 1.06 & 1.11 & 1.01 & 1.20 & 1.34 & 0.62 & $\begin{array}{c}\text { Transverse } \\
\text { shear }\end{array}$ & Tension plate \\
\hline BS2 & 4.0 & 1738 & 1946 & 0.96 & 0.89 & 1.08 & 1.10 & 1.10 & 0.62 & $\begin{array}{c}\text { Transverse } \\
\text { shear }\end{array}$ & Tension plate \\
\hline BS3 & $>4.1$ & $>1984$ & $>1984$ & 0.92 & - & - & - & - & - & $\begin{array}{c}\text { Transverse } \\
\text { shear }\end{array}$ & No failure \\
\hline BS4 & 6.1 & 553 & 727 & 0.81 & 1.16 & 1.17 & 1.14 & 1.56 & 0.75 & $\begin{array}{c}\text { Transverse } \\
\text { shear r }\end{array}$ & Tension plate \\
\hline BS5 & 7.9 & 786 & 873 & 0.79 & 1.04 & 1.28 & 1.06 & 1.30 & 0.74 & $\begin{array}{c}\text { Transverse } \\
\text { shear }\end{array}$ & Concrete shear \\
\hline BS6 & $>10.9$ & $>1110$ & 1110 & 1.17 & - & 1.62 & 0.93 & 1.02 & 0.80 & $\begin{array}{c}\text { Transverse } \\
\text { shear }\end{array}$ & Concre \\
\hline BS7 & 7.1 & 333 & 545 & 1.08 & 1.30 & 1.05 & 0.96 & 1.39 & 0.84 & $\begin{array}{c}\text { Transverse } \\
\text { shear }\end{array}$ & Tension plate \\
\hline BS8 & 9.1 & 465 & 577 & 1.04 & 1.19 & 1.30 & 1.01 & 1.31 & 0.91 & $\begin{array}{c}\text { Transverse } \\
\text { shear }\end{array}$ & Bar shear \\
\hline BS9 & $>17.0$ & $>674$ & 674 & 1.21 & - & 1.80 & 0.95 & 1.12 & 1.02 & Bar shear & Bar shear \\
\hline BS10 & 8.9 & 245 & $\geq 415$ & 1.27 & 1.30 & 1.02 & 0.91 & 1.37 & 0.99 & Bar shear & Tension plate \\
\hline BS11 & 9.2 & 303 & 477 & 1.34 & 1.36 & 1.18 & 0.89 & 1.19 & 0.97 & Bar shear & $\begin{array}{c}\text { Bar/concrete } \\
\text { shear }\end{array}$ \\
\hline BS12 & $>20.0$ & $>501$ & 501 & 1.11 & - & 1.81 & 0.93 & 1.13 & 1.17 & Bar shear & $\begin{array}{c}\text { Bar/concrete } \\
\text { shear }\end{array}$ \\
\hline BS13 & 8.3 & 1201 & 1526 & 0.80 & 1.09 & 1.09 & 0.99 & 1.11 & 0.76 & $\begin{array}{c}\text { Transverse } \\
\text { shear }\end{array}$ & Tension plate \\
\hline BS14 & 13.2 & 1458 & 1583 & 0.56 & 1.04 & 1.27 & 0.97 & 1.08 & 0.83 & $\begin{array}{c}\text { Transverse } \\
\text { shear }\end{array}$ & Bar shear \\
\hline BS15 & $>20.0$ & $>1047$ & 1047 & 0.95 & - & 1.37 & 0.94 & 1.08 & 0.84 & $\begin{array}{c}\text { Transverse } \\
\text { shear }\end{array}$ & $\begin{array}{c}\text { Bar } \\
\text { tension/shear }\end{array}$ \\
\hline BS16 & $>13.3$ & $>985$ & 985 & 0.99 & - & 1.80 & 1.01 & 1.16 & 1.01 & Bar shear & Bar tension \\
\hline BS17 & 13.2 & 758 & 851 & 0.84 & 1.13 & 1.29 & 1.11 & 1.33 & 1.05 & $\begin{array}{c}\text { Transverse/bar } \\
\text { Shear }\end{array}$ & $\begin{array}{c}\text { Bar/concrete } \\
\text { shear }\end{array}$ \\
\hline BS18 & $>15.3$ & $->805$ & 805 & 1.06 & - & 1.68 & 1.18 & 1.41 & 1.25 & bar shear & $\begin{array}{c}\text { Concrete shear } \\
\text { bar tension }\end{array}$ \\
\hline
\end{tabular}

Note: Predicted transverse shear failure may result in either concrete shear or bar tension failure modes 
In Table 2, the ratios of the calculated to measured failure and yield loads are listed together with ratios of the calculated to measured (Eq. 5) midspan deflection at yield (where available) or at $2 / 3 \mathrm{P}_{\mathrm{u}}$. The predicted failure modes are also listed in Table 2. The mode for BS17 was taken as combined because the calculated failure load for bar shear was not more than $5 \%$ greater than that for transverse shear. Where a transverse shear failure is predicted, this may imply either a concrete shear failure mode or a bar tension failure mode.

According to the estimated maximum load for each possible failure mode, as listed in Table 2, the anticipated beam failure load is below the actual failure load. It can be seen in Table 2 that for the beams that developed tension plate failure in the tests, the measured tension plate yield load $\mathrm{P}_{0 \mathrm{p}}$ is generally below the predicted value, the ratio of prediction to test values ranging from 0.89 to 1.30 , and the predicted maximum load to cause tension plate failure is 1.01 1.17 times the actual load. This observation shows that the proposed method can overestimate the tension plate failure strength, mainly because the estimated plate forces were obtained by assuming the steel and the concrete to be linear elastic up to ultimate strength.

For the beams that developed bar shear failure in the tests, the predicted maximum load varies from 0.89 to 1.11 of the measured value. For beams BS15 and BS16, which had a bar tension failure, the calculated failure load for bar tension failure is respectively $108 \%$ and $116 \%$ of the measured maximum load. The ratio of the predicted transverse shear capacity to the measured value varies from beam to beam; for beam BS1 the estimated load to cause transverse shear failure is about $62 \%$ of the measured failure load to cause tension plate failure.

\subsection{Deflection}

Deflection has three quantifiable components - bending, slip, and transverse shear strain, that is:

$\Delta=\Delta_{B}+\Delta_{S L}+\Delta_{S H}$

The bending deflection for a beam with a central point load can be calculated by Eq. 6 :

$\Delta_{B}=\frac{P L^{3}}{48 E I_{e q}}$

where $I_{\text {eq }}$ is the second moment of area of the equivalent beam section as shown in Figure 2(b). The equation for slip deflection is developed from Wright and Oduyemi's model [7] assuming zero slip at the top plate. The approach proposed takes account of the bending deflection component of the beam and the additional deflection component due to interface slip between the steel plates and the concrete. It was observed in the beam tests that the slip at the top plate interface was nearly zero. Therefore, by introducing a further assumption of no top plate slip in the Wright \& Oduyemi model, a new equation was derived for the calculation of the midspan deflection due to interface slip only. The slip deflection for a simply supported beam loaded at midspan can be estimated by:

$\Delta_{S L}=\left(z_{b}-\frac{\left(C \cdot D \cdot z_{b}-1\right) z_{t}}{D}\right) H_{b} / q^{2} \Sigma E I$

where 


$$
\begin{aligned}
& C=\left[\frac{E_{c} A_{c u}\left(t_{t}+t_{c u}\right)}{2 \Sigma E I}\right] /\left[1+\frac{E_{c} A_{c u}}{E_{t} A_{t}}+\frac{E_{c} A_{c u}\left(t_{t}+t_{c u}\right) z_{t}}{2 \Sigma E I}\right], \quad D=1+\frac{E_{c} A_{c u}}{E_{t} A_{t}}+\frac{E_{c} A_{c u}\left(t_{t}+t_{c u}\right) z_{t}}{2 \Sigma E I} \\
& q=\sqrt{b_{1}+\frac{b_{2}}{D}\left(C D z_{b}-1\right)}, \quad H_{b}=C_{1} e^{q x}+C_{2} e^{-q x}+\beta L / 2 \\
& C_{1}=-C_{2}=-2 \beta e^{\frac{q L}{2}} / q\left(2+e^{q L}-\left(\frac{1-e^{q L}}{1-e^{-q L}}\right)\right), \quad \beta=\frac{\left(b_{o}+C b_{2}\right) P}{2 q^{2}} \\
& b_{1}=k_{b}\left[\frac{1}{E_{b} A_{b}}+\frac{1}{E_{c} A_{c u}}+\frac{z_{b}^{2}}{\Sigma E I}\right], \quad b_{2}=k_{b}\left[\frac{1}{E_{c} A_{c u}}-\frac{z_{t} z_{b}}{\Sigma E I}\right], \quad b_{0}=k_{b} \frac{z_{b}}{\Sigma E I}, \quad k_{b}=\frac{n_{b} K_{s, b}}{s_{x, b}}
\end{aligned}
$$

The slip stiffness given by Eq. 8 is based on the linear part of the load/slip curve for embedded bar-plate connections in shear [4].

$$
K_{s}=3.2 t+75 \quad \mathrm{kN} / \mathrm{mm} \quad \text { for } d=25 \mathrm{~mm}
$$

The shear deflection may be approximated by Eq. 9:

$$
\Delta_{S H}=\frac{P L}{4 G A_{c}}=\frac{\left(1+v_{c}\right)}{2 E_{c} B h_{c}} P L
$$

where $\mathrm{G}$ is the shear modulus $\mathrm{G}=\mathrm{E}_{\mathrm{d}} / 2\left(1+v_{\mathrm{c}}\right)$, and Poisson's ratio $v_{\mathrm{c}}=0.15$ is assumed for the concrete. $\mathrm{A}_{\mathrm{c}}$ is the cross-sectional area of concrete, which may be taken as. the total area $\mathrm{Bh}_{\mathrm{c}}$, which is assumed to include the effects of diagonal cracking. Table 2 compares calculated and experimental values of midspan deflection at tension plate yield, or $2 / 3 \mathrm{P}_{\mathrm{u}}$, as applicable.

\section{FATIGUE BEAM TESTS}

\subsection{Test Arrangement}

For each beam tested statically, a nominally identical beam was made to be tested in fatigue. The test arrangement and beam dimensions are shown in Figure 3 and Table 1. The cyclic load was provided by an Amsler pulsator operating at 4Hz, 24 hours per day. Prior to the fatigue test, each beam was loaded statically to the maximum fatigue load in three cycles. This enabled accurate measurements of the stresses and displacements, as well as a direct comparison with the measurements taken in the static tests.

\subsection{Test Results}

The calculated stress range was obtained from the truss model and neglecting friction between the steel plates and concrete. The plate tension is given at mid-span, where the highest stress range occurs, the bar shear is assumed to be nominally equal between bars, and the bar tension is also assumed to be nominally equal between bars according to the truss model and neglecting any effects arising from $\mathrm{s}_{\mathrm{X}} / \mathrm{h}_{\mathrm{c}} \neq 1$. Table 3 summarizes the test results. 


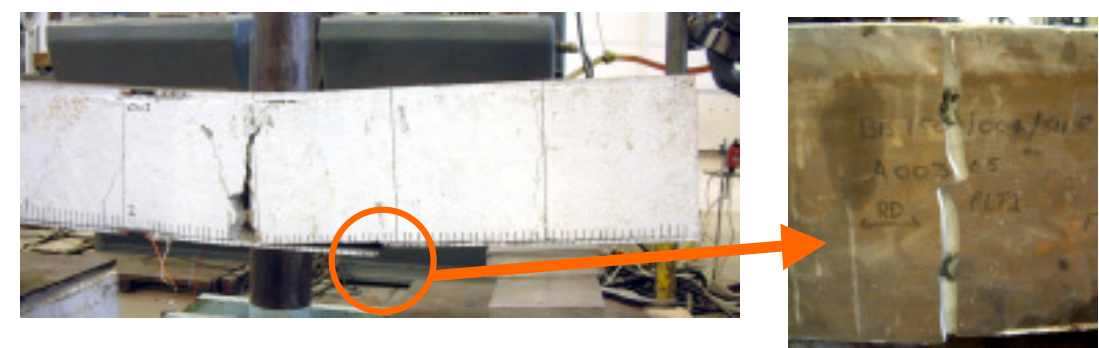

(a) Tension Plate Failure Mode (BF4)

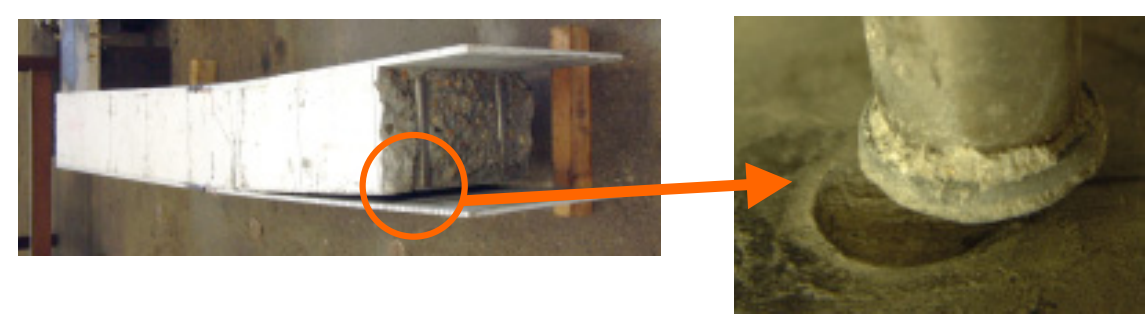

(b) Bar Shear Failure Mode (BF5)

Figure 5. Fatigue Failure Modes for the Tested Beams

Table 3. Beam Fatigue Test Results

\begin{tabular}{|c|c|c|c|c|c|c|c|}
\hline \multirow{2}{*}{$\begin{array}{c}\text { Test } \\
\text { No. }\end{array}$} & Beam ID & $\begin{array}{c}\mathrm{P}_{\min } \sim \\
\mathrm{P}_{\max } \\
\text { (tonne) }\end{array}$ & $\Delta \mathrm{P}(\mathrm{kN})$ & \multicolumn{2}{|c|}{$\begin{array}{c}\text { MCalculated Stress } \\
\text { Ranges }\left(\begin{array}{c}\mathrm{N}_{\mathrm{f}} \\
\text { (cycles) }\end{array}\right.\end{array}$} & Failure Mode \\
\hline B1 & $6 / 400 / 200 / 6$ & $7 \sim 70$ & 618.0 & 181.8 & 164.4 & 108,700 & Plate fracture \\
\hline B2 & $8 / 400 / 200 / 6$ & $6 \sim 60$ & 529.7 & 122.6 & 140.0 & 514,500 & Plate fracture \\
\hline B3 & $12 / 400 / 200 / 6$ & $10 \sim 100$ & 882.9 & 141.9 & 230.4 & 279,900 & Plate fracture \\
\hline B4 & $6 / 200 / 200 / 6$ & $4.5 \sim 45$ & 397.3 & 227.8 & 197.7 & 47,400 & Plate fracture \\
\hline B5 & $8 / 200 / 200 / 6$ & $4.5 \sim 45$ & 397.3 & 176.0 & 198.2 & 29,400 & Bar shear \\
\hline B6 & $12 / 200 / 200 / 6$ & $3.5 \sim 35$ & 309.0 & 94.1 & 154.8 & 442,000 & Bar shear \\
\hline B7 & $6 / 200 / 300 / 6$ & $1 \sim 10$ & 88.3 & 76.0 & 65.9 & 818,400 & Plate fracture \\
\hline B8 & $8 / 200 / 300 / 6$ & $1.5 \sim 15$ & 132.4 & 88.4 & 99.1 & 742,100 & Plate fracture \\
\hline B9 & $12 / 200 / 300 / 6$ & $2 \sim 20$ & 176.6 & 81.2 & 132.6 & 693,200 & Plate fracture \\
\hline B10 & $6 / 200 / 400 / 6$ & $2 \sim 11$ & 88.3 & 101.1 & 87.9 & 294,500 & Plate fracture \\
\hline B11 & $8 / 200 / 400 / 6$ & $2 \sim 11$ & 88.3 & 78.2 & 88.1 & 429,700 & Plate fracture \\
\hline B12 & $12 / 200 / 400 / 6$ & $2 \sim 11$ & 88.3 & 54.7 & 88.4 & $1,704,100$ & Plate fracture \\
\hline B13 & $10 / 300 / 200 / 8$ & $2 \sim 20$ & 176.6 & 44.1 & 45.8 & $2,945,200$ & Plate fracture \\
\hline B14 & $12 / 300 / 200 / 8$ & $3 \sim 30$ & 264.9 & 56.5 & 68.2 & $1,102,700$ & Plate fracture \\
\hline B15 & $10 / 300 / 300 / 6$ & $4.5 \sim 45$ & 397.3 & 148.0 & 206.2 & 109,200 & Plate fracture \\
\hline B16 & $12 / 300 / 300 / 6$ & $4.5 \sim 45$ & 397.3 & 125.8 & 203.9 & 29,700 & Bar shear \\
\hline B17* & $10 / 300 / 300 / 8$ & $2 \sim 16$ & 137.3 & 52.6 & 53.4 & $7,426,400$ & Plate fracture \\
\hline B18 & $12 / 300 / 300 / 8$ & $1.5 \sim 15$ & 132.4 & 43.1 & 51.1 & $2,404,500$ & Plate fracture \\
\hline
\end{tabular}

*Notes: (1) Ten preloading cycles of 1.5 45 tonnes were manually applied to beam BS17 before the pulsating load 2 16 tonnes was applied. 
Fatigue failure modes are illustrated in Figure 5. The bar forces cause local plate tension and bending, which adds to the effect of global plate tension. Fatigue loading caused local plate cracking which was initiated at a bar position and propagated across the plate. Bar failure without plate fracture occurred in three beams. In no case did the fracture occur at mid-span, which indicates that failure occurs where there is a combination of stress effects.

It is observed in Table 3 that for high load ranges and hence small fatigue life, bar shear fracture is the dominant mode of failure, and for smaller load ranges, the mode of failure is plate tension fracture. For high load ranges, local concrete crushing occurs and the bar bending stress increases, reducing the fatigue life of the connection in bar shear. For smaller stress ranges, the bar is better gripped by concrete and fatigue cracks propagate in the plate leading to plate fracture.

\subsection{Fatigue Life Calculation Method}

The current design guide method [2] assumes that the beam life is given by the smaller of the plate tension life and the bar shear life, determined from the BS 5400 [8] F and S curves respectively, assuming that each effect acts independently. Interaction between forces is not taken into account. Fatigue tests [5] on the bar plate connection in plate tension, bar shear and bar tension gave three $\mathrm{S}-\mathrm{N}$ curves for the fatigue life of the connection, given by the following equations:

$$
\begin{aligned}
& N_{f} \cdot \Delta \sigma_{P}^{3.5}=2.787 \times 10^{13} \cdot 0.657^{\alpha}, \quad \alpha=0 \text { and } 2 \\
& N_{f} \cdot \Delta \tau_{B}^{7.5}=2.767 \times 10^{21} \cdot 0.465^{\alpha} \quad, \quad \alpha=0 \text { and } 2 \\
& N_{f} \cdot \Delta \sigma_{B}^{5.2}=9.01 \times 10^{16} \cdot 0.638^{\alpha} \quad, \quad \alpha=0 \text { and } 2
\end{aligned}
$$

The plate tension fatigue curve is very close to the BS5400 F curve, however the bar shear curve lies below the BS5400 S-curve. This is due to concrete crushing around the connector, reducing the grip on the connector,introducing bending and therefore reducing the fatigue life. The predicted beam fatigue life is plotted in Figure $6 \mathrm{a}$, in relation to the calculated lives according to the design guide method. The plotted points are numbered, so the beams can be identified. The fatigue life by this method is non-conservative because the BS5400 S-type curve is non-conservative for embedded connections in shear and also because the bar tension component is ignored.

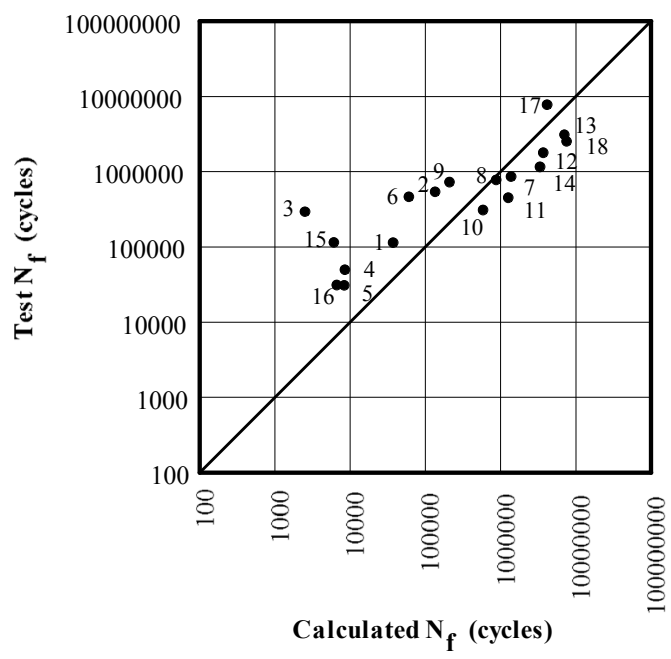

(a)

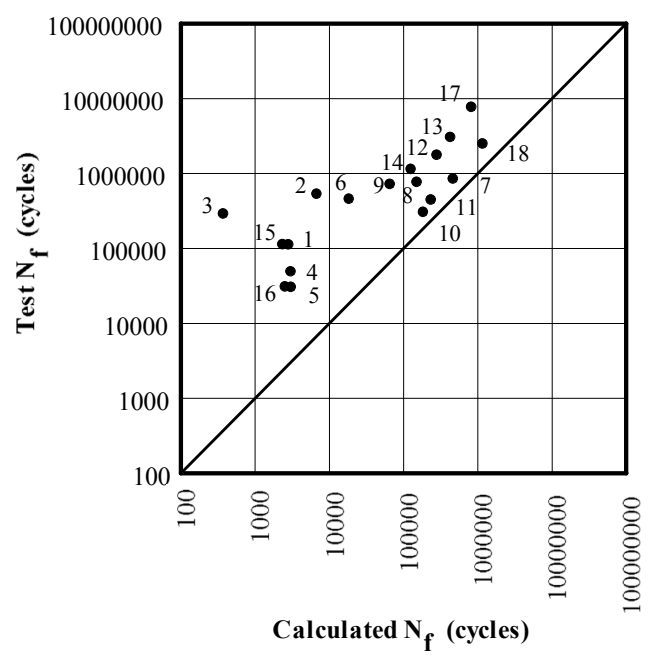

(b)

Figure 6. Comparison of Calculated to Predicted Beam Design Fatigue Life Using

(a) the Design Guide Calculation and (b) Proposed Method 
A method for calculating the interaction of load components at a connection is proposed, suggested by the Miner equation, which is used to estimate the cumulative effect of a load spectrum. The stress distribution within the connection will be different for each load component, but the damage caused by each component will reduce the lives of the other components compared to their lives if acting alone. That is, the force components interact. The suggested adaptation is as follows:

$$
\frac{N}{N_{\sigma P}}+\frac{N}{N_{\sigma B}}+\frac{N}{N_{\tau B}}=1
$$

where $\mathrm{N}$ is the number of cycles to cause failure of the connection, $\mathrm{N}_{\sigma \mathrm{P}}$ is the number of cycles to cause tensile failure of the plate with attached bars, according to Eq. 10; $\mathrm{N}_{\sigma \mathrm{B}}$ is the number of cycles to cause failure at the connection, resulting from bar tension, according to Eq. $12 ; \mathrm{N}_{\tau \mathrm{B}}$ is the number of cycles to cause failure at the connection, resulting from bar shear, according to Eq. 11. It was found that Eq. 13 can give non conservative estimates of life when the calculated life $\mathrm{N}_{\mathrm{f} \text {, calc }}$ exceeds $10^{5}$. A correction equation is therefore proposed for $\mathrm{N}_{\mathrm{f}, \text { calc }}>10^{5}$.

$$
N_{f, \text { calc }}^{\prime}=N_{f, \text { calc }}-\left(N_{f, \text { calc }}-10^{5}\right) \tan \theta \quad \text { for } N_{f, \text { calc }}>10^{5}
$$

$\theta$ rotates the data about $10^{5}$, and $\theta=40^{\circ}$ has been found to give satisfactory life estimates, as can be seen in Figure $6 b$.

\section{CONCLUSIONS}

The truss model gives conservative predictions of the beam failure loads. For ductile failure, beams should be designed to fail by yielding of the tension plate. For serviceability, it is tentatively suggested that beams should be designed so that the calculated load to cause plate yield is less than $2 / 3$ of the calculated load to cause any other mode of failure. A rational estimate of the beam deflection should take account of the influences of bending, slip, and shear deformation. It is recommended that for a Bi-Steel beam subjected to a central point load, deflection can be calculated in accordance with Eqs. 5-9. The fatigue lives of 18 beams were compared with the lives predicted by Eq. 13, which was found to over estimate life for lives greater than 100,000 cycles. This trend is corrected by Eq. 14.

\section{ACKNOWLEDGMENT}

The work reported here was sponsored by the Engineering and Physical Sciences Research Council (EPSRC) and by Corus. The authors would like to thank Mr Hugh Bowerman (Corus) for his technical support. 


\section{REFERENCES}

[1] Bowerman, H., Coyle, N. and Chapman, J.C., "An Innovative Steel/concrete Construction System”, The Structural Engineer, 2002, Vol. 80, No. 20, pp. 33-38.

[2] Bowerman, H.G, Gough, M.S. and King, C.M., "Bi-Steel Design and Construction Guide", British Steel Ltd, Scunthorpe, London, 1999.

[3] Xie, M. and Chapman, J.C., "Static and Fatigue Tensile Strength of Friction-welded Bar-plate Connections Embedded in Concrete", Journal of Constructional Steel Research, 2005, Vol. 61, pp. 651-673.

[4] Xie, M., Foundoukos, N. and Chapman, J.C., "Experimental and Numerical Investigation on the Shear Behaviour of Friction-welded Bar-plate Connections Embedded in Concrete", Journal of Constructional Steel Research, 2005, Vol. 61, pp. 625-649.

[5] Foundoukos, N., "Behaviour and Design of Steel-Concrete-Steel Sandwich Construction", Ph.D Thesis, Dept. of Civil and Environmental Engineering, Imperial College, London, 2005.

[6] European Committee for Standardization, Design of Concrete Structures, Eurocode 2, Brussels, 1992.

[7] Wright, H.D. and Oduyemi, T.O.S., "Partial Interaction Analysis of Double Skin Composite Beams”, Journal of Constructional Steel Research, 1991, Vol. 19, pp. 257-279.

[8] British Standard Institution, Steel Concrete and Composite Bridges, BS5400 Pt 10, Code of Practice for Fatigue. BSI, London 1980.

\section{NOTATION}

A

B

d

E

$\Delta$

$\sigma, \tau$ cross-sectional area

width of plate

bar diameter $(\mathrm{d}=25 \mathrm{~mm})$

elastic modulus

material strength

member force

depth of truss (Figure 3)

depth of concrete

horizontal shear force per bar

$2^{\text {nd }}$ moment of area

shear stiffness of bar connector

length of beam between supports

modular ratio between steel and concrete

number of cycles to failure

load applied at midspan of beam

longitudinal spacing of bar connectors

transverse spacing of bar connectors $\left(\mathrm{s}_{\mathrm{y}}=200 \mathrm{~mm}\right)$

plate thickness

distance from neutral axis to the top of compression plate

distance from neutral axis

stress range

midspan deflection of beam

stress

$\begin{array}{ll}\text { Common subscripts } \\ \text { B } & \text { Bar } \\ \text { BS } & \text { bar shear } \\ \text { BT } & \text { bar tension } \\ \text { b } & \text { bottom plate } \\ \text { c } & \text { concrete } \\ \text { cu } & \text { un-cracked concrete } \\ \text { P } & \text { plate } \\ \text { t } & \text { top plate } \\ \text { u } & \text { ultimate load } \\ \text { VS } & \text { vertical shear } \\ \text { y } & \text { yield load }\end{array}$




\title{
STRESS ANALYSIS AND FATIGUE TEST ON PARTIALLY OVERLAPPED CHS K-JOINTS
}

\author{
T. Sopha, T.B.N. Nguyen, S.P. Chiew ${ }^{1, *}$, C.K. Lee and S.T. Lie \\ ${ }^{1}$ School of Civil and Environmental Engineering, Nanyang Technology University \\ 50 Nanyang Avenue, Singapore 639798, Tel: (65) 6790 5294; Fax: (65) 67921650 \\ *(Corresponding author: E-mail: cspchiew@ntu.edu.sg)
}

\begin{abstract}
This paper presents the experimental studies of two partially overlapped CHS K-joints specimens (Specimens S1 and S2) with through brace subjected to basic and combined loads. The stress analysis of the joints revealed the maximum stress concentration factor (SCF) to be located on the brace side. Then, the maximum SCF was compared with existing Efthymiou's formulae. It is observed that the Efthymiou's formulae are over-conservative in in-plane bending load case (IPB), but in axial load case (AX) are not conservative. In addition, the fatigue life was also compared with existing S-N curves. The S-N curve was found to be marginally conservative for first specimen, but it was not conservative for other one.
\end{abstract}

Keywords: Partially overlapped K-joints, stress concentration and stress intensity factor, fatigue failure, surface and through-thickness cracks

\section{INTRODUCTION}

Due to the ease of fabrication and the existence of many direct calculation methods to assess the joint capacity, simple tubular T-, Y- and non-overlap K-joints are widely used connection types for the construction of offshore steel jackets. When compared with a K-joints with gap, a partially overlap K-joints may has a higher fabrication costs due to the complex end profile of the overlap brace. However, partially overlap K-joint has a higher residual capacity as a result of their optimized load transfer pattern. In fact, recently, in a case study comparing the costs of three K-joints design options [1], it was found that after having considered the material and fabrication costs, an overlap joint is the cheapest option, with the fabrication cost actually being significantly cheaper than that of the alternative canned gap joint. However, in the past, very few research works were carried out to study the fatigue behaviour of partially overlap circular hollow section (CHS) $\mathrm{K}$-joints and virtually no information regarding the fatigue strength of overlapped CHS K-joints is available. The main objective of this study is to investigate the stress concentration factor (SCF) and check measured SCF-values with existing formulae, investigate the stress intensity factor (SIF) distributions for a partially overlapped CHS K-joint under different cyclic loading conditions, and evaluate the applicability of present S-N curve in design of partially overlapped CHS K-joints.

\section{TEST RIG AND LOADING SYSTEM}

The "orange" test rig shown in Figure 1 was used to test a partially overlap CHS K-joint subjected to axial (AX), in-plane bending (IPB), out-of-plane bending (OPB) and the combination of these three basic load cases. The rig is capable of applying static loading to determine the hot spot stress (HSS) distributions, as well as cyclic loading to determine the fatigue life. Two $250 \mathrm{kN}$ and one $150 \mathrm{kN}$ capacity servo-hydraulic actuators were installed to apply the three basic load cases. The loads were applied along the three mutually perpendicular axes. 


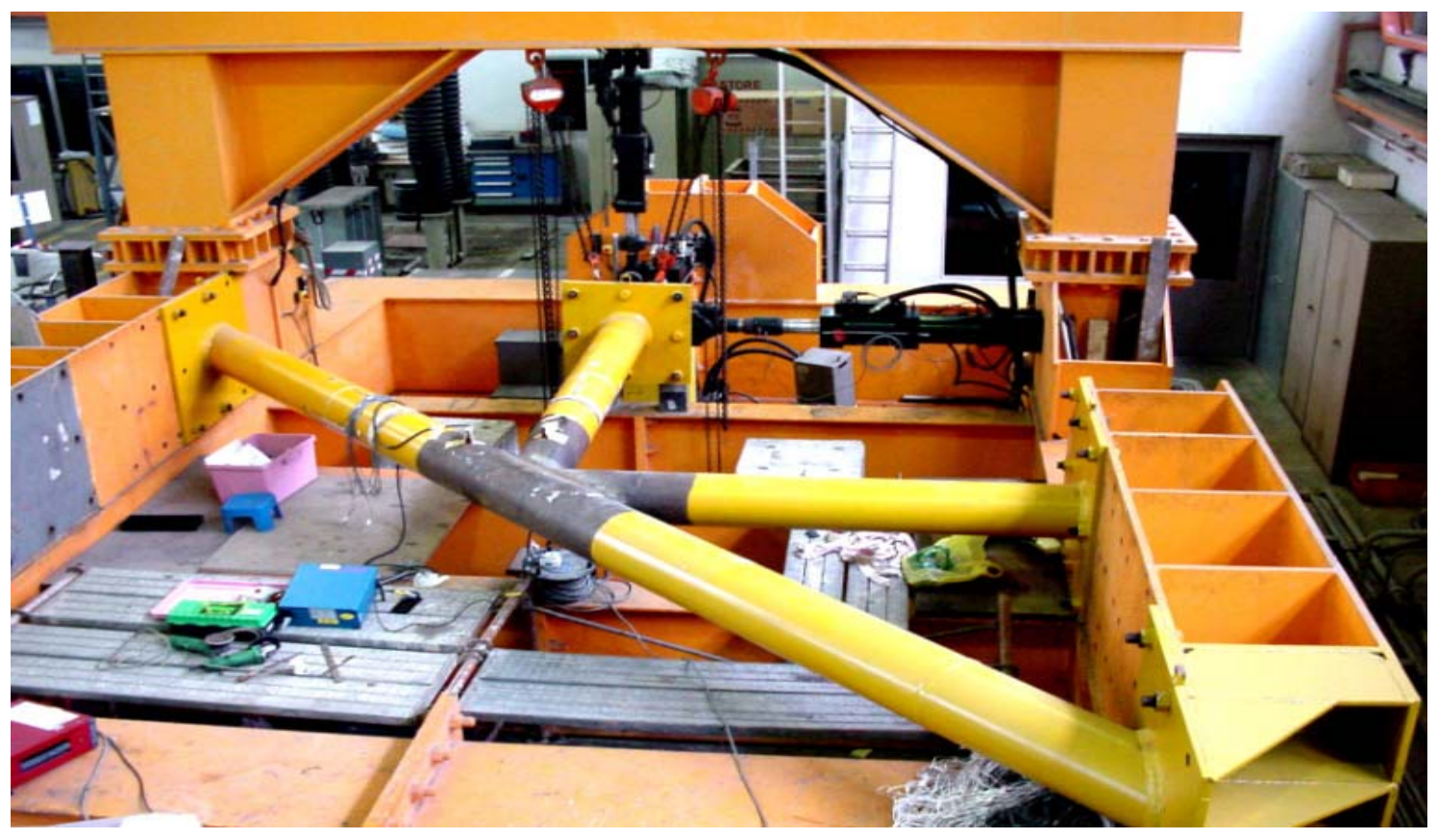

a) Overview of Test Rig

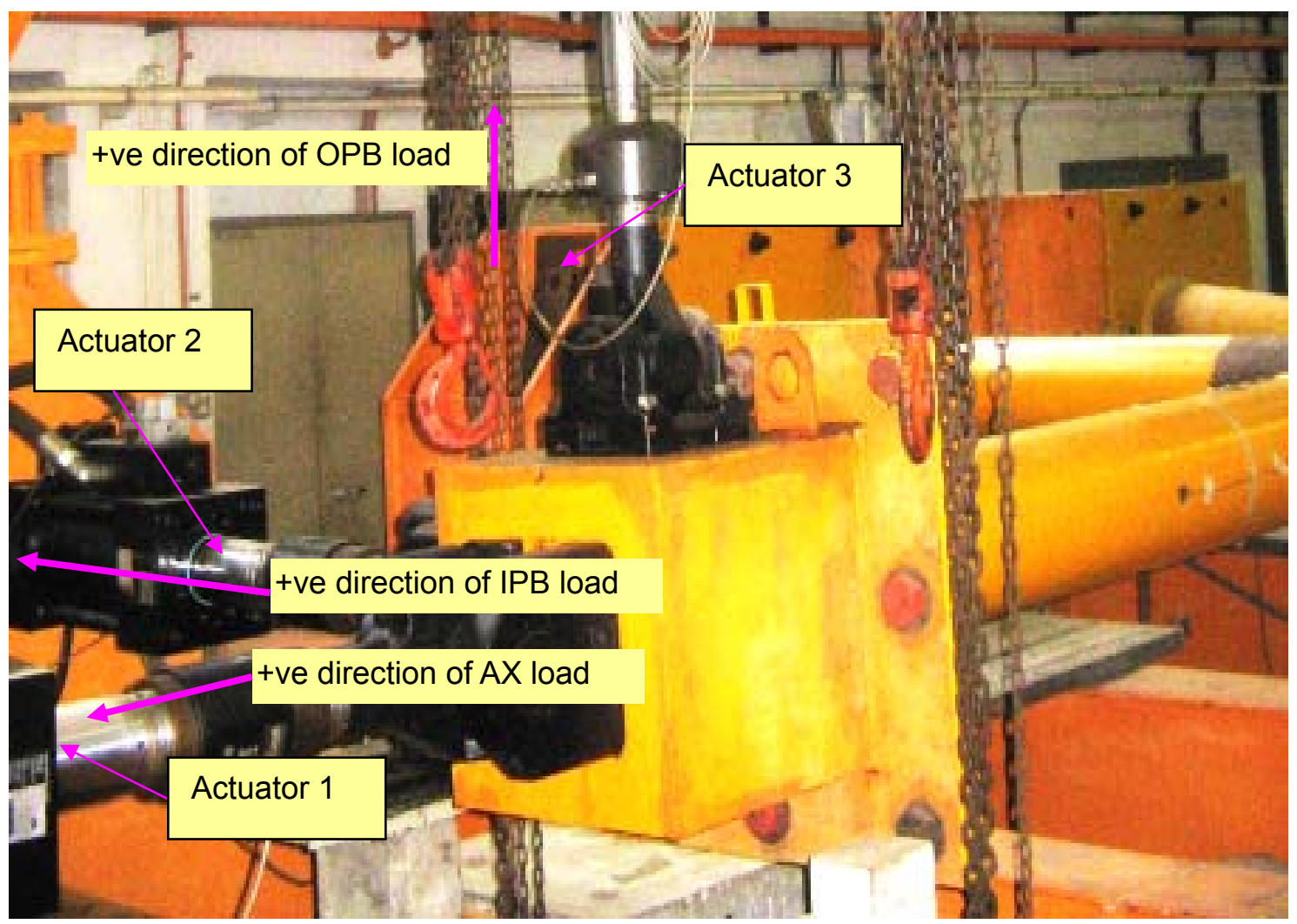

b) Three Actuators 1, 2 and 3

Figure 1. The “Orange” Test Rig 


\section{TEST SPECIMEN}

The two partially overlapped K-joint specimens (S1 and S2) were fabricated from circular hollow sections. The dimensions and geometric ratios of the joints are given in Figure 2 and Table 1. The material properties of these CHS are shown in Table 2. The intersecting profile of the braces was constructed according to the AWS specifications and ultrasonic checked was conducted to ensure the quality of the welding. Both specimens were installed by fixing the two ends of the chord and the overlapping brace. The external loads were applied at the end of the through brace.

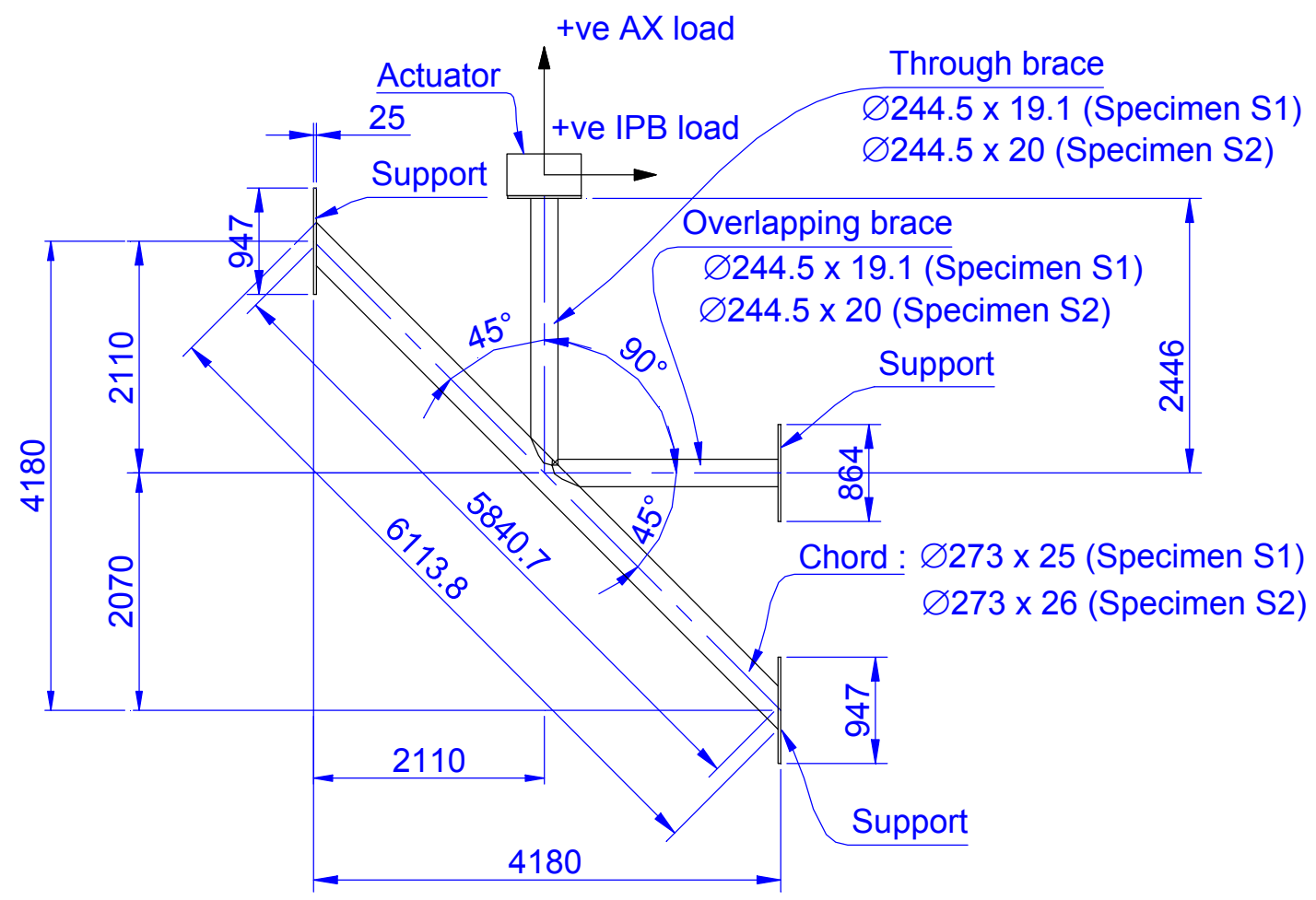

Figure 2. Configuration of Test Specimens

Table 1(a). Geometric Parameters of Specimens

\begin{tabular}{|c|c|c|c|c|c|}
\hline Specimens & $\begin{array}{c}\text { Chord } \\
\text { diameter } \\
(\mathrm{mm}), \mathrm{D}\end{array}$ & $\begin{array}{c}\text { Chord } \\
\text { thickness } \\
(\mathrm{mm}), \mathrm{T}\end{array}$ & $\begin{array}{c}\text { Brace } \\
\text { diameter } \\
(\mathrm{mm}), \mathrm{d}\end{array}$ & $\begin{array}{c}\text { Brace } \\
\text { thickness } \\
(\mathrm{mm}), \mathrm{t}\end{array}$ & $\begin{array}{c}\text { Eccentricity } \\
(\mathrm{mm}), \mathrm{e}\end{array}$ \\
\hline S1 & 273 & 25 & 244.5 & 19.1 & 0 \\
\hline S2 & 273 & 26 & 244.5 & 20.0 & 0 \\
\hline
\end{tabular}

Table 1(b). Non-dimension Parameters

\begin{tabular}{|c|c|c|c|c|}
\hline Specimens & $\beta=\frac{d}{D}$ & $2 \gamma=\frac{D}{T}$ & $\tau=\frac{t}{T}$ & $\begin{array}{c}\mathrm{O}_{\mathrm{v}} \\
(\%)\end{array}$ \\
\hline S1 & 0.895 & 10.92 & 0.764 & 21 \\
\hline S2 & 0.895 & 10.50 & 0.769 & 21 \\
\hline
\end{tabular}

Table 2. Material Properties of the Specimens

\begin{tabular}{|c|c|c|c|}
\hline \multirow{2}{*}{ Specimens } & Member & $\begin{array}{c}\text { Yield strength } \\
(\mathrm{MPa})\end{array}$ & $\begin{array}{c}\text { Modulus of } \\
\text { Elasticity (GPa) }\end{array}$ \\
\hline \multirow{2}{*}{ S1 } & Chord & 252.66 & 205.33 \\
\cline { 2 - 4 } & Brace & 404.54 & 204.42 \\
\hline \multirow{2}{*}{ S2 } & Chord & 403.9 & 207.5 \\
\cline { 2 - 4 } & Brace & 426.9 & 201.9 \\
\hline
\end{tabular}




\section{STRAIN GAUGE LOCATION}

Strain gauges were placed near the weld toe as shown in Figure 3. At each spot, pairs of strain gauges were used to measure the distribution of the strain components perpendicular and parallel to the weld toe. In addition, in order to detect any secondary bending moment caused by load eccentricity and joint flexibility [2,3,4], a pair of strain gauges were also installed at the two cross-sections along the through brace with a distance equal three times of the diameter of the brace.

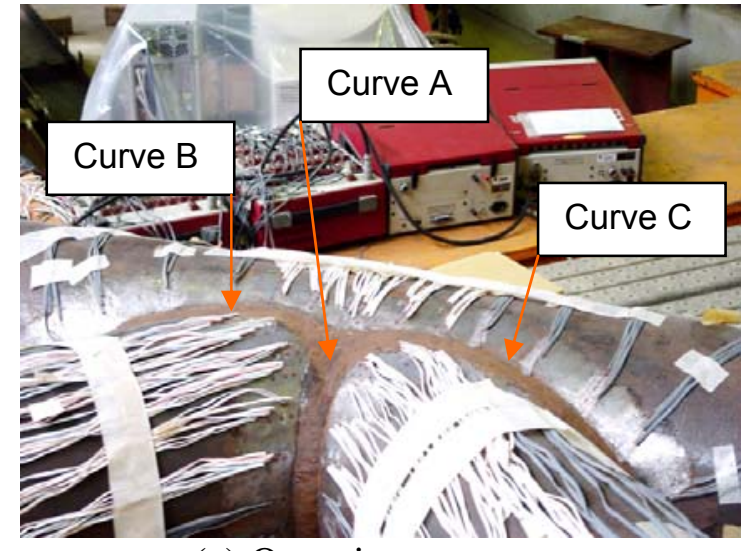

(a) Overview

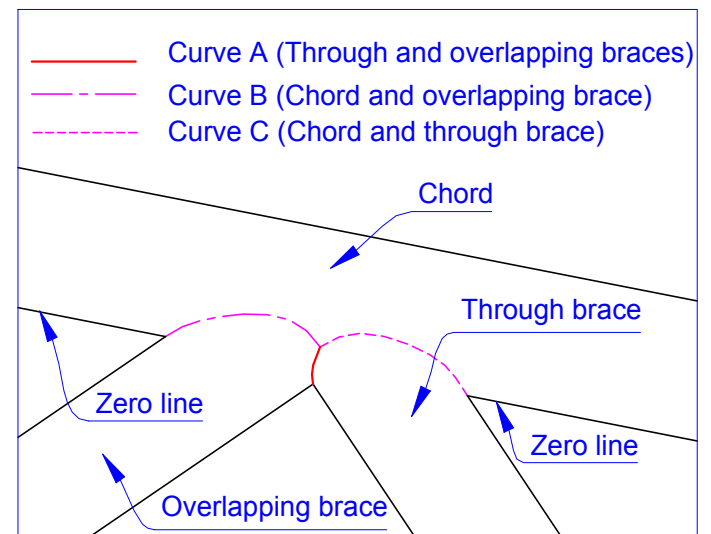

(b) Scheme of Curves

Figure 3: Strain Gauge Location

\section{STATIC TEST PROCEDURE}

A series of load cases consisting of AX, IPB, OPB loadings and combinations of them were chosen and tested. Each specimen was first subjected to an incremental static load on one axis, and the strains were checked against linearity and zero drift to indicate shakedown of residual stress [5]. Before starting the actual static tests, the applied loads on each actuator were preprogrammed. The actuators were then ramped to the predetermined loads. The strain gauge readings were eventually recorded by special software for further calculations.

\section{STATIC TEST RESULTS}

After strain gauges values were recorded, the hot spot strain perpendicular and parallel to the weld toe, $\left(\xi_{\perp}\right)$ and $\left(\xi_{/ /}\right)$, were obtained by the quadratic extrapolation method. The strain concentration factor (SNCF) was calculated as

$\mathrm{SNCF}=\xi_{\perp} / \xi_{\mathrm{n}}$

where $\xi_{\mathrm{n}}$ is the nominal strain obtained from the readings of the four strain gauges attached along the through brace member. The stress concentration factor (SCF) was calculated as

$\operatorname{SCF}=\operatorname{SNCF}\left(1+v \xi_{/ / /} \xi_{\perp}\right) /\left(1-v^{2}\right)$

where $v$ is the Poisson's ratio of the material.

The average value of experimental SCF distributions along the weld toe from two specimens had been obtained from the static tests under different basic load cases are shown in Table 3. The SCFs 
at the heel, crown and saddle positions of the chord and braces obtained by using Efthymiou's Formulae [6] are also listed in Table 3. From Table 3, it is observed that in all the load cases, SCFs at the through brace are greater than that at the chord. Meanwhile, for IPB load case, SCFs predicted by Efthymiou's formulae [6] show over-conservative by $47 \%$ and $15 \%$ for chord and brace respectively. However, for AX load case, the formula SCF values are not conservative by $40 \%$ and $26 \%$ for chord and brace respectively.

Table 3. Experimental SCF Values in HSS Location and Results Predicted By Efthymiou's Formulae [2]

\begin{tabular}{|c|l|c|c|c|c|}
\hline \multirow{2}{*}{ Load cases } & \multirow{2}{*}{ Method } & \multicolumn{2}{|c|}{ Through brace side } & \multicolumn{2}{c|}{ Overlapping brace side } \\
\cline { 3 - 6 } & & $\mathrm{SCF}_{\text {chord }}$ & $\mathrm{SCF}_{\text {brace }}$ & $\mathrm{SCF}_{\text {chord }}$ & $\mathrm{SCF}_{\text {brace }}$ \\
\hline \multirow{3}{*}{$\mathrm{AX}$} & Test & 2.67 & $\mathbf{2 . 8 8}$ & 2.02 & 1.37 \\
\cline { 2 - 6 } & $\begin{array}{l}\text { Efthymiou's } \\
\text { formulae }\end{array}$ & 1.6 & 2.11 & - & - \\
\hline \multirow{3}{*}{$\mathrm{IPB}$} & Test & 0.82 & 2.31 & - & 0.77 \\
\cline { 2 - 6 } & $\begin{array}{l}\text { Efthymiou's } \\
\text { formulae }\end{array}$ & 1.57 & $\mathbf{2 . 7 0}$ & - & - \\
\hline \multirow{2}{*}{ OPB } & Test & 0.86 & 1.22 & - & - \\
\cline { 2 - 6 } & $\begin{array}{l}\text { Efthymiou's } \\
\text { formulae }\end{array}$ & - & - & - & - \\
\hline
\end{tabular}

The stress distributions measured in the static test under combined AX and IPB loadings and the corresponding values computed by using the superposition method for both specimens are shown in Figure 4. From Figure 4, it can be seen that for Specimen S1, under the actions of AX and positive IPB loading, the peak HSS appeared at the heel of the through brace for curve $C$ with a value of 382.32 MPa. For Specimen S2, under the action of AX and negative IPB, the peak HSS appeared at the crown of the through brace for curve A with a value of $285.92 \mathrm{MPa}$. Furthermore, the results computed by the superposition methods agree well with the experimental results.

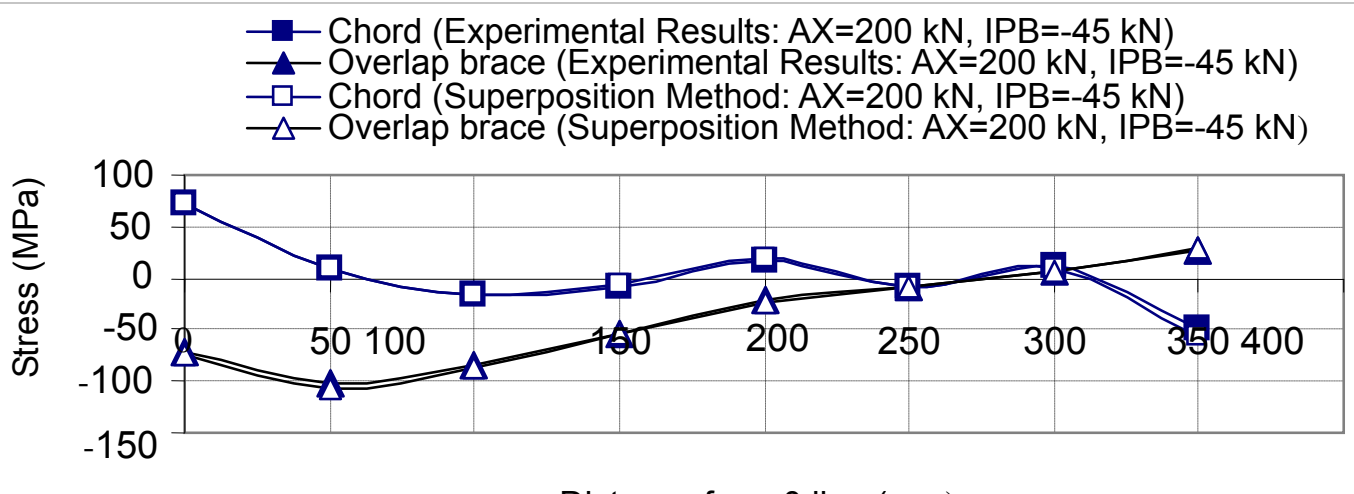

a) Curve $\mathrm{C}$ 


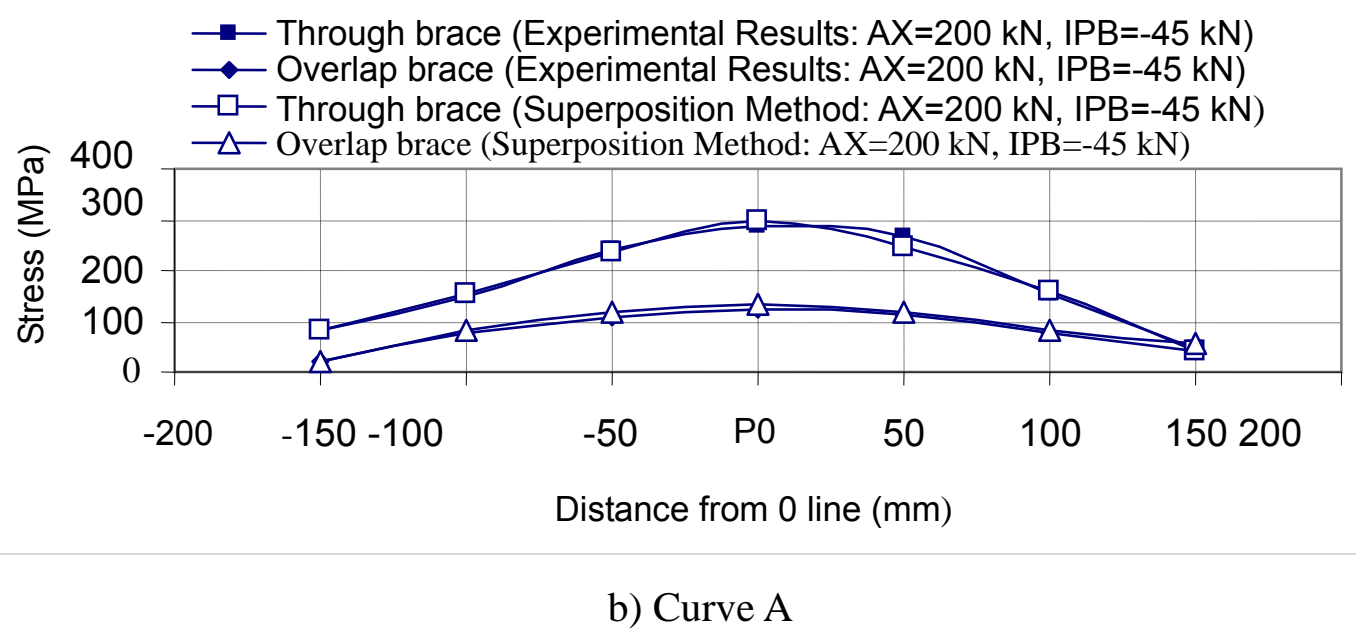

Figure 4. HSS Distributions

\section{FATIGUE TEST INVESTIGATION}

The alternating current potential drop (ACPD) technique [7-11] was used to monitor the growth of surface crack at expected crack growth location. Based on the peak HSS locations detected during the static test, 32 ACPD probes were placed at equal intervals of $10 \mathrm{~mm}$ along the weld toe of the through brace around curve C for Specimen S1 and around curve A for Specimen S2 (Figure 5). Both specimens were tested in air under sinusoidal constant amplitude loading with load frequency of $0.2 \mathrm{~Hz}$ through out the test. The cyclic loading patterns applied are shown in Figure 6.During the fatigue test, crack profiles were recorded using a scan interval equivalent to 180 cycles of the cyclic loading applied. For both specimens, the cyclic loading was applied until the crack had well penetrated the through brace thickness.

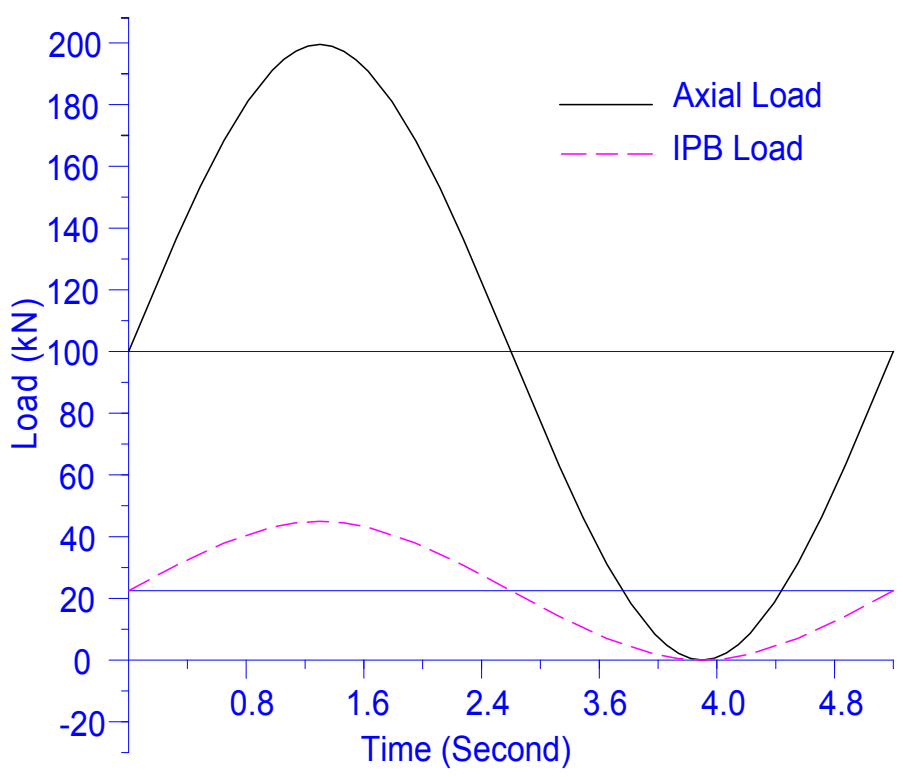

(a) Cyclic Load Applied to Specimen S1 


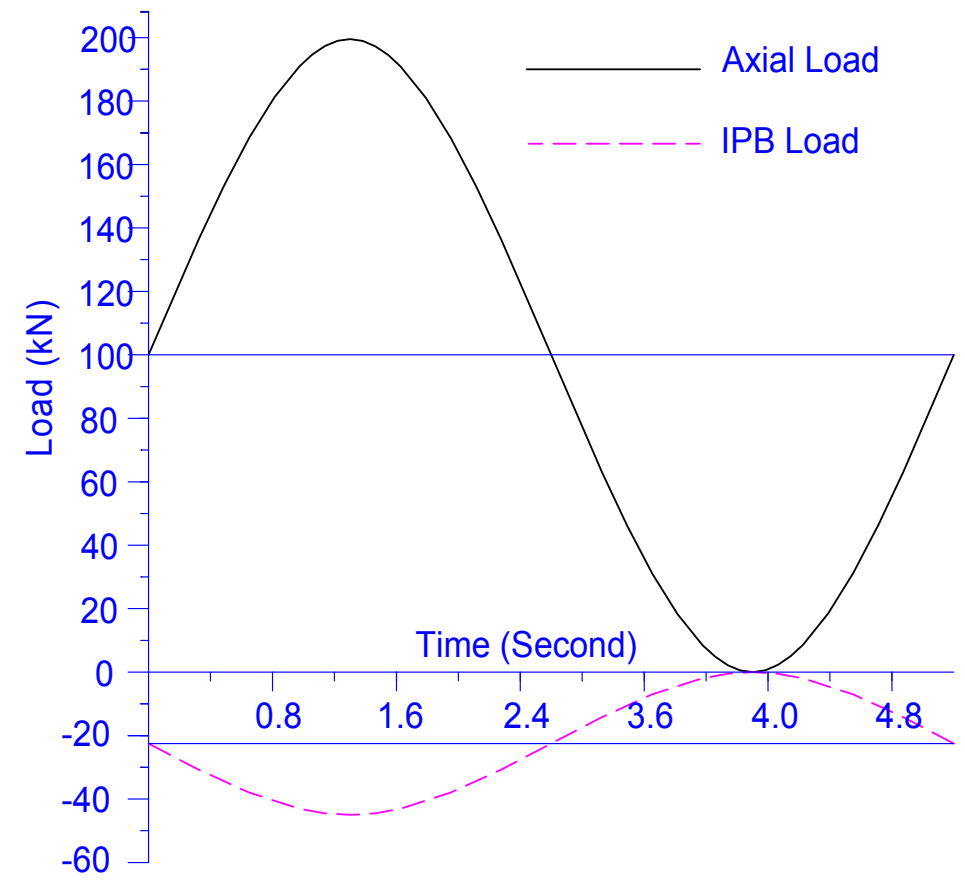

(b) Cyclic Load Applied to Specimen S2

Figure 5. Cyclic Load Applied to Specimens

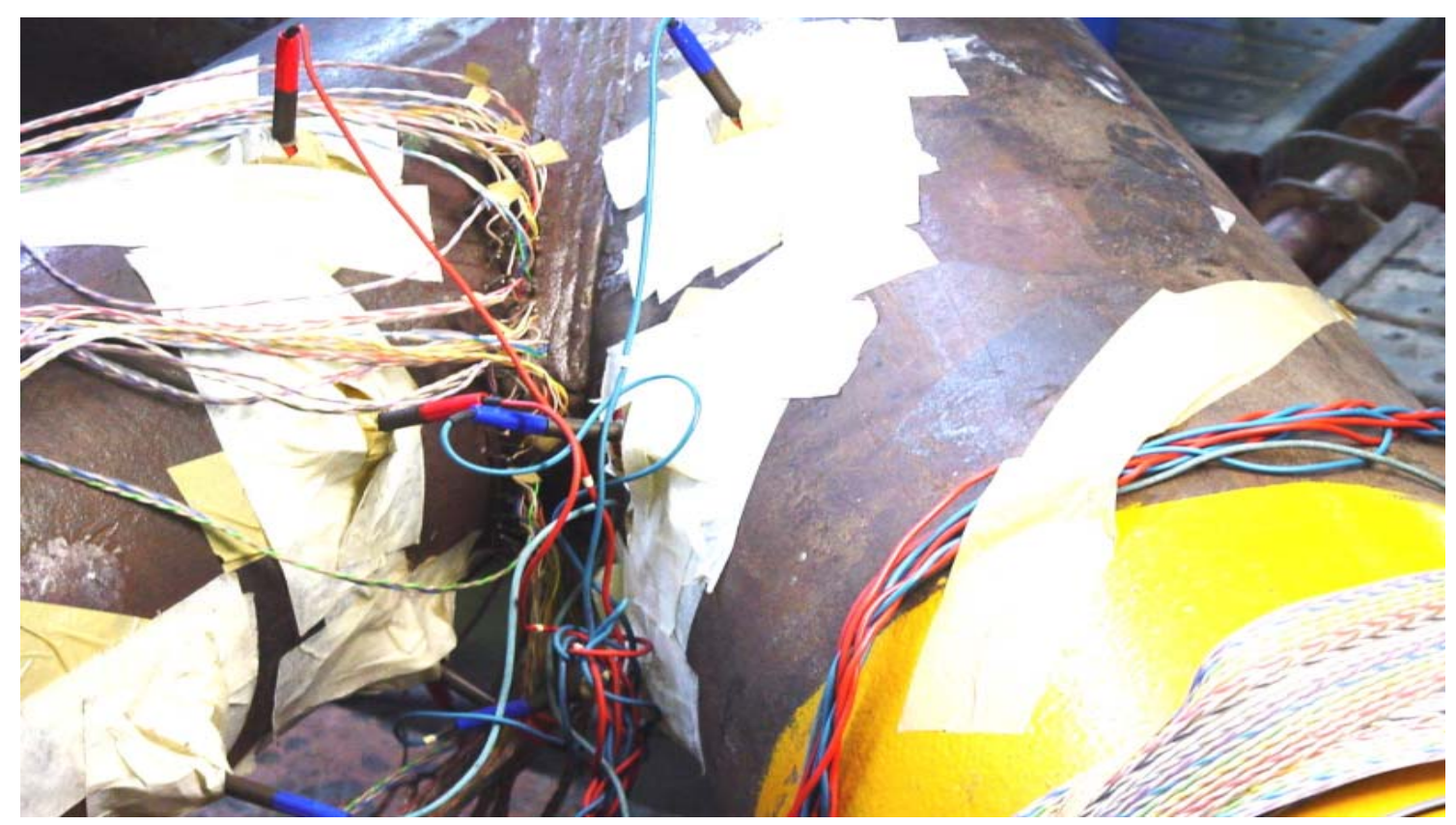

(a) Close-up View of Probes and the Connecting Cables of Specimen S1 


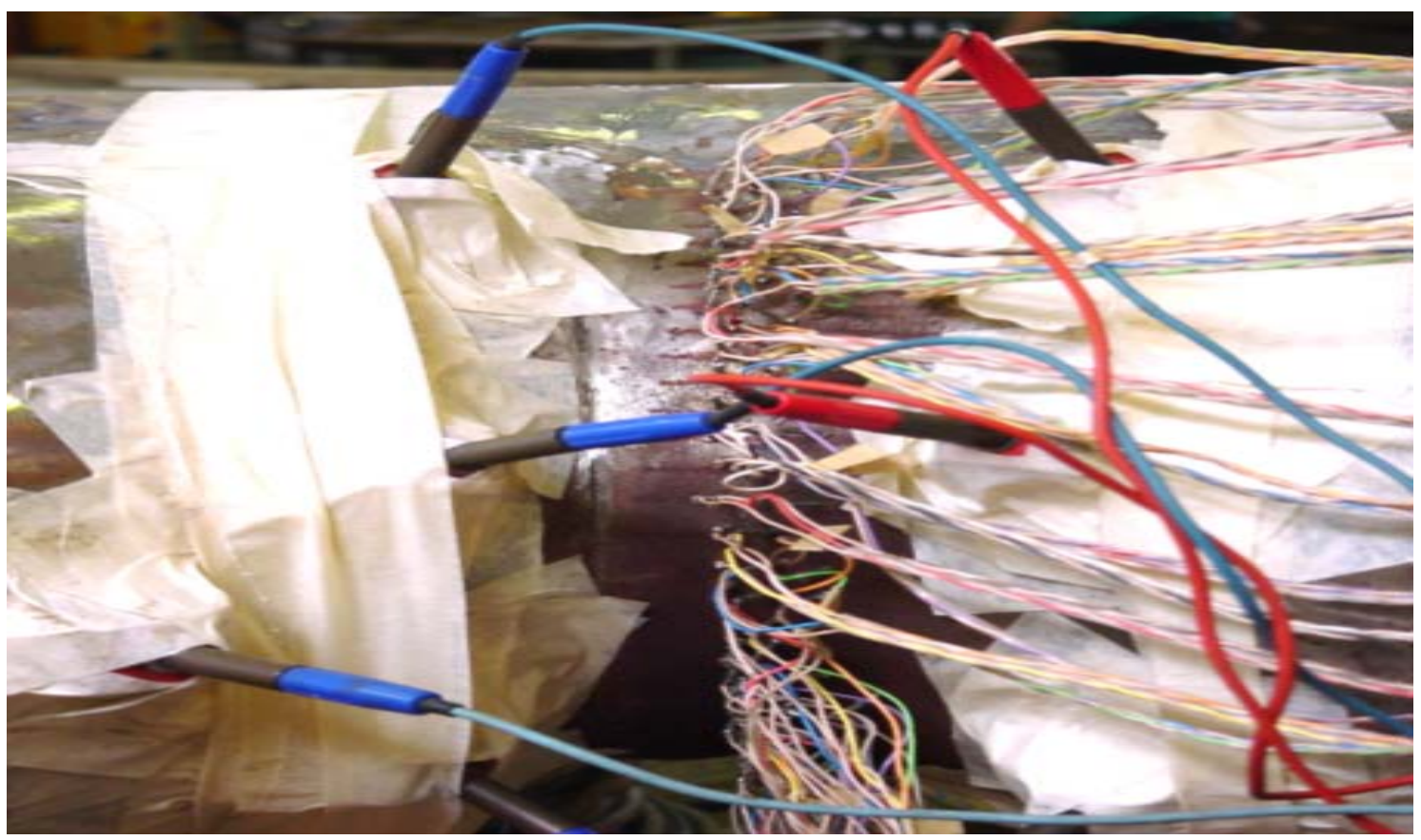

(b) Close-up View of Probes and the Connecting Cables of Specimen S2

Figure 6. Views of Probe Location and the Connecting Cables

\section{FATIGUE TEST RESULTS}

The ACPD crack profiles recorded are shown in Figure 7. The surface crack generated in Specimen S1 was initiated at the heel of the through brace near the ACPD probe P0 and propagated asymmetrically towards to saddle. The surface crack generated in Specimen S2 was initiated at the crown of the through brace near the ACPD probe P0 and propagated towards to saddle symmetrically. Figure 8 shows the surface cracks of both specimens at the through brace. In order to check the actual crack shapes, the tested joints were spilt into two parts along the crack surface (Figure 9). It can be seen that from the ACPD reading and the actual crack surface that the peak HSS positions are corresponding to the deepest position of the crack.

The crack growth curves and there growth rates at the deepest positions at which the cracks penetrated the through brace wall according to ACPD reading are plotted in Figures 10 and Figure 11 respectively. Figure 12 shows the plot of the design S-N curve [12] for a thickness of $19.1 \mathrm{~mm}$ for Specimen S1 and 20mm for Specimen S2 together with the fatigue life (the number of load cycles for the formation first through-thickness crack) of these specimens. It is observed that the $\mathrm{S}-\mathrm{N}$ curve is only marginally conservative when predicting the life of the joint Specimen S1, while for Specimen S2 the S-N curve is not conservative. 


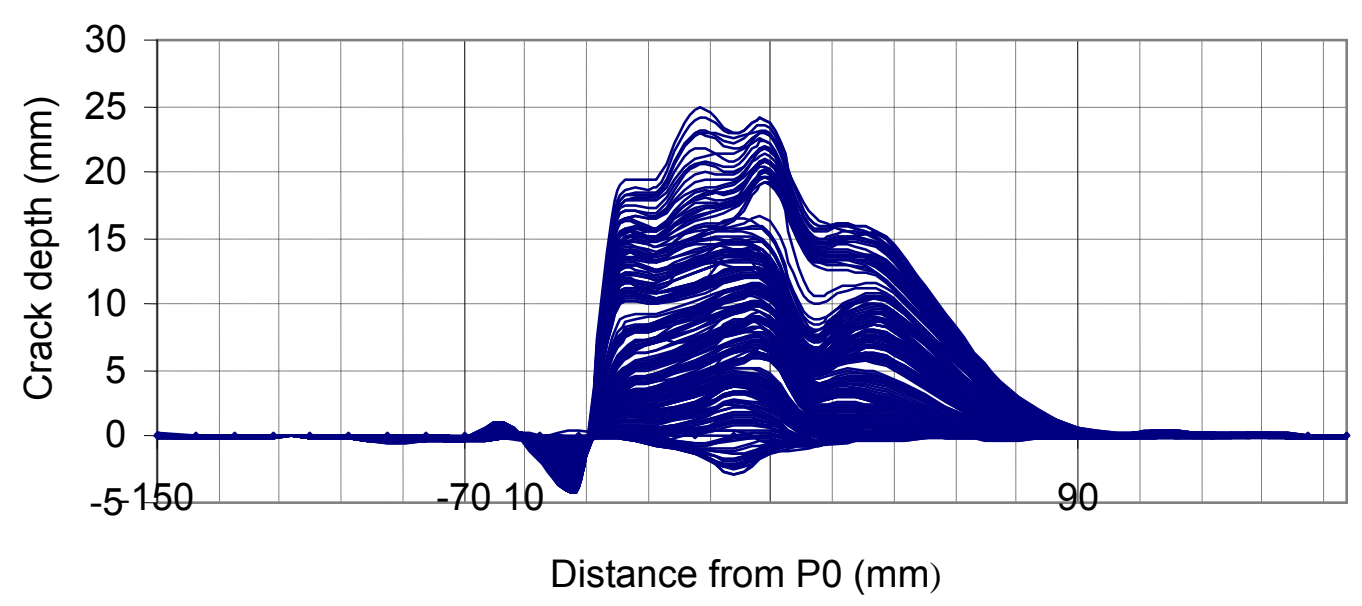

(a) ACPD Crack Development Shape of Specimen S1

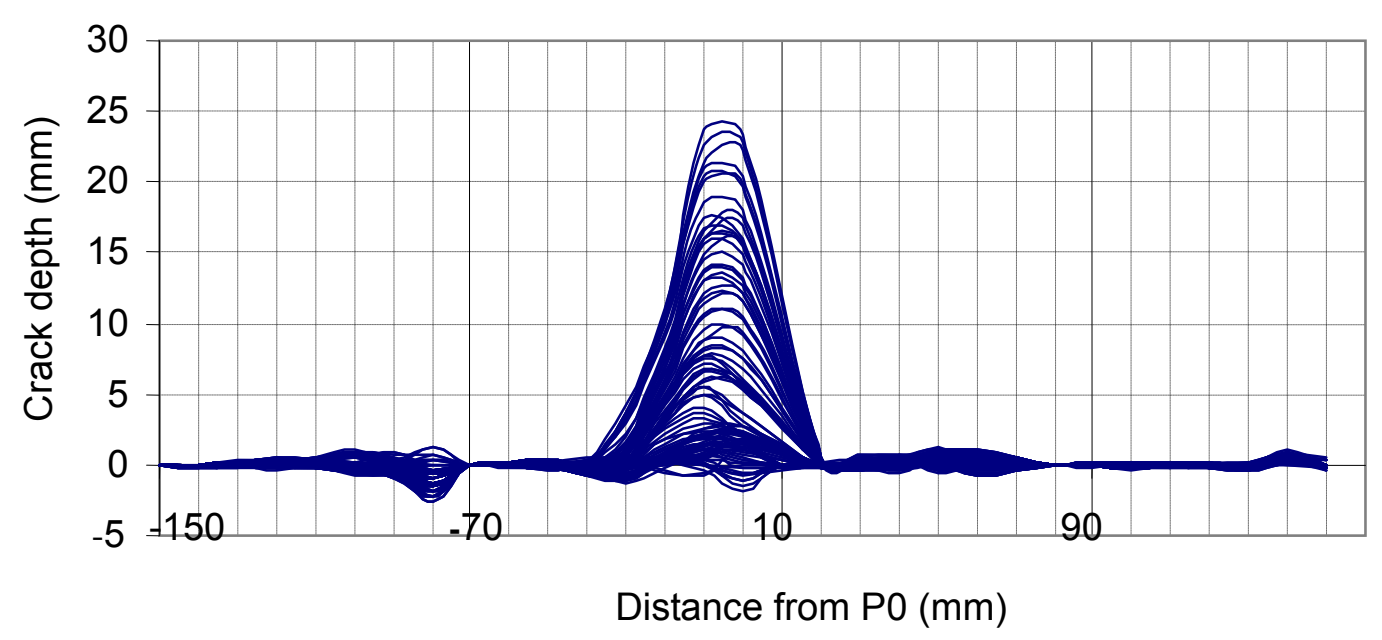

(b) ACPD Crack Development Shape of Specimen S2

Figure 7. ACPD Crack Development of Partially Overlapped CHS K-joints

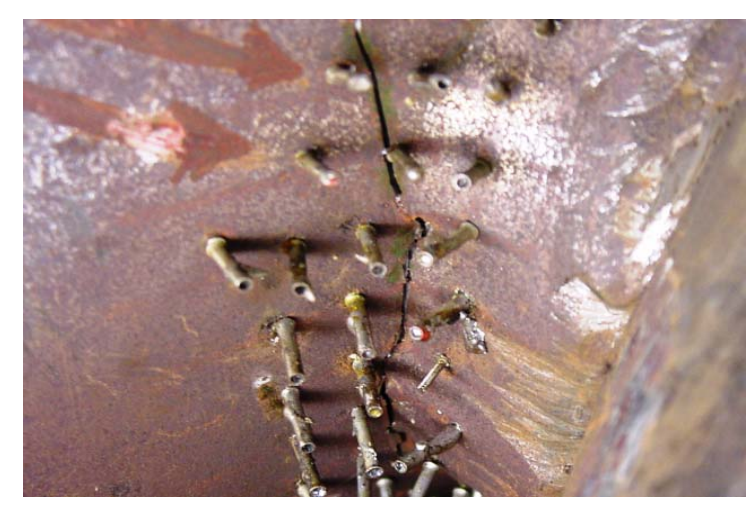

(a) Surface Crack of Specimen S1

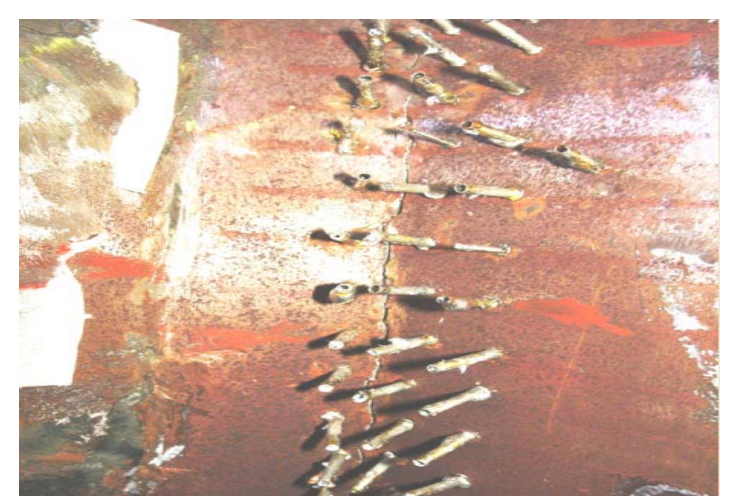

(b) Surface Crack of Specimen S2

Figure 8. Surface Cracks 


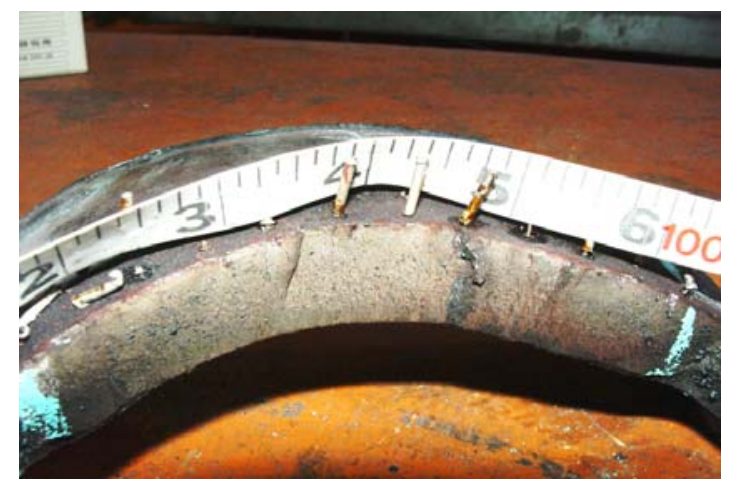

(a) Opened Surface Crack of Specimen S1

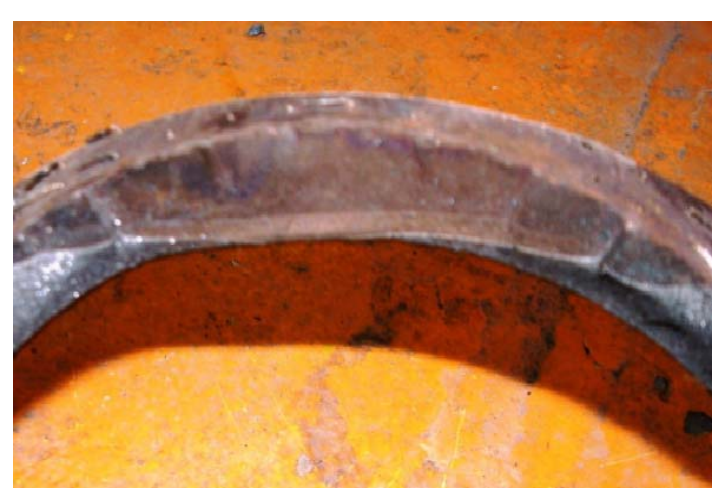

(b) Opened Surface Crack of Specimen S2

Figure 9. Opened Surface Cracks

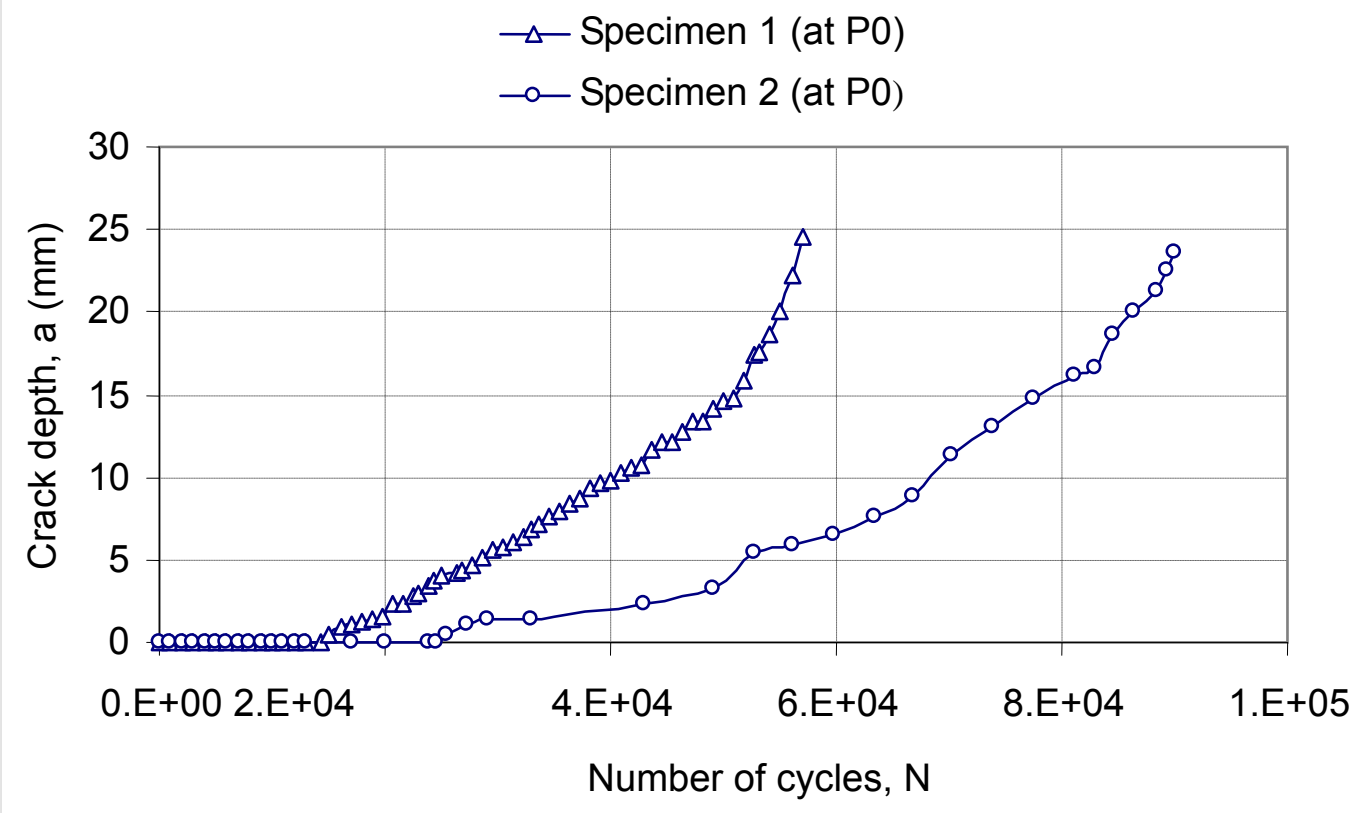

Figure 10. Crack Growth Curves of Partially Overlapped CHS K-joints at the Deepest Position 


$$
\begin{aligned}
& \multimap-\text { Specimen } 1 \text { (at P0) } \\
& \multimap-\text { Specimen } 2 \text { (at P0) }
\end{aligned}
$$

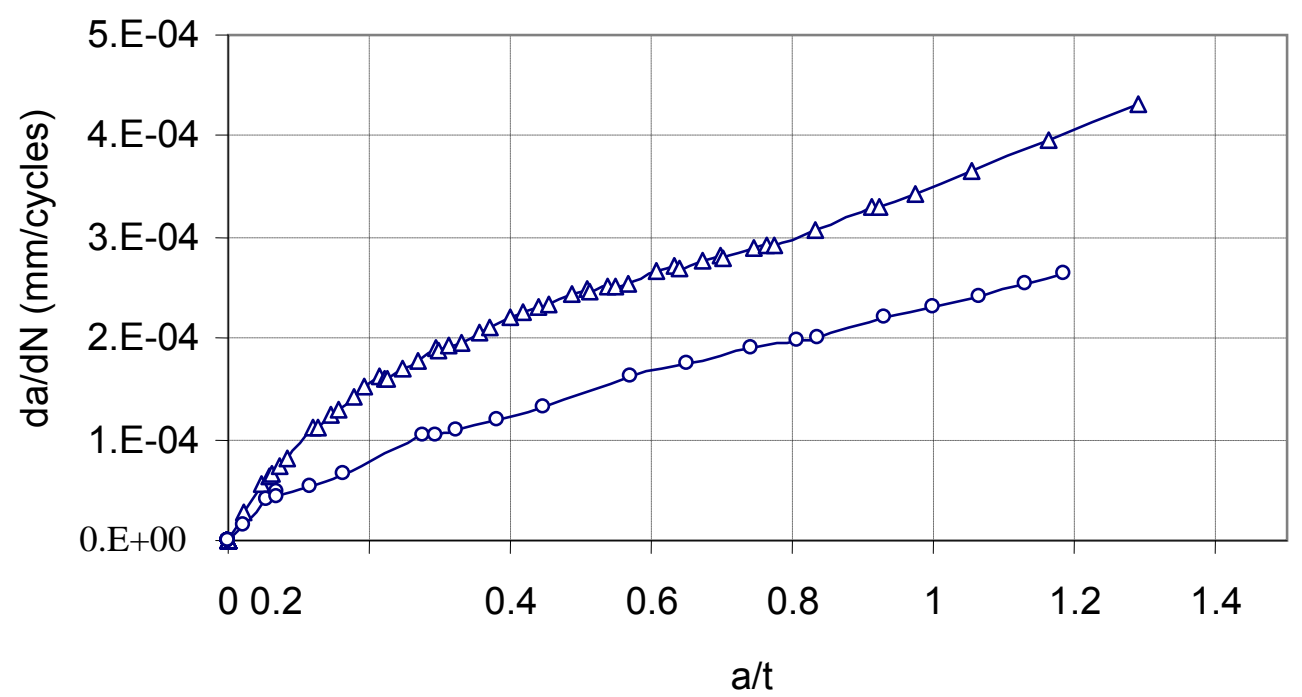

Figure 11. Crack Growth Rates of Partially Overlapped CHS K-joints at the Deepest Position

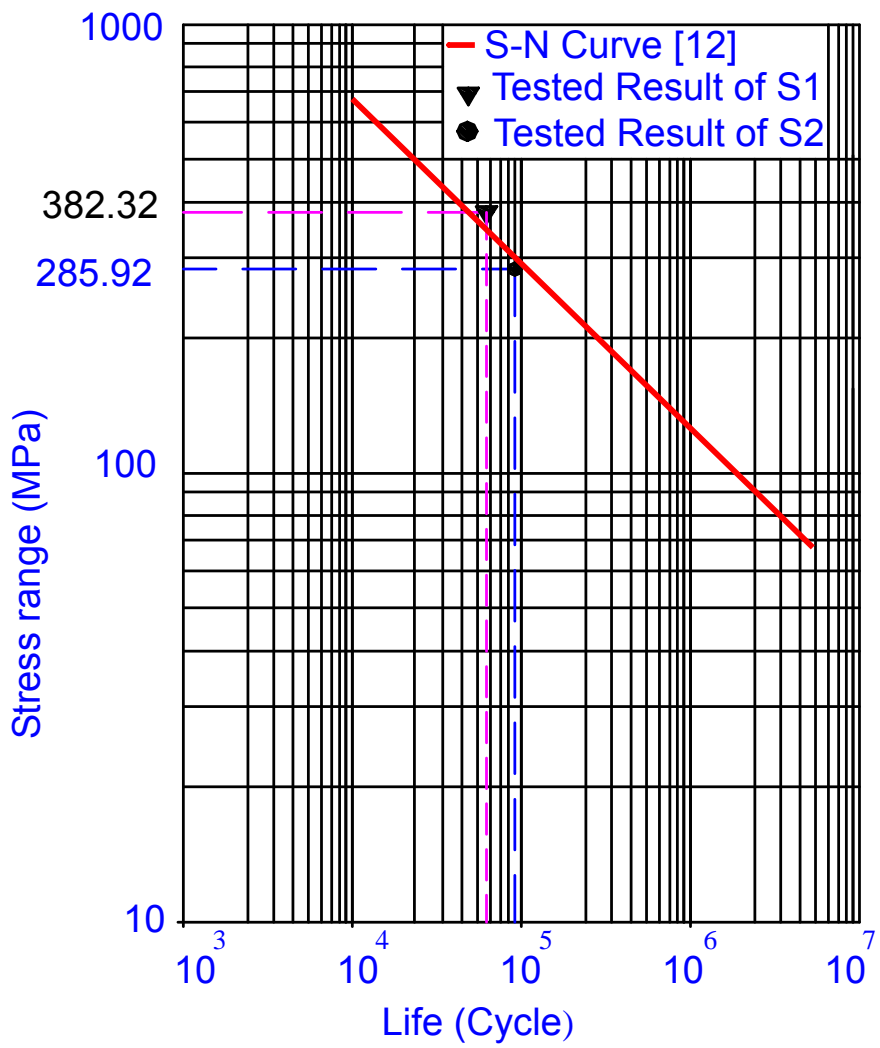

Figure 12. Fatigue Test Results Comparing with S-N Curve Data 


\section{CONCLUSIONS}

1. The stress analysis results show that the HSSs were located on the brace side. This may lead to somewhat shorter fatigue life of this kind of joint compared with previous chord failure mode which is common seen in T-, Y-, N-, and gapped CHS K-joints, since the most of the real offshore structures have a thinner brace thickness than the chord thickness.

2. In addition, the experimental stress analysis also shows that that the Ethymoui's formulae may not be completely suitable for design of partially overlapped CHS K-joints as the results show that the SCF formula values are over-conservative in IPB load case, but in AX load case they are not conservative.

3. Fatigue tests were carried out to investigate the behavior of two partially overlapped CHS K-joints under combined AX and IPB loadings. For Specimen S1, the test results indicated that peak HSS occurred at the through brace weld toe near the heel of the intersection of the through brace and the chord. For Specimen S2, when the IPB loading direction is reversed, the peak HSS occurred at the through brace weld toe near the crown of the through brace and overlapping brace. The fatigue test results demonstrated that the S-N curve proposed in the current codes is marginally conservative when predicting fatigue life of Specimen S1, but for Specimen S2 nonetheless S-N curve is not conservative.

Therefore, the existing formulae and current S-N curves may not be completely suitable for design of partially overlapped CHS K-joints.

\section{REFERENCES}

[1] Tizani, W.M.K., Yusurf, K.O., Davies, G. and Smith, N.J., “A Knowledge Based System to Support Joint Fabrication Decision Making at the Design Stage- Case Study for CHS Trusses", Proceeding of the $7^{\text {th }}$ International Symposium of Tubular Structures, Hungary, 1996, pp. 483-489.

[2] Wardenier, J., “Hollow Section Joints”, Delft University Press, Delft, The Netherlands, 1982.

[3] Romeijn, A., Karamonus, S.A. and Wardenier, J., "Effects of Joint Flexibility on Fatigue Design of Welded Tubular Lattice Structures”, The Seventh International Offshore and Polar Engineering Conference, San Frncisco, USA, 1997, Vol. IV, pp 27-36.

[4] Herion, S. and Puthli, R.S., "Fatigue Design and Secondary Bending Moments in RHS K-joints with Gap”, The Eighth International Symposium on Tubular Structures, Singapore, 1998, pp. 315-322.

[5] Wydle, J.G.. and McDolald, A., "The Influence of Joint Dimensions on Fatigue Strength of Welded Tubular Joints”, Proceeding of $2^{\text {nd }}$ International Conference, Behaviour of Offshore Structures, BHRA Fluid Engineering, Cranfield, U.K. 1979, paper 42, pp. 535-500.

[6] Efthymiou, M. and Durkin, S., "Stress Concentrations in T/Y and Gap/Overlap K-joints", Behavior of Offshore Structures, Elsevier, Amsterdam, Netherlands, 1985, pp. 429-440

[7] Dover, W.D., Dharmavasan, S., Brenan, F.P. and Marsh, K.J., "Fatigue Crack Growth in Offshore Structures”, Engineering Materials Advisory Services (EMAS) Ltd., Chamelon Press, London, 1995.

[8] Chiew, S.P., Lie, S.T., Lee, C.K. and Huang, Z.W., "Fatigue Performance of Cracked Tubular T- Joints under Combined Loads-Part I- Experimental”, Journal of Structural Engineering, American Society of Civil Engineers, ASCE, 2004, Vol. 130, No. 4, pp. 562-571. 
[9] Lee, C.K., Lie, S.T., Chiew, S.P. and Shao, Yongbo, "Numerical Models Verification of Cracked Tubular T, Y and K-Joints Under Combined Loads", Engineering Fracture Mechanics (United States), 2005, Vol. 72, No. 7, pp. 983 - 1009.

[10] Lie, S.T., Lee, C.K., Chiew, S.P. and Shao, Yongbo, "Validation of Surface Crack Stress Intensity Factors of a Tubular K-joint”, International Journal of Pressure Vessels and Piping (United Kingdom), 2005, Vol. 82, No. 8, pp 610 - 617.

[11] Lie, S.T., Lee, C.K., Chiew, S.P. and Shao, Yongbo, "Mesh Modelling of Cracked Uni-planar Tubular K-joints”, Journal of Constructional Steel Research (United Kingdom), 2005, Vol. 61, No. 2, pp 235 - 264.

[12] Zhao, X.L., Herion, S., Packer, J.A., Puthli, R., Sedlacek, G., Wardenier, J., Weynand, K., van Wingerde, A., and Yeomans, N., "Design Guide for Circular and Rectangular Hollow Section Joints under Fatigue Loading”, CIDECT Publication No. 8, TUV-Verlag, Germany, 2001. 


\title{
STRUCTURAL EFFICIENCY OF DEPLOYABLE STRUT-TENSIONED MEMBRANE STRUCTURES
}

\author{
T.C. $\operatorname{Tran}^{1}$ and J.Y.R. Liew ${ }^{2}$ \\ ${ }^{I}$ Department of Civil Engineering, National University of Singapore, \#02-18, BLK E1A, 1 Engineering Drive 2, \\ Singapore, 117576 \\ Tel: +65 6874 6498; Fax: +65 6779 1635, Email: tranchitrung@nus.edu.sg \\ ${ }^{2}$ Department of Civil Engineering, National University of Singapore, \#05-13, BLK E1A, 1 Engineering Drive 2, \\ Singapore, 117576 \\ Tel: +65 6874 2154; Fax: +65 6779 1635, Email: cveljy@nus.edu.sg
}

\begin{abstract}
A novel system of deployable strut-tensioned membrane structures (DSTMS) has been proposed recently for the purpose of fast-track construction of large span enclosures. The objective of this paper is to determine the most optimum design parameters for the proposed DSTMS. Efficiency studies are carried out on $48 \mathrm{~m} \times 48 \mathrm{~m}$ square grid of two DSTMS groups which are the Cone-shaped and the Umbrella DSTMS. Geometrical non-linear analysis is performed to evaluate the weight efficiency of different configurations of DSTMS. The minimum weight of the structures required to support predetermined load combinations is used as an optimization algorithm. DSTMS are proved to be capable of enclosing large span with weight efficiency as of double-layer space truss. The deployment efficiency of DSTMS is verified by building prototype models.
\end{abstract}

Keywords: Deployable strut-tensioned membrane structures, geometrical non-linear analysis, efficiency studies

\section{INTRODUCTION}

The concept of deployable strut-tensioned membrane lies on the idea of combining a system of deployable skeleton with high strength membrane to span over large space in one shot. This combination makes use of high strength membrane as a tension component to stabilize the deployable skeleton. On the other hand, membrane can be pre-tensioned by the deployment of the deployable skeleton, thus reducing the tensioning work.

This design concept was first proposed by Liew and Tran [1], followed by two classes of deployable strut-tensioned membrane structures (DSTMS) which are the Umbrella DSTMS and the Cone-shaped DSTMS. On one hand, the structures benefit the capability of rapid erection, easy transportation of deployable structures [2]. On the other hand, they inherit the appealing shape and light weight of tensioned membrane structures [3]. They are also proved to be capable of enclosing large span space with weight efficiency as of double-layer space trusses, thus overcoming the inherit weakness of deployable structures.

In this paper, the conceptual design of the Umbrella DSTMS and the Cone-shaped DSTMS is briefly reviewed. After that, the efficiency studies are conducted to determine the most optimum geometry of the two proposed DSTMS.

\section{CONCEPTUAL DESIGN OF DSTMS}

Deployable strut-tensioned membrane structures (DSMTS) are constructed from modules formed by interconnected struts, continuous membrane and cables to achieve self-stress equilibrium in the fully deployed configuration, thus removing the need of anchoring system. 
Based on this concept, two novel DSTMS groups and their versatility are generated. Figure 1 shows the geometry of an Umbrella DSTMS module. This configuration is inspired by the umbrella mechanism, in which the cloth on top is opened and tensioned by the opening of the rods attached to it.

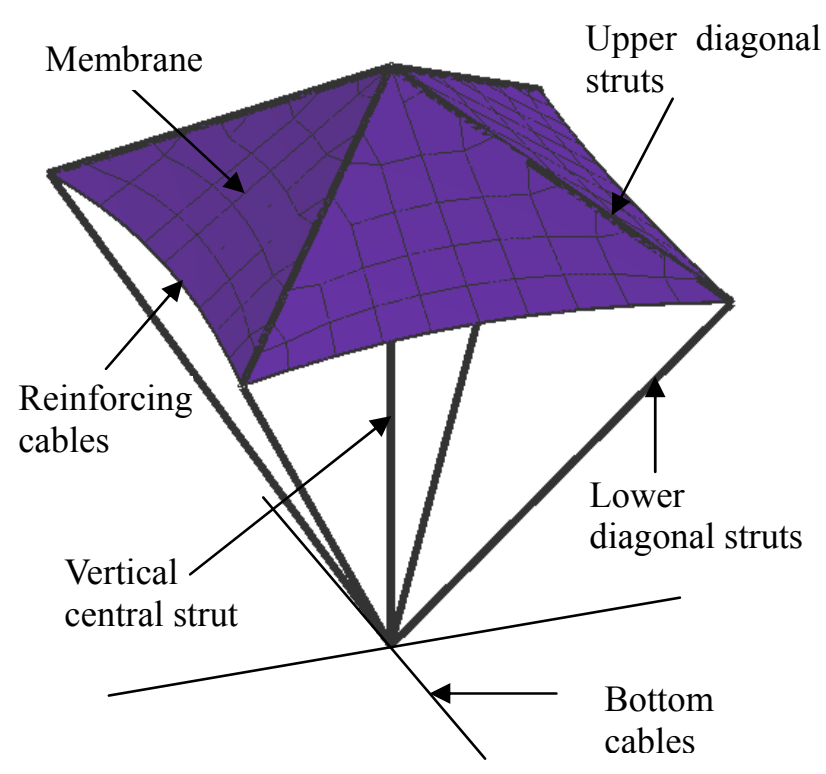

Figure 1. Geometry of an Umbrella DSTMS in Deployed Configuration

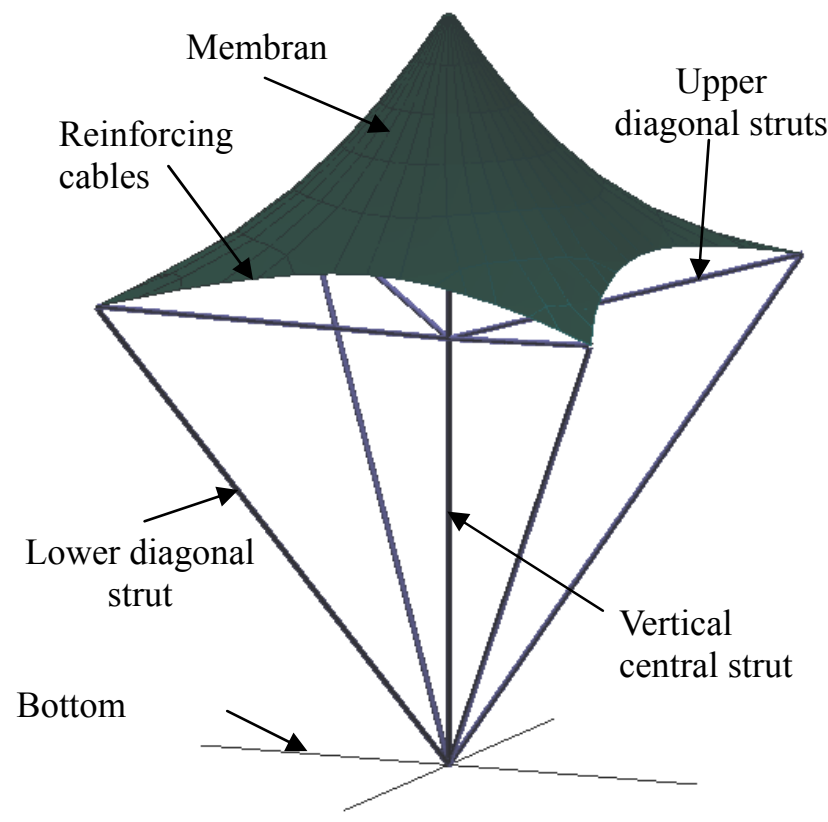

Figure 2. Geometry of a Cone-shaped DSTMS in Deployed Configuration

Each Umbrella DSTMS module consists of four upper diagonal struts which form a top pyramid, four lower diagonal struts which form a bottom up-side down pyramid, a vertical strut and membrane. The deployment process of the Umbrella DSTMS module is illustrated in Figure 3. Membrane attached on the top pyramid is opened and tensioned as of an umbrella. The deployment is locked by the vertical strut, which is in tension due to the self-stress equilibrium of the module.
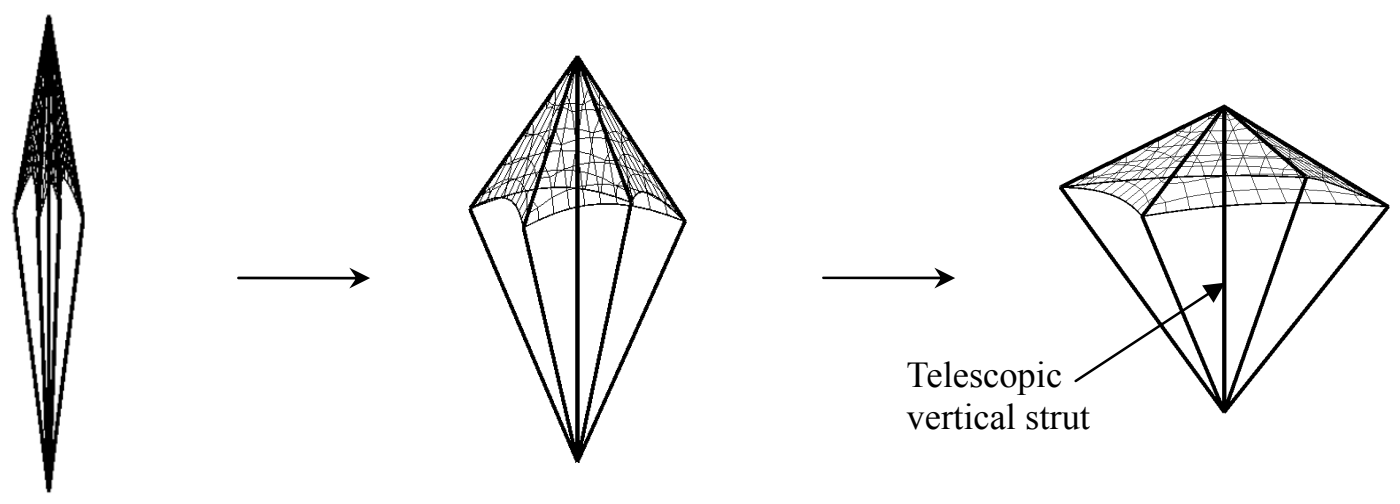

Figure 3. Deployment Process of Umbrella DSTMS Module

The geometry of a Cone-shaped DSTMS module is as shown in Figure 2. Basically, each module consists of four upper diagonal struts which form an up-side down inner pyramid, four lower diagonal struts which form an up-side down outer pyramid, a vertical strut and membrane. When the module is deployed, the membrane is propped at the center by the vertical strut and pulled down at four corners by diagonal struts. Therefore, the membrane forms a cone shape at 
the deployed configuration. The deployment process of Cone-shaped DSTMS module is illustrated in Figure 4. Unlike the Umbrella DSTMS, the vertical strut of Cone-shape DSTMS module is acting as a mast, and thus it is in compression. However, there are four upper diagonal struts connected to the vertical strut, providing an effective restraint point at its intermediate length. Hence, the effective buckling length of the vertical strut is reduced significantly.

Versatility of the DSTMS can be achieved by assembling identical modules in different ways to suit the shape and size of the applications. DSTMS modules are interconnected at their middle nodes while their bottom nodes are linked together by a layer grid of bottom cables. Typically, there are two general types of DSTMS which can be formed: flat structure and curved structures. By adjusting the grid size of the bottom cable layer to be equal to or smaller than the module width, a flat or a curved DSTMS is generated accordingly as shown in Figures. $5 \& 6$.

When DSTMS modules are interconnected together, the membrane is laid and tensioned continuously from module to module. Therefore, there is an interaction between adjacent connected modules due to the tension action in membrane. Hence, in the deployed configuration, the whole structure is in self-stress equilibrium state. The bottom cables are thus self-pretensioned to balance the tensile stress in the membrane. In addition, these bottom cables are pre-tensioned further due to the self-weight of structure. These prestressed cables also help the structure resist reversal load when subjecting to uplift wind force. The uplift wind force may be partly resisted by the top tensioned membrane.

Under gravity load, the top bars are in compression and the bottom cables are in tension forming a couple to resist bending action. The diagonal and vertical struts are the web elements to resist shear force.
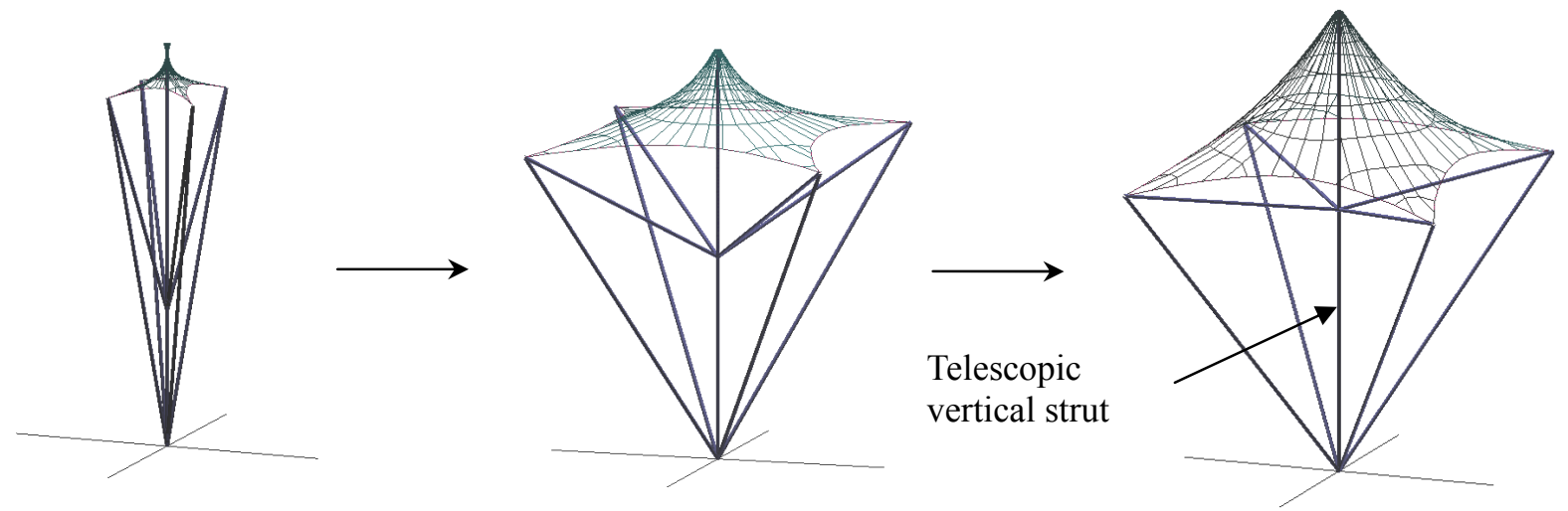

Figure 4. Deployment Process of Cone-shaped DSTMS Module

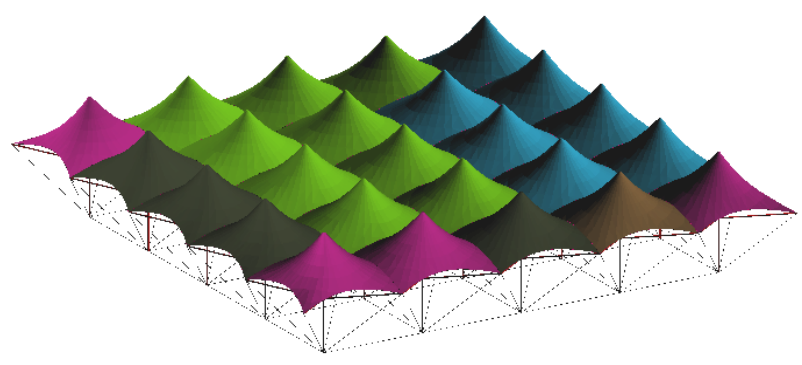

Figure 5. Flat Cone-shaped DSTMS

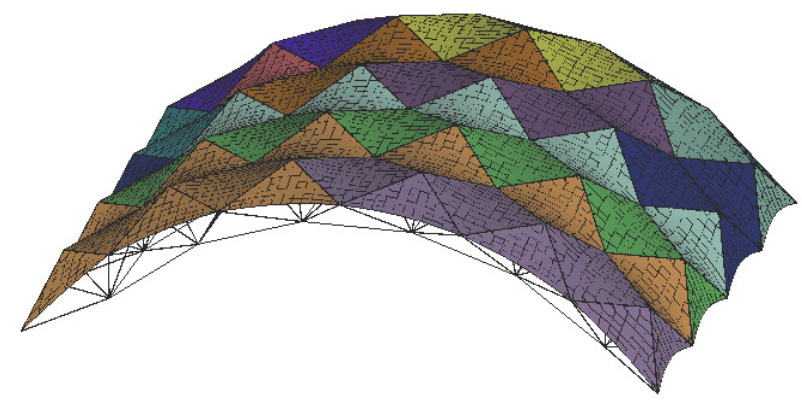

Figure 6. Curved Umbrella DSTMS 
A reduced scale model of the Umbrella DSTMS was built to verify the deployment efficiency of the proposed structures. The model is a curved structure comprising of two bays. Each bay consists of seven identical modules crossing a span of $3.1 \mathrm{~m}$. The structure covers an area of $1.3 \mathrm{~m}$ by $3.1 \mathrm{~m}$ and has a total weight of approximately $4 \mathrm{~kg}$. The prototype model is shown in Figure 7.

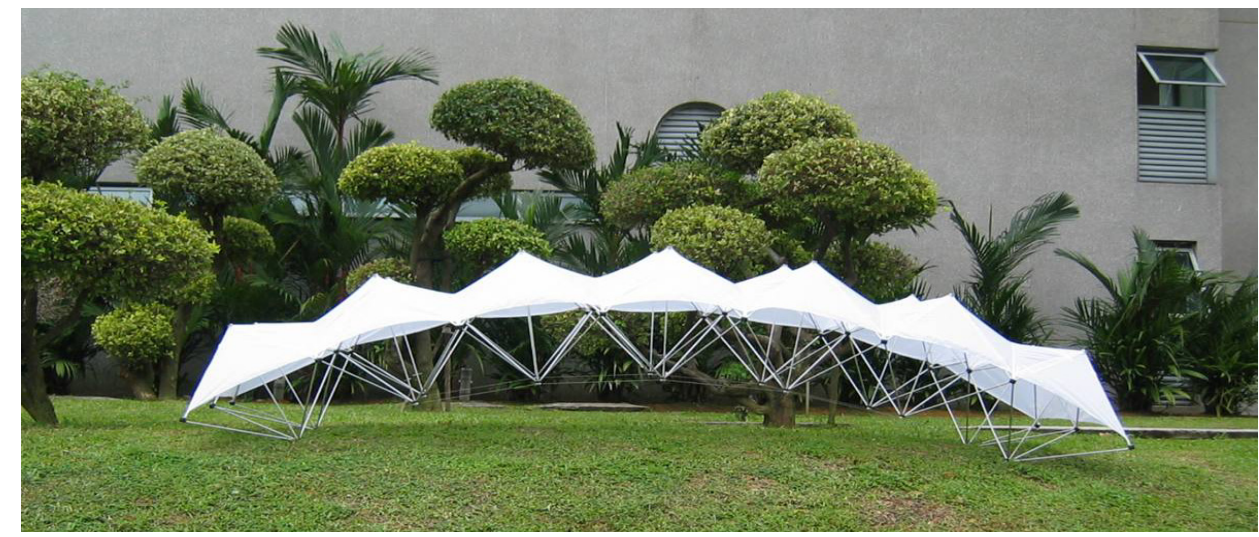

Figure 7. Ultra-lightweight Scale Model of Umbrella DSMTS

The deployment process of the Umbrella DSMTS model is shown in Figure 8. The structure was deployed from two ends within a minute. This structure can also be deployed easily from one end with the other end fixed on the ground. Experimentation with this small scale model has demonstrated the capability of the proposed DSTMS for rapid deployment on site. It was observed that the membrane could be tensioned efficiently by the deployment of the strut system. On the other hand, the strut system became more stable due to the tensioning effect from the tensioned membrane.

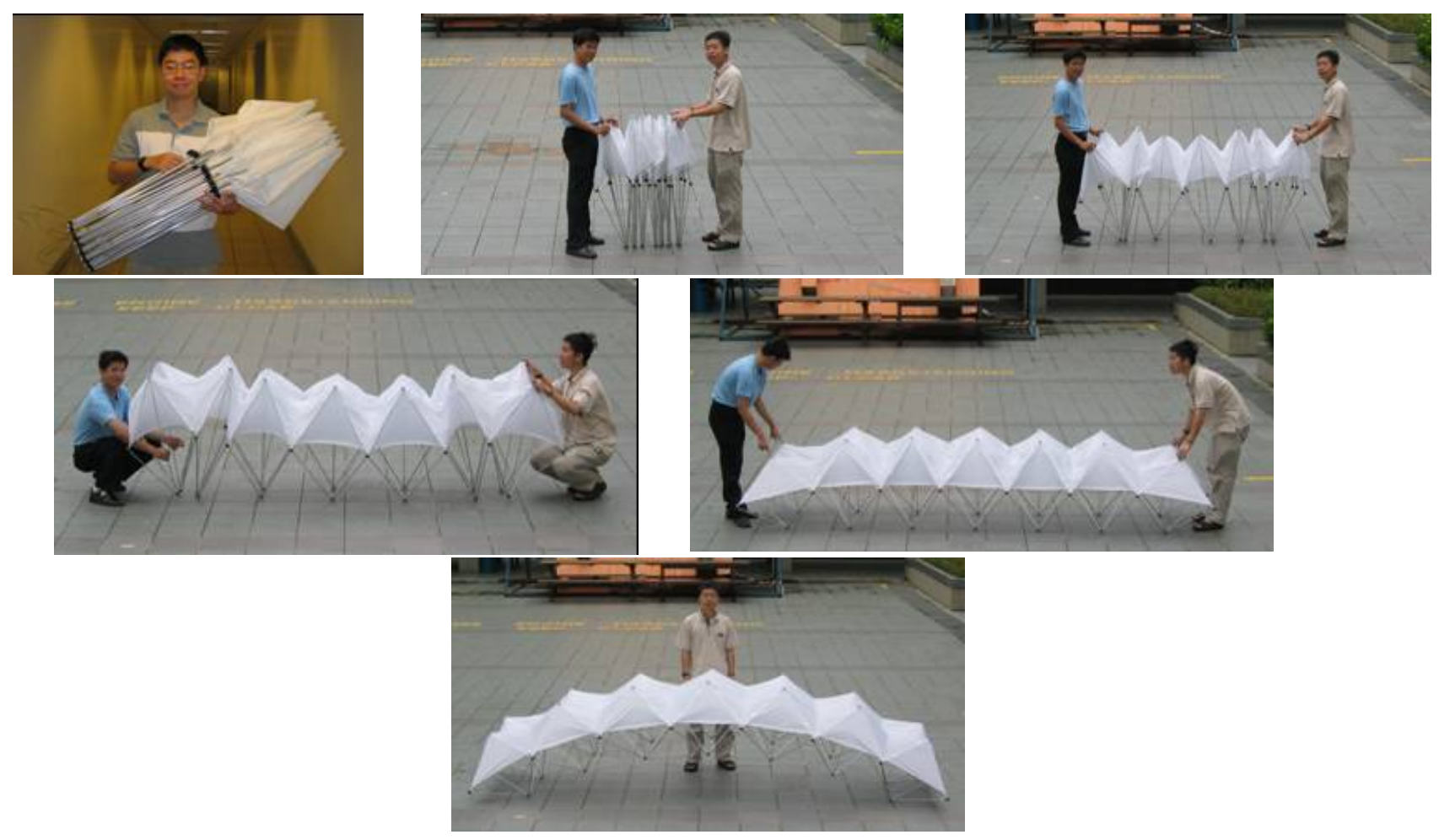

Figure 8. Deployment Process of Umbrella DSMTS Prototype 


\section{EFFICIENCY STUDIES}

There are three important design parameters which define the geometry of DSTMS: the span/depth ratio $(L / H)$, the span/modular width ratio $(L / W)$ and the inclination height/modular width ratio $(h / W)$. The inclination height $h$, the depth $H$, the modular width $W$ and the span $L$ are defined as shown in Figure 14 and Figure 15.

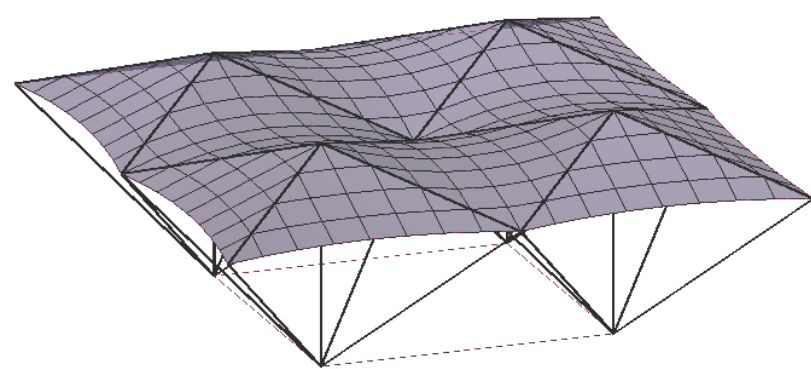

Figure 9. Saddle form of Membrane Surface between Umbrella DSTMS Modules

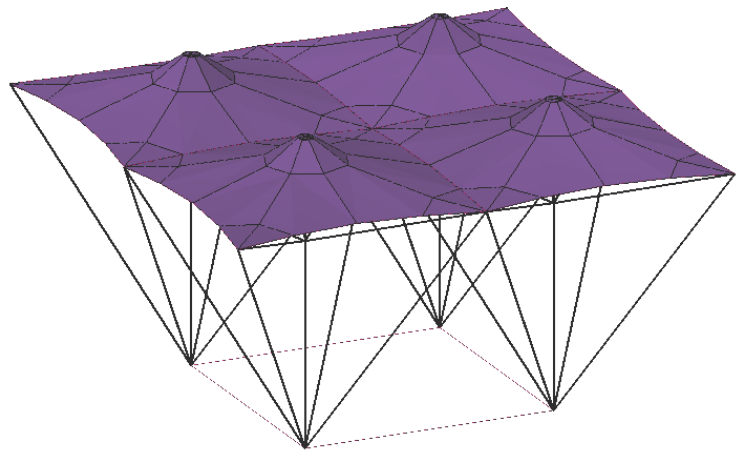

Figure 10. Conic form of Umbrella DSTMS Modules

The $h / W$ ratio determines the effective membrane shape of DSTMS. A good membrane surface will result in smaller resultant forces induced by applied loads. Smaller forces results in lighter structures [5]. DSTMS possess the two basic anticlastic shapes of membrane structure which are the saddle form between those modules of Umbrella DSTMS (except the triangular membrane shape along the boundary) and the conic form of series connected modules of Cone-shaped DSTMS as shown in Figures. $9 \& 10$. In order to tension the membrane of DSTMS more effectively, it is possible to adjust the inclination height/modular width $(h / W)$ ratio. Considering the case in which the two proposed DSTMS are subjected to wind uplift pressure of $0.45 \mathrm{kN} / \mathrm{m}^{2}$. Table 1 show the maximum membrane stress, maximum membrane displacement and the membrane usefulness (which is the ratio of membrane area/plan area). The results are plotted in Figures. $11,12 \& 13$ respectively.

It can be seen that the maximum membrane stress and maximum membrane displacement decrease when the $h / W$ ratio increases. The reason is that the higher $h / W$ ratio will provide more curvature for the saddle and conic shape of DSTMS. The more curvature the smaller the forces that will develop as the result of applied loads. When the $h / W$ ratio is larger than 0.2 , the maximum membrane stress and displacement do not reduce much or start increasing due to significant increase in the membrane area exposed to wind force. In addition, higher $h / W$ ratio means larger membrane area is required for a given plan area, resulting in higher cost. It can be observed that optimum $h / W$ ratio is about 0.2. In the subsequent parametric studies of span/depth and span/modular width ratios, the $h / W$ ratio of 0.2 is selected for both DSTMS. 
Table 1. Maximum Membrane Stress and Displacement of Umbrella and Cone-shaped DSMTS

\begin{tabular}{|l|l|l|l|l|l|l|}
\hline \multirow{3}{*}{$h / W$} & \multicolumn{4}{l}{ Umbrella DSTMS } & \multicolumn{3}{l|}{ Cone-shaped DSTMS } \\
\cline { 2 - 7 } & $\begin{array}{l}\text { Max stress } \\
(\mathrm{kN} / \mathrm{m})\end{array}$ & $\begin{array}{l}\text { Max } \\
\text { displacement } \\
(\mathrm{cm})\end{array}$ & $\begin{array}{l}\text { Membrane } \\
\text { usefulness }\end{array}$ & $\begin{array}{l}\text { Max stress } \\
(\mathrm{kN} / \mathrm{m})\end{array}$ & $\begin{array}{l}\text { Max } \\
\text { displacement } \\
(\mathrm{cm})\end{array}$ & $\begin{array}{l}\text { Membrane } \\
\text { usefulness }\end{array}$ \\
\hline 0.1 & 6.34 & 27.5 & 1.013 & 19.23 & 51.7 & 1.013 \\
\hline 0.2 & 5.48 & 20.7 & 1.051 & 5.59 & 20.2 & 1.05 \\
\hline 0.3 & 4.43 & 21.9 & 1.11 & 4.5 & 17.5 & 1.107 \\
\hline 0.4 & 4.38 & 23.3 & 1.187 & 4.51 & 15.2 & 1.179 \\
\hline
\end{tabular}

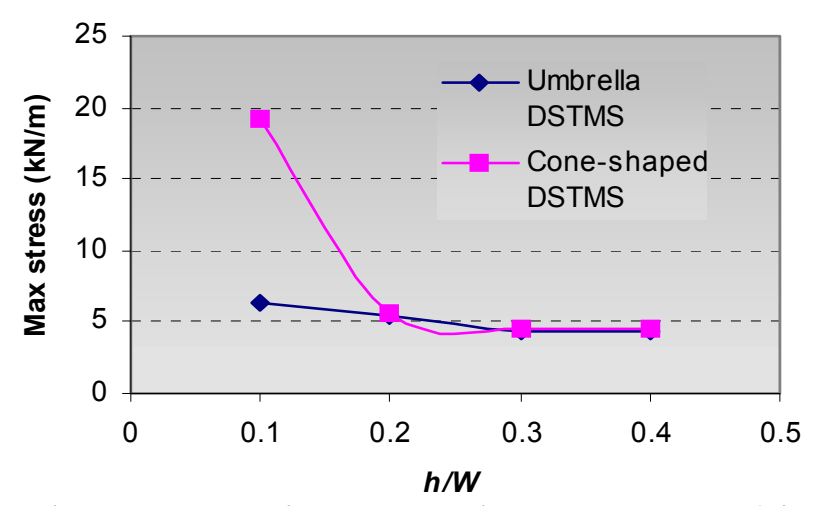

Figure 11. Maximum Membrane Stress vs. $h / W$ Ratio

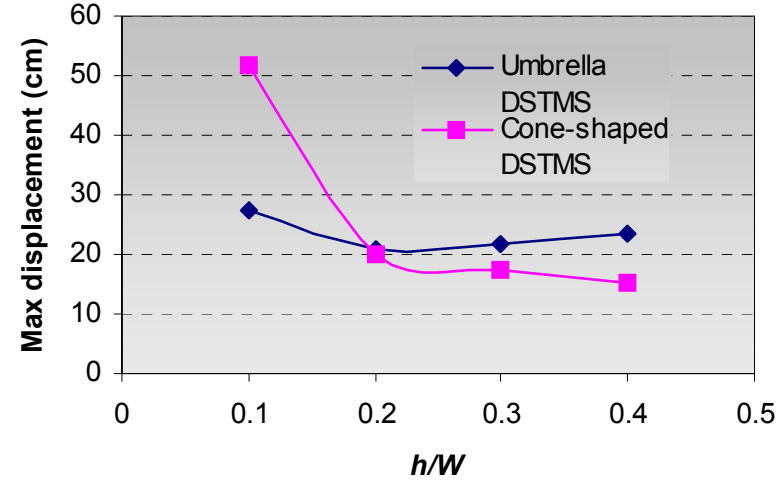

Figure 12. Maximum Membrane Displacement vs. $h / W$ Ratio

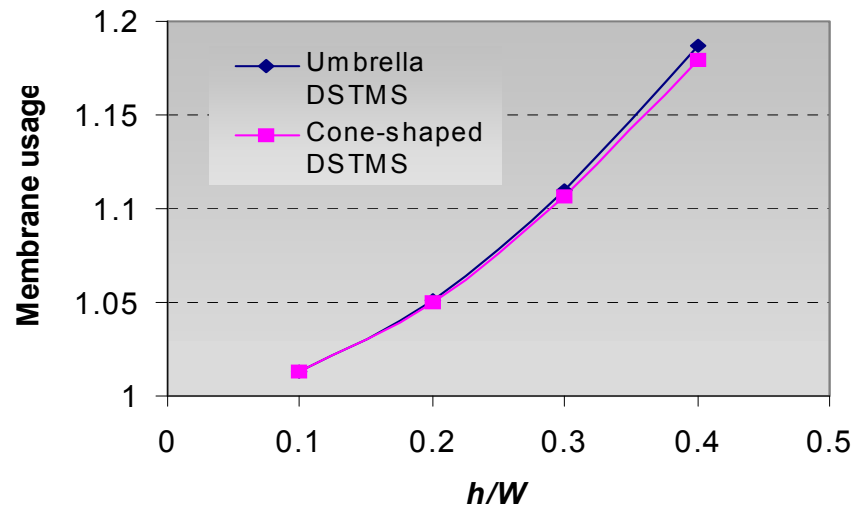

Figure 13. Membrane Usefulness vs. $h / W$ Ratio

The optimum span/depth $(L / H)$ and span/modular width $(L / W)$ ratios of DSTMS are determined from efficiency studies of weight-to-strength ratio of the structures. In this paper, the minimum weight of structural elements that is designed to resist predetermined load combinations is used as a basis for comparing different span/depth and span/modular width ratios. Geometrical nonlinear analysis is carried out on $48 \mathrm{~m} \times 48 \mathrm{~m}$ square grids of the Cone-shaped DSTMS and the Umbrella DSTMS with pinned supports at four sides. The span/depth ratios studied are $6,8,10$ and 12 while the span/modular width ratios are chosen to be 6,8 and 10 (Figures. $14 \& 15$ ). 


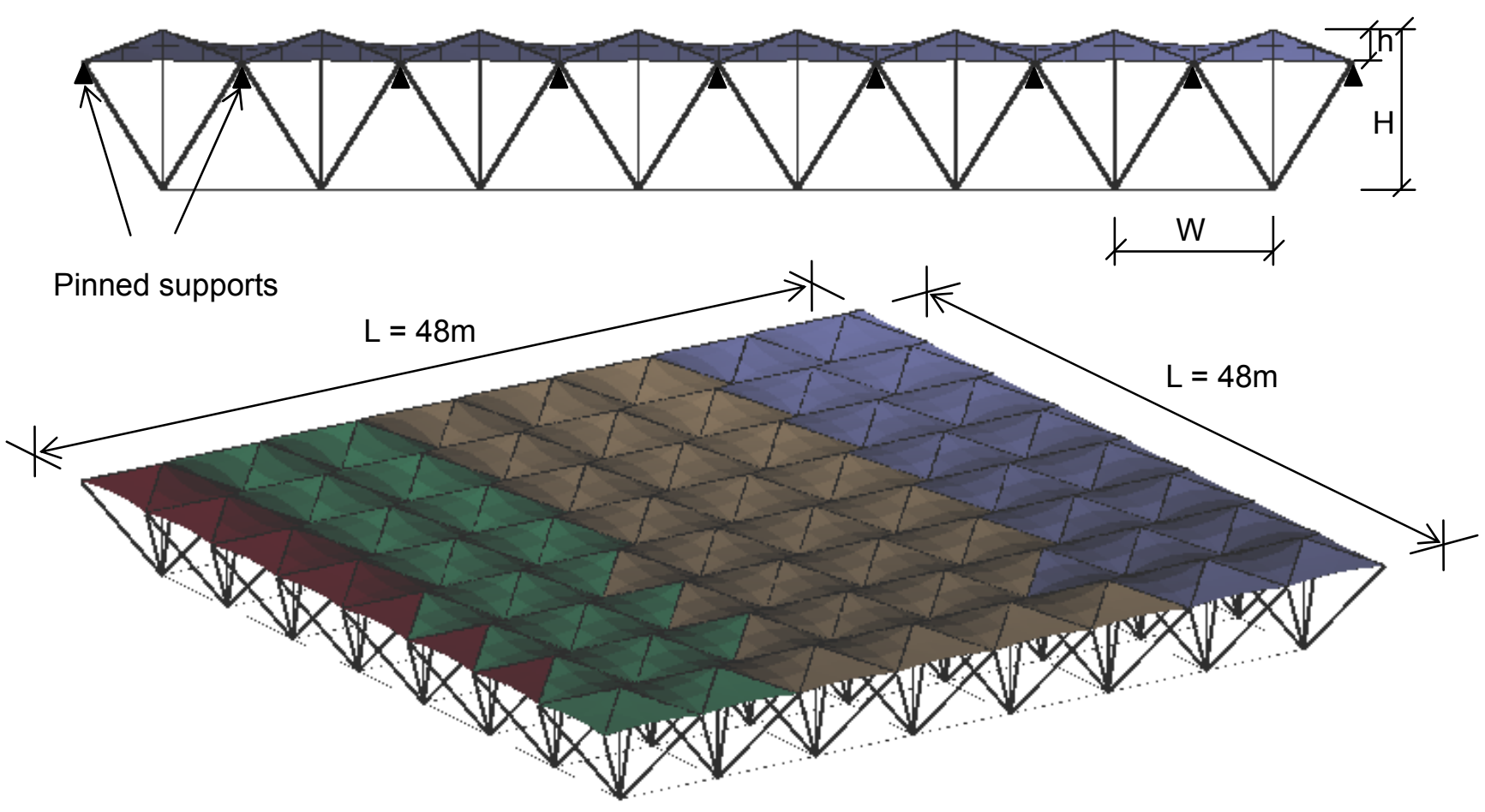

Figure 14. Configuration of Umbrella DSMTS, Span of 48m x 48m, 8x8 Modules

In this study, two major load combinations are used for designing DSTMS. The first load combination includes gravity loadings which are the self-weight of the structure and an imposed live load of $0.75 \mathrm{kN} / \mathrm{m}^{2}$. The load is distributed at the bottom nodes of the structures. The factored gravity load combination is $1.4 \mathrm{x}$ self-weight of structure $+1.6 \mathrm{x}$ imposed load in accordance with BS 5950, Part 1 (2000) [4]. The second load combination includes wind uplift loading. Wind is often the predominant loading on membrane fabric roof. A typical wind speed of Singapore of $35 \mathrm{~m} / \mathrm{s}$ which is equivalent with a design wind suction load of $0.45 \mathrm{kN} / \mathrm{m}^{2}$ is assumed. The wind uplift force is applied uniformly and normal to the membrane surface. The factored uplift load combination is $1.0 \mathrm{x}$ self-weight of structure $+1.4 \mathrm{x}$ wind uplift load in accordance with BS5950, Part 1 (2000) [4].

The following procedure has been adopted for the design of DSTMS.

a. The structure is modelled with one section for struts and one for cables.

b. Form-finding process is performed using Force density method to find the initial equilibrium shape of structure.

c. Geometric nonlinear analysis is performed with load combination 1: (1.4 x self-weight of structure $+1.6 \mathrm{x}$ imposed load) and load combination 2 : $(1.0 \mathrm{x}$ self-weight $+1.4 \mathrm{x}$ wind uplift load) to determine member forces.

d. Section capacity and member buckling of struts and cables are checked against ultimate limit state. Membrane stress is checked to ensure no membrane part is under compression or exceeds allowable stress. Maximum deflection of supporting structure is recorded to check against serviceability limit state as specified in BS 5950, Part 1 (2000) [4]. In this study, the deflection limit of L/200 for steel beam [4] is used.

e. The members are resized if necessary and the design procedure is repeated from step 2 . 

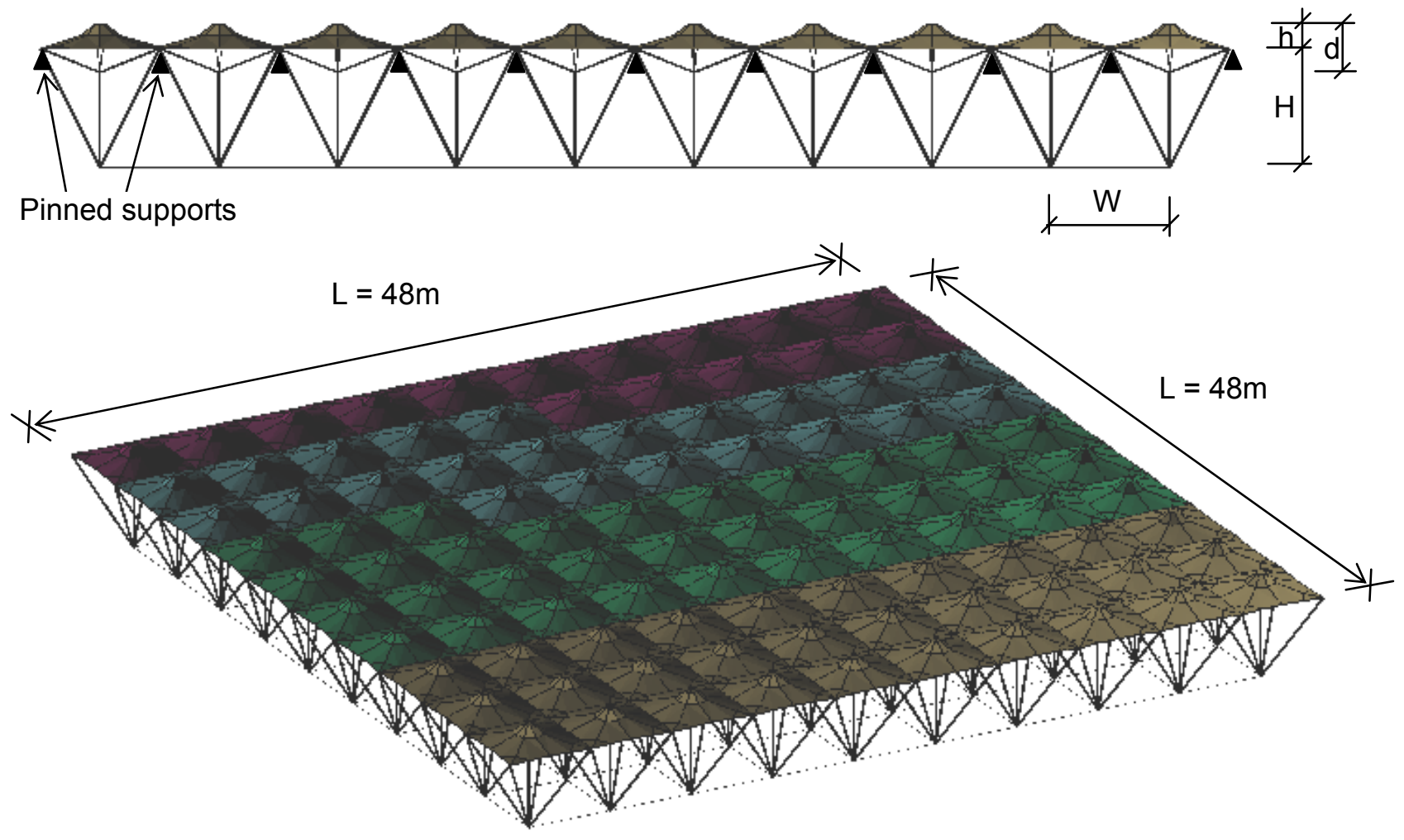

Figure 15. Configuration of Cone-shaped DSMTS, span of 48m x 48m, 10x10 Modules

Parametric studies show that the optimum span/depth ratio falls in between 9 and 10 and the optimum span/modular width ratio occurs from 6 to 8 as illustrated in Figures. $16 \& 17$.

For structures with the same span/modular width ratio, the change in span/depth ratio will affect the length of the struts. If the span/depth ratio is small, the forces induced in upper diagonal struts (chord) are small but the lower diagonal struts and the vertical struts are very long. The strength reduction due to buckling is significant, thus the required member sizes of diagonal struts and vertical struts are large resulting in high self-weight. When the span/depth ratio increases, the forces induced in both the upper and lower diagonal struts increase while the lengths of the lower diagonal struts and vertical struts are reduced. As a result, the member size of the upper diagonal struts is increased as their length is unchanged. On the other hand, a decrease in buckling length of the lower diagonal struts will be accommodated with the increase of forces induced, thus the member size of lower diagonal struts is not influenced much. Therefore, the weight of diagonal vertical struts is reduced considerably due to the decrease in length. In addition, the forces induced in the vertical strut is kept unchanged while the buckling length is reduced, requiring smaller section size (lighter weight). Thus, in overall, the self-weight of the structures decreases with the increase of span/depth ratio. However, at a very high span/depth ratio, the self-weight starts to increase if the span/depth ratio continues increasing. This is because the strength of lower diagonal struts increase due to the decrease in buckling length is not significant compared to the increase of force induced in them. Hence, the required size of the lower diagonal struts is larger, resulting in significant increase in self-weight of the structures. As can be observed in Figures. 16 \& 17, the relationships between self-weight of structures and span/depth ratio for different span/modular width ratios follow the same trend. The minimum weight of each system occurs around a span/depth ratio of 10 . 


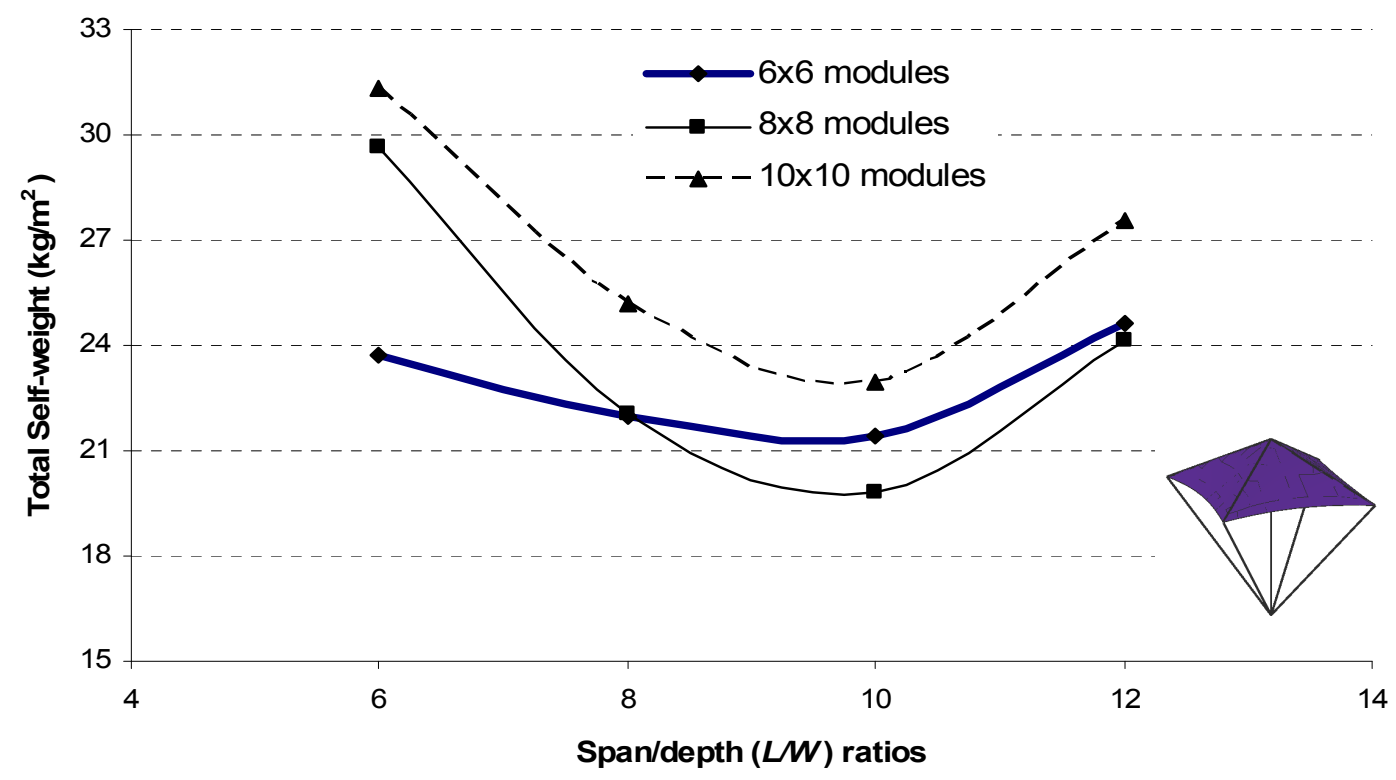

Figure 16. Self-weight of Umbrella DSTMS with Span of $48 \mathrm{~m}$

Different span/modular width ratios also affect the design weight of structures. The increase in span/modular width ratio results in higher grid density and lower forces induced in structural elements. At low span/depth ratio, although member forces induced in struts are smaller with higher grid density, significant strength reduction due to buckling length requires larger member sizes. Thus the structure with higher span/modular width ratio has larger section size and higher self-weight. However, at large span/depth ratio, the effect of buckling length is less pronounced with higher span/modular width ratio due to shorter element lengths. Therefore, the decrease in self-weight due to the increase in span/depth ratio of structures with higher span/modular width ratio is more significant. The minimum weight of each system occurs around a span/modular width ratio of 8 .

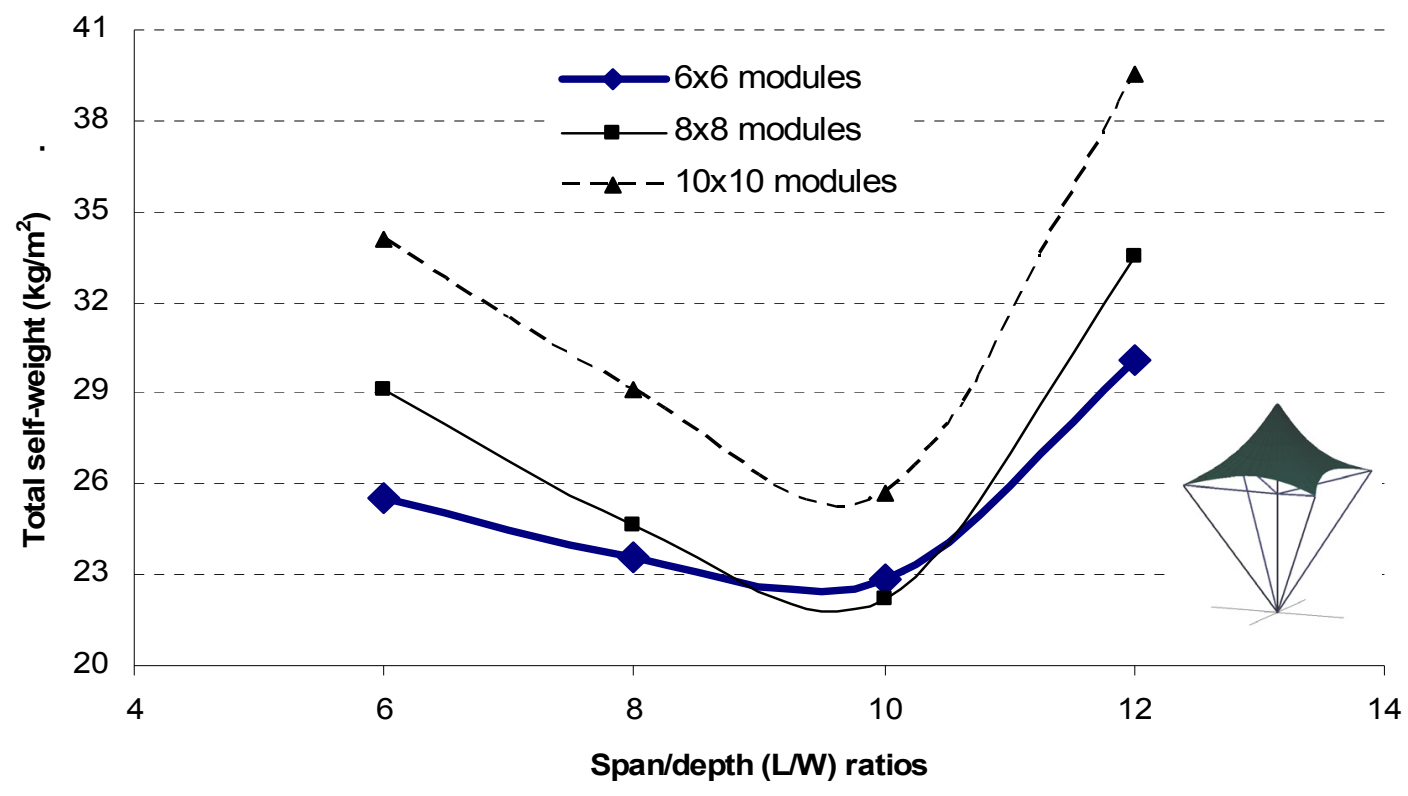

Figure 17. Self-weight of Cone-shaped DSTMS with Span of $48 \mathrm{~m}$ 
In general, the span/depth ratio has more significant influence on the self-weight of DSTMS than the span/modular width ratio. It is found that the self-weight of Umbrella DSTMS is smaller than that of Cone-shaped DSTMS. The reason is that, for the same span/depth and span/modular width ratios, the length of lower diagonal struts of Cone-shaped DSTMS is larger than that of Umbrella DSTMS. Although Cone-shaped DSTMS has shorter vertical struts, the contribution of lower diagonal struts on self-weight is much greater.

Based on optimal range of span/depth and span/modular width ratios, the relationship between the depth and the modular width of DSTMS can be deduced as shown in Figure 18. It can be observed that optimum depth/modular width ratio is around 0.8 . This ratio can be used as a reference to determine the optimum span/depth and span/modular width ratios for curved DSTMS.

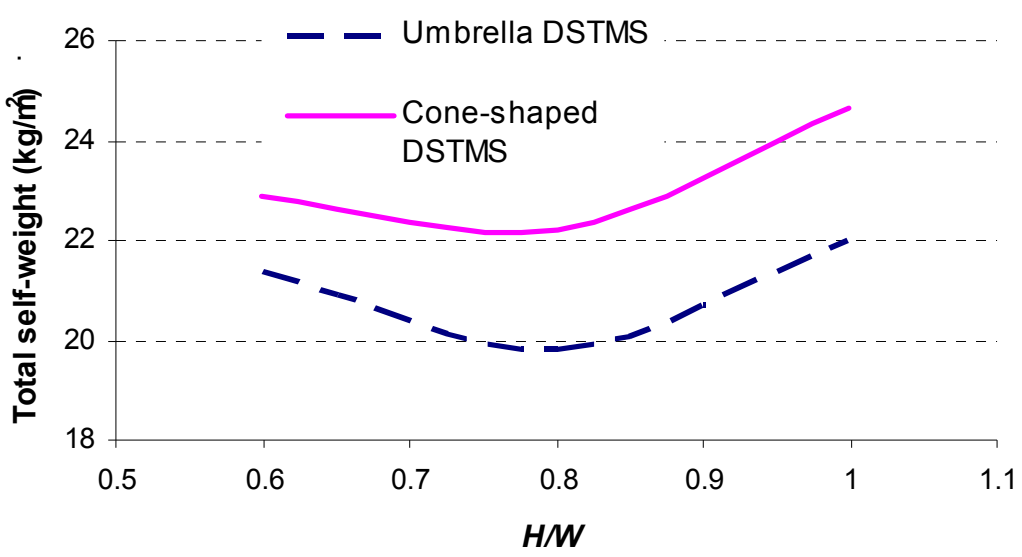

Figure 18. Total Self-weight vs. $H / W$ ratio of Umbrella and Cone-shaped DSTMS

A summary of the optimum span/depth ratio and span/modular width ratio is given in Table 2 . The lowest weight of Umbrella DSTMS is $19.8 \mathrm{~kg} / \mathrm{m}^{2}$ while the lightest weight of Cone-shaped DSTMS is $21.8 \mathrm{~kg} / \mathrm{m}^{2}$. They are comparable with the self-weight of similar layout double-layer space trusses excluding roofing material and fabric support framing (in case of using membrane roof) [6]. Therefore it can be concluded that DSTMS possess good structural efficiency as of double-layer space trusses.

Table 2. Optimum Design Parameters and Weight of DSTMS (Span 48m x 48m)

\begin{tabular}{|l|l|l|l|l|l|}
\hline Type of DSTMS & $\begin{array}{l}\text { Optimum } \\
h / W \text { ratio }\end{array}$ & $\begin{array}{l}\text { Optimum } \\
L / H \text { ratio }\end{array}$ & $\begin{array}{l}\text { Optimum } \\
L / W \text { ratio }\end{array}$ & $\begin{array}{l}\text { Optimum } \\
H / W \text { ratio }\end{array}$ & $\begin{array}{l}\text { Optimum } \\
\text { total } \\
\text { self-weight }\end{array}$ \\
\hline Umbrella DSTMS & 0.2 & 10 & 8 & 0.8 & 19.8 \\
\hline $\begin{array}{l}\text { Cone-shaped } \\
\text { DSTMS }\end{array}$ & 0.2 & 10 & 8 & 0.8 & 21.8 \\
\hline
\end{tabular}




\section{CONCLUSIONS}

Two novel groups of DSTMS have been introduced and developed. Those structures combine the advantages of both deployable structures and tensioned membrane structures, thus they have the capability of rapid erection on site incorporated with eye-catching membrane appearance. Series of parametric studies are carried out to determine the most efficient geometry of two proposed DSTMS. A summary of optimum design parameters for the two DSTMS is given as a design recommendation. It is proved that DSTMS are capable of enclosing large span space with equivalent structural efficiency as of double-layer space truss. Prototype model has demonstrated the deployment efficiency of the proposed DSTMS.

\section{REFERENCES}

[1] Liew, J.Y.R., "Tran T.C., Novel Deployable Strut-tensioned Membrane Structures", Journal of the International Association for Shell and Spatial Structure, 2005, Paper accepted for publication.

[2] Gantes, C., "Deployable Structures: Application and Design”, WIT Press, USA, 2001.

[3] Huntington, C.G., "The Tensioned Fabric Roof", ASCE Press, USA, 2004.

[4] British Standard Institute, BS 5950, Part 1, 2000, Code of Practice for Design: Rolled and Welded Sections, BSI.

[5] Forster, B., Mollaert, M., European Design Guide for Tensile Surface Structures, Tensinet, 2004.

[6] Makowski, Z.S., "Analysis, Design and Construction of Double-layer Grids", Applied Science Publisheds, London, 1981. 


\title{
BEHAVIOR AND DESIGN OF ALUMINUM ALLOY STRUCTURAL MEMBERS
}

\author{
Ji-Hua $\mathrm{Zhu}^{1}$ and Ben Young ${ }^{2, *}$ \\ ${ }^{I}$ Shenzhen Key Lab on Durability of Civil Engineering, College of Civil Engineering, ShenZhen University, \\ ShenZhen, PRChina. (zhujh@szu.edu.cn) \\ ${ }^{2}$ Department of Civil Engineering, The University of Hong Kong, Pokfulam Road, Hong Kong \\ *(Corresponding author: E-mail: young@hku.hk)
}

\begin{abstract}
This paper summarizes recent research on aluminum alloy structural members. The research program formed the basis of the $\mathrm{PhD}$ thesis of the first author. The behavior of aluminum alloy structural members was investigated experimentally and numerically. Tests were conducted on aluminum alloy columns, beams and beam-columns of square, rectangular and circular hollow sections. Numerical investigation was performed on fixed-ended aluminum alloy tubular columns with and without transverse welds at the ends of the columns. The effects of transverse welds on aluminum alloy columns were also investigated. The experimental and numerical results were compared with the design strengths calculated using the current American, Australian/New Zealand and European specifications for aluminum structures. In addition, the direct strength method, which was developed for cold-formed carbon steel members, was used in this study for aluminum alloy columns. Furthermore, design rules modified from the direct strength method were proposed. It is shown that the proposed design rules accurately predicted the ultimate strengths of aluminum non-welded and welded columns. The reliability of the current and proposed design rules for aluminum columns was evaluated using reliability analysis.
\end{abstract}

Keywords: Aluminum alloys; beams, beam-columns, buckling; columns; experimental investigation; heat-affected zone; numerical investigation; structural design; transverse welds

\begin{tabular}{|ll|}
\hline Nomenclature & \\
$A$ & $=$ gross cross-section area; \\
$B$ & $=$ overall width of SHS and RHS; \\
$D$ & $=$ dead load; \\
DL & $=$ plate width or depth; \\
$d$ & $=$ Young's modulus; \\
$E$ & $=$ axial shortening; \\
$e$ & $=$ measured loading eccentricity; \\
$e_{0}$ & $=$ finite element analysis; \\
FEA & $=$ material yield strength; \\
$f_{\mathrm{y}}$ & $=$ non-welded material yield strength; \\
$f_{\mathrm{y}-\mathrm{nw}}$ & $=$ overall depth of SHS and RHS; \\
$H$ & $=$ length of specimen; \\
$L$ & $=$ column effective length; \\
$\mathrm{LL}$ & $=$ moment; \\
$l_{e}$ & $=$ end moment; \\
$M$ & $=$ maximum inelastic moment; \\
$M_{\text {end }}$ & $=$ ultimate moments; \\
$M_{m i}$ & $=$ axial load; \\
$M_{u}$ & $=$ critical elastic buckling load in flexural buckling, $\pi^{2} E A /\left(l_{e} / r\right)^{2} ;$ \\
$N$ & $=$ critical elastic local column buckling load; \\
$P_{\text {cre }}$ & $=$ column design strength calculated using the direct strength method; \\
$P_{\text {crl }}$ & $=$ non-welded column design strength calculated using the modified direct \\
$P_{\mathrm{DSM}}$ & strength method; \\
$P_{\mathrm{DSM}-\mathrm{NW}}$ &
\end{tabular}




\begin{tabular}{|l|l|}
\hline$P_{\mathrm{ne}}$ & $=$ nominal axial strength for flexural buckling; \\
$P_{u}$ & $=$ column strength; \\
$P_{\mathrm{y}}$ & $=$ yield strength of the section $\left(f_{\mathrm{y}} A\right) ;$ \\
$P_{\mathrm{y}-\mathrm{nw}}$ & yield strength of the section calculated using the non-welded material \\
& properties $\left(f_{\mathrm{y}-\mathrm{nw}} A\right) ;$ \\
$r$ & $=$ radius of gyration of gross cross-section about the minor $y$ - axis of buckling; \\
$t$ & $=$ thickness of section; \\
$z$ & $=$ reliability index; \\
$\beta$ & $=$ non-dimensional slenderness for flexural buckling; \\
$\lambda_{\mathrm{c}}$ & $=$ non-dimensional slenderness for interaction of local and flexural buckling; \\
$\lambda_{l}$ & $=$ heat-affected zone (HAZ) softening factor specified in the Eurocode $9 ;$ \\
$\rho_{\text {haz-EC9 }}$ & $=$ heat-affected zone (HAZ) softening factor obtained from the FEA; \\
$\rho_{\text {haz-FEA }}$ & $=$ resistance factor. \\
$\rho_{\text {haz-P }}$ &
\end{tabular}

\section{INTRODUCTION}

Aluminum tubular members are used in curtain walls, space structures and other structural applications. The aluminum tubular members are normally manufactured by heat-treated aluminum alloys, because heat-treated alloys have notably higher yield stress than non-heat-treated alloys. The advantages of using aluminum alloys as a structural material are the high strength-to-weight ratio, lightness, corrosion resistance and ease of production.

There are drawbacks of using aluminum alloys for structural applications, such as the low Young's modulus of aluminum that is roughly one third of steel and cause aluminum member to easily fail by buckling. The American Aluminum Design Manual (AA) [1], Australian/New Zealand Standard (AS/NZS) [2] and European Code (EC9) [3] provide design rules for aluminum structural members. Previous research of aluminum structural members was mainly focused on the ultimate strength of compact (non-slender) sections. However, the use of aluminum thin-walled sections has increase in recent years. Hence, it is necessary to investigate the behavior and design of aluminum columns, beams and beam-columns of slender sections.

In addition, when heat-treated aluminum alloys are welded, the heat generated from the welding reduces the material strength significantly in a localized region, and this is known as the heat-affected zone (HAZ) softening. It is assumed that the heat-affected zone extends 1 inch $(25.4$ $\mathrm{mm}$ ) to each side of the centre of a weld [1]. In the case of the 6000 Series alloys, the heat generated from the welding can locally reduce the parent metal strength by nearly half [4]. The effects of welding on the strength and behavior of aluminum structural members depend on the direction, location and number of welds. In aluminum structures, welds are divided into two types, namely (1) transverse welds; (2) longitudinal welds, for the purpose of divining their influence on member strength. Generally, transverse welds are often used in connections, whereas longitudinal welds are used for the fabrication of built-up members [5]. The current American Aluminum Design Manual [1], Australian/New Zealand Standard [2] and European Code [3] for aluminum structures provide design rules for structural members containing transverse and longitudinal welds. The behavior of non-welded and longitudinally welded columns have been investigated. Summaries of these research can be found in Mazzolani [4] and Sharp [6]. However, there are not many research being carried out on the behavior of aluminum columns containing transverses welds. Some numerical investigations have been mentioned by Mazzolani [4], whereas test data have been reported by Brungraber and Clark [7]. 
The purpose of this paper is to briefly summarize the experimental and numerical investigations as well as design of aluminum alloy structural members. The research program formed the basis of the $\mathrm{PhD}$ thesis [8] of the first author. The research findings have been published recently in international journals, and reference is made to these publications for further details. Table 1 summarizes the number of specimens investigated experimentally and numerically as well as the reference of the investigation.

Table 1. Data of Aluminum Alloy Structural Members

\begin{tabular}{|l|c|c|}
\hline Type & No. of specimens & References \\
\hline Fix-ended columns (experimental) & 70 & {$[9,10]$} \\
\hline Fix-ended columns (numerical) & 248 & {$[8,15]$} \\
\hline Beams and beam-columns (experimental) & 50 & {$[11,12]$} \\
\hline
\end{tabular}

\section{EXPERIMENTAL INVESTIGATION}

\subsection{Column Tests}

A series of tests described by Zhu and Young [9, 10] provide experimental ultimate loads and failure modes of aluminum columns with and without transverse welds at the ends of the columns. The tests were performed on square (SHS), rectangular (RHS) and circular (CHS) hollow section aluminum columns. The test specimens were fabricated by extrusion using 6063-T5 and 6061-T6 heat-treated aluminum alloys. Each specimen was cut to a specified length ranging from 300 to $3000 \mathrm{~mm}$. The test program included 50 fixed-ended columns with both ends welded to aluminum end plates, and 20 fixed-ended columns without the welding of end plates. In this paper, the term "welded column" refers to a specimen with transverse welds at the ends of the column to the aluminum end plates. The term "non-welded column" refers to a specimen without transverse welds at the ends of the column, but still using aluminum end plates in the test. Therefore, the testing conditions of the welded and non-welded columns are identical, other than the absence of welding in the non-welded columns. The specimens were separated into nine series for different type of aluminum alloy and cross-section geometry, as shown in Tables 2 and 3 using the symbols illustrated in Figure 1.

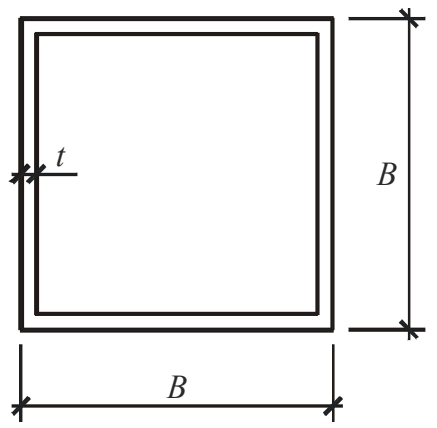

(a) SHS

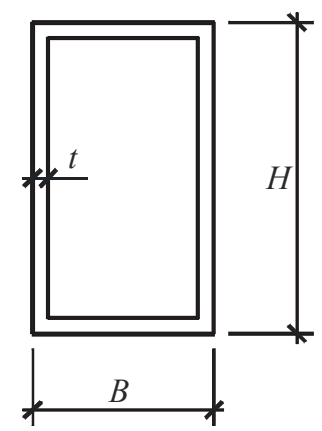

(b) RHS

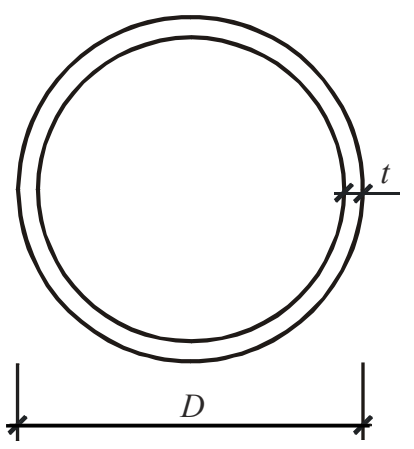

(c) $\mathrm{CHS}$

Figure 1. Definition of Symbols 
Table 2. SHS and RHS Column Test Series

\begin{tabular}{|c|c|c|}
\hline Test series & Type of material & $\begin{array}{c}\text { Dimension } \\
H \times B \times t \\
(\mathrm{~mm})\end{array}$ \\
\hline N-S1 & $6063-\mathrm{T} 5$ & $44 \times 44 \times 1.1$ \\
\hline N-R1 & $6063-\mathrm{T} 5$ & $100 \times 44 \times 1.2$ \\
\hline N-R2 & $6063-\mathrm{T} 5$ & $100 \times 44 \times 3.0$ \\
\hline H-S1 & $6061-\mathrm{T} 6$ & $44 \times 44 \times 1.1$ \\
\hline H-R1 & $6061-\mathrm{T} 6$ & $100 \times 44 \times 1.2$ \\
\hline H-R2 & $6061-\mathrm{T} 6$ & $100 \times 44 \times 3.0$ \\
\hline
\end{tabular}

Table 3. CHS Column Test Series

\begin{tabular}{|c|c|c|}
\hline Test series & Type of material & $\begin{array}{c}\text { Dimension } \\
D \times t \\
(\mathrm{~mm})\end{array}$ \\
\hline N-C1 & $6063-\mathrm{T} 5$ & $50 \times 1.6$ \\
\hline N-C2 & $6063-\mathrm{T} 5$ & $50 \times 3.0$ \\
\hline H-C1 & $6061-\mathrm{T} 6$ & $50 \times 1.6$ \\
\hline H-C2 & $6061-\mathrm{T} 6$ & $50 \times 3.0$ \\
\hline
\end{tabular}

Longitudinal tensile coupon tests were performed to determine the non-welded material properties. The coupon specimens included flat coupons taken from the SHS and RHS, and curved face coupons taken from the CHS. Longitudinal compression coupon tests were also performed on coupon specimens taken from the RHS. Two types of welded longitudinal tensile coupons with gauge length of either 25 or $250 \mathrm{~mm}$ were tested to determine the welded material properties. The measured material properties determined from the non-welded and welded coupon tests are detailed in Zhu and Young $[9,10]$.

A typical column test is shown in Figure 2. A servo-controlled hydraulic testing machine was used to apply compressive axial force to the specimen. The specimens were tested between fixed ends. Details of the test rig are given in Zhu and Young [9]. The observed failure modes include local buckling, flexural buckling, as well as interaction of local and overall buckling. Some welded columns failed by material yielding at the heat-affected zone (HAZ) as detailed in Zhu and Young $[9,10]$. Figure 2 shows the specimen failed by local buckling. Initial local and overall geometric imperfections were measured on the test specimens prior to testing, as detailed in Zhu and Young [9, 10]. A typical measured local imperfection profiles for the RHS of Series H-R1 is shown in Figure 3. The column strengths, failure modes and the comparison of test strengths with design strengths are detailed in Zhu and Young $[9,10]$. 


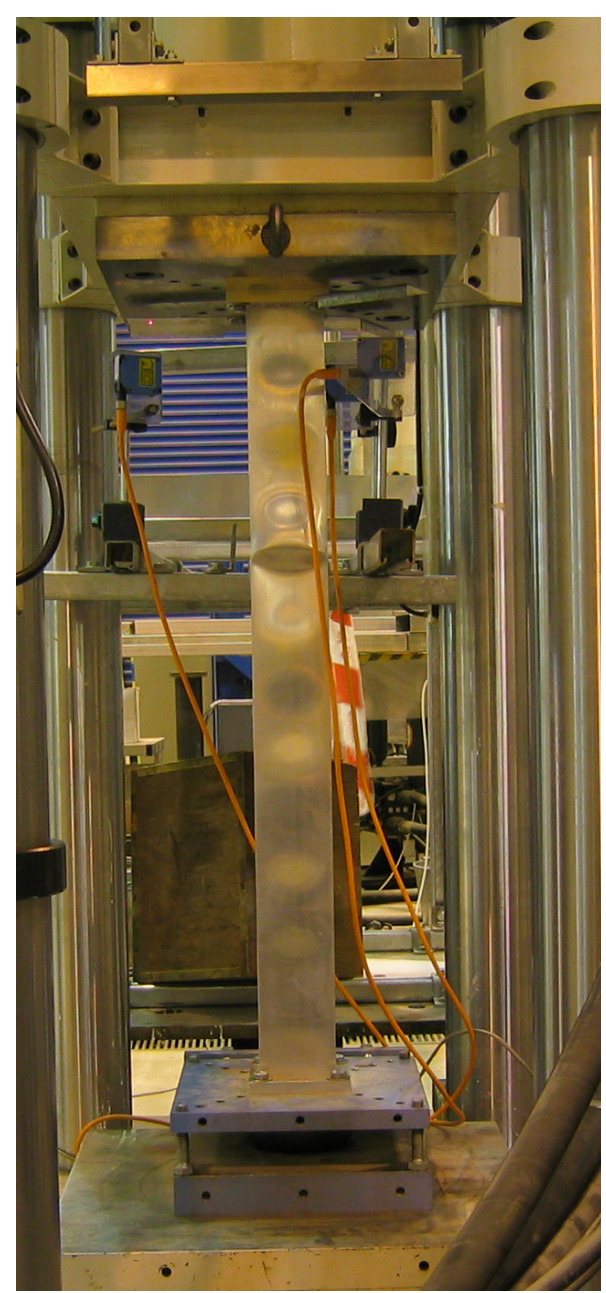

Figure 2. Column Specimen Failed by Local Buckling

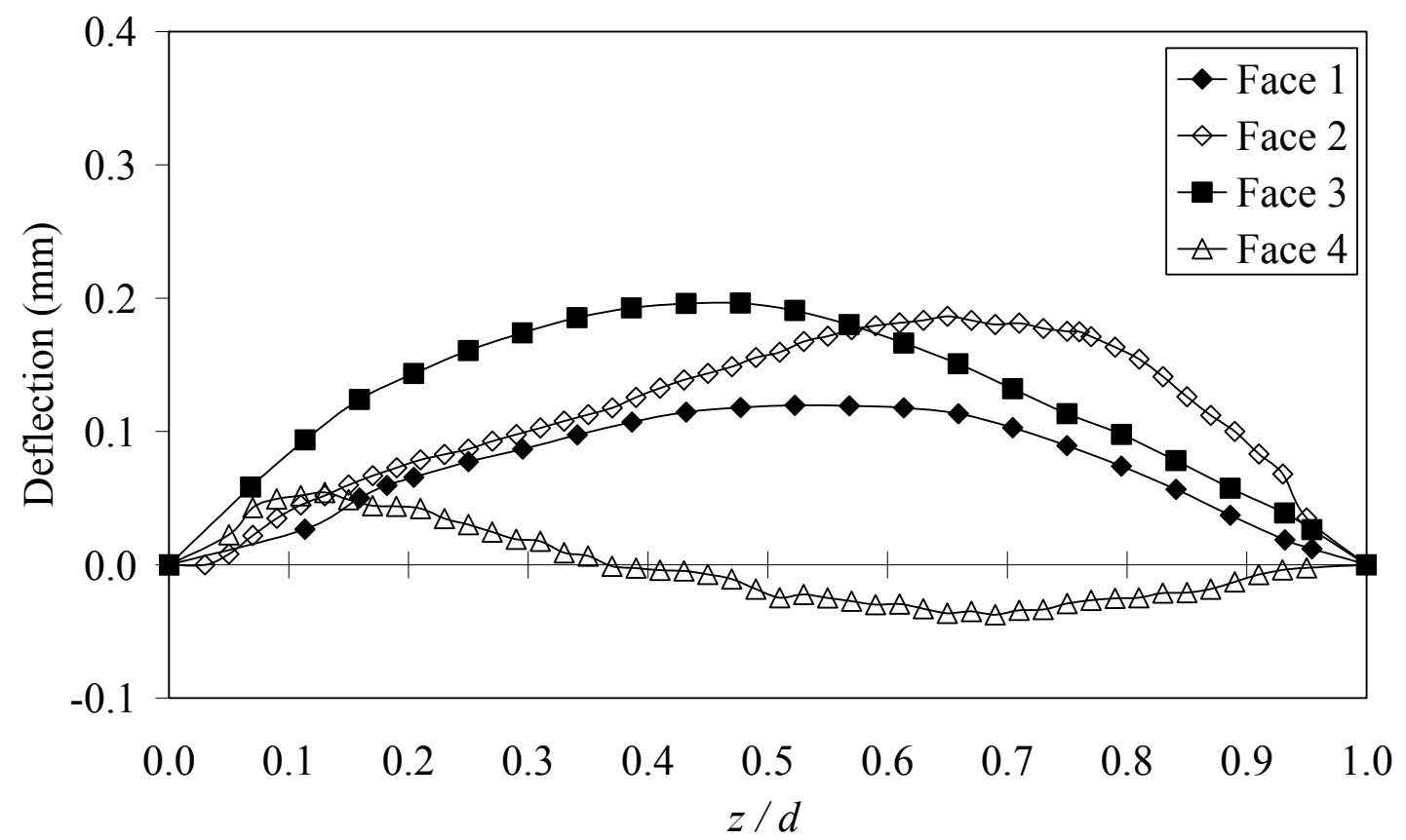

Figure 3. Measured Local Geometric Imperfection Profiles for RHS of Series H-R1 


\subsection{Beam Tests}

Tests on aluminum alloy beams and beam-columns have been conducted by Zhu and Young [11, 12]. Six beam tests were performed on SHS, RHS and CHS specimens of aluminum alloy 6061-T6, as shown in Table 4. The bending capacity of the test specimens was used to obtain the complete experimental interaction curves of aluminum alloy beam-columns. Hence, the beam specimens were tested under pure bending condition. The beam specimens were cut from those specimens belonged to the same batch of specimens as the column and beam-column tests. The length of the specimens was chosen such that the section bending capacity could be obtained.

Table 4. Beam Test Results

\begin{tabular}{|l|c|c|c|c|}
\hline Specimen & $\begin{array}{c}\text { Type of } \\
\text { material }\end{array}$ & \multirow{2}{*}{$\begin{array}{c}\text { Dimension } \\
(\mathrm{mm})\end{array}$} & \multicolumn{2}{|c|}{ Test results } \\
\cline { 3 - 5 } & $6061-\mathrm{T} 6$ & $44 \times 44 \times 1.1$ & Failure Mode & $M_{u}(\mathrm{kNmm})$ \\
\hline S1-PB & $6061-\mathrm{T} 6$ & $100 \times 44 \times 1.2$ & $\mathrm{~L}$ & 814.5 \\
\hline R1-PB & $6061-\mathrm{T} 6$ & $100 \times 44 \times 3.0$ & $\mathrm{~F}$ & 34017.5 \\
\hline R2-PB & $6061-\mathrm{T} 6$ & $100 \times 44 \times 3.0$ & $\mathrm{~F}$ & 3450.0 \\
\hline R2-PB\# & $6061-\mathrm{T} 6$ & $50 \times 1.6$ & $\mathrm{~F}$ & 1152.0 \\
\hline C1-PB & $6061-\mathrm{T} 6$ & $50 \times 3.0$ & $\mathrm{~F}$ & 2138.0 \\
\hline C2-PB & 6 & & \\
\hline
\end{tabular}

Note: $\#=$ Repeated test; $\mathrm{F}=$ Flexural buckling; $\mathrm{L}=$ Local buckling.

A typical beam test is shown in Figure 4. The test rig and test operation are detailed in Zhu and Young $[11,12]$. The experimental ultimate moments $\left(M_{u}\right)$ of the beam specimens are shown in Table 4. The $M_{u}$ was obtained using half of the ultimate applied load from the actuator multiplied by the lever arm (distance from the support to the loading point) of the specimens. The mass of the spread beam, half round, roller and bearing plates were included in the calculation of the ultimate moments. Specimens S1-PB and R1-PB failed by local buckling, whereas specimens R2-PB, R2-PB\#, C1-PB and C2-PB failed by flexural buckling (material yielding due to large deflection). Figure 4 shows the failure of specimen R2-PB.

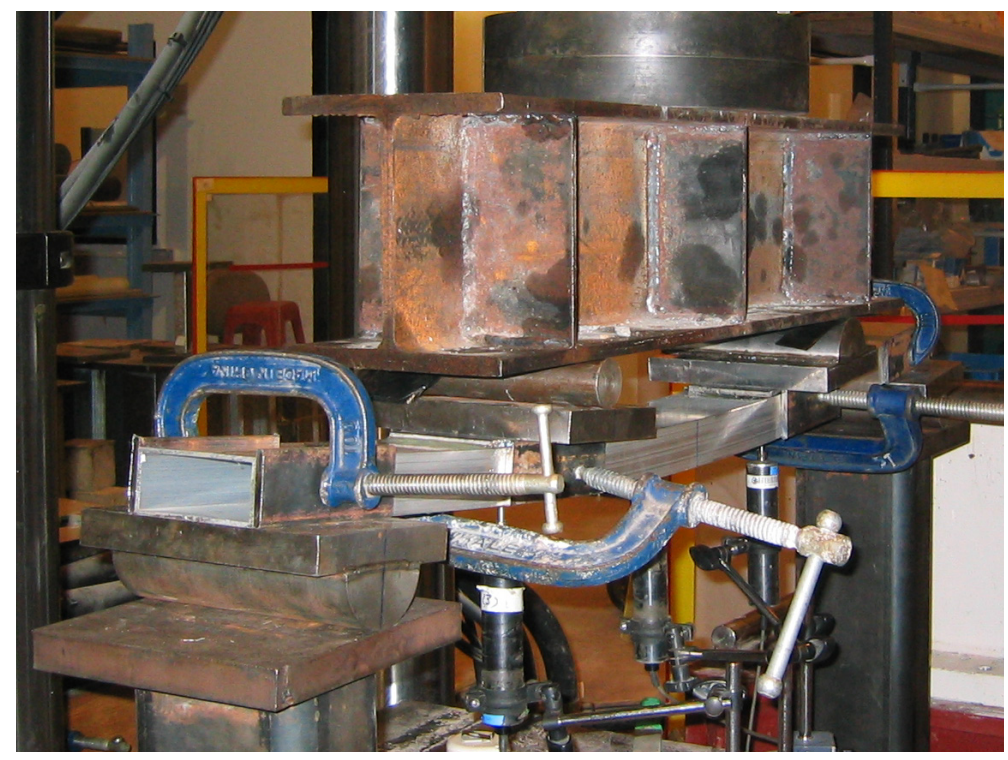

Figure 4. Flexural Buckling of Beam Specimen R2-PB 


\subsection{Beam-column Tests}

The beam-column tests were performed on aluminum alloy square (SHS), rectangular (RHS) and circular (CHS) hollow sections, as reported by Zhu and Young $[11,12]$. The test specimens were manufactured by extrusion using 6061-T6 heat-treated aluminum alloy. The specimens were cut from those specimens belonged to the same batch of specimens as the column and beam tests. The beam-column specimens were separated into ten series of different cross-section geometry and specimen length, as shown in Tables 5 and 6 using the symbols illustrated in Figure 1.

Table 5. SHS and RHS Beam-column Test Series

\begin{tabular}{|l|c|c|c|}
\hline Test series & $\begin{array}{c}\text { Type of } \\
\text { material }\end{array}$ & $\begin{array}{c}\text { Length } \\
L \\
(\mathrm{~mm})\end{array}$ & $\begin{array}{c}\text { Dimension } \\
H \times B \times t \\
(\mathrm{~mm})\end{array}$ \\
\hline S1L600 & $6061-\mathrm{T} 6$ & 600 & $44 \times 44 \times 1.1$ \\
\hline S1L1200 & $6061-\mathrm{T} 6$ & 1200 & $44 \times 44 \times 1.1$ \\
\hline R1L600 & $6061-\mathrm{T} 6$ & 600 & $100 \times 44 \times 1.2$ \\
\hline R1L1200 & $6061-\mathrm{T} 6$ & 1200 & $100 \times 44 \times 1.2$ \\
\hline R2L600 & $6061-\mathrm{T} 6$ & 600 & $100 \times 44 \times 3.0$ \\
\hline R2L1200 & $6061-\mathrm{T} 6$ & 1200 & $100 \times 44 \times 3.0$ \\
\hline
\end{tabular}

Table 6. CHS Beam-column Test Series

\begin{tabular}{|l|c|c|c|}
\hline Test series & $\begin{array}{c}\text { Type of } \\
\text { material }\end{array}$ & $\begin{array}{c}\text { Length } \\
L \\
(\mathrm{~mm})\end{array}$ & $\begin{array}{c}\text { Dimension } \\
D \times t \\
(\mathrm{~mm})\end{array}$ \\
\hline C1L500 & $6061-\mathrm{T} 6$ & 500 & $50 \times 1.6$ \\
\hline C1L1000 & $6061-\mathrm{T} 6$ & 1000 & $50 \times 1.6$ \\
\hline C2L500 & $6061-\mathrm{T} 6$ & 500 & $50 \times 3.0$ \\
\hline C2L1000 & $6061-\mathrm{T} 6$ & 1000 & $50 \times 3.0$ \\
\hline
\end{tabular}

For the SHS and RHS, the test program included 27 beam-columns compressed between pinned ends at different eccentricities in order to obtain an interaction curve for each series of test. Each test series contained one specimen tested with an eccentricity near zero (concentrically loaded) to determine the axial capacity. Each specimen was cut to a specified length of either 600 or $1200 \mathrm{~mm}$. For the CHS, the test program included 17 beam-column specimens. Similar to the SHS and RHS beam-column test program, each test series contained one specimen tested with an eccentricity near zero to determine the axial capacity. Each specimen was cut to a specified length of either 500 or $1000 \mathrm{~mm}$. Both ends of the specimens were welded to aluminum end plates to connect the specimens to the pinned bearings.

Figure 5 shows a typical beam-column test. The test rig and test operation are detailed in Zhu and Young $[11,12]$. A computer program has been written for this study to calculate the measured loading eccentricity $\left(e_{0}\right)$ of the beam-column specimens during the initial part of the tests by measuring the applied load, longitudinal strains and overall deflection at mid-length about the bending axis of the specimens. The measured loading eccentricity $\left(e_{0}\right)$ was calculated for each load increment during the initial loading and the average value is adopted for each beam-column specimen, as shown in Zhu and Young [11, 12]. Initial overall geometric imperfections were measured for the beam-column specimens of 1200 and $1000 \mathrm{~mm}$ in length prior to testing. 
The plot of axial load $(N)$ versus moments for Series C2L1000 is shown in Figure 6, where the curves with thick line represent the axial load versus the maximum inelastic moment $\left(M_{m i}\right)$, and the curves with thinner line represent the axial load versus the end moment $\left(M_{\text {end }}\right)$. The ultimate points for the axial load versus maximum inelastic moment curves are also shown in Figure 6 . The observed failure modes include local buckling, flexural buckling, as well as interaction of local and overall flexural buckling. Figure 5 shows the specimen failed by flexural buckling. It should be noted that some short specimens tested with small eccentricity failed by material yielding at the heat-affected zone (HAZ).

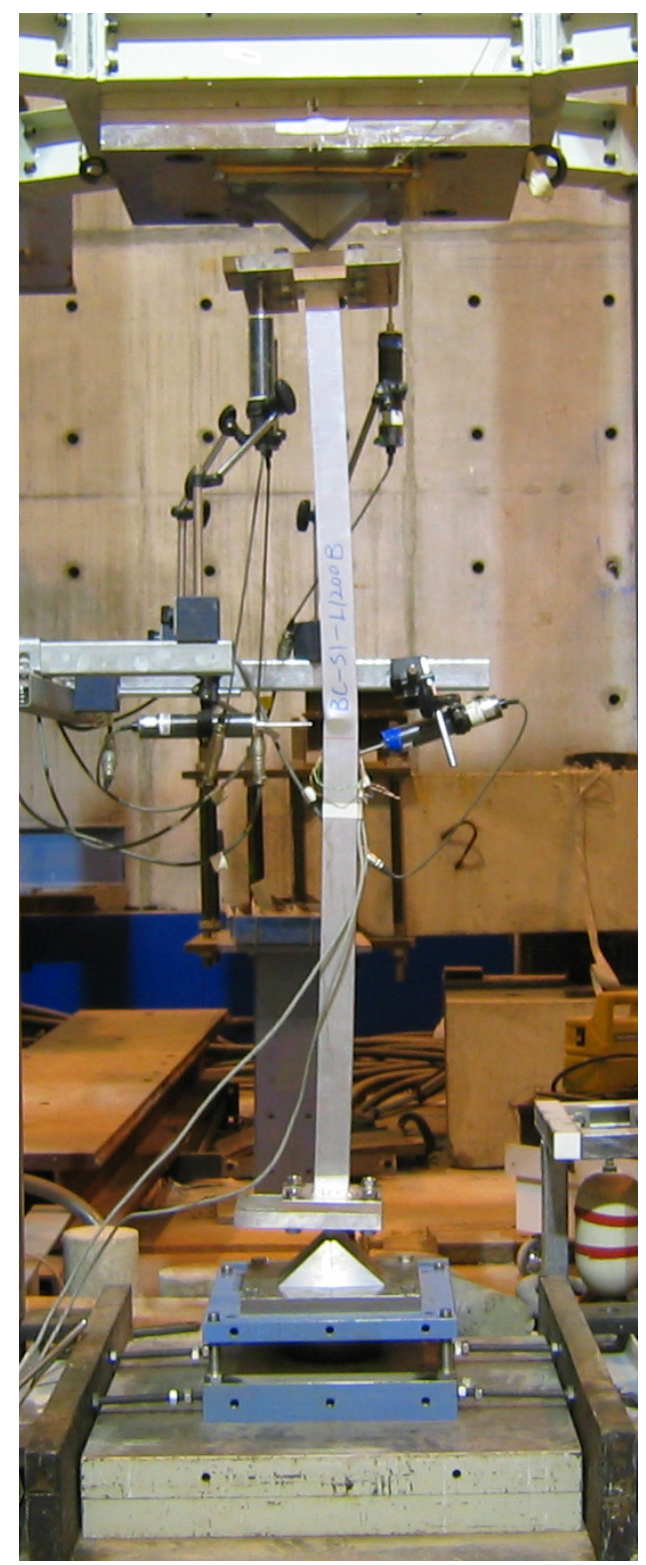

Figure 5. Beam-column Specimen Failed by Flexural Buckling 


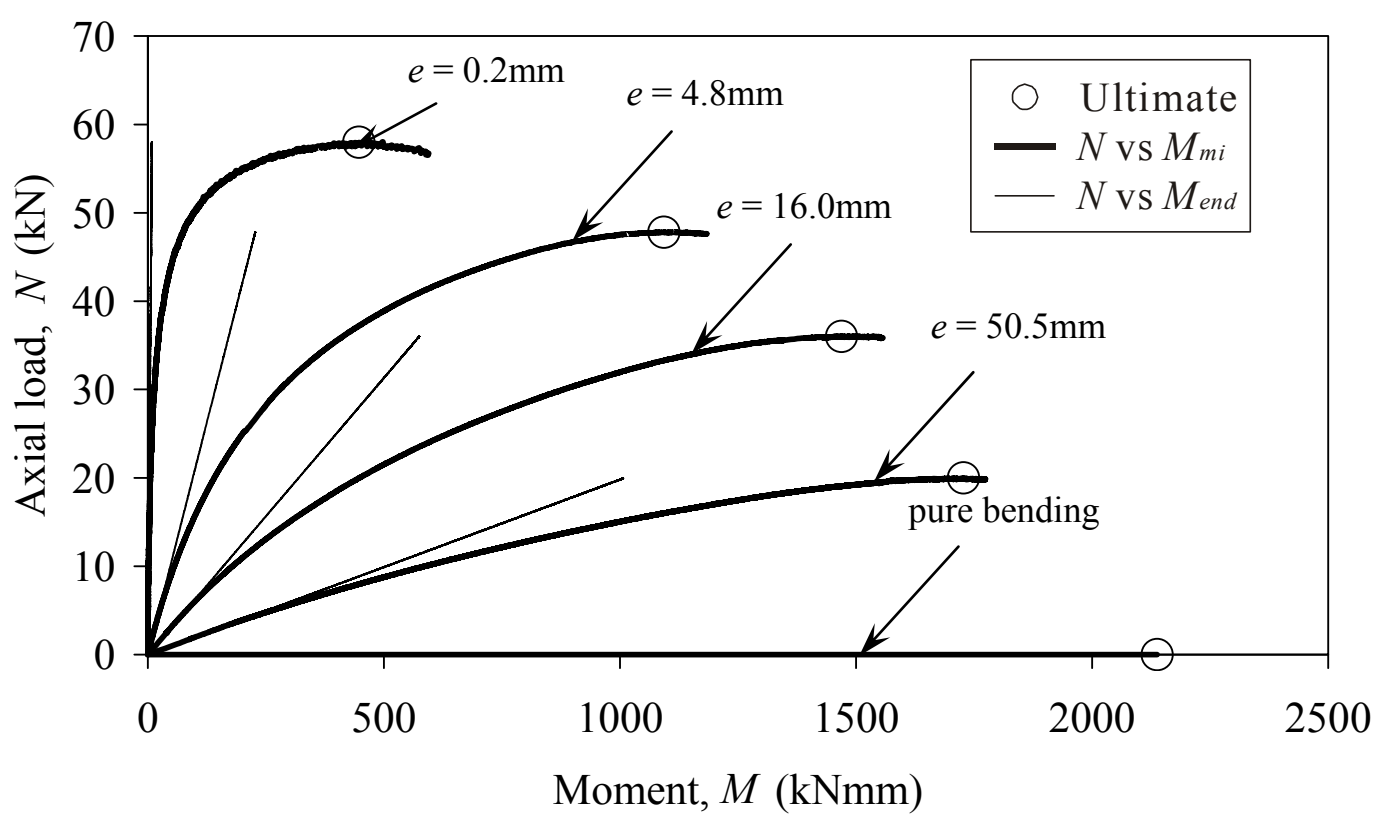

Figure 6. Axial Load versus Moment for Beam-column Series C2L1000

\section{NUMERICAL INVESTIGATION}

The finite element program ABAQUS [13] was used in the analysis for the simulation of aluminum alloy fixed-ended columns $[9,10]$. An accurate and reliable non-linear finite element model for aluminum non-welded and welded columns has been presented by Zhu and Young [14, 15]. The development of the finite element model (FEM) is detailed in Zhu and Young [14]. In the FEM, the measured cross-section dimensions, material properties and initial geometric imperfections of the test specimens were modeled. The fixed-ended boundary condition was modeled by restraining all the degrees of freedom of the nodes at both ends of the column, except for the translational degree of freedom in the axial direction at one end of the column. The nodes other than the two ends were free to translate and rotate in any directions. The material non-linearity was included in the FEM by specifying the true values of stresses and strains. The plasticity of the material was simulated by a mathematical model, known as the incremental plasticity model, in which the true stresses and true plastic strains were calculated in accordance with ABAQUS [13]. The geometric imperfections were included in the FEM by using the Eigenvalue analyses. The displacement control loading method was used in the finite element analysis (FEA) that was identical to the loading method used in the column tests. The S4R general-purpose shell elements were used in the FEM. The welded columns were modeled by dividing the columns into different portions along the column length. Therefore, the heat-affected zone (HAZ) softening at both ends of the columns were simulated.

The FEM closely predicted the experimental ultimate loads and failure modes of the tested aluminum columns, as detailed in Zhu and Young [14]. Figure 7 shows the comparison of the load-shortening curves obtained from the test and predicted by the FEA for the non-welded column specimen H-R2-NW-L1000. Hence, the model was used for an extensive parametric study. The parametric study included 120 SHS and RHS columns that consisted of 24 series, as well as 80 CHS columns that consisted of 16 series. Each series contained 5 specimens with column lengths of $500,1200,2000,2700$ and $3500 \mathrm{~mm}$. The column strengths obtained from the parametric study are detailed in Zhu and Young [15]. 


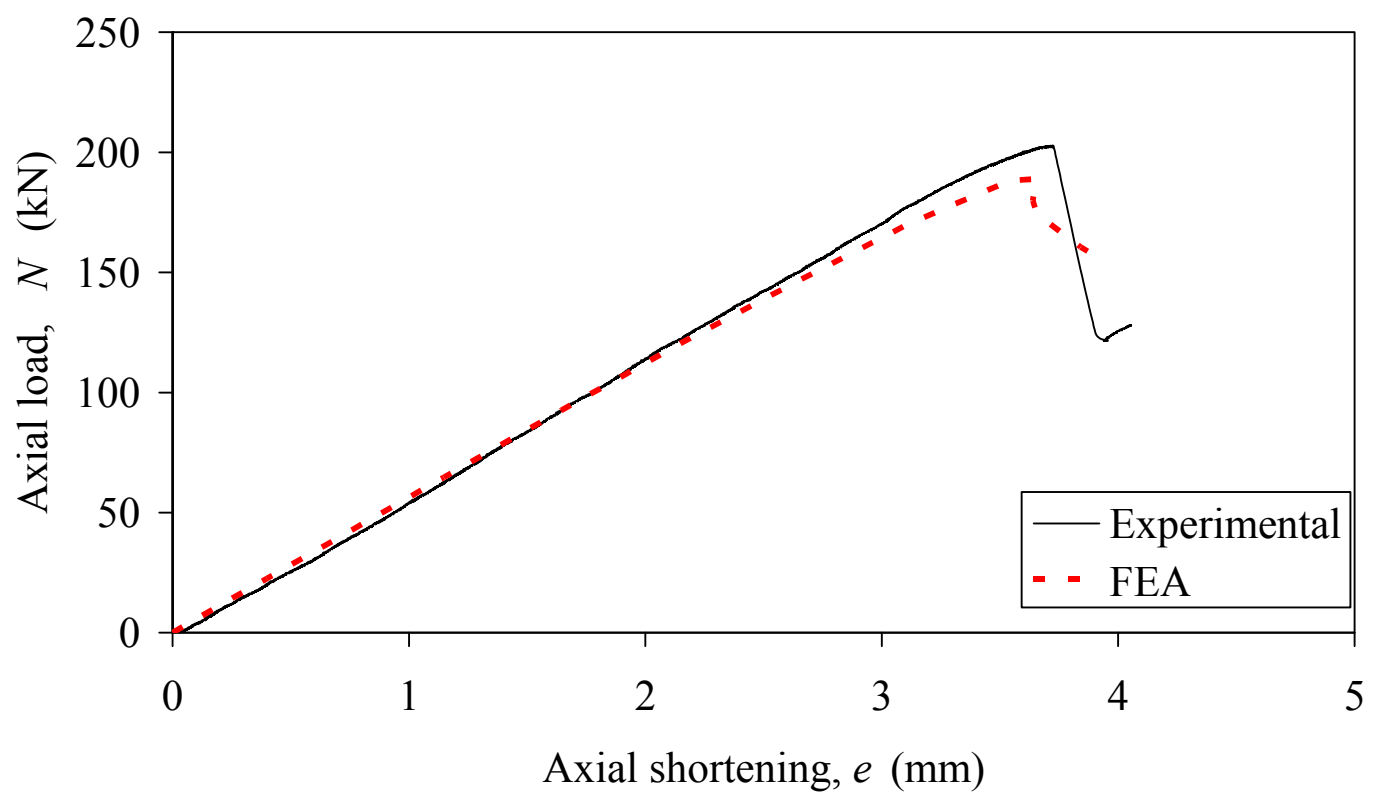

Figure 7. Comparison of Experimental and FEA Axial load-shortening Curves for Specimen H-R2-NW-L1000

\section{EFFECTS OF TRANSVERSE WELDS ON ALUMINUM ALLOY COLUMNS}

Research on aluminum columns containing transverse welds are summarized by Mazzolani [4] and Sharp [6]. However, previous research was mainly focused on the effects of transverse welds with respect to different column lengths. A numerical investigation described by Zhu and Young [16] is focused on the effects of transverse welds on aluminum alloy columns with respect to section slenderness.

The parametric study included 48 columns of six SHS and six CHS of different section thickness, as detailed in Zhu and Young [16]. Non-welded and welded columns of aluminum alloy 6063-T5 and 6061-T6 were modeled for each section. This study focused on the effects of transverse welds on column strengths with respect to section slenderness. Hence, the parametric study was performed on stub columns of $600 \mathrm{~mm}$ in length that generally followed the stub column length suggested by Galambos [17]. The heat-affected zone softening factor $\left(\rho_{\text {haz-FEA }}\right)$ obtained from the parametric study is detailed in Zhu and Young [16]. Figure 8 shows the $\rho_{\text {haz-FEA }}$ results plotted against the overall diameter-to-thickness ratio $(D / t)$ for the CHS columns. The value of the HAZ softening factor $\left(\rho_{\text {haz-FEA }}\right)$ obtained from the parametric study is clearly decreases as the value of $D / t$ increases for the CHS columns, as shown in Figure 8. The proposed heat-affected zone softening factor $\left(\rho_{\text {haz-P }}\right)$ for CHS is also shown in Figure 8. Details of the proposed equation are shown in Zhu and Young [16]. The HAZ softening factors obtained from the parametric study ( $\left.\rho_{\text {haz-FEA }}\right)$ are compared with the values $\left(\rho_{\text {haz-EC9}}\right)$ specified in the EC9 Code for the SHS and CHS specimens, as described by Zhu and Young [16]. 


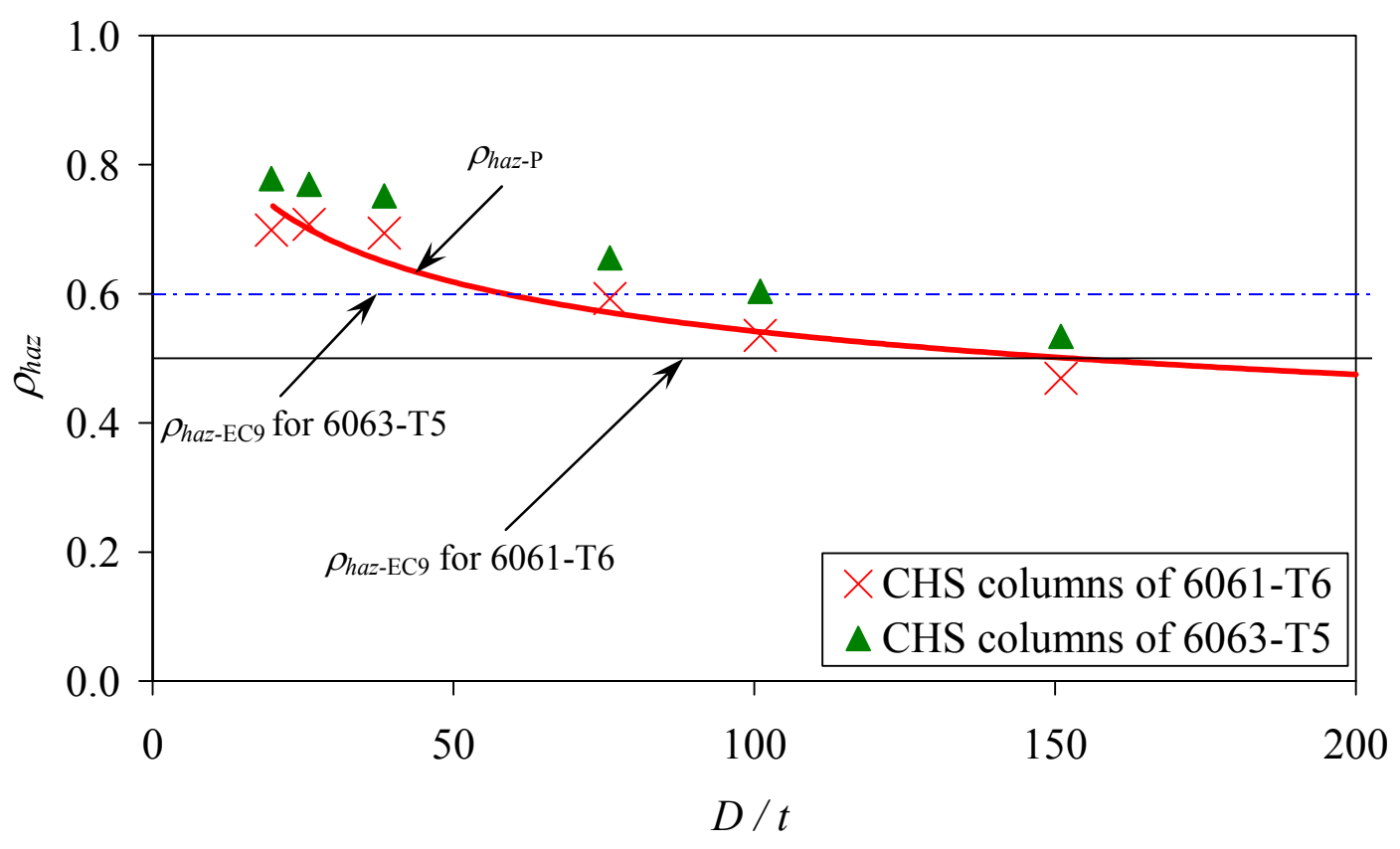

Figure 8. Heat-affected Zone Softening Factor of CHS Columns

\section{DESIGN RECOMMENDATIONS}

The fixed-ended column strengths obtained from the experimental investigation [9, 10] and numerical investigation $[8,15]$ were compared with the design strengths calculated using the current American Aluminum Design Manual [1], Australian/New Zealand Standard [2] and European Code [3] for aluminum structures, as detailed in Zhu [8] and Zhu and Young [9, 10]. It is shown that these design rules are generally conservative for non-welded columns. It is also shown that these design rules are generally quite conservative for welded columns.

The direct strength method (DSM) that detailed in the North American Specification (NAS) [18, 19] for cold-formed steel structures was used for the design of aluminum alloy columns as described by Zhu and Young [15]. As summarized in the North American Specification for cold-formed steel structures, the column design rules of the direct strength method that considered the local and overall flexural buckling are shown in Eqs. (1) - (3). The values of 0.15 and 0.4 are the coefficient and exponent of the direct strength equation, respectively, that were calibrated against test data of concentrically loaded pin-ended cold-formed steel columns for certain cross sections and geometric limits.

$$
\begin{aligned}
& P_{\mathrm{DSM}}=\min \left(P_{\mathrm{ne}}, P_{\mathrm{n} l}\right) \\
& P_{\mathrm{ne}}= \begin{cases}\left(0.658^{\lambda_{\mathrm{c}}^{2}}\right) P_{\mathrm{y}} & \text { for } \lambda_{\mathrm{c}} \leq 1.5 \\
\left(\frac{0.877}{\lambda_{\mathrm{c}}^{2}}\right) P_{\mathrm{y}} & \text { for } \lambda_{\mathrm{c}}>1.5\end{cases}
\end{aligned}
$$


$P_{\mathrm{n} l}= \begin{cases}P_{\mathrm{ne}} & \text { for } \lambda_{l} \leq 0.776 \\ {\left[1-0.15\left(\frac{P_{\mathrm{cr} l}}{P_{\mathrm{ne}}}\right)^{0.4}\right]\left(\frac{P_{\mathrm{cr} l}}{P_{\mathrm{ne}}}\right)^{0.4} P_{\mathrm{ne}}} & \text { for } \lambda_{l}>0.776\end{cases}$

where $P_{\mathrm{y}}=f_{\mathrm{y}} A ; \quad \lambda_{\mathrm{c}}=\sqrt{P_{\mathrm{y}} / P_{\mathrm{cre}}} ; \quad \lambda_{l}=\sqrt{P_{\mathrm{ne}} / P_{\mathrm{cr} l}}$.

$A=$ Gross cross-section area;

$f_{\mathrm{y}}=$ Material yield strength which is the static $0.2 \%$ proof stress $\left(\sigma_{0.2}\right)$ using the non-welded material properties in this paper;

$P_{\text {cre }}=\pi^{2} E A /\left(l_{e} / r\right)^{2}$, critical elastic buckling load in flexural buckling for tubular columns;

$P_{\text {crl }}=$ Critical elastic local column buckling load;

$E=$ Young's modulus;

$l_{e}=$ Column effective length;

$r=$ Radius of gyration of gross cross-section about the minor $y$ - axis of buckling.

It should be noted that the direct strength method was developed based on open sections, such as simple lipped channel, lipped channel with web stiffeners, Zed section, hat section and rack upright section. In this study, square, rectangular and circular hollow sections are investigated. Therefore, the direct strength method for cold-formed carbon steel members was modified for aluminum alloy columns. The proposed design equations for aluminum alloy SHS and RHS columns without transverse welds at the ends of the columns (non-welded columns) are described in Zhu and Young [15] and shown as follows:

$P_{\mathrm{DSM}-\mathrm{NW}}=\min \left(P_{\mathrm{ne}}, P_{\mathrm{n} l}\right)$

$P_{\mathrm{ne}}= \begin{cases}\left(0.658^{\lambda_{\mathrm{c}}^{2}}\right) P_{\mathrm{y}-\mathrm{nw}} & \text { for } \lambda_{\mathrm{c}} \leq 1.5 \\ \left(\frac{0.877}{\lambda_{\mathrm{c}}^{2}}\right) P_{\mathrm{y}-\mathrm{nw}} & \text { for } \lambda_{\mathrm{c}}>1.5\end{cases}$

$P_{\mathrm{n} l}= \begin{cases}P_{\mathrm{ne}} & \text { for } \lambda_{l} \leq 0.713 \\ {\left[1-0.15\left(\frac{P_{\mathrm{cr} l}}{P_{\mathrm{ne}}}\right)^{0.3}\right]\left(\frac{P_{\mathrm{crl}}}{P_{\mathrm{ne}}}\right)^{0.3} P_{\mathrm{ne}}} & \text { for } \lambda_{l}>0.713\end{cases}$

where $P_{\mathrm{y}-\mathrm{nw}}=f_{\mathrm{y}-\mathrm{nw}} A ; \quad \lambda_{\mathrm{c}}=\sqrt{P_{\mathrm{y}-\mathrm{nw}} / P_{\mathrm{cre}}} ; \quad \lambda_{l}=\sqrt{P_{\mathrm{ne}} / P_{\mathrm{cr} l}}$.

$f_{\mathrm{y}-\mathrm{nw}}=$ Non-welded material yield strength.

The design equations were verified against the numerical results [15] and the test results [9]. The proposed design Eqs. (4) - (6) for aluminum SHS and RHS non-welded columns require only small modifications to the current direct strength method for cold-formed steel members. In Eq. (3), the value of the exponent 0.4 was modified to 0.3 , and the non-dimensional slenderness $\left(\lambda_{l}\right)$ has been adjusted to 0.713 for a smooth transition of the elastic and inelastic buckling loads as shown in Eq. (6). As a result, the reliability index ( $\beta$ ) of 2.86 was obtained for the proposed design rules, which is closer to the target value of 2.5 compared with the reliability index $(\beta)$ of 3.07 for the current direct strength method, as shown in Figure 9. The load combination of 1.2DL (dead load) +1.6LL (live load) was used in calculating the reliability index as specified in the AA Specification [1]. The 
resistance factor $(\phi)$ of 0.85 was used in the calculation. The reliability analysis is detailed in Zhu and Young [15]. Figure 9 shows the comparison of FEA and experimental results of SHS and RHS non-welded columns against the current and modified direct strength curves plotted from Eq. (3) and Eq. (6), respectively. Generally, the results predicted using the current and modified direct strength methods compared reasonably well with the FEA and experimental results. However, the modified direct strength method provided a reliability index closer to the target value compared with the current direct strength method.

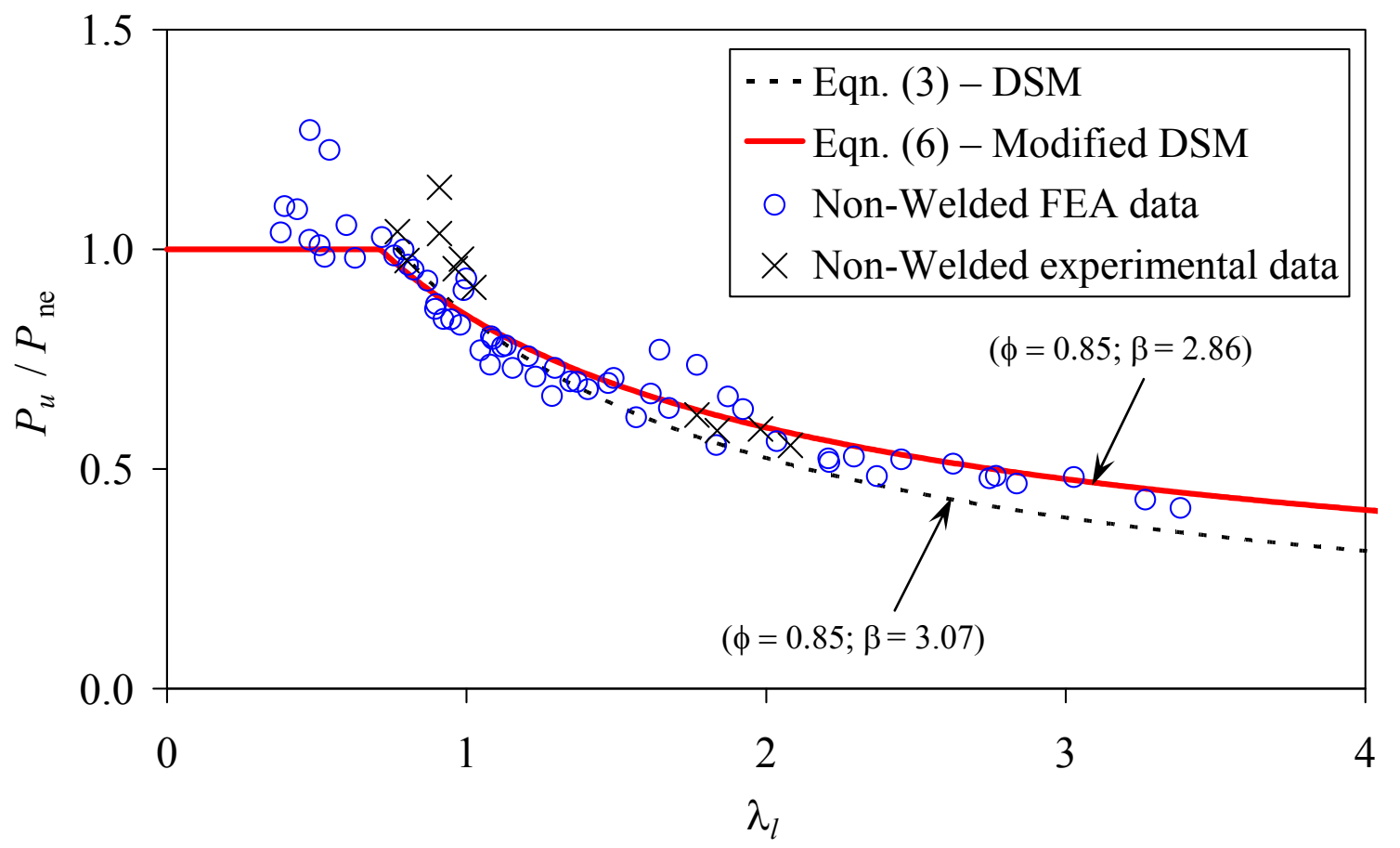

Figure 9. Comparison of FEA and Experimental Data with Direct Strength Curves for SHS and RHS Non-welded Columns

It is also shown that the current direct strength method is not suitable for the design of aluminum welded columns, as detailed in Zhu and Young [15]. Two design approaches were proposed for aluminum SHS and RHS columns with transverse welds at both ends of the columns (welded columns), as shown in Zhu and Young [15]. The two design approaches were also modified from the current direct strength method as well as the current nominal axial strength $\left(P_{\text {ne }}\right)$ equations for flexural buckling. The first approach adopts the non-welded material properties in calculating the welded column strength. The second approach adopts the welded material properties in calculating the welded column strength. Furthermore, design equation was also proposed based on the current direct strength method for aluminum alloy CHS welded columns, as presented by Zhu [8]. The design strengths calculated using the proposed design equations were compared with the column strengths obtained from the experimental investigation $[9,10]$ and numerical investigation $[8,15]$ for SHS, RHS and CHS columns. The reliability of the design rules was evaluated using reliability analysis. It is shown that the proposed design rules are accurate and reliable. 


\section{CONCLUSIONS}

The research program of the $\mathrm{PhD}$ thesis of the first author has been summarized. The program included experimental and numerical investigations as well as design of aluminum alloy structural members.

Tests were performed on aluminum alloy columns, beams and beam-columns of square, rectangular and circular hollow sections. Material properties of the test specimens were obtained from coupon tests. Local and overall geometric imperfections were measured. Test results were compared with the design strengths calculated using the current American, Australian/New Zealand and European specifications for aluminum structures. It is shown that the design strengths predicted by the three specifications are generally conservative.

A non-linear finite element model incorporating geometric imperfections and material non-linearity was developed for fixed-ended aluminum alloy non-welded and welded columns. The welded columns were modeled by dividing the column into different portions along the column length, so that the heat-affected zone softening at both ends of the welded columns was included in the simulation. The finite element model was verified against the test results. It is shown that the finite element model provides accurate predictions of the experimental ultimate loads and failure modes for both the non-welded and welded columns. Parametric study was conducted using the verified finite element model.

The effects of transverse welds on aluminum alloy columns of square and circular hollow sections have been investigated. The heat-affected zone softening factors obtained from the parametric study were compared with the corresponding values specified in the European Code for aluminum structures. It is shown that the values of the heat-affected zone softening factor specified in the European Code are generally conservative for the square and circular hollow section columns. The heat-affected zone softening factors have been proposed for square and circular hollow sections based on the results obtained from the parametric study. It is shown that the proposed heat-affected zone softening factors are in good agreement with the numerical results.

The column strengths were compared with the design strengths calculated using the current direct strength method that was developed for cold-formed steel members. It is shown that the direct strength method can be used for the design of aluminum alloy non-welded tubular columns. It is also shown that the current direct strength method is not suitable for the design of aluminum welded columns. Based on the data obtained from the experimental and numerical investigations, design rules modified from the direct strength method were proposed for aluminum non-welded and welded columns. Reliability analysis was performed to evaluate the reliability of the design rules. It is shown that the design strengths calculated using the proposed design rules are in good agreement with the experimental and numerical results. It is also shown that the proposed design rules are reliable.

\section{ACKNOWLEDGMENT}

The test specimens were sponsored by the Asia Aluminum Manufacturing Company. 


\section{REFERENCES}

[1] AA. Aluminum Design Manual, Washington, D.C.: The Aluminum Association, 2000.

[2] AS/NZS, Aluminum Structures Part 1: Limit State Design, Australian/New Zealand Standard AS/NZS 1664.1:1997. Sydney, Australia: Standards Australia, 1997.

[3] EC9, Eurocode 9: Design of Aluminum Structures - Part 1-1: General Rules - General Rules and Rules for Buildings, DD ENV 1999-1-1:2000, Final Draft Oct. 2000. European Committee for Standardization, 2000.

[4] Mazzolani, F.M., “Aluminum Alloy Structures”, 2nd Edition. London: E \& FN Spon; 1995.

[5] Kissell, J.R., Ferry, R.L., "Aluminum Structures - A Guide to their Specifications and Design", 2nd Edition, New York: John Wiley \& Sons, 2002.

[6] Sharp, M.L., "Behavior and Design of Aluminum Structures", New York: McGraw-Hill; 1993.

[7] Brungraber, R.J. and Clark, J.W., "Strength of Welded Aluminum Columns", Journal of Structural Division, ASCE, 1960.

[8] Zhu, J.H., "Behaviour and Design of Aluminum Alloy Structural Members", PhD Thesis, Department of Civil Engineering, The University of Hong Kong, Hong Kong; 2006.

[9] Zhu, J.H. and Young, B., "Tests and Design of Aluminum Alloy Compression Members", Journal of Structural Engineering, ASCE, 2006; Vol. 132, No. 7, pp 1096-1107.

[10] Zhu, J.H. and Young, B., "Experimental Investigation of Aluminum Alloy Circular Hollow Section Columns", Engineering Structures, 2006, Vol. 28, No. 2, pp. 207-215.

[11] Zhu, J.H. and Young, B., "Experimental Investigation of Aluminum Alloy Thin-walled Tubular Members in Combined Compression and Bending", Journal of Structural Engineering, ASCE, 2006; Vol. 132, No. 12, pp 1955-1966.

[12] Zhu, J.H. and Young, B., "Aluminum Alloy Circular Hollow Section Beam-columns", Thin-Walled Structures, 2006, Vol. 44, No. 2, pp. 131-140.

[13] ABAQUS Analysis User's Manual, Version 6.5, ABAQUS, Inc., 2004.

[14] Zhu, J.H. and Young, B., "Aluminum Alloy Tubular Columns - Part I: Finite Element Modeling and Test Verification", Thin-Walled Structures, 2006, Vol. 44, No. 9, pp. 961-968.

[15] Zhu, J.H. and Young, B., "Aluminum Alloy Tubular Columns - Part II: Parametric Study and Design using Direct Strength Method", Thin-Walled Structures, 2006, Vol. 44, No. 9, pp. 969-985.

[16] Zhu, J.H. and Young, B., "Effects of Transverse Welds on Aluminum Alloy Columns. Thin-Walled Structures", 2007, Vol. 45, No. 3, pp. 321-329.

[17] Galambos, T.V., "Guide to Stability Design Criteria for Metal Structures", 5th Edition, New York: John Wiley \& Sons, 1998.

[18] North American Specification for the Design of Cold-formed Steel Structural Members, American Iron and Steel Institute, Washington, D.C., 2001.

[19] Supplement to the North American Specification for the Design of Cold-formed Steel Structural Member, American Iron and Steel Institute, Washington, D.C., 2004. 